
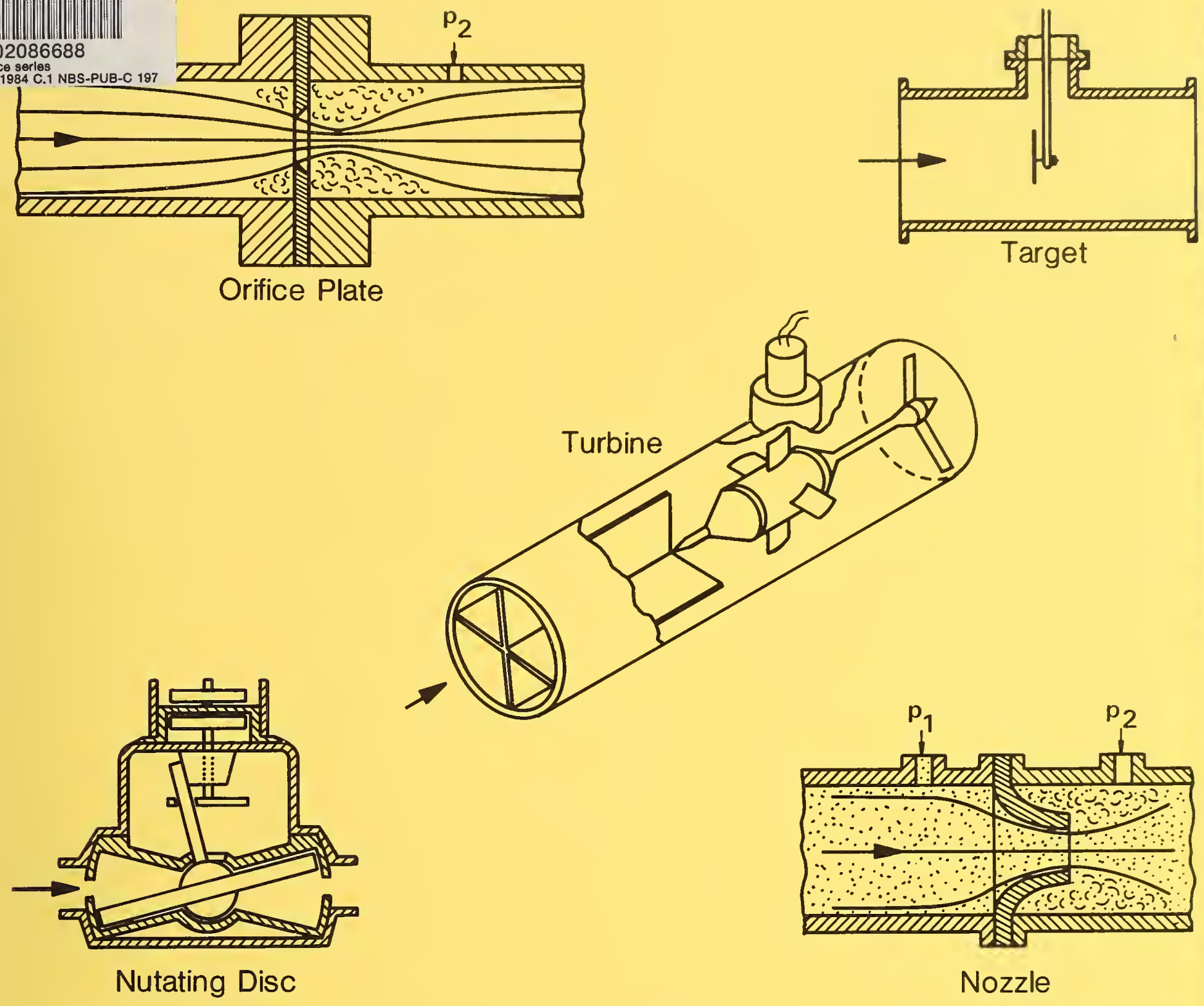

NBS BUILDING SCIENCE SERIES 159

\title{
On-Site Calibration of Flow Metering Systems Installed in Buildings
}

0.159 


\section{NATIONAL BUREAU OF STANDARDS}

The National Bureau of Standards' was established by an act of Congress on March 3, 1901. The Bureau's overall goal is to strengthen and advance the Nation's science and technology and facilitate their effective application for public benefit. To this end, the Bureau conducts research and provides: (1) a basis for the Nation's physical measurement system, (2) scientitic and technological services for industry and government, (3) a technical basis for equity in trade, and (4) technical services to promote public safety. The Bureau's technical work is performed by the National Measurement Laboratory, the National Engineering Laboratory, and the Institute for Computer Sciences and Technology.

THE NATIONAL MEASUREMENT LABORATORY provides the national system of physical and chemical and materials measurement; coordinates the system with measurement systems of other nations and furnishes essential services leading to accurate and uniform physical and chemical measurement throughout the Nation's scientific community, industry, and commerce; conducts materials research leading to improved methods of measurement, standards, and data on the properties of materials needed by industry, commerce, educational institutions, and Government; provides advisory and research services to other Government agencies; develops, produces, and distributes Standard Reference Materials; and prevides calibration services. The Laboratory consists of the following centers:

\section{Absolute Physical Quantities ${ }^{2}$ - Radiation Research - Chemical Physics - Analytical Chemistry - Materials Science}

THE NATIONAL ENGINEERING LABORATORY provides technology and technical services to the public and private sectors to address national needs and to solve national problems; conducts research in engineering and applied science in support of these efforts; builds and maintains competence in the necessary disciplines required to carry out this research and technical service; develops engineering data and measurement capabilities; provides engineering measurement traceability services; develops test methods and proposes engineering standards and code changes; develops and proposes new engineering practices; and develops and improves mechanisms to transfer results of its research to the ultimate user. The Laboratory consists of the following centers:

Applied Mathematics - Electronics and Electrical Engineering ${ }^{2}$ - Manufacturing Engineering - Building Technology - Fire Research - Chemical Engineering ${ }^{2}$

THE INSTITUTE FOR COMPUTER SCIENCES AND TECHNOLOGY conducts research and provides scientific and technical services to aid Federal agencies in the selection, acquisition, application, and use of computer technology to improve effectiveness and economy in Government operations in accordance with Public Law 89-306 (40 U.S.C. 759), relevant Executive Orders, and other directives; carries out this mission by managing the Federal Information Processing Standards Program, developing Federal ADP standards guidelines, and managing Federal participation in ADP voluntary standardization activities; provides scientific and technological advisory services and assistance to Federal agencies; and provides the technical foundation for computer-related policies of the Federal Government. The Institute consists of the following centers:

Programming Science and Technology - Computer Systems Engineering.

'Headquarters and Laboratories at Gaithersburg, MD, unless otherwise noted; mailing address Washington, DC 20234

'Some divisions within the center are located at Boulder, CO 80303. 


\section{On-Site Calibration of Flow Metering Systems Installed in Buildings}

David W. Baker

C. Warren Hurley

Building Equipment Division

Center for Building Technology

National Bureau of Standards

Washington, D.C. 20234

Prepared for:

U.S. Navy

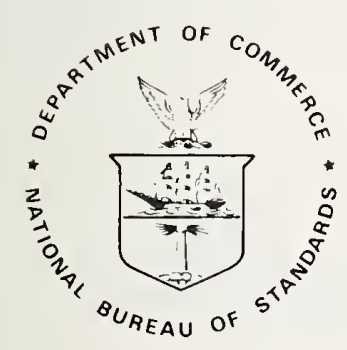

U.S. DEPARTMENT OF COMMERCE, Malcolm Baldrige, Secretary NATIONAL BUREAU OF STANDARDS, Ernest Ambler, Director

Issued January 1984 
Library of Congress Catalog Card Number: 83-600626

National Bureau of Standards Building Science Series 159

Natl. Bur. Stand. (U.S.), Bldg. Sci. Ser. 159, 154 pages (Jan. 1984)

CODEN: BSSNBV 
The measurement of flow of the various fluids (air, water, steain) used in building service systems is usually the most difficult paraneter to obtain and maintain. Consequently, in energy management and control systems (EMCS), the flowrate or the total quantity of flow is often the least accurate measurement. However, in nost systems the energy consumed depends directly on this parameter.

Since the majority of fluid flow measuring techniques require the sensing element to be located in the stream of the fluid being monitored, flow measuring devices often are the most difficult instruments to calibrate initially and to maintain in calibration within the required accuracy. This report surnmarizes the various types of flowmetering devices used in EMCS, various methods for their initial calibration and, when practical, techniques for maintaining their calibration while they are in service. Emphasis is placed on the use of transfer reference meter systems, where the working meter is calibrated on site by connecting it in series with a calibrated transfer meter of any variety. other methods of calibration are also described.

Reference tables and the necessary equations for flow calculations are presented throughout the text and in the appendicies. Illustrative examples are given in detail for the calculation of flow using each type of metering device described. These examples are extremely helpful in field calibration when the metering being calibrated is of a different type than the meter being used as a reference. Because of this, the reader is encouraged to review these examples.

Key words: calibration methods; flowmetering devices; flow nozzle meters; multiple pitot-static tube assemblies; orifice meters; positive displacement meters; reverse-pitot tube assemblies; target meters; turbine meters; ultrasonic flowmeters; venturi meters; vortex shedding meters. 


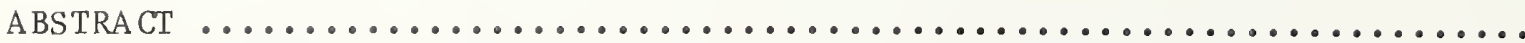

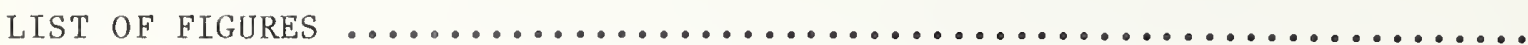

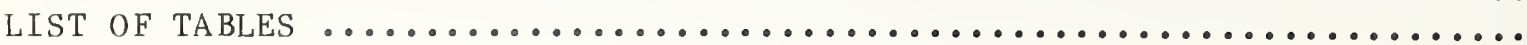

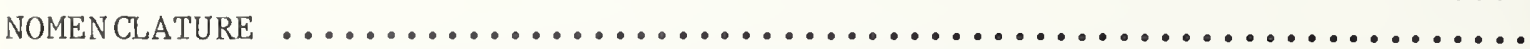

viii

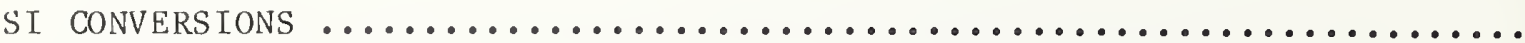

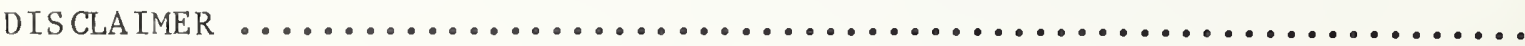

1. InTRODUCTION $\ldots \ldots \ldots \ldots \ldots \ldots \ldots \ldots \ldots \ldots \ldots \ldots \ldots \ldots \ldots \ldots \ldots \ldots \ldots \ldots \ldots \ldots$

2. ORIFICE, FLOW NOZZLE AND VENTURI METERS ................... 4

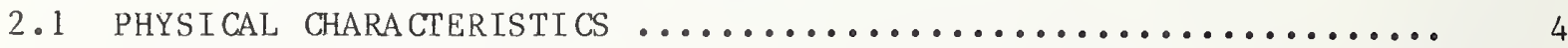

2.2 HYdRAULIC EQUATION $\ldots \ldots \ldots \ldots \ldots \ldots \ldots \ldots \ldots \ldots \ldots \ldots \ldots \ldots \ldots \ldots \ldots \ldots \ldots \ldots \ldots$

3. CALIBRATION METHODS FOR DIFFERENTIAL PRESSURE AND OTHER TYPES OF

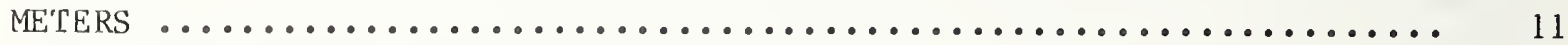

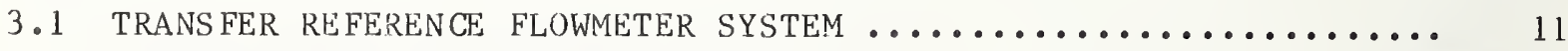

3.2 DIRECT CALIBRATLON METHOD ....................... 15

3.3 PERFORMANCE EVALUA TON PROM DIRECT CALIBRATION OF $\triangle P$

TRANSTLCER SYSTEMS

........................ 19

3.4 ADD ITIONAL FACTOR S BE CONSLDEREI) LN THE ON-SITE CALIBRATLON OF DIFFERENTIAL PRESSURE METERS USING TRANSFER REFERENCE

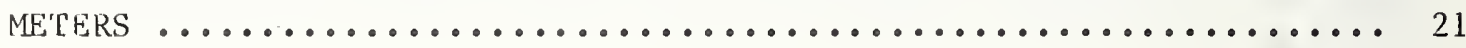

4. ON-SETE CALIBRATION OF OTHER FLOW METERING SYSTEMS ............. 29

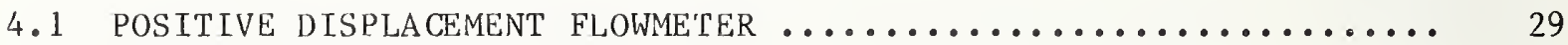

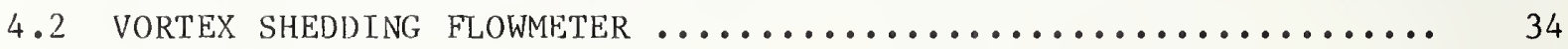

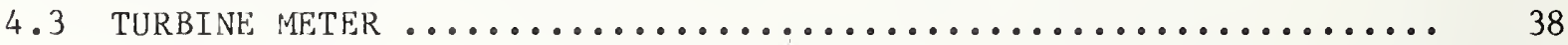

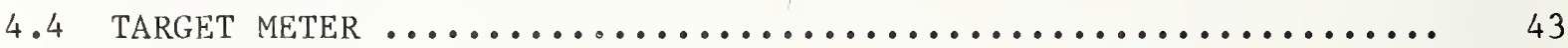

4.5 MULTIPLE PITOT-STATIC AND REVERSE-PITOT TUBE ASSEMBLIES $\ldots \ldots \ldots 48$

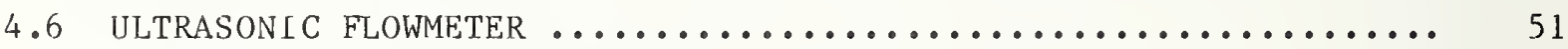

4.7 Insertion tYPe turbine meter $\ldots \ldots \ldots \ldots \ldots \ldots \ldots \ldots \ldots \ldots \ldots \ldots \ldots \ldots \ldots$

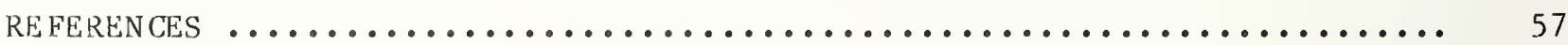

ACKNOWLEDGMENTS....................................... 59

APPENDIX A. COEEFICIENT OF DISCHARGE C AND FLUID EXPANSION FACTOR Y FOR ORIFICES, FLOW NOZZLES AND VENTURI METERS .......... A A

APPENDIX B. FLUID PROPERTIES AND FLOW QUANTITY CONVERSION FACTORS ..... B-1

APPENDIX C. TEMPERATURE AND PRESSURE RELATIONS $\ldots \ldots \ldots \ldots \ldots \ldots \ldots \ldots \ldots \ldots \ldots$

APPENDIX D. RELATION BETWEEN MASS AND VOLUME RATE OF FLOW $\ldots \ldots \ldots \ldots \ldots \ldots$ D-1 
APPENDIX E. ILLUSTRATIVE EXAMPLES $\ldots \ldots \ldots \ldots \ldots \ldots \ldots \ldots \ldots \ldots \ldots \ldots \ldots \ldots$

E. 1 MASS AND VOLUME RATES OF FLOW, SUPERHEATED STEAM $\ldots \ldots \ldots \ldots \ldots$ E- 1

E.2 MASS AND VOLUME RATES OF FLOW, WET STEAM ............... E-2

E.3 MASS AND VOLUME RATES OF FLOW, DRY AIR .............. E-3

E.4 DENSITY OF MOIST AIR ............................ E-5

E.5 DIRECT CALIBRATION OF AN ORIFICE METER ON SITE WITH A GRAVIMETRIC CALIBRATOR ............................ E-7

E.6 CALIBRATION OF AN ORIFICE METER ON SITE USING THE TRANSFER METER METHOD ............................... E -11

E.7 ON-SITE CALIBRATION OF A POSITIVE DISPLACEMENT METER USING THE TRANSFER METER METHOD .......................... E-14

E.8 ON-SITE CALIBRATION OF A VORTEX SHEDDING METER USING THE TRANSFER METER METHOD .......................... E-18

E.9 ON-SITE CALLBRATION OF A TURBINE METER $\ldots \ldots \ldots \ldots \ldots \ldots \ldots \ldots \ldots$ E-22

E. 10 ON-S LTE CALIBRATION OF A TARGET METER .................. E-25 


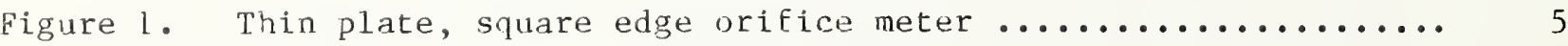

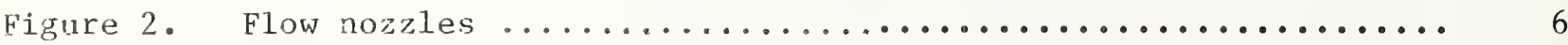

Figure 3. Nozzle venturi meter $\ldots \ldots \ldots \ldots \ldots \ldots \ldots \ldots \ldots \ldots \ldots \ldots \ldots \ldots \ldots$

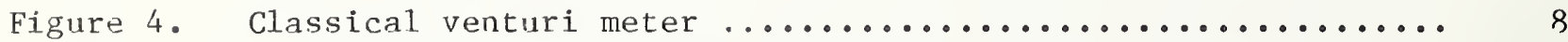

Figure 5. On-site calibration, transfer meter system downstream ...... 12

Figure 6. On-site calibration, transfer meter system upstream ....... 12

Figure 7. Transfer and working meter systems ................ 14

Figure 8. Gravimetric calibration system $\ldots \ldots \ldots \ldots \ldots \ldots \ldots \ldots \ldots \ldots \ldots$

Figure 9. Calibration system for steam .................... 20

Figure 10 . Systematic error in flowrate $M \ldots \ldots \ldots \ldots \ldots \ldots \ldots \ldots \ldots \ldots$

Figure 11. Orifice plate sensing line and valve schematic .......... 24

Figure 12. Tubular flow straightener design .................. 26

Figure 13. Perforated plate flow straightener ................... 27

Figure 14. Cross plate flow straightener $\ldots \ldots \ldots \ldots \ldots \ldots \ldots \ldots \ldots \ldots \ldots \ldots$

Figure 15. Cross section of a positive displacement meter .......... 30

Figure 16. Positive displacement meter performance .............. 33

Figure 17. Mechanical design of a vortex shedding flowmeter ......... 35

Figure 18. Vortex shedding flowmeter performance ............... 37

Figure 19. Axial flow turbine meter ........................ 39

Figure 20. Performance of a turbine meter $\ldots \ldots \ldots \ldots \ldots \ldots \ldots \ldots \ldots \ldots \ldots . . . . .41$

Figure 21 . Sketch of a target meter $\ldots \ldots \ldots \ldots \ldots \ldots \ldots \ldots \ldots \ldots \ldots \ldots$

Figure 22. Drag coefficient for two target meters .............. 45

Figure 23. Target meter flowrate outputs $\ldots \ldots \ldots \ldots \ldots \ldots \ldots \ldots \ldots \ldots \ldots$

Figure 24. Pitot-static rake assembly ....................... 49 


\section{LIST OF FIGURES ( Continued)}

$\underline{\text { Page }}$

Figure 25. Reversed pitot tube assembly ..................... 50

Figure 26. Single path, transit time ultrasonic flowmeter .......... 53

Figure 27 . Insertion type turbine meter $\ldots \ldots \ldots \ldots \ldots \ldots \ldots \ldots \ldots \ldots \ldots$

Figure 28. Velocity profiles for fully developed turbulent flow ....... 56

Figure A.1. Fluid expansion factor Y for orifice plates ............ A-20

Figure A.2. Fluid expansion factor $Y$ for flow nozzles and yenturi

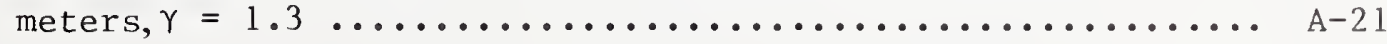

Figure A.3. Fluid expansion factor $\mathrm{Y}$ for flow nozzles and venturi

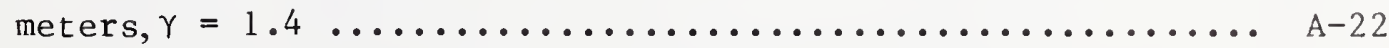

Figure B.1. Compressibility factor for air $\ldots \ldots \ldots \ldots \ldots \ldots \ldots \ldots \ldots$ B -7

Figure $\mathrm{B} .2$. Area factor $\mathrm{F}_{\mathrm{a}} \ldots \ldots \ldots \ldots \ldots \ldots \ldots \ldots \ldots \ldots \ldots \ldots \ldots \ldots \ldots \ldots$

Figure B.3. Dynamic viscosity of water $\mu$, and kinematic viscosity $\nu \ldots . . \quad B-9$

Figure B.4. Dynamic viscosity of saturated and superheated steam ...... B-10

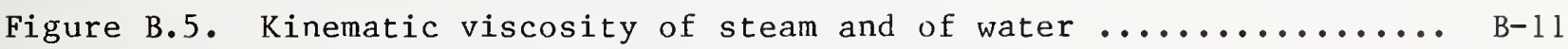

Figure B.6. Dynamic viscosity of air $\ldots \ldots \ldots \ldots \ldots \ldots \ldots \ldots \ldots \ldots \ldots \ldots \ldots$

Figure C.1. Conversion factor $\mathrm{F}_{w 1}$ for water columns ................. C-8

Figure C.2. Conversion factor $\mathrm{F}_{\mathrm{m} 1}$ for mercury columns ............ C-9

Figure C.3. Water manometer correction factor $F_{w 2}$ for air column density ................................. c-10

Figure C.4. Mercury manometer correction factor $F_{m 2}$ for air column density .................................. $c-11$

Figure E.1. Coefficient of discharge for an orifice meter ......... E-15

Figure E.2. Calibration factor for a turbine meter ............. E-26

Figure E.3. Performance of a target meter ................... E-30 
Table 1. Pressure Loss through Differential Pressure Primary

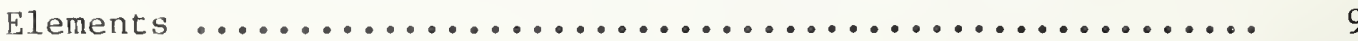

Table A.l Coefficient of Discharge C, Orifice Plates ............. A-2

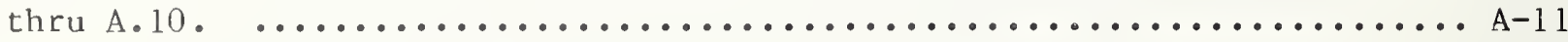

Table A.11. Coefficient of Discharge C, 1932 ISA Flow Nozzle ......... A-12

Table A.12. Coefficient of Discharge C, Long Radius Flow Nozzle ....... A-13

Table A.13. Coefficient of Discharge C, Nozzle Venturi Meter ......... A-14

Table A.14. Coefficient of Discharge C, Classical Venturi Meter ........ A-15

Table A.15. References, Equations for Coefficient of Discharge........ A-16

Table A.16. Fluid Expansion Factor Y for Flow Nozzles and Venturi

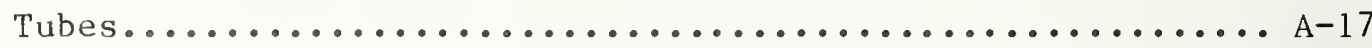

Table A.17. Uncertainty of Discharge Coefficients..................18

Table A.18. Uncertainty of Expansion Factors......................

Table B.1. Density of Saturated and Compressed Water ............ B-2

Table B.2. Density of Mercury $\ldots \ldots \ldots \ldots \ldots \ldots \ldots \ldots \ldots \ldots \ldots \ldots \ldots \ldots \ldots$

Table B.3. Conversion Factors for Mass, Volume, and Mass and Volume

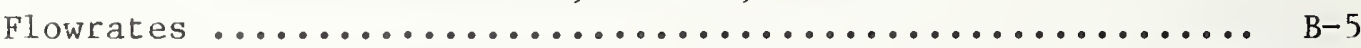

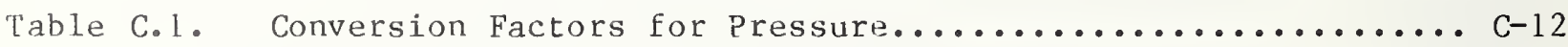

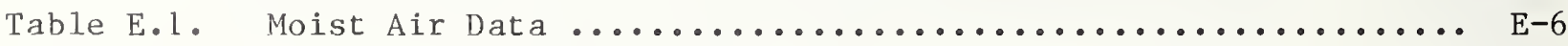

Table E.2. Sample Data for Calibration of an Orifice Meter ......... E-8

Table E.3. Turbine Meter Calibration Data ........................ E

Table E.4. Target Meter Calibration Data ..................... E-29 


\section{Units}

a

C

CF

d

D

$\left(\frac{10}{20}\right.$

F

$$
\mathrm{F}_{\mathrm{g}}
$$

$\mathrm{F}_{\mathrm{ml}}$ Combined conversion factor for mercury to convert inches of mercury at a known temperature to psi

$F_{m 2}$ Correction factor for density of air in the high pressure leg of a mercury manometer

$\mathrm{F}_{\mathrm{m} 3} \quad$ Correction factor for density of water in the high pressure leg of a mercury manometer

$\mathrm{F}_{\mathrm{W} 1} \quad$ Combined conversion factor for water to convert inches of water at a known temperature to psi

$\mathrm{F}_{\mathrm{W} 2}$ Correction factor for density of air in the high pressure leg of a water manometer

$\mathrm{f}$

Frequency

$g_{C}$

Dimensional and proportional constant relating force, mass and acceleration $(=32.1740)$

$\mathrm{g}_{\mathrm{L}}$

Local acceleration due to gravity $\mathrm{ft} / \mathrm{s}^{2}$

none

*

in.

in.

$1 b_{\overline{1}}$

none

none

psi/in. $\mathrm{Hg}$

none

none

psi/in. $\mathrm{H}_{2} \mathrm{O}$

none

$\mathrm{Hz}$

$(1 b \cdot f t) /(1 b$

$\mathrm{ft} / \mathrm{s}^{2}$

* As designated 
Units

\begin{tabular}{|c|c|c|}
\hline h & Differential pressure at manometer temperature & $\begin{array}{l}\text { in. } \mathrm{H}_{2} \mathrm{O} \text {, or } \\
\text { in. } \mathrm{Hg}\end{array}$ \\
\hline$h_{W}$ & $\begin{array}{l}\text { Differential pressure at reference conditions, } 68^{\circ} \mathrm{F} \\
\text { and standard gravity }\end{array}$ & in. $\mathrm{H}_{2} \mathrm{O}$ \\
\hline I & Transmitter current & ma $\mathrm{DC}$ \\
\hline K & Meter calibration factor & * \\
\hline $\mathrm{m}$ & Mass & $1 b$ \\
\hline M & Mass rate of flow & $1 \mathrm{~b} / \mathrm{hr}$ \\
\hline $\mathrm{p}$ & Pressure relative to existing atmospheric pressure & psig \\
\hline $\mathrm{P}$ & Absolute pressure & psia \\
\hline$P_{b}$ & Barometric pressure & $\begin{array}{l}\text { psia } \\
\text { in. } \mathrm{Hg} \text { at } 32\end{array}$ \\
\hline$P_{g}-$ & Saturation pressure & psia \\
\hline$\Delta \mathrm{P}$ & $\begin{array}{l}\text { Differential pressure between points in a flow } \\
\text { system; flowmeter differential pressure }\end{array}$ & * \\
\hline Q & Volumetric rate of flow & $\mathrm{ft}^{3} / \mathrm{min}$ \\
\hline $\mathrm{r}$ & Pressure ratio $\mathrm{P}_{2} / \mathrm{P}_{1}$ where $\mathrm{P}_{1}-\mathrm{P}_{2}=\Delta \mathrm{P}$ & none \\
\hline $\mathrm{R}$ & Gas constant & $(\mathrm{psia}) \mathrm{ft} / 1 \mathrm{~b}$ \\
\hline $\mathrm{R}_{\mathrm{D}}$ & Pipe Reynolds number $D V \rho / \mu$ & none \\
\hline$t$ & Temperature & ${ }^{\circ} \mathrm{F}$ \\
\hline $\mathrm{T}$ & Absolute temperature & ${ }^{\circ} \mathrm{R}$ \\
\hline $\mathrm{v}$ & Specific volume & $\mathrm{ft}^{3} / 1 \mathrm{~b}$ \\
\hline V & Velocity & $\mathrm{ft} / \mathrm{s}$ \\
\hline Y & Expansion factor for air or steam & none \\
\hline
\end{tabular}


NOMENCLATURE ( Continued)

Units

Z Gas compressibility factor

none

$3 \quad$ Ratio d/D

none

$\gamma \quad$ Specific heat ratio $c_{p} / c_{v}$

none

$\rho \quad$ Density

$\mathrm{lb} / \mathrm{ft}^{3}$

lb/gallon

$\mu \quad$ Dynamic viscosity

$\mathrm{lb} /(\mathrm{ft} \cdot \mathrm{s})$

V

Kinematic viscosity

$\mathrm{ft}^{2} / \mathrm{s}$

$\emptyset$

Denotes "function of"

none

Note: This list comprises principal symbols; additional symbols are defined as needed 
In view of the presently accepted practice of the building industry in the United States and the status of engineering references and tables used by Engineering Management Control Systems (EMCS) personne1, common U.S. units of measurements have been used in this report. In recognition of the United States as a signatory to the General Conference of Weights and Measures, which gave official status to the SI system of units in 1960, appropriate conversion factors have been provided in the table below. The reader interested in making further use of the coherent system of SI units is referred to: NBS SP330, 1972 Edition, "The International System of Units;" E830-72, ASTM Metric Practice Guide (American National Standards 2210.1); or 1976 Edition of ASHRAE SI Metric Guide for Heating, Refrigerating, Ventilating and Air-Conditioning. Additional SI conversions are given in appendices $B$ and $C$ of this report.

\section{Metric Conversion Factors}

To convert from

\section{Acceleration}

$\mathrm{ft} / \mathrm{s}^{2}$

$\frac{\text { Area }}{\mathrm{ft}^{2}} 2$
in.

$\underline{\text { Energy }}$

British thermal unit joule (J)

$\underline{\text { Force }}$

pound-force (1bf)

\section{$\underline{\text { Length }}$}

ft

in.

$\underline{\text { Mass }}$

$1 b$

metre (m)

metre (m)

b
To

Multiply by*

metre per second ${ }^{2}\left(\mathrm{~m} / \mathrm{s}^{2}\right)$

3.048000E-01

$\operatorname{metre}_{2}^{2}\left(\mathrm{~m}^{2}\right)$

9. 290304E-02

metre $2\left(\mathrm{~m}^{2}\right)$

$6.451600 \mathrm{E}-04$

$1.055056 \mathrm{E}+03$

newton (N)

$4.448222 E+00$

3. 048000E-01

2. 540000E-02

kilogram (kg)

4. 535924E-01

\footnotetext{
*The notation "xE+y," where $\mathrm{x}$ and $\mathrm{y}$ are numbers, is a standard form for indicating multiplication of the number $x$ by the number 10 raised to the power $\pm \mathrm{y}$.
} 
Mass per unit time

$1 \mathrm{~b} / \mathrm{h}$
$1 \mathrm{~b} / \mathrm{min}$
$1 \mathrm{~b} / \mathrm{s}$

Mass per unit volume kilogram per second $(\mathrm{kg} / \mathrm{s})$ kilogram per second $(\mathrm{kg} / \mathrm{s})$ kilogram per second $(\mathrm{kg} / \mathrm{s})$
1. $259979 \mathrm{E}-04$

7. $559873 \mathrm{E}-03$

4. $535924 \mathrm{E}-01$

1. $601846 \mathrm{E}+01$

$2.767990 \mathrm{E}+04$

1. $198264 \mathrm{E}+02$

\section{Pressure or stress}

atmosphere (standard)

in. of mercury $\left(32^{\circ} \mathrm{F}\right)$

in. of mercury $\left(60^{\circ} \mathrm{F}\right)$

in. of water $\left(39.2^{\circ} \mathrm{F}\right)$

in. of water $\left(60^{\circ} \mathrm{F}\right)$

$1 \mathrm{bf} / \mathrm{ft}^{2}$

lbf/in ${ }^{2}$ (psi)

Temperature

degree Fahrenheit

degree Celsius

degree Fahrenheit

degree Celsius

kelvin

degree Rankine kilogram per metre
kilogram per metre
$\left(\mathrm{kg} / \mathrm{m}^{3}\right)$

kilogram per metre ${ }^{3}\left(\mathrm{~kg} / \mathrm{m}^{3}\right)$
1. $013250 \mathrm{E}+05$

$3.38638 E+03$

3. $37685 E+03$

$2.49082 \mathrm{E}+02$

$2.4884 E+02$

4. $783026 \mathrm{E}+01$

$6.894757 \mathrm{E}+03$ degree Celsius $\left({ }^{\circ} \mathrm{C}\right)$

degree Fahrenheit $\left({ }^{\circ} \mathrm{F}\right)$

kelvin (K)

kelvin (K)

degree Celsius $\left({ }^{\circ} \mathrm{C}\right)$

kelvin (K) subtract 32 and divide by 1.8

multiply by 1.8 and add 32

add 459.67 and divide by 1.8

add 273.15

subtract 273.15

divide by 1.8

\section{Velocity (includes speed)}

$\mathrm{ft} / \mathrm{h}$

$\mathrm{ft} / \mathrm{min}$

$\mathrm{ft} / \mathrm{sec}$

in./s metre per second (m/s)

metre per second $(\mathrm{m} / \mathrm{s})$

metre per second $(\mathrm{m} / \mathrm{s})$ metre per second $(\mathrm{m} / \mathrm{s})$
$8.466667 \mathrm{E}-05$

5. $080000 \mathrm{E}-03$

3. 048000E-01

2. 540000E-02

*(see preceding page) 
Metric Conversion Factors (cont.)

To convert from

Viscosity (dynamic)

$\mathrm{lb} /(\mathrm{ft} \cdot \mathrm{s})$

Viscosity (kinematic)

$f t^{2} / s$

Volume

$\mathrm{ft}^{3}$

gallon (U.S. liquid)

in. 3

Volume per unit time

$\mathrm{ft}^{3} / \mathrm{min}$

$\mathrm{ft}^{3} / \mathrm{s}$

gal (U.S. Iiquid)/min $\underline{\text { To }}$

$1.488164 \mathrm{E}+00$

pascal-second $(\mathrm{Pa} \cdot \mathrm{s})$

metre ${ }^{2}$ per second $\left(\mathrm{m}^{2} / \mathrm{s}\right)$

$9.290304 \mathrm{E}-02$

metre ${ }^{3}\left(\mathrm{~m}^{3}\right)$

metre ${ }^{3}\left(\mathrm{~m}^{3}\right)$

metre ${ }^{3}\left(\mathrm{~m}^{3}\right)$

$2.831685 \mathrm{E}-02$

$3.785412 \mathrm{E}-03$

$1.638706 \mathrm{E}-05$

metre $_{3}^{3}$ per second $\left(\mathrm{m}_{3}^{3} / \mathrm{s}\right)$

metre $\mathrm{m}_{3}$ per second $\left(\mathrm{m}_{3}^{3} / \mathrm{s}\right)$

metre ${ }^{3}$ per second $\left(\mathrm{m}^{3} / \mathrm{s}\right)$
4.719474E-04

$2.831685 \mathrm{E}-02$

$6.309020 \mathrm{E}-05$

*(see preceding page) 
Certain commercial equipment and instrumentation are identified by name in this report in order to adequately describe the types, capabilities, and technical features of hardware available for flow metering and the on-site calibration of flow metering instrumentation. In no case does such identification imply recommendation or endorsement by the National Bureau of Standards, nor does it imply that the material or equipment identified is necessarily the best available for the purpose. 
In monitoring the performance of building service systems, one of the most difficult parameters to measure is the flow of the various fluids (air, water, steam). As a consequence, in Energy Management and Control Systems (EMCS), the flowrate or the total quantity of flow is often the least accurate measurement. The energy consumed, however, normally depends directly on this parameter.

This document is intended as an aid or guide to building services personnel (service managers, engineers, technicians) who have a basic understanding of fluid flow and who may be faced with the task of making flow measurements in building systems. The main purpose of this document is to summarize calibration methods for flowmeter systems installed in buildings and to present under one cover essentially all hecessary data and equations needed, with the exception of steam tables, for the calculation of meter performance. Flowmeter types and their characteristics as they relate to calibration are also discussed. Fluids covered are air, water, and dry or super-heated steam. Emphasis is placed on the use of transfer reference meter systems where the working meter is calibrated on site by connecting it in series with a transfer meter, which need not be the same type as the working meter. Design characteristics of various types of flowmeters are listed in chapter 13 of reference 1.

While the transfer meter method is usually considered the most desirable choice, a second method used is the direct calibration method. In this case, either the working meter is removed from the building system and calibrated directly at a primary calibration facility employing a volumetric or weighing-type fluid collection and measurement system, or the working meter is calibrated on site against a volumetric or weighing system.

A third method, employed with differential pressure ( $\mathrm{P}$ ) meter systems of orifice, nozzle or venturi types, is to perform a direct calibration of the $\Delta P$ transducer. Then, using published data for discharge coefficients and fluid expansion factors for the meter primary element, the system accuracy can be estimated and the flow characteristics for the complete metering system can be determined.

For best accuracy, all flowmeters need to be calibrated using the working or service fluid under typical operating conditions including flowrates, temperatures, and pressures. Accuracies approaching those of primary calibration facilities (tenths of a percent) may be obtained with an on-site calibration using a volumetric or weighing-type collection and measurement system. However, this approach is usually too costly, requiring excessive time, space and/or labor. Also, this degree of accuracy is not often needed in EMCS. The transfer meter method is considered most feasible since the on-site installation and operational efforts are generally less demanding and good accuracy is possible. Reliable, accurate flow measurements depend on certain factors or conditions which often receive too little attention. Two of these factors are: (1) improper meter installation causing a distorted, asymmetrical flow pattern at the meter entrance, and (2) lack of sufficient follow-up or continuing calibration effort to assess the system performance for its entire service period. Admittedly, an adequate installation in existing EMCS lines of the transfer 
reference meter system and/or the working meter is often difficult, impractical, or virtually impossible. In any new construction, facilities for a transfer reference meter should be considered along with the design of the building mechanical systems.

The types of meters to he discussed include differential pressure types (orifice, flow nozzle, venturi, pitot-static tube, and reversed-type pitot); volumetric types (positive displacement, turbine and vortex); target (impact) and the ultrasonic meter (transit time). Each type will be discussed for use on water, air and steam as appropriate. A brief description of each meter is given, followed by the basic hydraulic or performance equation, installation notes, and sample calculations. Emphasis is placed on the orifice, nozzle, and venturi meters since they are used extensively as both transfer and working meters.

In an effort to make this publication most helpful to the intended user, supplementary data and information are included in the appendix sections as follows: Discharge coefficients and fluid expansion factors for orifice plates, flow nozzles, and venturi meters along with corresponding tolerance (uncertainty, accuracy) data for these quantities are given in appendix A. The sources for these data are references 2, 10, and 11. Properties of air, water, and steam along with mass/volume conversion factors needed for calculation of flow quantities are presented in appendix B. Temperature and pressure relations are given in appendix C. In particular, conversion factors for mechanical pressure gauges, pressure transducers, and liquid manometers are discussed. The relations between mass and volume rate of flow for gases are discussed in appendix D. Appendix $\mathrm{E}$ is a compilation of several example calculations given in detail. Those readers already familiar with the flow measurement techniques discussed here may prefer to read these examples first, before reviewing the main body of this report.

Many flow measurements involve the quantities force and mass. In the English system, the same word "pound" refers to both and therefore it becomes necessary to distinguish between the two quantities. In this report, " $1 b$ " refers to pound mass, and " $1 b_{f}$ " refers to pound force. These two quantities are related through Newton's second law, force = mass $x$ acceleration. The pound mass is defined in terms of the kilogram and the pound force is defined as the force exerted on a pound mass when it is subjected to the standard acceleration of gravity of $32.1740 \mathrm{ft} / \mathrm{s}^{2}$. When Newton's second law is used in equation form, a conversion factor designated $\mathrm{g}_{\mathrm{C}}$ is necessary to maintain both numerical and dimensional equality, i.e., $F=\mathrm{ma} / \mathrm{g}_{c}$. In the English system when the unit of force is designated $1 b_{f}$ and the unit of mass is $1 b, g_{c}=32.1740(1 b \cdot f t) /\left(1 b_{f} \cdot s^{2}\right)$.

Throughout this report, the reader will find references to scheduled maintenance calibration of the various types of metering methods described. Scheduled onsite calibration is recommended for all types of flow meters and their transmitting systems. The extent and type of on-site calibration varies from one type of meter to another. However, one major factor applicable to all types of flow metering calibration must be called to the attention of the reader in the introduction of this report to avoid repeating it throughout the text and to emphasize its importance when carrying out the actual on-site calibration and 
when setting up maintenance schedules for routine calibration: the deterioration of primary elements of the meter (the parts which interact with the flowing fluid) by abrasion and chemical and/or electrolytic reactions has been found to be a major problem in the continuous monitoring of fluids. This is especially true in monitoring the flow of liquids. The designer of a flow system is not always aware of the characteristics of the components in a metering device nor is he always aware of possible changes in the characteristics of the fluid which is to be monitored. In general, the deterioration of a metering system by abrasion and chemical and/or electrolytic reactions is a continuing problem that is hidden in the initial design and is often found to be the basis of onsite meter calibration problems. When continuous deterioration of any metering system becomes apparent from previous calibration records or from an erratic response of a metering system which cannot be readily diagnosed, one should always examine the primary parts of the meter for evidence of abrasion and chemical and/or electrolytic reaction with other components in the system. The transducer (i.e., a device which converts one form of energy into another) is also subject to deterioration from environmental conditions. In the case of the metering devices utilizing differential pressure ( $\Delta P$ ) measurements, the calibration of the transducers often is more critical than that of the primary elements.

3 
Since differential pressure meters of the orifice, flow nozzle, and venturi types are used extensively as both transfer and working meters, a brief description of them and the hydraulic equation from which the performance is calculated will be given here. These meters have been used for flow measurements in closed conduits dating back to the past century. Their characteristics have been investigated extensively and are well known. Bernoulli's theorem (1738) is the basis for the hydraulic equation.

\subsection{PHYSICAL CHARACTERISTICS}

Figures 1, 2, 3, and 4 indicate the shapes and pressure tap locations for orifice, flow nozzle, and venturi meters. When the meter is to receive a direct calibration, the choice of meter type is largely a matter of allowable building system pressure loss versus meter cost. Orifice meters are simple in design. They are manufactured from flat plates and therefore are relatively inexpensive, but they produce the largest pressure losses. The design of nozzle and venturi meters is more complex, with manufacture necessary from machined castings or welded sections, but these meters offer lower pressure losses. Table 1 gives pressure loss data for these types as a function of the beta ratio, $\beta=d / D$, where $d$ is the meter orifice or throat diameter and $D$ is the inside diameter of the pipe.

The primary element is known as that part of the meter system which interacts with the flowing fluid. In these meters, this is the orifice plate, flow nozzle, or venturi. The interaction causes fluid acceleration and pressure change. The secondary element is the instrument system which senses and measures this interaction; in these cases, the secondary element is a $\Delta \mathrm{P}$ transducer system or a differential manometer including the pressure sensing lines.

\subsection{HYDRAULIC EQUATION}

Two forms of the hydraulic equation from which the flowrate is calculated are:

$$
\begin{aligned}
& M=358.93\left(C Y d^{2} F_{a}\right)\left[\rho h_{W} /\left(1-\beta^{4}\right)\right]^{1 / 2} \\
& Q=5.982\left(C Y d^{2} F_{a}\right)\left[h_{W} / \rho\left(1-B^{4}\right)\right]^{1 / 2}
\end{aligned}
$$

where $358.93\left(1 b^{1 / 2 / h r}\right)\left(\mathrm{ft}^{3 / 2} / \mathrm{in}^{5 / 2}\right)$

$$
5.982\left(\mathrm{ft}^{3 / 2} / \mathrm{min}\right)\left(1 \mathrm{~b}^{1 / 2} / \mathrm{in}^{5 / 2}\right)
$$

$M=$ mass flowrate, $1 \mathrm{~b} / \mathrm{hr}$

$\mathrm{Q}=$ volume flowrate, $\mathrm{ft}^{3} / \mathrm{min}$

$\mathrm{C}=$ coefficient of discharge, dimensionless

$\mathrm{Y}=\mathrm{fluid}$ expansion factor, dimensionless

$\mathrm{d}=$ diameter of orifice, nozzle throat, or venturi throat, in.

$p=$ density of fluid entering primary element, $1 \mathrm{~b} / \mathrm{ft}^{3}$

$\mathrm{h}_{\mathrm{W}}=$ differential pressure $\mathrm{P}_{1}-\mathrm{P}_{2}$, inches of water at $68^{\circ} \mathrm{F}$

$\beta=$ ratio $d / D$, dimensionless, where $D$ is the pipe inside diameter

$\mathrm{F}_{\mathrm{a}}=$ area factor for thermal expansion of a primary element, dimensionless 


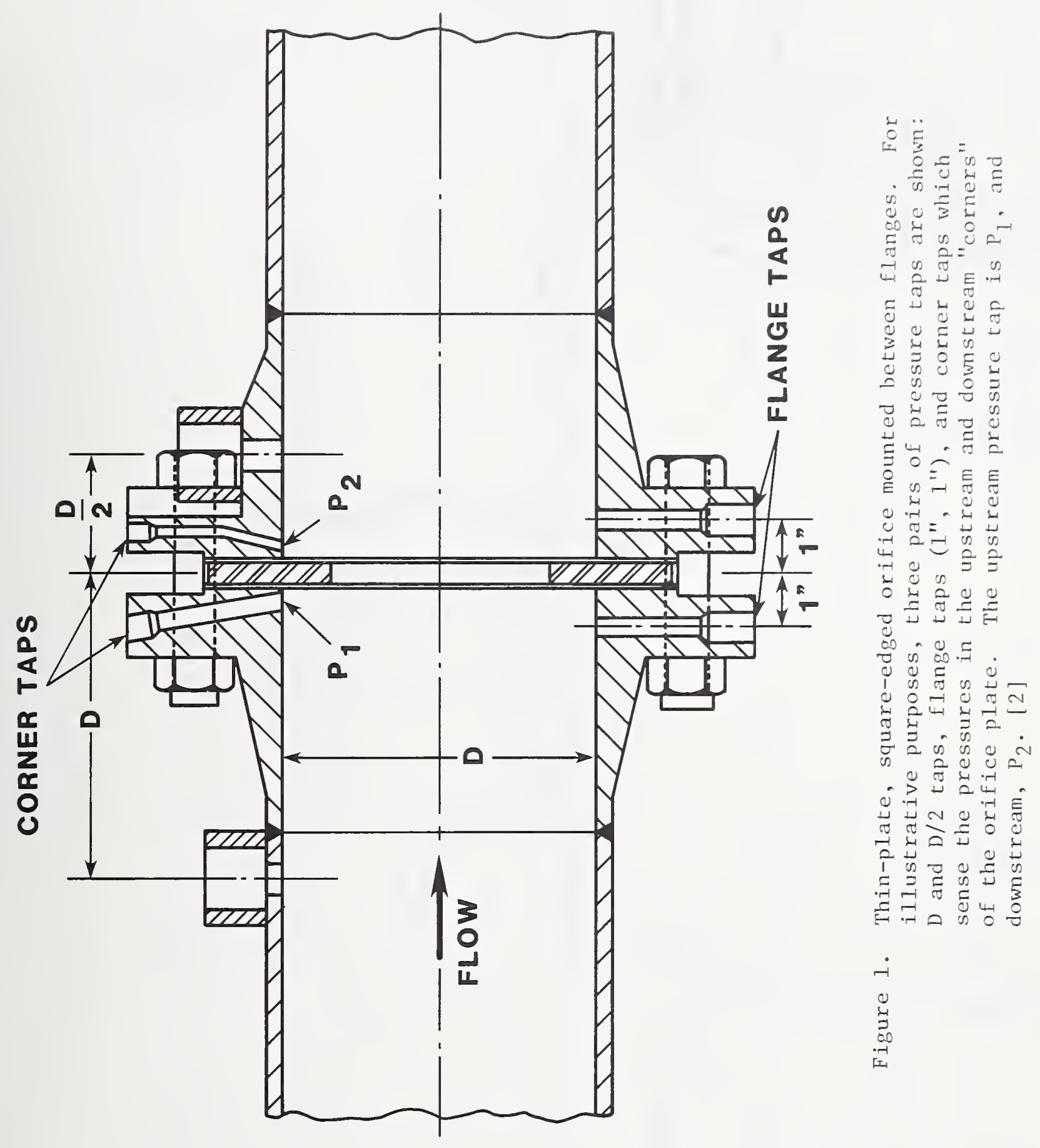




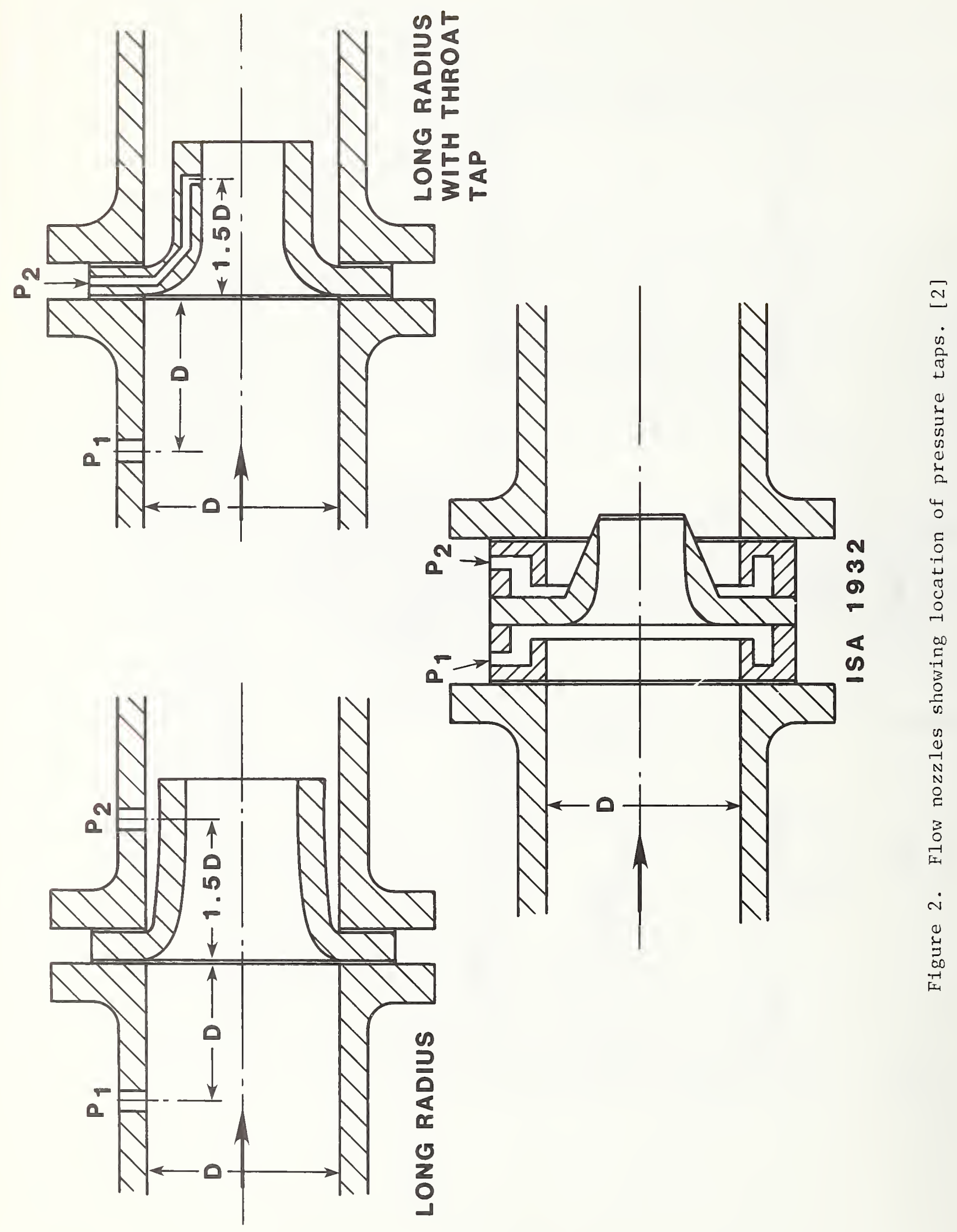




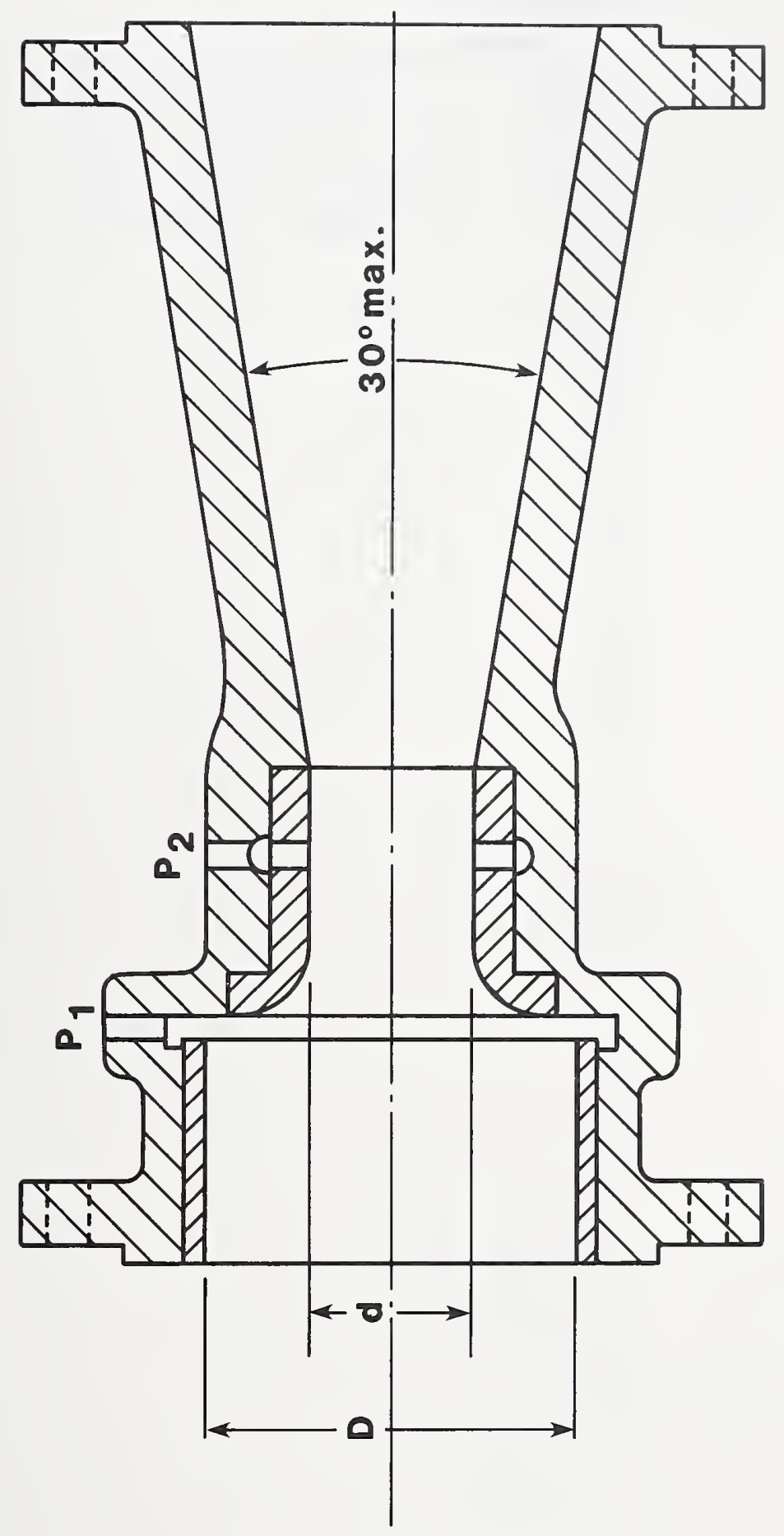

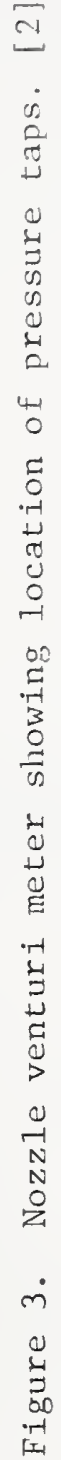




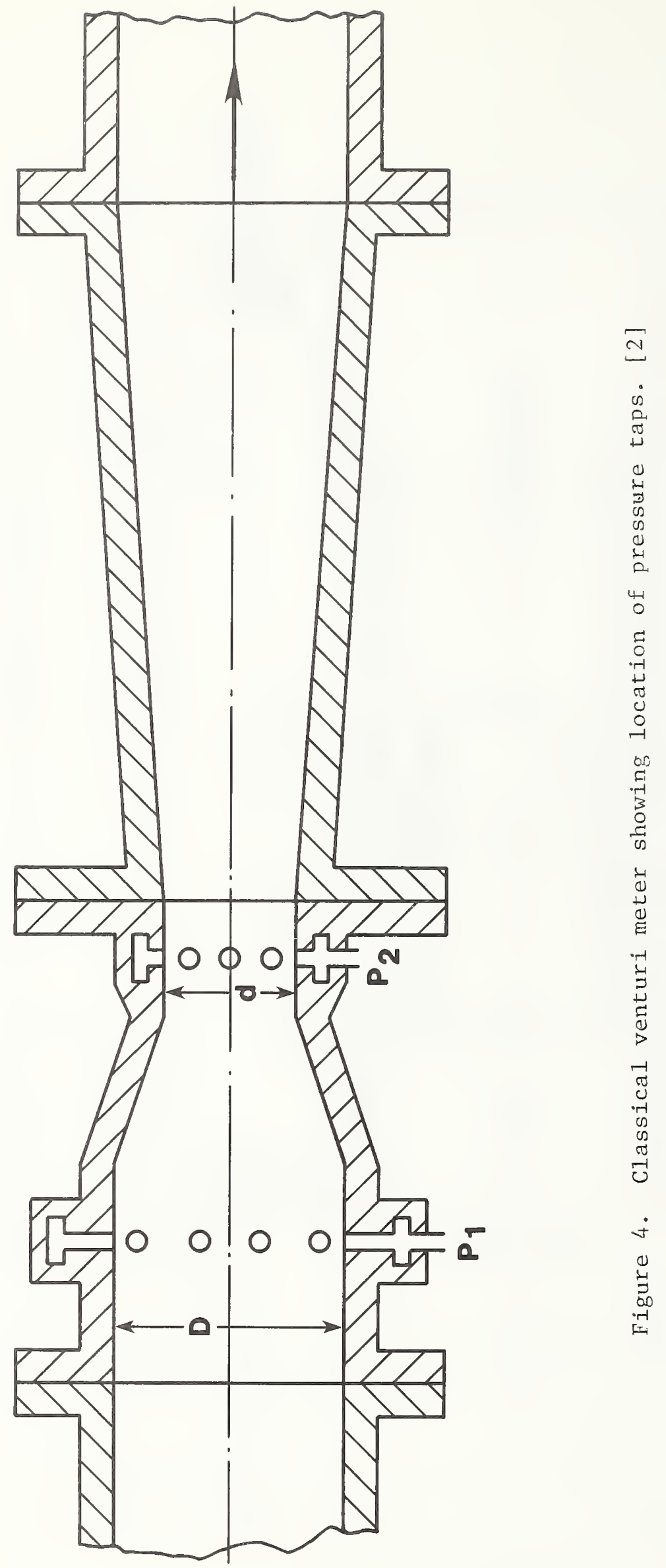


Table 1. Pressure Loss Through Differential

Pressure Primary Elements

\begin{tabular}{c|cccc}
\hline & & Pressure Loss in Percent of Actual Differential Pressure \\
\hline $\begin{array}{c}\text { Ratio } \\
\beta\end{array}$ & Orifice* & Flow Nozzle* & Nozzle Venturi** & Classical Venturi* \\
0.3 & 88 & 86 & 26 & 13 \\
.4 & 82 & 75 & 22 & 12 \\
.5 & 73 & 64 & 17 & 11 \\
.6 & 63 & 53 & 15 & 10 \\
.7 & 52 & 41 & 13 & 11 \\
\hline
\end{tabular}

Classical venturi meters, $7^{\circ}$ outlet cone

* Reference 2

** BARCO (Aeroquip) catalog 866 
The theory of flow of fluids in terms of pressure differences and a derivation of these equations may be found in reference 2, pages 47-56. Equations (2-1) and (2-2) apply for subsonic flow.

When calibrating a working meter on site, the flowrate $M$ or $Q$ is measured either by the transfer reference meter system or by a direct calibration system. The quantity $h_{W}$ is the working meter output. The fluid expansion factor is considered a known quantity; for liquids, $Y=1.000$ and for gases, $Y$ is calculated from gas relations. Thus, with $\mathrm{d}, \mathrm{Fa}, \rho$, and $\beta$ known, common practice is to determine the discharge coefficient, C, for the particular working meter.

The coefficient of discharge is defined as

$$
C=\frac{\text { Actual rate of flow }}{\text { Theoretical rate of flow }}
$$

In turbulent flow, this coefficient must be measured experimentally. It depends on the shape of the primary element (orifice, nozzle, venturi), the pressure tap locations (flange; 1D, 1/2D; corner), the $\beta$ ratio, and the Reynolds Number, $\mathrm{R}_{\mathrm{D}}=\mathrm{DV} \rho / \mu$, where $\mathrm{V}$ is the fluid average velocity and $\mu$ is the dynamic viscosity. Its dependence on flowrate is through $V$, and on fluid properties through $\rho$ and $\mu$. It is important to note that once a $\Delta \mathrm{P}$ meter is calibrated using one fluid, its performance with other fluids can be predicted through this $C$ vs $R_{D}$ relationship. Data for this relationship are given in appendix $A$ for reference purposes.

The fluid expansion factor, $Y$, accounts for any change in density as the fluid flows through the primary element. For flow through nozzle and venturi meters, a correction based on ideal flow is used. This correction is dependent on the pressure ratio $\mathrm{P}_{1} / \mathrm{P}_{2}$, on the $\beta$ ratio, and on the gas specific heat ratio $\gamma=\mathrm{C}_{\mathrm{p}} / \mathrm{C}_{\mathrm{v}}$. For flow through orifices, an empirical relation is used. For liquids, $\mathrm{Y}=1$. Appendix A gives equations and tabular data for $\mathrm{Y}$.

The factor $\mathrm{F}_{\mathrm{a}}$ accounts for any expansion or contraction in the meter throat or orifice area due to temperature increase or decrease from the (ambient) temperature which existed when diameter d was determined. For operating temperatures within $50^{\circ} \mathrm{F}$ of ambient, this effect can usually be ignored. Figure B-8 in appendix $B$ includes graphical data for $F_{a}$ as a function of temperature for several materials used in primary elements. 


\subsection{TRANSFER REFERENCE FLOWMETER SYSTEM}

A transfer reference flowmeter system consists of one or more flowmeters with upstream and downstream piping sections along with flow straightening vanes and (usually) all necessary transducer and readout equipment. This system is calibrated at a primary calibration facility such as NBS or a qualified independent laboratory and then installed and used on site as the reference meter to calibrate the working meter(s). For $\Delta \mathrm{P}$ reference systems, the pressure transducers and their sensing lines must be included in all primary and routine calibrations since they may be influenced by the system performance. For maximum accuracy, the transfer flowmeter should be calibrated using the same fluid at test conditions (pressure, temperature, flowrates) which can be expected to occur during later use on site. In this way, the performance of the working meter can be "traceable" to a primary calibration facility. Periodic recalibration of the transfer reference flowmeter system is imperative. Maintenance of a reference file on each meter will help the user determine the frequency of a recalibration schedule.

Use of transfer reference systems is often the most practical method for calibrating building-systems working flowmeters. Direct calibration may be too expensive, particularly where large numbers of on-site meters are involved. While there is some loss of accuracy over that achievable by direct calibration of the working meter at a primary calibration facility, perhaps of order $2: 1$, there is a compensating gain in efficiency since one transfer meter may be used to calibrate many working meters. On-site calibration may tend to mask errors in meter performance due to local piping system characteristics such as distorted flow patterns downstream of pipe bends, or temperature gradient effects in $\Delta \mathrm{P}$ meter sensing lines. Although such effects may be unknown, every effort should be made to eliminate distorted flow patterns through use of good meter installation practices. For example, the configuration shown in figure 5 is preferred over that shown in figure 6 .

An ideal fluid flowmeter responds only to flowrate or fluid quantity collected and, for a given flow, it will always produce the same output. In the real world, however, many factors can affect the flowmeter performance. To serve as a suitable transfer (or working) meter, all parameters or factors which affect performance must be known and must remain under adequate control. For example, many types of meters are influenced by fluid viscosity. Furthermore, the $\Delta \mathrm{P}$ meter calibration factor or discharge coefficient often varies with flowrate. In addition, swirling flow or transverse flow components such as those immediately downstream from elbows and valves influence the accuracy of many meters. Many meters fail to operate satisfactorily in dirty fluids containing foreign particles such as rust or pipe scale which have detrimental effects on meter repeatability. All such factors need adequate attention and control.

Figure 5 shows a flow schematic for on-site calibration of a working meter system with the transfer meter system downstream, and figure 6 gives a similar schematic with the transfer meter system upstream. In each, valve functions are as follows: 

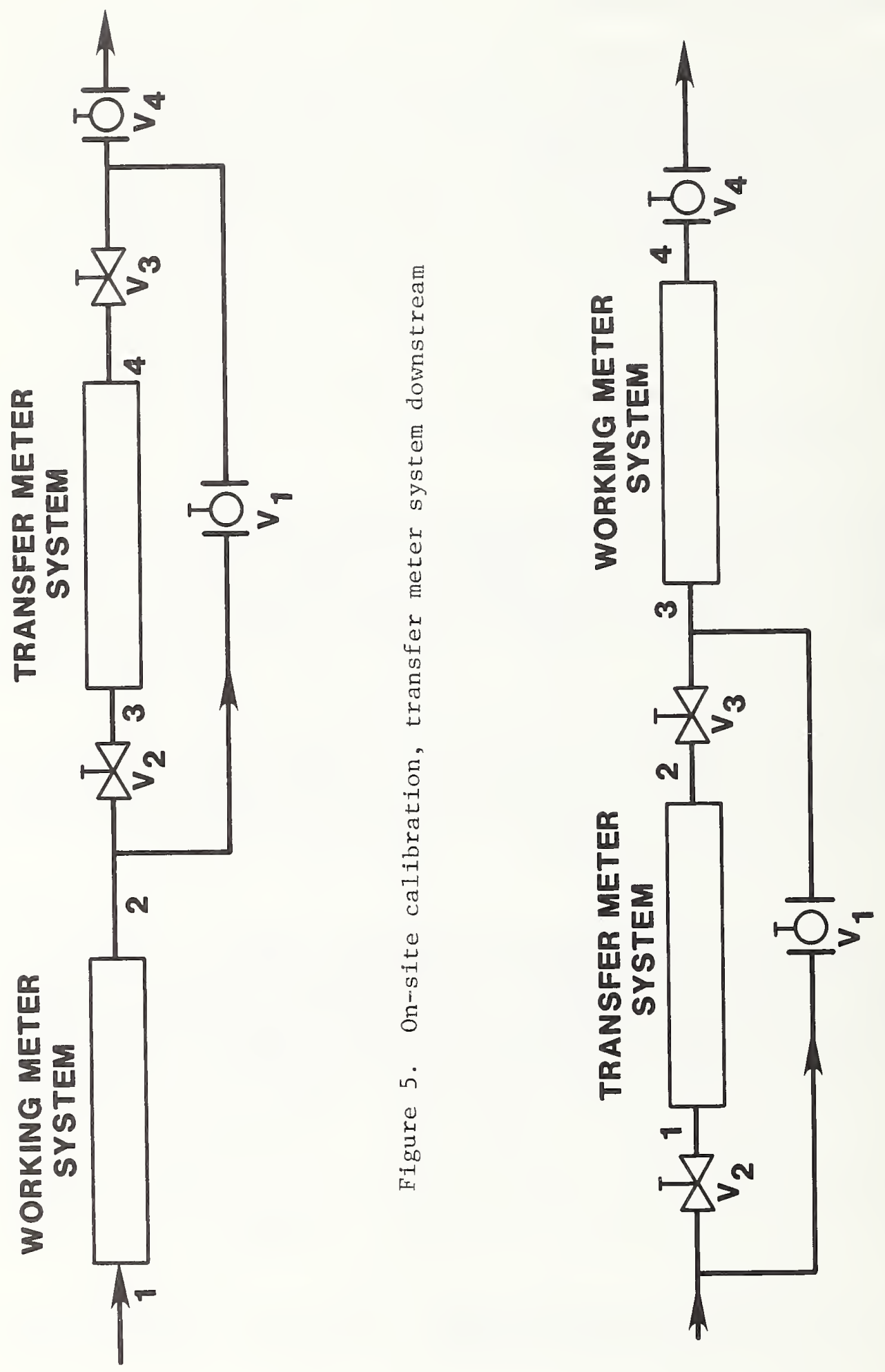

D 


\begin{tabular}{|c|c|c|c|}
\hline Valve & Calibration & Norma1 & Notes \\
\hline V1 & Closed & Open & $\begin{array}{l}\text { Blocking valve, positively no leakage } \\
\text { allowed, low } \Delta \mathrm{P} \text {, suggest ball valve }\end{array}$ \\
\hline V2, V3 & Open & Closed & $\begin{array}{l}\text { Isolation valves, full open during } \\
\text { calibration, low } \Delta P \text {, suggest gate } \\
\text { valves }\end{array}$ \\
\hline V4 & Control & Open & $\begin{array}{l}\text { Flowrate control valve, must be } \\
\text { downstream of both systems, fine con- } \\
\text { trol necessary, low } \Delta \mathrm{P} \text { when open, } \\
\text { suggest ball valve }\end{array}$ \\
\hline
\end{tabular}

Note: Valves V1 - V4 should be permanent in the working system to permit periodic re-calibration.

Since all fluid must pass through both meters, the need for a high quality, non-leaking blocking valve Vl, can not be overemphasized. An alternative would be the use of three valves in lieu of V1 in a Tee arrangement with the leg valve vented to the atmosphere during calibration. Any leakage would be apparent through this vent valve. Likewise, there should be no leakage through the branch circuits between the two meter systems. Valves V2 and V3 allow the transfer meter system to be deactivated or used elsewhere during normal operation. With the transfer meter system downstream (figure 5), V4 could be eliminated, with flow control accomplished through V3. However, V2 should never be used for flow control in either case because this could disturb the flow pattern in the transfer meter system. For the same reason (flow pattern control), the transfer meter system downstream configuration is preferred.

Figure 7 gives minimum straight pipe requirements for each part of the transfer and working meter systems. Each metering system requires a minimum of about 20D of straight pipe. Flow straightening vanes or tube bundles are necessary in both cases, unless very long straight pipe lengths (estimated greater than 100D to $150 \mathrm{D}$ minimum) exist upstream. It is noted that most standards, including reference 2, recommended shorter lengths when no straightening vanes are used. However, more recent research indicates that these lengths are too short to eliminate the predicted effects on accuracy. See reference 4 for experiments conducted with elbows upstream of orifice plates and reference 5 for experimental results which show that swirling flow decays at quite low rates in pipes at Reynolds numbers comparable to those existing in building systems (turbulent flow). Also, it must be realized that tubular type flow straighteners only eliminate swirling or transverse velocity components; they will not completely reshape the axial velocity profile to a fully developed or even a symmetrical one. Therefore, a meter which requires a fully developed velocity profile such as the transit time ultrasonic type may not perform to best accuracy unless some other flow conditioning device such as a perforated plate type flow straightener or very long straight runs are used to aid in development of a fully developed profile. However, positive displacement (PI) meters are not normally affected by swirling flow and flow straighteners may often be 


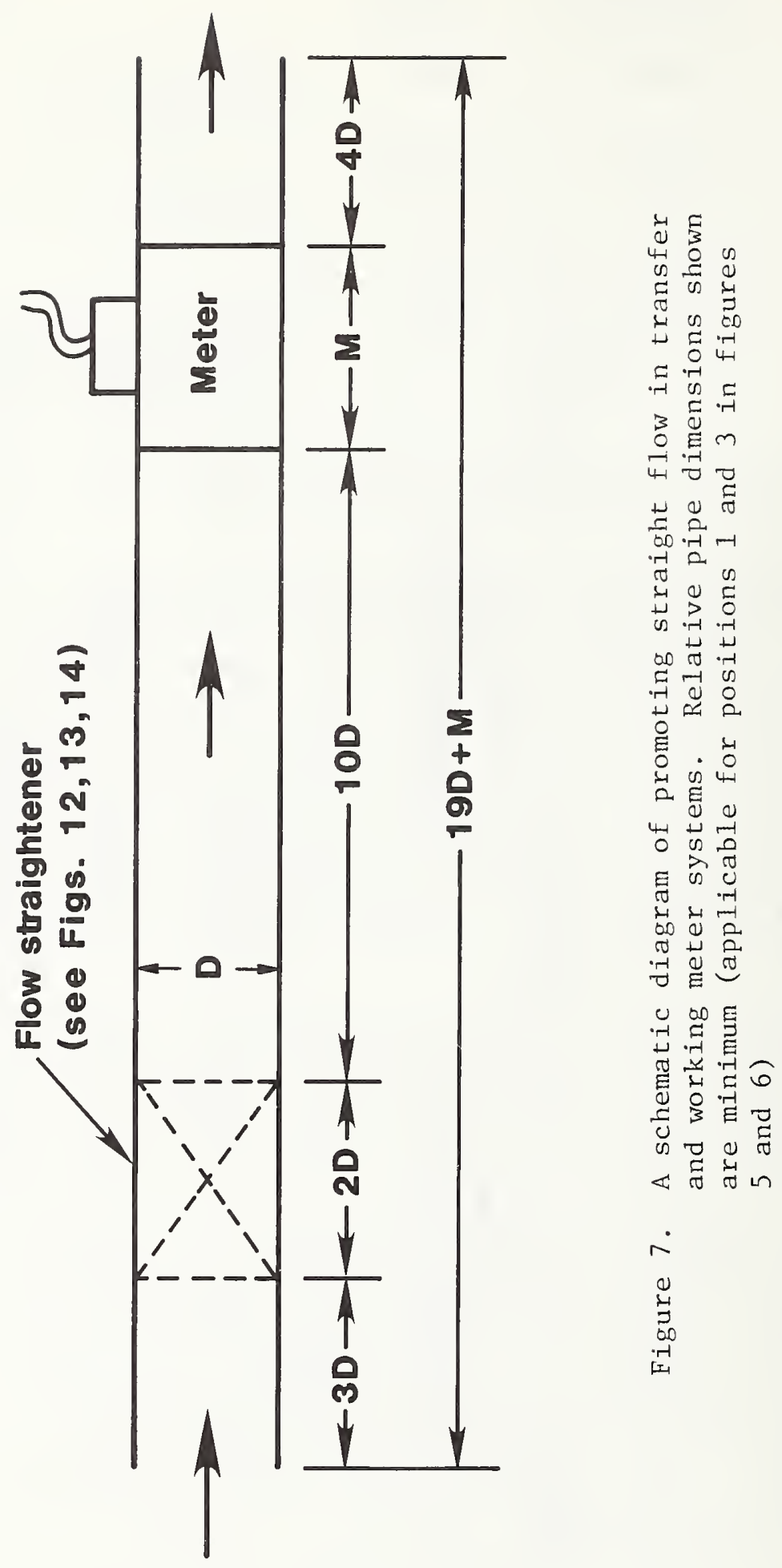


eliminated. Consequently, PD meters are often recommended for situations where adequate straight piping runs are unavailable.

\subsection{DIRECT CALIBRATION METHOD}

The calibration of the working meter system against a volumetric or weighing type fluid measurement system is known as a direct calibration. The working meter system is either removed from the building system and calibrated at the primary calibration facility, or the working meter is calibrated using on-site volumetric or weighing facilities. When it is to be calibrated at the primary facility, it is important that the entire working meter system (figure 7 ) be removed and calibrated at this facility. During on-site calibration, the fluid is directed into the volumetric or weighing system downstream of the working meter with precautions taken to ensure that no leakage or branch circuits cause fluid to be lost before entering the calibration equipment. The following comments pertain to direct calibration on site.

For building systems involving flowing water, a direct on-site calibration may be more satisfactory than the transfer method for differential pressure $(\Delta P)$ meters of sizes accommodating less than 2-inch pipe for the following reasons: the uncertainties of the discharge coefficients are large and sometimes unavailable; and, flow measurements in these smaller sizes can usually be made with satisfactory accuracy using commercially available equipment of reasonable size and cost. (For example, commercially available scales offer good accuracy at reasonable cost.)

The calibration of a volumetric metering system by use of smaller reference volumes or by physical measurement is often considered less convenient. Therefore, volumetric-type meters are often calibrated using a volumetric-type meter which has been calibrated using the gravimetric calibration method with the water in the same temperature range.

A gravimetric-type calibrator system for water is shown in figure 8 . The basic equipment are the scales and weigh tank, a timer, a thermometer, valves, and a timer switch. Gravimetric systems are classified into two types according to the method used in collecting the water: the static-weigh and the dynamic-weigh methods.

\section{Static-Weigh}

Operation consists of:

1. Set flowrate.

2. Determine tare weight (mass) while water is diverted to drain or storage.

3. Divert flow to weigh tank, starting timer (or working meter counter for totalizing operation).

4. After collection of desired amount of water, divert flow to drain or storage, stopping timer or counter. 


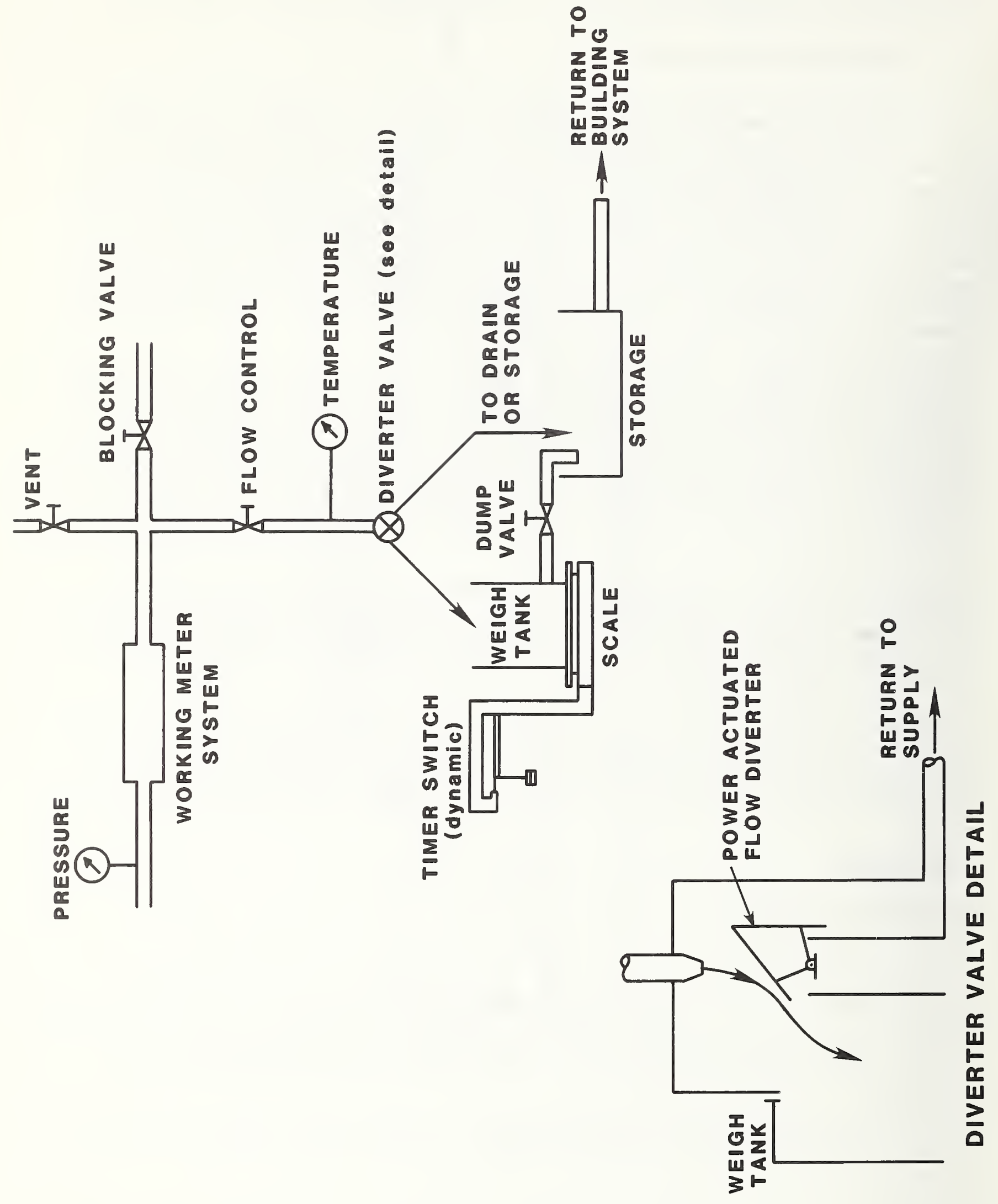


5. Determine gross weight (mass).

6. Drain weigh tank through dump valve (or pump out).

Flowrate $=$ Net Weight (mass) $/$ Time Interval

Meter Output/Pulse $=$ Net Weight (mass)/Total Count (pulse type output).

Weighing is performed with water stationary in the tank and the net weight (mass) can be determined quite accurately. The weighing, however, requires two operations and thus becomes time consuming. A critical component is the diverter valve. Its function is to direct the flow as desired to drain or storage, or to the weigh tank without disturbing the rate of flow through the working meter. The timer switch is connected directly to the diverter valve and should be adjusted to activate at the midpoint of the diverter operation. This switching is often performed using a suitable photocell and light source to develop a sharp on/off relationship at the midpoint. When the desired uncertainty is one percent or more, manual timing will usually be satisfactory if the diverter valve and timer are operated with the required care.

Dynamic-Weigh

Operation consists of:

1. Set flowrate with dump valve open and tare weight on the weigh beam.

2. Close dump valve. Tank begins to fill.

3. When tare weight is balanced, beam rises, starting timer or counter.

4. Place weights on scale beam pan corresponding to the desired amount of water being collected, lowering beam.

5. When total counterpose weights are balanced, beam rises again, stopping timer or counter.

Thus, the time interval or total count for a preselected amount of water to enter the weigh tank is determined, and the weighing operation is completed "on the run" while the water enters the tank. This method has the advantage of consuning less time and offers greater convenience compared to the static method. The timer switch activated by the weigh beam may be a direct contact, magnetic, capacitance, or optical type. When load cells are used for weighing, the timer start/stop circuitry must, of course, sense the load cell system output. Possible errors due to the change in inertia of the water and added weights should be considered. This inertia error is discussed in reference 22 . When the desired uncertainty is one percent or nore, manual tiner actuation may be used.

Pertinent features of both of these systems include:

The weigh tank capacity should be sufficient for a minimum collection time of 30 seconds at the maximum flowrate plus tare weight collection time. For manual timing, a minimura collection time of l minute is recomended. 
It j.s important that no part of the system touches or rubs against the weigh tank. If it is mandatory that the system be connected to the weigh tank, then the construction should be such that no vertical force components are exerted on the scale from the system.

( It is essential that all of the flow and only that flow passing through the working meter be collected in the weigh tank. There nust be no leakage through the blocking valve or through any branch circuits. Any air or vapor must be vented at the high points. Keep all meter discharge lines as short as possible.

- Commercially available scales of conventional design with weigh beam and counterpoise wejghts are recommended for high accuracy at reasonable cost. For a calibration accuracy of 0.5 percent, a desirable scale accuracy would be 0.05 to 0.1 percent of reading. The scale should be calibrated in place with static weights, Commercial Class $C$, before the weigh tank is installed, and after the installation of the tank connections is complete. This procedure checks on possible interference from any connections. In selecting a scale, the scale sensitivity (weight necessary for shifting the weigh beam from an equilibrium position at the midpoint to an equilibrium position at either extremity) should be sufficient for the desired accuracy. However, more sensitivity than necessary should be avoided because scale "settling time" usually increases with sensitivity which increases the static weighing time unnecessarily. During dynamic weighing, increasing beam oscillations may generate unnecessary problems.

a When weighing to an accuracy of 0.5 percent or better, the air buoyancy effect should be considered. This effect is about 0.12 percent when water is weighed in air.

No leakage is allowed through the dump valve during the weighing or collection operations.

- The minimum net weight (mass) of water collected should be at least 10 percent of the scale capacity. When totalizing pulse-type meter outputs, the minimum net weight (mass) should correspond to at least 1000 pulses, preferably 5000 .

2 Water density is determined from the temperature and pressure, table B-1. Linear interpolation may be used if necessary. A mercury-in-glass thermometer is preferred, and it should be graduated in single degrees, accurate to one degree Fahrenheit or better.

(5) Water temperature should not exceed about $150^{\circ} \mathrm{F}$ due to liquid volatility and possible evaporation losses. At this temperature level, the weigh tank should be provided with a cover to reduce this loss. Safety precautions should be taken to avoid personnel injury when handling water at these temperatures in a system open to the atmosphere.

An example calibration of an orifice meter with a gravimetric calibrator system, including sample data and calculations, is included in appendix E, example E.5. 
Direct calibration of meters used to measure the flow of a gas such as air requires a closed weigh tank or a volumetric tank. Such approaches are used in primary calibration facilities, but because of their complexity and costs they are considered generally impractical for calibrating working meters on-site.

Flowmeters in building systeras monitoring steam flow may receive a direct calibration by measuring condensate flow provided all steam flowing through the working meter is condensed and flows through a single pipe at a convenient location. Great care must be exercised to trace all lines to assure that no loss through branch lines and that no leakage occurs. The major advantage to the steam-condensate method is that liquid flow is easier to measure accurately than is gas flow. Figure 9 shows a flow schematic for a calibration for steam flowmeters. Long pipe lines and service equipment such as heaters will normally be located between the working meter and the calibrator. Thus, calibration should be attempted only during periods of steady steam load. Even then, long periods may be required to obtain a steady flowrate in the meter and at the calibrator. The system should be vented as necessary to expel all air. The calibrator may be a gravimetric type as discussed above, or a positive displacement meter properly calibrated at a primary facility.

Procedures and equipment which can result in accurate measurements of the mass flowrate, $M$, have been described above. Such measurements require the services of personnel who are knowledgeable and experienced in measurement techniques and have access to the required equipment, space and labor. The level of accuracy thus attained may not be needed nor economical. Alternatives include the use-of a transfer reference meter system as discussed previously. For a $\Delta$ p meter, a differential-pressure performance evaluation of the flow measurement system based on the direct calibration of the $\Delta \mathrm{P}$ transducer only is required.

\subsection{PERFORMANCE EVALUATION FROM DIRECT CALIBRATION OF $\triangle P$ TRANSDUCER SYSTEMS ONLY}

In some situations, an on-site calibration of the working meter using a direct calibration or a transfer reference meter may not be feasible. However, with differential pressure $(\Delta \mathrm{P})$ transducers used on meters of the orifice, venturi, or flow nozzle types, their performance can be evaluated by performing direct calibration of the $\Delta \mathrm{P}$, pressure, $\mathrm{P}$, and temperature, $\mathrm{T}$, monitoring systems only. By using published data to obtain discharge coefficients and fluid expansion factors for the meter primary element, the flow characteristics or performance of the complete working meter system can then be determined. This approach requires relatively little straight pipe run since no transfer meter system is involved. However, the $\Delta \mathrm{P}, \mathrm{P}$, and $\mathrm{T}$ systems need to be calibrated. Appendix A is a compilation of available data and equations for discharge coefficients and fluid expansion factors for orifice, flow nozzle, and venturi type primary elements. Equations which may be used to assign uncertainties to the discharge coefficient and expansion factor are also included.

The disadvantages of this method include loss of accuracy due to the uncertainties assigned to the discharge coefficient and the expansion factor. In addition, when the $\Delta \mathrm{P}$ transducer is required to perform only within a narrow band corresponding to its full scale output, the loss of accuracy at the low or 


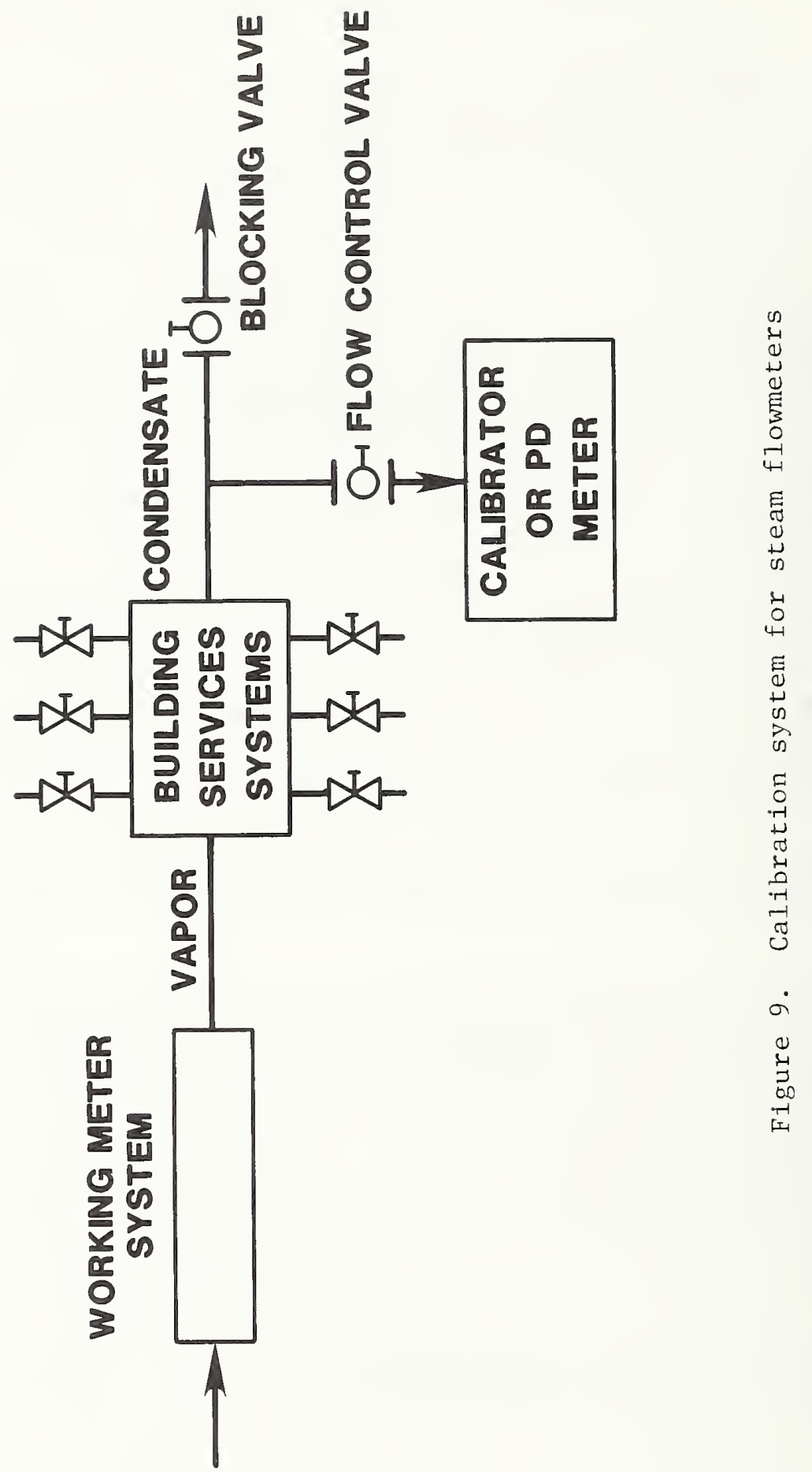


part scale $\Delta \mathrm{P}$ values can become quite large. For example, a transducer rated at 0.5 percent full scale would need only produce a differential pressure measurement accurate to within 5 percent at a $\Delta \mathrm{P}$ value of 10 percent full scale to still comply with its rated performance. This indicates the importance of using a transducer which has excellent repeatability characteristics and the need for periodic calibration over the operating range. Transducers are available which specify accuracy of the actual reading plus a small portion of the full scale reading ( Regardless of the specifie $\bar{d}$ accuracy, when a transducer is first put into service, 3 or 4 calibrations might be performed over a period of 6 months to a year and the results used to establish a performance curve from which linearity and hysteresis corrections can be made if necessary. Once the transducer performance has been established, intervals between the periodic calibrations may be increased. It should be noted that the $\Delta \mathrm{P}$ transducers often require a specified "warm-up" period and respond to changes in the ambient conditions by loss of accuracy.

When a system's flow rate more than doubles (range 4:1 in $\Delta \mathrm{P}$ ), the use of two $\triangle \mathrm{P}$ transducers may be preferred; one for HIGH $\triangle \mathrm{P}$ and one for LOW $\triangle \mathrm{P}$. Significant improvements in the uncertainty are possible through the use of this technique. For example, figure 10 shows the actual systematic error $e_{M S} / \mathcal{A}$, percent of rate, as a function of flowrate, M, for a HVAC system installed at NBS which uses two such transducers. For a flow range of 500 to $2000 \mathrm{lb} / \mathrm{hr}$, the systematic error ranged from about 2 to 5 percent with two transducers, whereas with one transducer ( $\mathrm{HIGH}$ ), the error would have ranged from about 2 to 15 percent. While $e_{M S}$ depended on the combined effects of several errors in this case, the error in $\Delta \mathrm{P}$ dominated at low $\Delta \mathrm{P}$ values. In this example, the $\Delta \mathrm{P}$ transducer error was expressed on a full scale basis and no linearity corrections were made.

Reference 23 is a detailed analysis of the performance of an energy monitoring system for steam flow at NBS using the above approach of direct calibration of the $\Delta \mathrm{P}, \mathrm{P}$, and $\mathrm{T}$ systems only. An appropriate method and sample calculation is given for estimating the uncertainty in the total energy consumed over a one-year period.

\subsection{ADDITIONAL FACTORS TO BE CONSIDERED IN THE ON-SITE CALIBRATION OF DIFFERENTIAL PRESSURE METERS USING TRANSFER REFERENCE METERS}

This section deals with on-site calibration of $\Delta \mathrm{P}$ meters of the orifice, flow nozzle, and venturi types using transfer meter systems as the reference. The transfer reference meter is calibrated off site and its flow characteristics or performance including an estimated uncertainty, are known. The transfer reference meter is not necessarily a $\Delta \mathrm{P}$ meter. Reasons for calibrating a $\Delta \mathrm{P}$ meter on site include the situations when a direct flowmeter-system calibration using a gravimetric calibrator approach is not practical; when the assignable accuracy would be too low with calibration of the $\Delta \mathrm{P}$ transducer only; or, when the performance must be verified. 


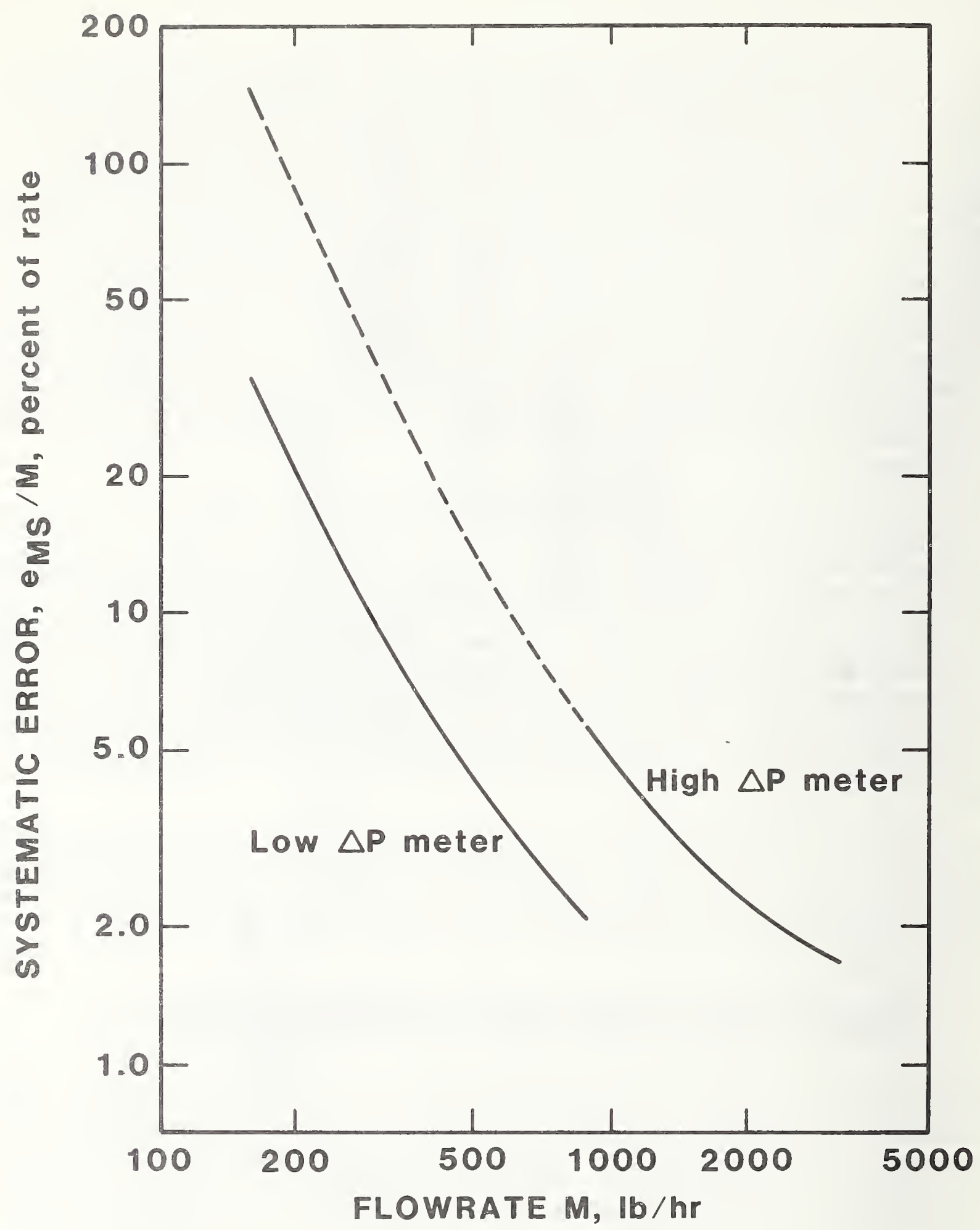

Figure 10. Systematic error in flowrate M 
Pertinent features of $\Delta \mathrm{P}$ meters include:

- Flowrate varies with the square root of the pressure differential $(\Delta P)^{1 / 2}$, as indicated in equations $(2-1)$ and $(2-2)$.

- Primary elements (the parts which interact with the flowing fluid) may be used in air, water, or dry (superheated) steam. For wet steam, consult reference 1 .

- Discharge coefficients and fluid expansion factors for these primary elements are well established and used extensively. However, the on-site calibration determines the discharge coetficient which may vary with conditions at the particular installation.

- Accurate measurement of the output of a $\Delta \mathrm{P}$ metering system is relatively difficult (particularly at $\Delta P$ values of a few inches of water) compared with meters producing a pulse type output (e.g., vortex shedding, positive displacement, turbine).

- Since flowrate varies with $(\Delta P)^{1 / 2}$, the practical flow range is often limited to about $3: 1$ for a single $\Delta \mathrm{P}$ transducer because many transducers are rated on a full scale $\Delta \mathrm{P}$ basis.

- For best accuracy of an on-site calibration, the transfer reference meter should be calibrated using the working fluid under test conditions which include temperatures and flowrates that duplicate those of the working meter.

- The detailed calculations necessary to obtain the flowrate or total flow through equations (2-1) or (2-2) make a strong case for an automatic data processing approach when measurements are to be made over a long period or when many flows are to be monitored.

Meter system design, construction, and installation should receive careful attention regardless of whether or not the meter is to be directly calibrated. Common trouble areas include the pressure taps and the pressure sensing lines. The pressure differential sensed by the transducer should be exactly the same as that existing at the meter taps. The pressure tap hole at the inner surface of the pipe or meter section should contain no burrs or roughness or other irregularities. Special precautions should be taken when installing the sensing lines, keeping these lines short and close together, and including adequate provisions for flushing, venting, and drainage. Figure ll shows a recommended sensing line schematic. The bypass valves facilitate transducer zero $\Delta \mathrm{P}$ checks. To ensure a positive check on bypass valve leakage (liquids) during normal operation, the leg valve in the Tee network remains open to the atmosphere. The likelihood of accumulation of rust, scale, and other solids in the lines and in the $\Delta \mathrm{P}$ cell make periodic flushing of the lines imperative.

Another common trouble area is the lack of sufficient straight pipe lengths upstream and downstream. As discussed previously, it is important that the flow field posseses no swirling components. According to recent research 


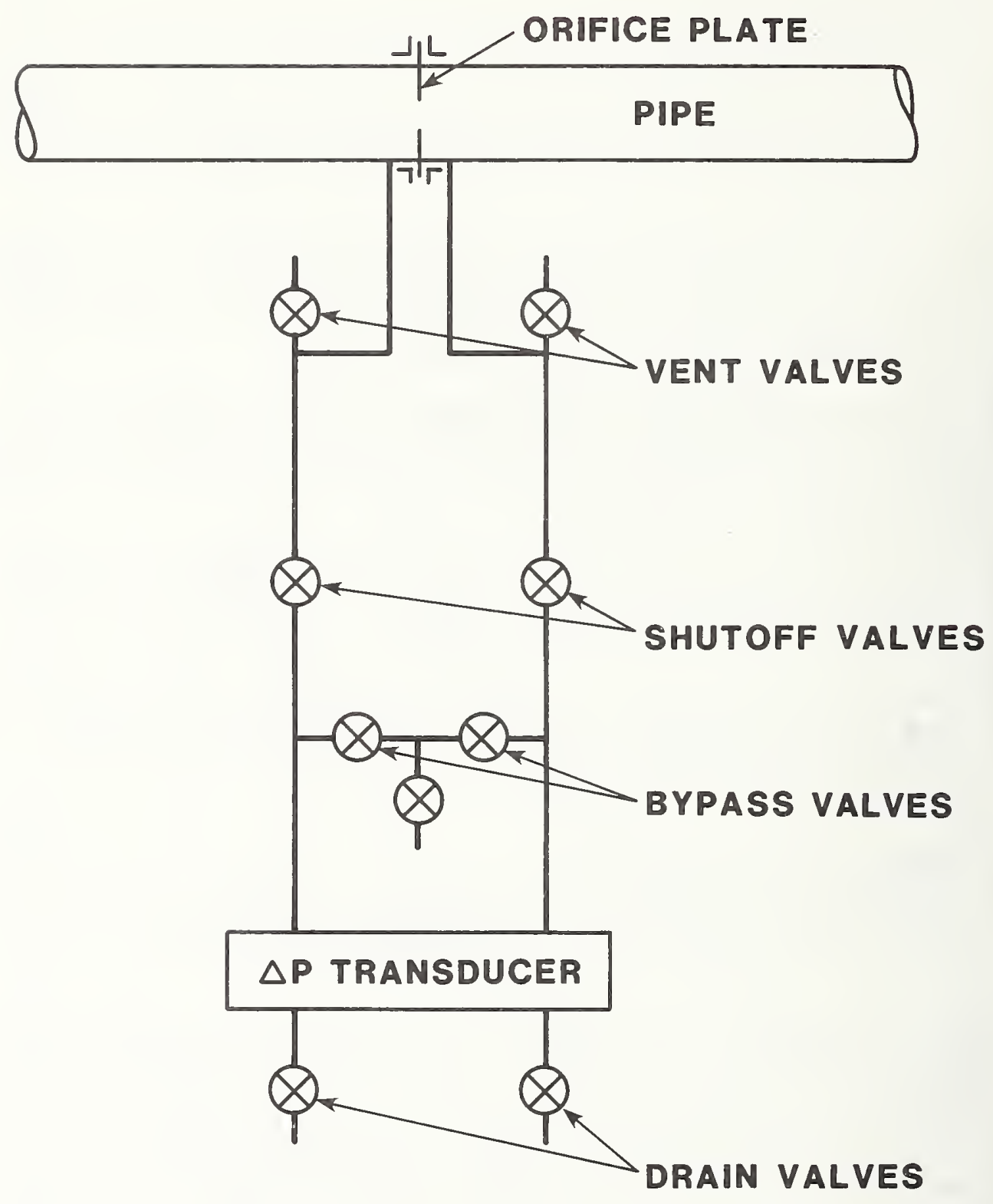

Figure 11. Orifice plate sensing line and valve schematic. Applies to flow nozzles and venturi meters as well. 
(references 4 and 5) most standards are simply too optimistic about the lengths of straight pipe needed to dampen the swirling components. This fact alone can often justify calibration on site when specific accuracy requirements are to be met. For best accuracy, the straight length upstream should be 100 to 150 pipe diameters minimum. If this is not feasible, a flow straightener section or vane assembly should be located a minimum of $10 \mathrm{D}$ upstream of the meter as indicated in figure 7. Suitable flow straightener designs are shown in figures 12,13 , and 14. The diameter of the straightener tubes in the tubular design should be D/4 maximum. Whẹn thin wall tubes are used, the pressure losses will be small. The perforated plate design will cause relatively large pressure loss but it will tend to reshape and improve the symmetry of the axial velocity profile. For more detailed discussions of design and construction, consult references 2 and 3 .

An example calculation of the calibration of an orifice meter system using a transfer meter system is given in appendix $\mathrm{E}$, example E.6. 


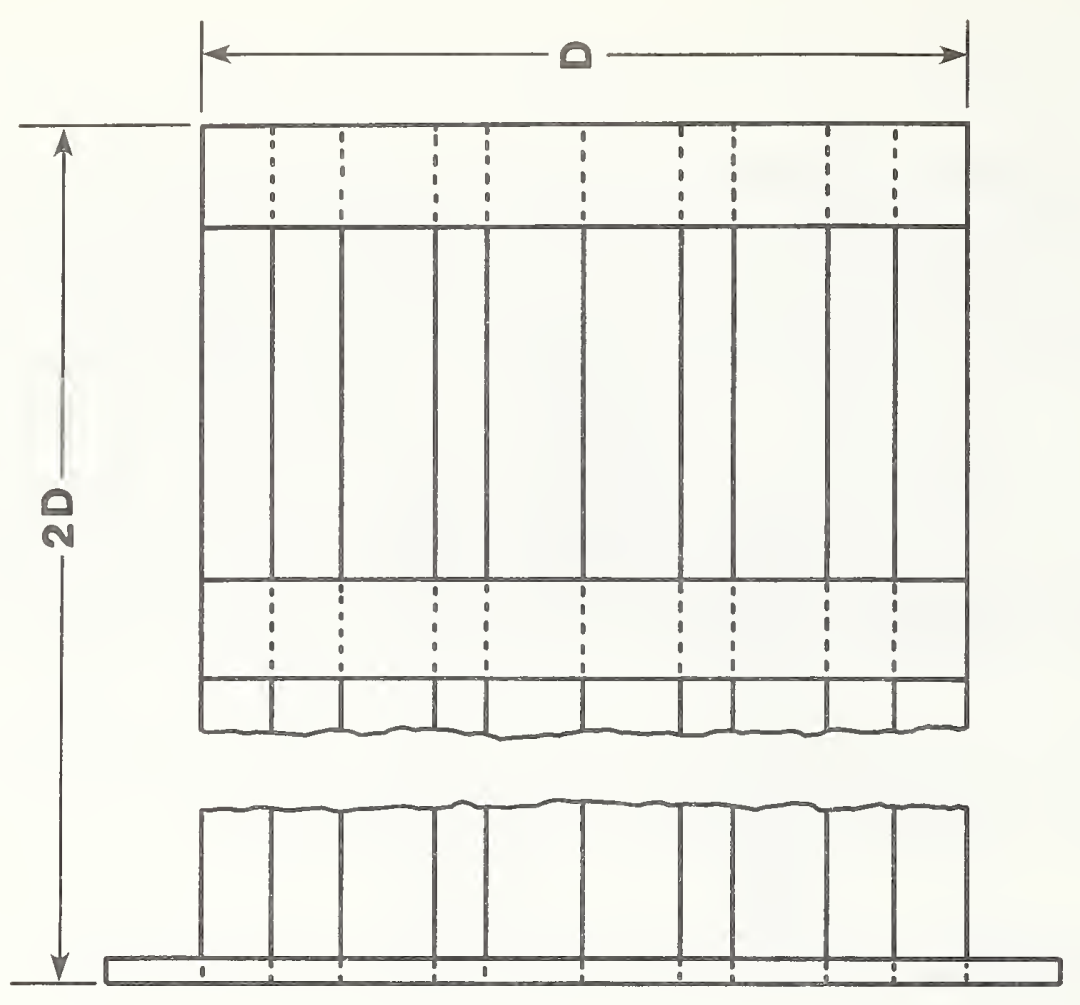

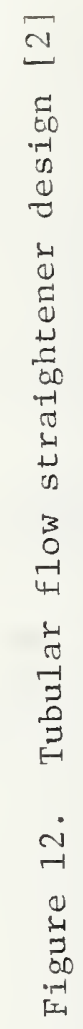




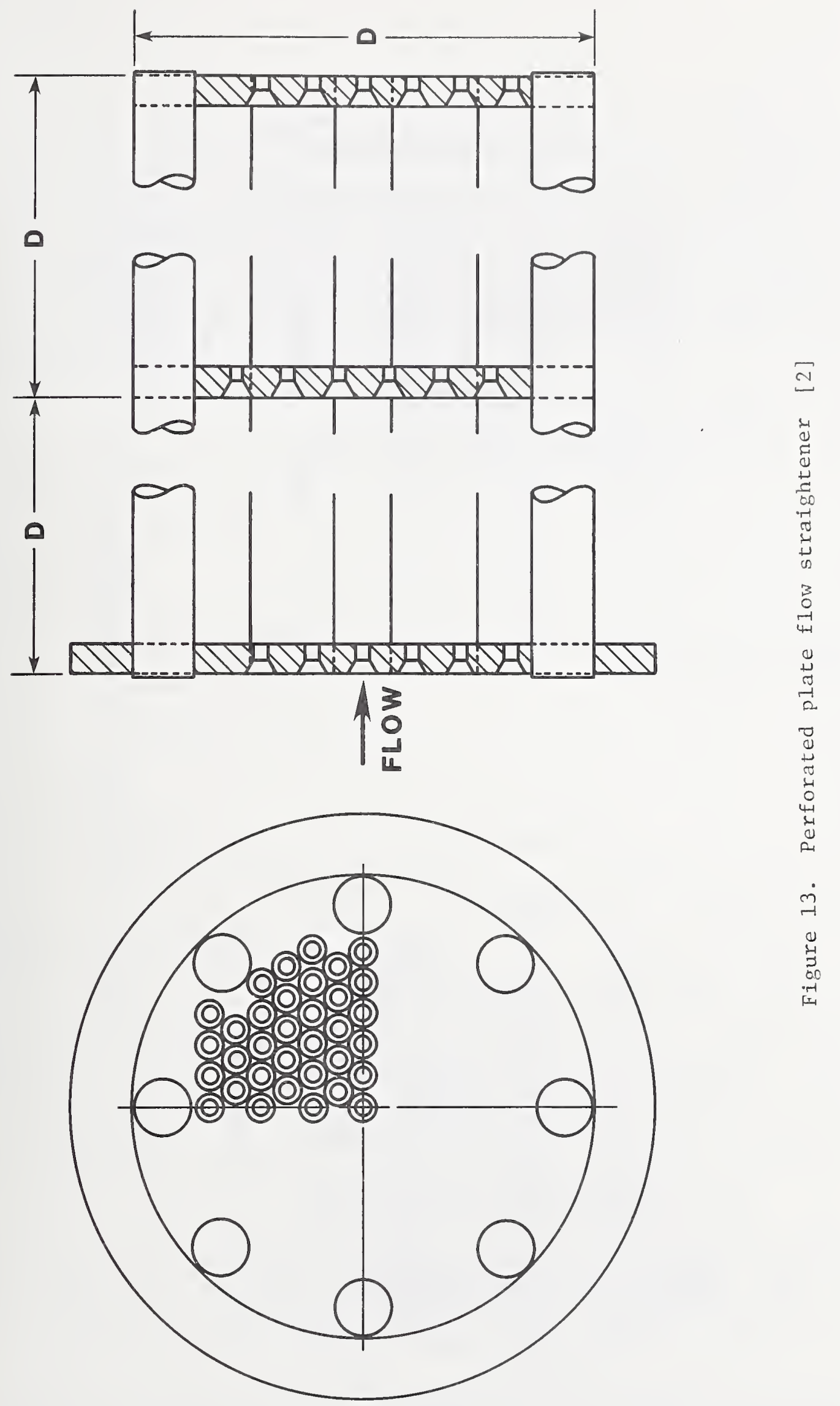




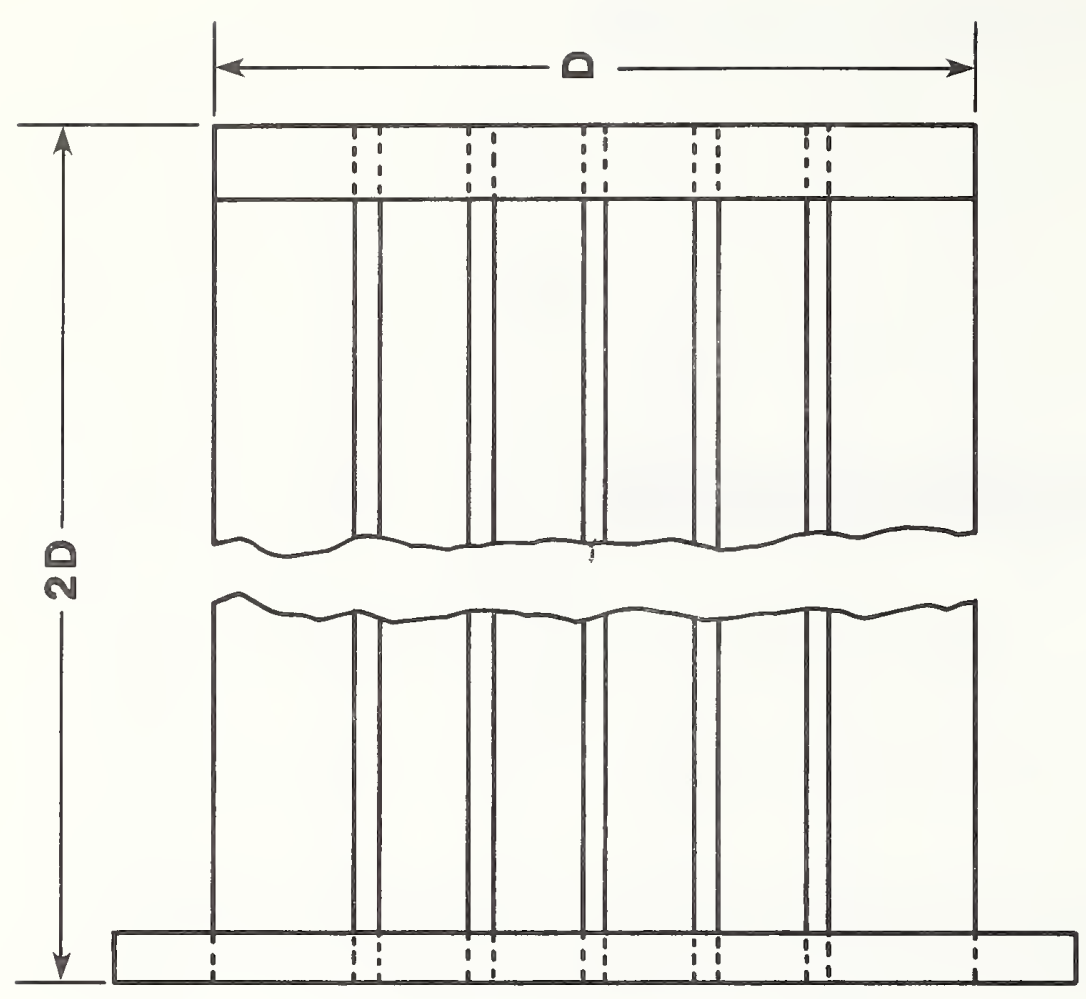

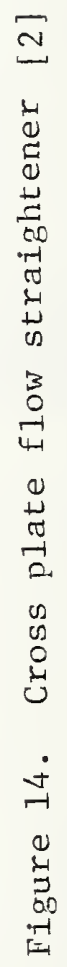




\section{ON-SITE CALIBRATION OF OTHER FLOW METERING SYSTEMS}

The types of flowmeters discussed in this "other" category are indicated in the table below. Depending upon the application and accuracy requirements, they all require calibration. The fluids indicated are those considered most likely to be encountered in building service and do not necessarily encompass all possible fluid applications. Included in this section are meter descriptions and summaries of operating principles, graphs showing typical performance, installation and use notes, basic equations for calculating the flow, and sample calculations for on-site calibration.

Flowmeter Type

Positive Displacement

Vortex Shedding

Turbine

Pitot-Static Types

Reverse Pitot

Multiple Pitot Static

Target

Ultrasonic

Insertion Type Turbine
Water

$\mathrm{x}$

$\mathrm{x}$

$\mathrm{x}$

$x$

$x$

$x$

$\mathrm{x}$

$\mathrm{x}$

$\mathrm{x}$

$\mathrm{x}$

$\mathrm{x}$

$x$

$\mathrm{x}$

Air

$\mathrm{x}$

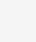$$
\mathrm{x}
$$

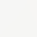

$\mathrm{x} \quad \mathrm{x}$

\subsection{POSITIVE DISPLACEMENT (PD) FLOWMETER}

This is a quantity-type meter in which a chamber is completely filled with fluid and then emptied. Counting each filling indicates the flow. The counter may be a mechanical, totalizing type with disc or wheel type readout; or an electromagnetic pulse or optical type readout may be used. This will allow the meter to be used for either flowrate or totalizing applications. In some cases, the primary element is magnetically coupled to the counter, eliminating shaft sealing. The PD meter may be considered a special type of fluid motor with a high volumetric efficiency and operating under light load.

The PD meter is widely used in commercial, industrial and domestic applications, metering both gases and liquids, including water. For liquids, the types of primary elements used include the nutating disc; reciprocating piston; oscillating or rotary piston; rotating gear, lobed impeller; and sliding and rotating vanes. Figure 15 is a cross-section view of a nutating disc type.

The advantages of the PD meter include the ability to measure flow despite a wide range of fluid viscosities, a digital type output, and accuracy which is 


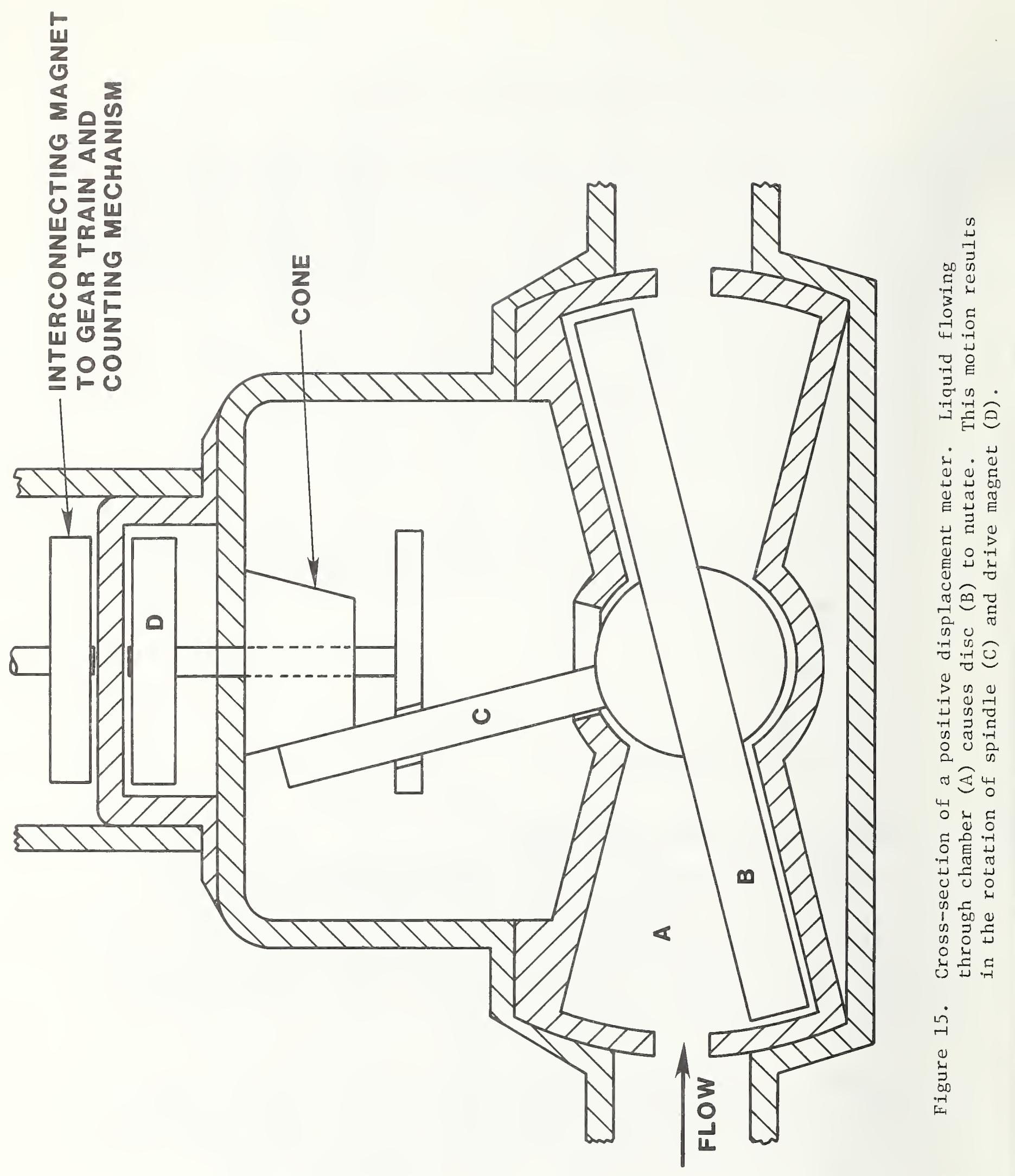


relatively insensitive to upstream flow patterns. Thus, long straight pipes or flow straighteners upstream may not be necessary. Disadvantages include the presence of significant loading due to the mechanical and fluid friction of the metering element as well as that arising from the torque required to drive the readout or registering mechanism. Because of this loading, a pressure differential is required to drive the meter; as a result there is a small amount of fluid leakage past the "sealing" surfaces. This leakage is known as "slip" or "slippage". The accuracy of the meter is largely determined by this leakage or "slip". No two meters, even of the same design, will have identical proportions of leakage. Therefore it is important, for applications requiring accuracies better than about one half percent, that each meter be calibrated individually, and that all parameters or factors which affect the performance be known and adequately controlled.

Factors associated with leakage which are known to affect the meter performance include: liquid properties, viscosity and lubricity, meter design, meter temperature, and readout loading. Other factors influencing meter performance include flowrate; pressure level in the meter; contamination in the fluid; and, possibly, meter operating position.

Thus, in the selection of a PD meter either as a working meter or as a transfer reference meter, the flowing fluid properties (viscosity, lubricity, and temperature) should be considered. The pressure level and allowable pressure loss also need consideration. For water, typical pressure losses at the rated flow may range from 2-5 psi for capillary or film seal meters (example: nutating disc, oscillating piston) and from 10-15 psi for packed seal (reciprocating piston) meters. For most applications, an absolute pressure level (psia) equivalent to the vapor pressure plus 3 or 4 times the meter pressure loss at the rated flow is probably sufficient for proper operation. The user should refer to the manufacturer's specifications for details on each meter. In calibration, the pressure drop across the meter should be noted.

The meter should be treated as a precision instrument. Filtering of the fluid so that solid particle size is much smaller than the meter clearances is necessary. Although optimum conditions are not known, filtration in the range of 25 to 50 microns appears adequate to ensure normal meter operation without excessive wear. No meter, including the nutating-disc type widely used in domestic and industrial water applications, should operate continuously in fluids containing solid particles.

Before use as a transfer reference meter, a PD meter should first be calibrated using the same fluid at or near the temperatures and pressures which will exist during field usage. Thus fluid viscosity and lubricity, meter dimensions, and seal leakage are duplicated during calibration and use as a transfer reference device. In this manner, meter performance is duplicated. Meter performance is affected by meter orientation (vertical vs. horizontal, if permitted by the manufacturers). Positional changes vary the mechanical friction in the metering element and in the readout mechanism, and modify the lubricant level in the gear reduction mechanism of the readout. A safe approach is to calibrate and use the meter in the same position. Magnetic and optical readouts may not impose the same positional operating restriction. The user should always refer to the manufacturer's specifications regarding the positioning of the meter. 
Several points should be noted with regard to the meter readout, when the PD meter is used as a transfer reference. Although the mechanical readout has long been the "work horse" for domestic, commercial and industrial applications, other types such as the magnetic or optical types are available. A small change in the loading of the metering element by a mechanical readout may have a significant effect on the slip characteristics of the meter, especially those of the film seal type. Piston-type meters with packed seals are said to be less affected by small changes in readout loading. Because wear or the presence of dirt or corrosion can change readout loading, recalibration of the meter on a regular schedule, with more frequent intervals at the beginning of the program, should be considered for long term measurement programs.

Also, with regard to readouts, the meter should not be calibrated with one readout and used with angther because of the influence of readout loading on the meter accuracy. The readout and metering element should be connected by a positive drive, without cams, clutches or the like which may cause relative motion between the readout and the metering element; the sole exception is the case where the meter and readout have been designed to be coupled magnetically. In this type, the rotary motion of the metering element is magnetically coupled to a mechanical readout or else it drives a pulse generator, producing an AC voltage which varies with a frequency exactly proportional to the speed of the metering element. Such a system, by proper design, should result in decreased loading on the metering element and increased resolution in the readout. The meter is also more readily adaptable to both rate and totalization applications. Suitable external instrumentation such as an electronic counter is used to count the pulses received from the meter.

Air and vapor in the PD meter should be avoided because of effects on meter operation and accuracy. Thus, during installation, meter layout should be planned to avoid locations where air could accumulate and valves should be provided for venting the system during use, usually at points of high elevation. Throttling upstream of the meter should be avoided whenever possible.

Pulsed-readout meter performance can be expressed conveniently in terms of a "calibration factor" plotted as a function of meter output frequency when the fluid, viscosity, and meter temperature are known, i.e., when a given meter is operated on a single fluid at a known temperature. Figure 16 shows such a plot of meter performance. While the sample calibration factor, pulses/gallon, is shown to vary with frequency (flowrate), the calibration factor may be essentially constant over considerable flow ranges such as 10:1 or larger for a typical meter operating on a single fluid. Also, large changes in kinematic viscosity such as $1 \times 10^{-5}$ to $20 \times 10^{-5} \mathrm{ft}^{2} / \mathrm{s}$ may have a rather small influence on the meter factor, tyically \pm 0.5 percent for a five or ten-fold increase in flow.

Denoting the calibration factor by the symbol $\mathrm{K}$, the volume flowrate $\mathrm{Q}$, is

$$
\mathrm{Q}=60(\mathrm{f} / \mathrm{K}) \mathrm{GPM}
$$

and the mass flowrate $M$, is

$$
M=3600(\rho)(f / K) 1 b / h r
$$




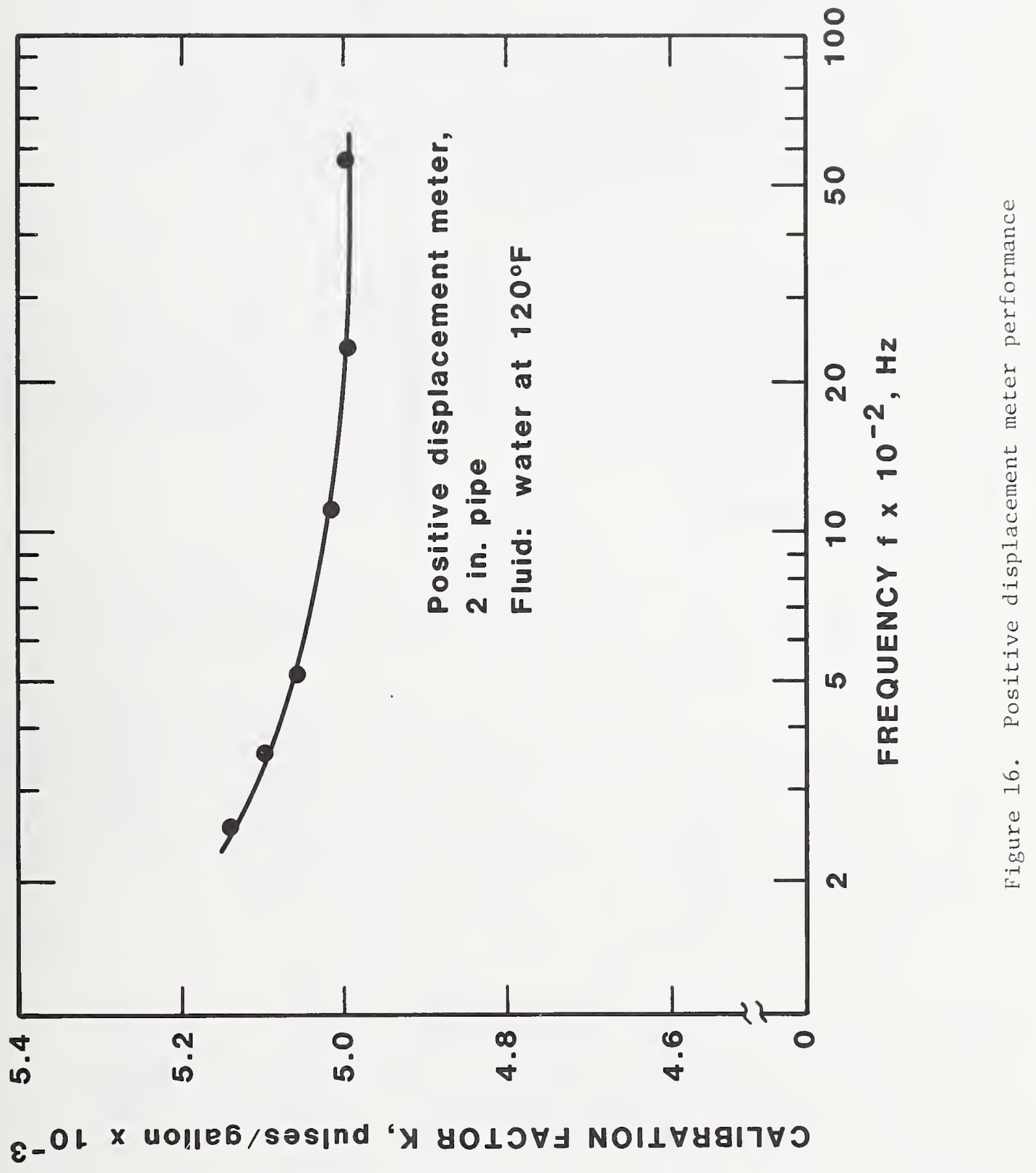


where, $t$, is the pulse frequency in $\mathrm{Hz}, \mathrm{K}$ has units pulses/gallon, and $p$ is the density, lb/gallon.

The actual totalized flow (ATF) where the meter register reads directly in volune units, is

$$
\operatorname{ATF}=\left[\left(K_{O} / K\right) \text { (net meter registration) }\right] \text {, }
$$

where $K_{0}$ is the calibration factor corresponding to the current setting of the meter register. The quantity $\mathrm{K}_{\mathrm{O}} / \mathrm{K}$ is defined as the meter Eactor (MF), a dimensionless number, ideally equal to 1.000 .

An example calculation for on-site calibration of a positive displacement meter is given in appendix E, example E.7.

In summary, the PD meter is considered quite suitable for building system applications. Advantages include: (1) a digital output, (2) frequent calibrations are usually not needed once a meter element is calibrated and used with clean fluids, (3) elimination of periodic and long term calibration programs for output signal transducer systems, and (4) a calibration factor essentially independent of flowrate.

\subsection{VORTEX SHEDDING FLOWMETER}

This meter, part of the industrial scene for about 10 years, operates on the principle that the frequency of vortex shedding for fluid flow around a submerged object is proportional to the fluid stream velocity. Flowrate is measured by detecting the frequency. Figure 17 shows design details of one meter. The vortices are shed behind the bluff body.

Advantages include lack of moving parts in the primary element* and a digital output. Accurate measurenent of the probe output is a much simpler measurement task than accurate measurement of, for example, the $\Delta \mathrm{P}$ from a differential pressure meter. Meter configurations are available for both gases and liquids in pipes one inch or more in diameter, and at temperatures up to about $400^{\circ} \mathrm{F}$ or $500^{\circ} \mathrm{F}$. The meter output is usually expressed in dimensionless terms according to the following equation:

$$
\mathrm{f} D / \mathrm{V}=\phi(\mathrm{D} V \mathrm{\rho} / \mu)=\phi(\mathrm{D} V / \nu)
$$

$$
\text { Whe } \begin{aligned}
\mathrm{f} D / \mathrm{V} & =\text { Strouhal number, dimensionless } \\
\mathrm{D} \mathrm{V} / \mathrm{P} & =\text { Reynolds number, dimensionless } \\
\mathrm{V} & =\text { fluid velocity } \\
\mathrm{D} & =\text { characteristic linear dimension of the meter } \\
\mathrm{f} & =\text { frequency of vortex shedding } \\
\rho & =\text { fluid density }
\end{aligned}
$$

* Some models do employ moving parts in the secondary element that detects the vortex frequency. 


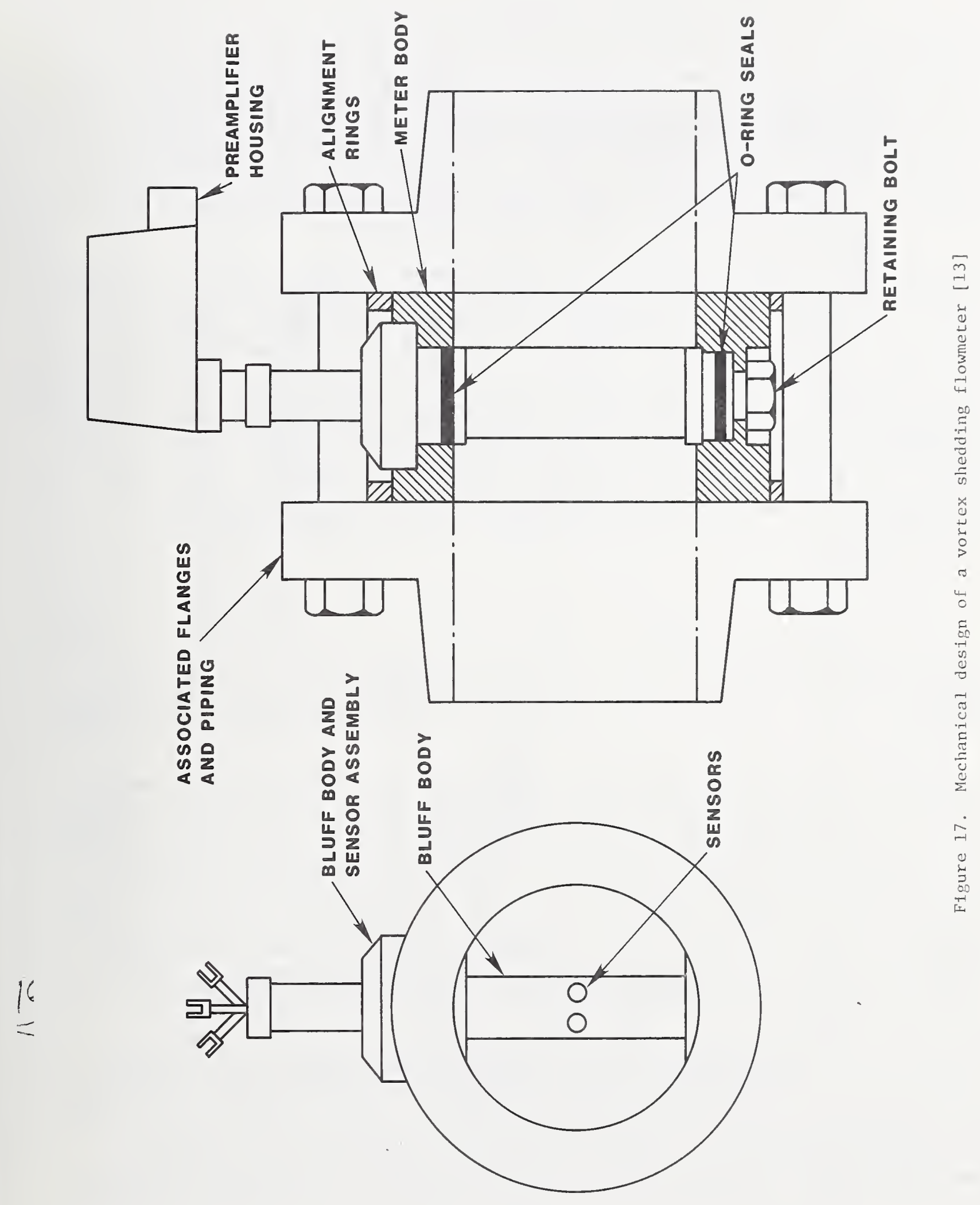




$$
\begin{aligned}
& \mu=\text { fluid dynamic viscosity } \\
& \nu=\text { fluid kinematic viscosity }(\nu=\mu / \rho) .
\end{aligned}
$$

The function $\emptyset$ is determined by calibration for each geometrical shape of meter in the same sense that the coefficient of discharge $C$ for an orifice is determined experimentally for each geometry (such as concentric orifice, beta ratio, pressure tap configuration). In principle, the performance of a meter calibrated on one fluid is predictable when used with another fluid provided that each fluid is incompressible and that its properties $\rho$ and $\mu$ are known. The meter is a volumetric type as indicated by use of the Strouhal number $\mathrm{f} \mathrm{D} / \mathrm{V}$, where $V$ is proportional to $Q$, the volumetric flowrate.

When a vortex shedding meter is calibrated using a single fluid at a specific temperature, its performance can be conveniently expressed in terms of a calibration factor $K$, such as pulses/ft ${ }^{3}$ plotted as a function of frequency $f$, rather than the dimensionless parameters of equation (4-4). When a meter is to be used for several fluids, a function $\mathrm{f} / \nu$ may be used instead of $\mathrm{DV} / \nu$ since $\mathrm{D}$ is constant for a given meter and $f$ varies nearly directly with $V$. Verification of the meter's accuracy requires calibrating the meter with several fluids to encompass the range of interest for $\nu$. Note that the function $\emptyset$ accounts for changes in meter performance with fluid kinematic viscosity, $\nu$, only. Any changes in performance due to changes in dimensions with temperature are uncorrected. In both of these cases, the volume and mass flowrates are computed from:

$$
\begin{aligned}
-Q & =(60)(f / K) G P M \\
M & =(3600)(\rho)(f / K) 1 b / h r
\end{aligned}
$$

where $\mathrm{f}$ is the frequency in $\mathrm{Hz}, \mathrm{K}$ has units $\mathrm{ft}^{3} / \mathrm{gallon}$, and $\rho$ is the liquid density, $1 \mathrm{~b} / \mathrm{ft}^{3}$. Figure 18 is a sample plot of meter performance on different fluids.

At Reynolds numbers greater than about 15,000, the vortex shedding flowmeter calibration factor $\mathrm{K}$, in units such as gallon/pulse, is essentially constant within 0.5 to 2 percent for flowrates varying from about $10: 1$ to $100: 1$, according to the manufacturers' specifications. Pressure losses at the rated flow can vary from a few inches of water to a few psi depending upon the fluid. Pulse output frequencies are relatively low. For example, a particular 2-inch diameter meter in water flowing at a rate of 100 GPM produced an output pulse frequency of about $50 \mathrm{~Hz}$. Thus, for adequate resolution, sampling times of several seconds or more may be needed for frequency measurements, or interval measurement techniques can be used (time to count, say, 10 pulses).

The vortex shedding meter should not be considered a "cure-all" for meter installation troubles encountered in building systems. The same requirements exist for vortex meters as for orifice meters in terms of straightening vanes and straight runs of pipe upstream and downstream. Such conditions are needed to minimize the effects of transverse velocity components and (abnormal) upstream turbulence on the steady formation of vortices behind the meter obstruction body. The meter system design of figure 7 is considered adequate, 


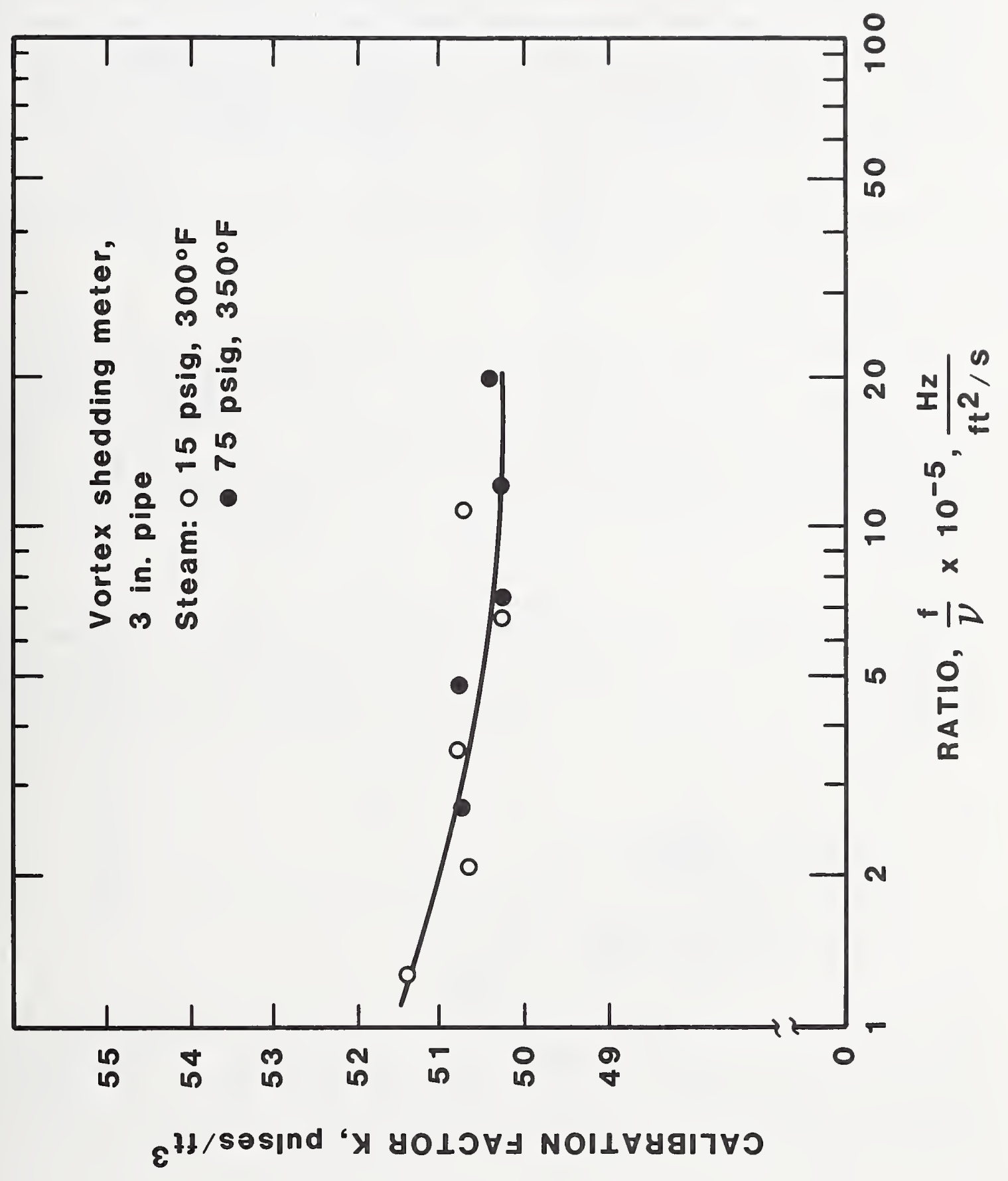


although some manufacturers may recommend longer straight pipe lengths between the meter and the flow straightener.

No effect on the performance of the meter due to the position or orientation of the section of pipe enclosing the meter should be expected. The pressure level should be high enough to ensure that no vapor formation (in the case of liquid flow) occurs in the meter. An absolute pressure, psia, equal to the fluid vapor pressure plus 3 on 4 times the pressure loss at the rated flow should be sufficient. Since this meter element has no moving parts, fluid filtration or straining is usually not required. However, changes in internal dimensions caused by excessive scale build up or abrasion could influence the calibration factor. Internal passages to the vortex sensing transducers must remain clear and open. With each meter design, there will be a minimum fluid flow necessary to create a steady vortex flow.

An example calculation for on-site calibration of a vortex shedding meter is given in appendix E, example E.8.

\subsection{TURBINE METER}

Figure 19 shows a typical turbine meter. This meter contains a bladed rotor which rotates at a velocity proportional to the volume rate of flow. Most models employ a magnetic pickup, as shown, in which passing rotor blades vary the reluctance of a magnetic circuit, and generate an AC voltage in the pickup coil. The pulse frequency is directly proportional to rotor speed. This signal is sensed as an indication of flow. It can be counted by an electronic counter, or converted to an analog signal using circuits converting frequency to voltage.

The calibration factor is expressed in electrical pulses generated per unit volume of throughput, e.g., pulses/gallon. This factor is sensitive to flowrate, fluid density, and viscosity, the fluid flow pattern at the meter entrance, and sometimes the meter orientation. For a meter of a specified shape, meter performance can be expressed in terms of dimensionless parameters as

$$
Q /\left(n D^{3}\right)=\phi\left(n D^{2} \rho / \mu\right)=\phi\left(n D^{2 / \nu}\right)
$$

where $Q=$ volume flowrate

$\mathrm{n}=$ speed of rotor

$\mathrm{D}=\mathrm{a}$ characteristic linear dimension of the meter

$p=$ fluid density

$\mu=$ dynamic viscosity

$\nu=$ kinematic viscosity $(\nu=\mu / \rho)$.

The function $\phi$, determined by calibration, describes the performance provided retarding forces acting on the rotor (bearing friction and electromagnetic forces) are insignificant and the fluid is incompressible. When considering one particular meter of fixed size and shape, the quantity $D$ is constant and the above dimensionless quantities may be reduced to the form 


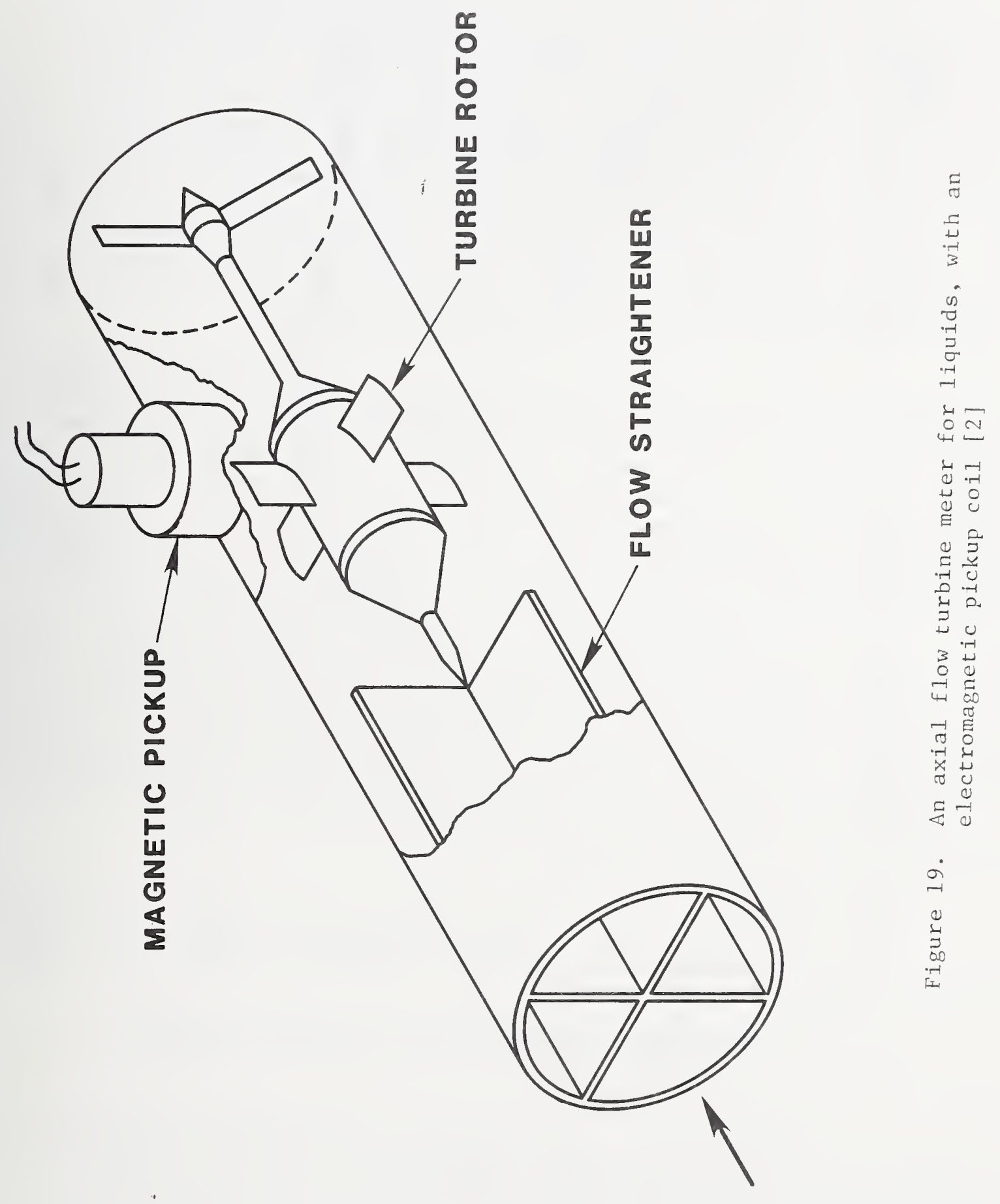




$$
\mathrm{f} / \mathrm{Q}=\phi(\mathrm{f} / \mathrm{v})
$$

where $f$ is the pulse frequency and $f / Q$ has dimensions pulses/unit volume.

Unfortunately no single performance curve (function $\$$ ) exists for all turbine meters such as the corresponding coefficient of discharge data which exists, for example, for orifice meters. Therefore, each meter must be calibrated to obtain its performance or function $\phi$ given above. When used as a transfer reference meter and for best accuracy, each meter should be calibrated using the same liquid to be used during the application. This applies in particular to a liquid such as water which has a different lubricity characteristic as compared to, say, liquid hydrocarbons. Meter performance on water may be different from that obtained using liquid hydrocarbons of similar viscosity as noted in reference 14. The difference is apparently due to changes in retarding forces and bearing friction. Also, the temperature during calibration and application should not differ appreciably since the function $\phi$ does not account for change in meter dimensions with temperature.

The frequency output of a typical turbine meter can be linear, (i.e., $\mathrm{f} / \mathrm{Q}=$ constant) within \pm 0.5 percent at its higher rates of flow when operating with low viscosity fluids, such as water. This range of linear operation may extend over a flow range of 10:l or higher, depending on meter design and size, and on liquid viscosity. For example, with water in the range $40-450^{\circ} \mathrm{F}$, the kinematic viscosity $\nu$, varies from $1.66 \times 10^{-5}$ to $0.16 \times 10^{-5} \mathrm{ft}^{2} / \mathrm{s}$. Thus, the temperature range needs consideration for each application, and $\mathrm{f} / \nu$ remains the controlling variable when temperature varies significantly. At the lower rates of flow for each meter, frequency output becomes very nonlinear presumably resulting from the combined effects of retarding forces due to electromagnetic and mechanical loading on the turbine. There is always some minimum flowrate below which retarding forces are greater than the fluid forces causing rotation and the rotor ceases to turn. Figure 20 shows performance characteristics of a turbine meter in which the calibration factor $\mathrm{K}=\mathrm{f} / \mathrm{Q}$ is plotted as a function of $\mathrm{f} / \mathrm{v}$. When the meter is calibrated and the operator is using a single fluid at a known temperature, the usual case in building system applications, a convenient graph, as with the vortex shedding meter, is a plot of $\mathrm{f} / \mathrm{Q}$ vs $\mathrm{f}$. With both plots, the volume flowrate is once again:

$$
Q=60(f / K) G P M
$$

where $\mathrm{f}$ is the pulse frequency in $\mathrm{Hz}$ and $\mathrm{K}$ has units pulses/gallon. Similarly, the mass flowrate is

$$
M=3600(\rho)(f / K) 1 b / h r
$$

where $\rho$ is the density, 1b/gallon.

The pressure drop through the meter depends on its design and varies with $\rho Q^{2}$. Typically, this may be 5 to $10 \mathrm{psi}$ at the rated flow. The pressure level in the meter should be high enough so that cavitation or formation of vapor does not occur. An entrance pressure of 50 psia plus the vapor pressure of the water is 


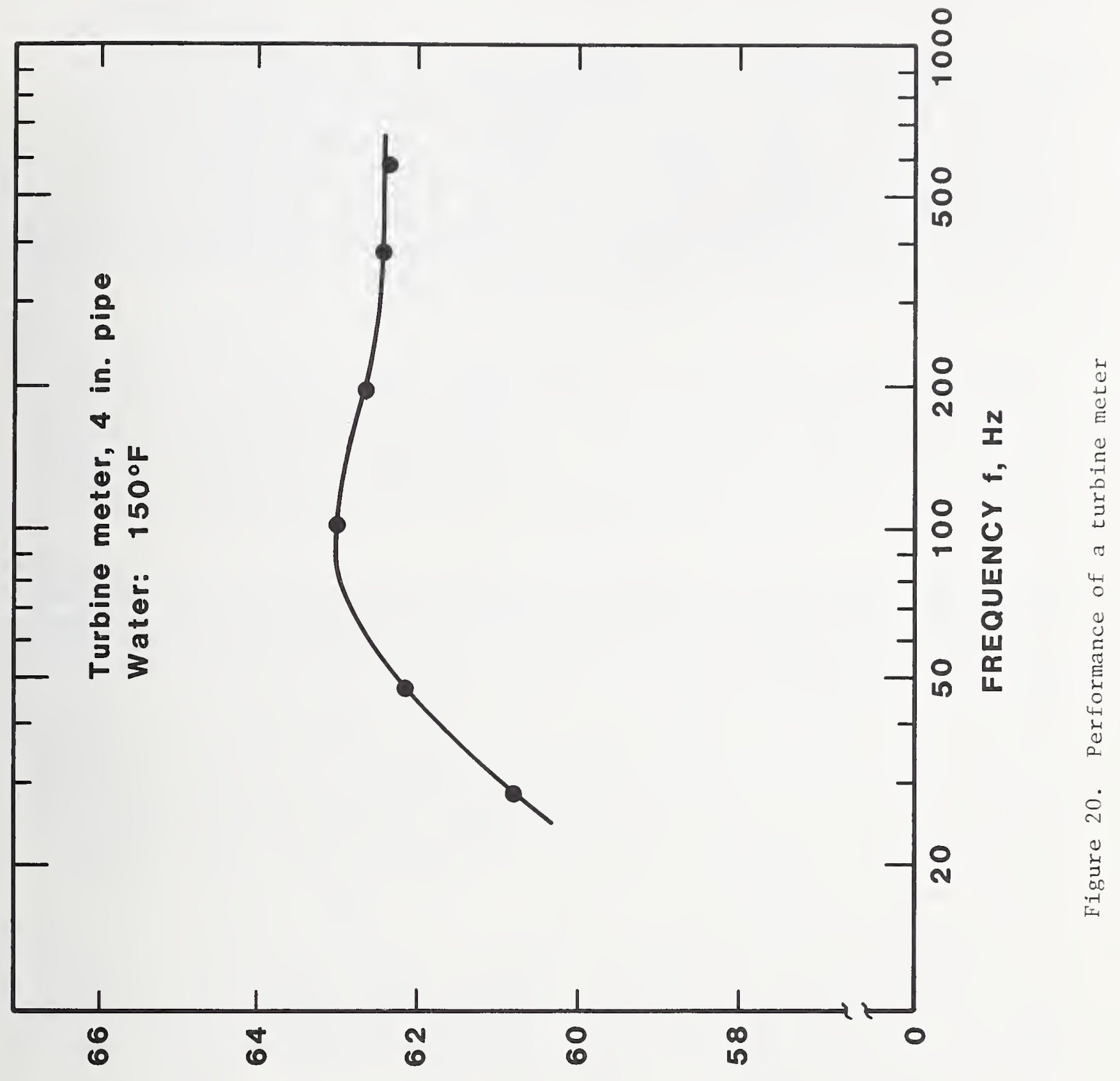

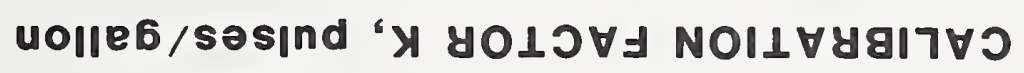


usually adequate to overcome pressure losses in the meter and connecting piping, and to prevent cavitation in the meter.

Long term, satisfactory turbine meter operation requires a clean fluid. When dirt or particulate matter are entrained in the fluid, meter performance may be adversely affected due to increased bearing friction. Therefore, a suitable filter upstream is needed. The dirt problem is one of the common difficulties in using turbine meters in the water lines of building systems because these systems easily may become contaminated. The level of contamination tolerable for heating, ventilating and air-conditioning (HVAC) equipment may very likely be intolerable for turbine meters. The required level of filtration depends on both the meter size and the bearing design. For smaller meters such as the oneinch size, filtration to 50 microns is typical. Meter bearing material and design should be compatible with operation in water.

Calibration should be performed periodically and may be performed either on a flowmeter calibration facility or on site using suitable transfer reference flowmeters as shown in figure 5 or 6 . In either case, for best accuracy, it is important that the flow straightener, the meter, and the necessary lengths of upstream and downstream piping, as shown in figure 7 for example, be calibrated as a unit. For best accuracy, both the meter and the pickup unit should be installed in the same positions as that used during calibration.

Maintenance procedures should include servicing the filter equipment, including changing filters as necessary to avoid excessive flow blockage and/or pressure loss. Also, the meter should be removed from the line periodically and examined for possible deterioration of its components or for solids deposited on them. Recalibration should be conducted during these maintenance activities.

Severe overspeeding of the meter should be avoided. Such a problem may occur when venting air from a piping system or by subjecting the meter to very high flowrates above the rated value. High rotor speeds when the meter is dry, in particular, can hasten bearing wear and failure. Subjecting the meter to intense pressure or flow pulsations or to mechanical vibration may hasten bearing failure. Exposure to excessive dirt and solid particles may cause bearing seizure.

In summary, the turbine meter has advantages of small size, excellent repeatability, and a digital output. Also, the calibration factor is often essentially constant when the meter is operated within specified ranges of flowrate and viscosity; this fact simplifies flow calculations. Installation as part of a meter system using a flow straightener and calibration in water at the required temperature are essential for best accuracy. However, the amount of dirt often encountered in building systems raises a question as to its general suitability for this application. Clean liquids are required for satisfactory long term operation.

An example calculation for calibration in water is given in appendix E, example E.9. 


\subsection{TARGET METER}

A sketch of a target meter for closed channel flow is shown in figure 21. Other names used for this type meter include vane, force, and drag force. The change in momentum of the fluid as it accelerates past the target causes a drag force which deflects the target. This deflection is measured by a force transducer such as a strain gauge system or linear differential transformer. With incompressible flow past the target, this drag force depends on the size and shape of the target and the proportion of the pipe cross section it occupies, the fluid velocity, and the fluid properties of density and viscosity. The drag coefficient is dimensionless and is defined as:

$$
C_{d}=\frac{2 g_{c} F}{\rho a v^{2}}
$$

where

$$
\begin{aligned}
\mathrm{F} & =\mathrm{drag} \text { force, } 1 \mathrm{~b}_{\mathrm{f}} \\
\rho & =\mathrm{fluid} \text { density, } 1 \mathrm{~b} / \mathrm{ft}^{3} \\
\mathrm{~g}_{\mathrm{c}} & =32.1740(\mathrm{ft} \cdot 1 \mathrm{~b}) /\left(1 \mathrm{~b}_{\mathrm{f}} \mathrm{s}^{2}\right) \\
\mathrm{a} & =\text { target area, ft }{ }^{2} \\
\mathrm{~V} & =\mathrm{fluid} \text { velocity upstream, } \mathrm{ft} / \mathrm{s} .
\end{aligned}
$$

While the drag coefficient has been studied for such shapes as the flat plate, the sphere, and the circular cylinder in a free stream, expressing $C_{d}$ as a function of target Reynolds number, drag coefficients for the various shapes of target meters used in closed channel flow are not well known. Each meter, therefore, needs an individual calibration covering the Reynolds number ranges of interest. Figure 22 is a plot of $C_{d}$ versus Reynolds number for two target meters, where $R_{D}=D V \rho / \mu$.

When $C_{d}$ is known, the volumetric flowrate $Q$ and the mass flowrate $M$ are calculated from the following equations:

$$
Q=C_{d}\left(\frac{D^{2}-d^{2}}{d}\right) \sqrt{\frac{\pi}{4} \frac{2 g_{c} F}{\rho}}=C_{d}\left(\frac{D^{2}-d^{2}}{d}\right)\left(\frac{\pi g_{c}}{2 p}\right)^{1 / 2}
$$

and

$$
M=C_{d}\left(\frac{D^{2}-d^{2}}{d}\right) \sqrt{\frac{\pi}{4} \cdot 2 g_{C} F p}=C_{d}\left(\frac{D^{2}-d^{2}}{d}\right)\left(\frac{\pi g_{c} F_{\rho}}{2}\right)^{1 / 2}
$$

where $d=$ target diameter.

Although the theory for the target meter is "old", these meters have been on the industrial scene only about 25 years. Their principal advantages include their ability to handle fluids with suspended particles, their lack of moving parts, and their absence of pressure sensing lines. 


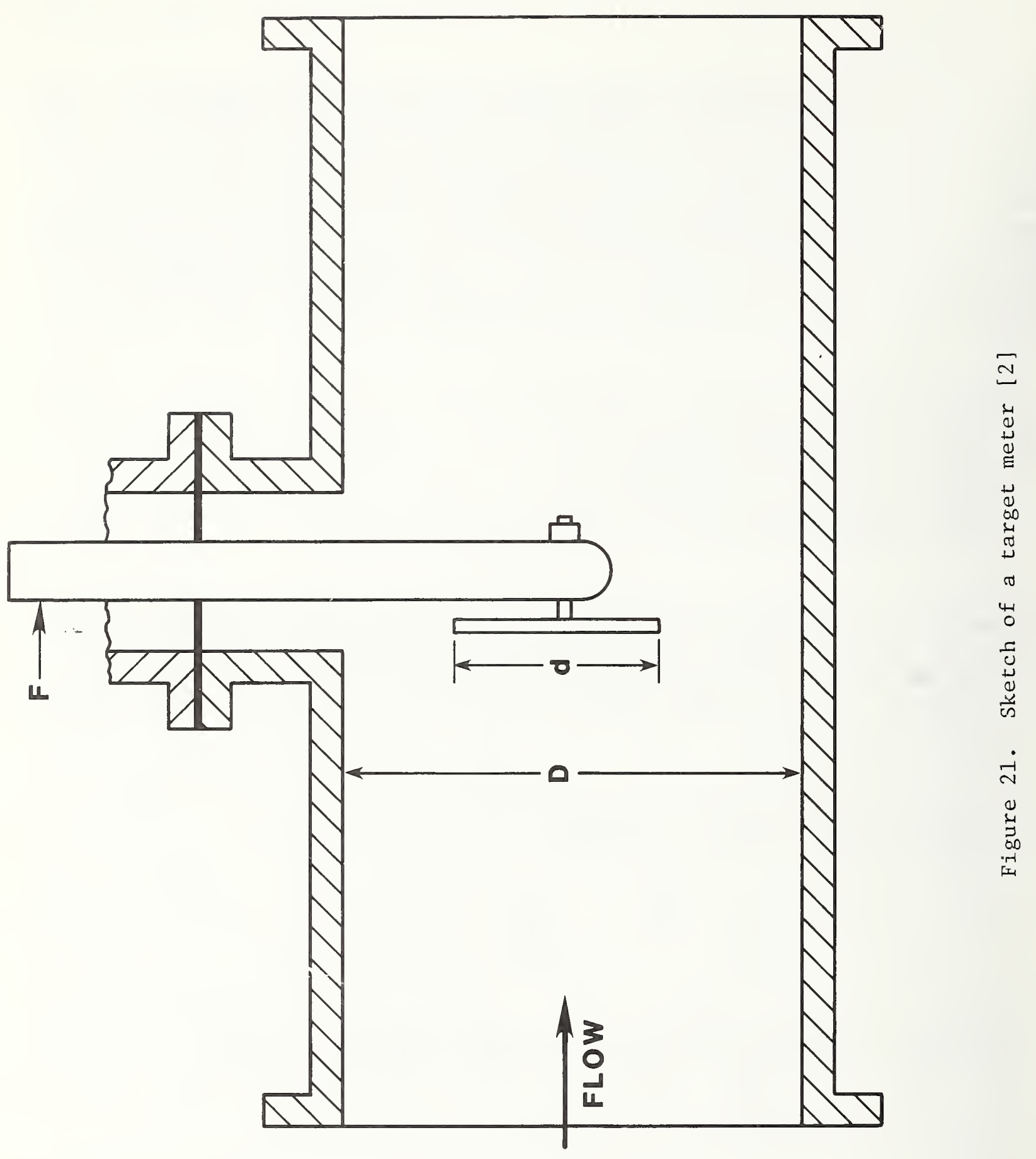



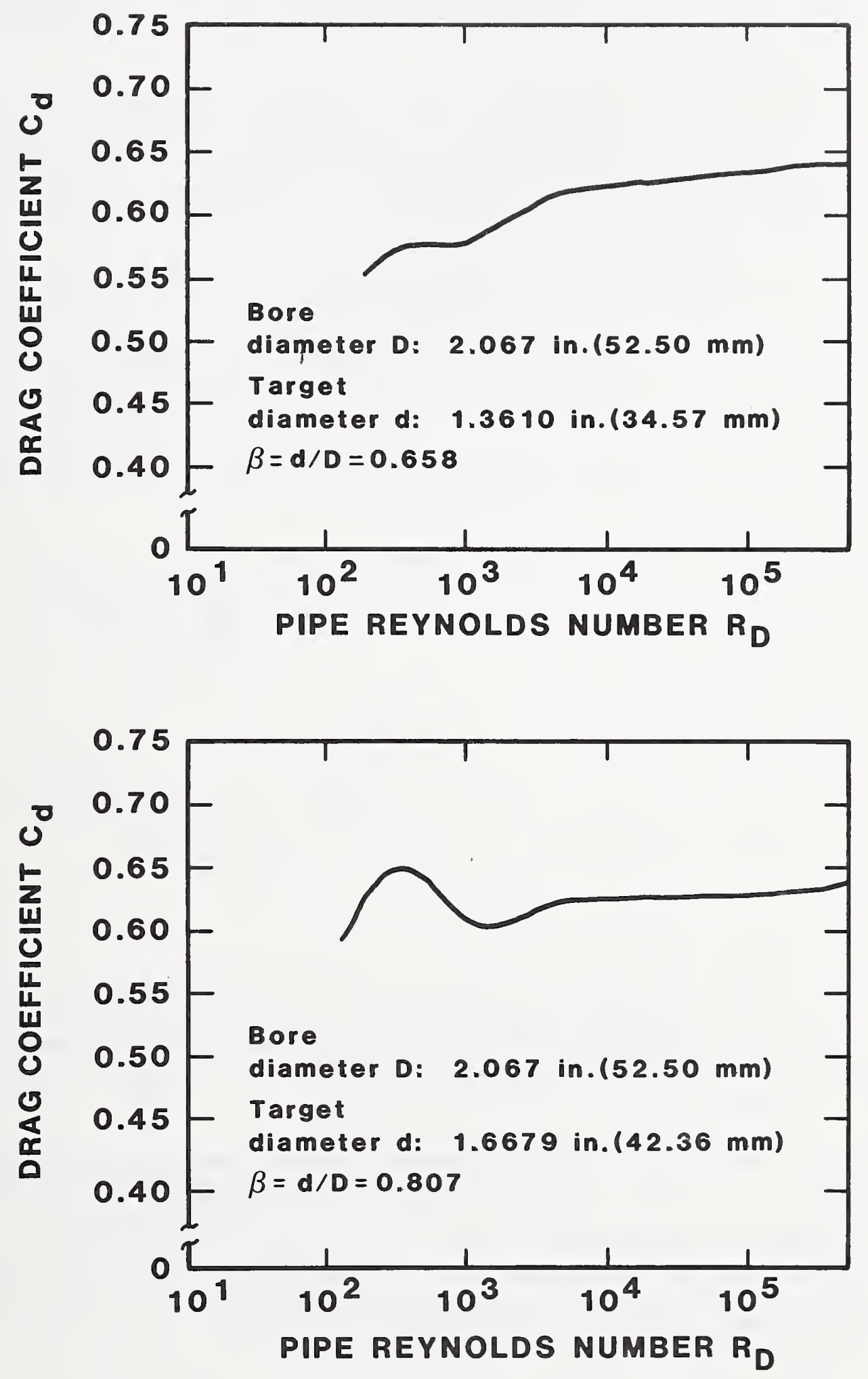

Figure 22. Drag coefficient $C_{d}$ for two 2-inch target meters, $\mathrm{d} / \mathrm{D}=0.658$ and 0.807 [15] 
The output is usually an analog signal, nonlinear with flowrate. Additional electronics are needed to convert it to a digital signal, linearize it with flowrate and/or totalize the flow. Accurate measurement of the meter output is deemed comparable to accurate measurement of pressure or differential pressure, except that a problem in limiting the noise in the electrical lines to acceptable limits may exist.

Since no study has been published to date on the effects of installation conditions, it is recommended that each meter be mounted in a metering section with straight lengths of pipe upstream and downstream together with a flow straightener, as shown in figure 7. Some manufacturers may recommend more than 10D of straight pipe upstream between the meter and the flow straightener.

Target meter systems are available for water in pipe sizes $1 / 2$ inch to 8 inches and larger, flowrates to 2000 GPM and larger, with full scale pressure drops as low as a few tenths of a psi for the larger-size meters. Nominal flow range ratio is $10: 1$ (transmitter output 100:1). Available transmitter output signals include 0-10 volts DC and 4-20 mA DC. These outputs vary directly with force input as in equations (4-8) and (4-9). Outputs which vary linearly with flowrate, i.e., with $(F)^{1 / 2}$ are also available. These two outputs are illustrated in figure 23. While the linear $Q$ output is generally more useful, accuracy suffers because of the added electronics.

For best accuracy, the target meter should be calibrated with the fluid to be used on site using the $Q^{2}$ transmitter. Thus, for on-site calibration using flowing water at a known temperature, the meter performance can be given through a plot of a calibration factor $C F$ as a function of transmitter output, volts or $\mathrm{mA}$, where

$$
\mathrm{CF}=\mathrm{GPM} /(\text { volts })^{1 / 2} \text { or } \mathrm{GPM} /(\mathrm{mA})^{1 / 2}
$$

Then flowrates can be calculated directly from an expression, for example:

$$
\mathrm{Q}=(\mathrm{CF})\left(\mathrm{I}-\mathrm{I}_{\mathrm{O}}\right)^{1 / 2}=\left[\mathrm{GPM} /(\mathrm{mA})^{1 / 2}\right]\left(\mathrm{mA}^{1 / 2}=\mathrm{GPM}\right.
$$

where $I_{O}=$ current at zero flow

$\mathrm{I}=$ current at flowrate Q

The calibration factor $C_{F}$ will then account for variation in $C_{d}$ with flowrate and for the nonlinear characteristics of the transmitter electronics. Corresponding expressions can be written for mass flowrate $M$. Example E. 10 in appendix E inclides sample calculations and a plot of meter performance for the calibration of a target meter in water.

The target meter is attractive for building services because of its ability to handle particulate matter and the absence of pressure sensing lines. For best accuracy, the meter should be calibrated with the fluid to be used. As with the $\Delta \mathrm{P}$ meter, the output signal varies with $\mathrm{Q}^{2}$ which may limit its useful operating flow rate as compared to a PD meter. For calculating flowrates, the nonlinearity characteristic can be accomodated by using a calibration factor having the dimensions of flowrate/(output) $1 / 2$. 


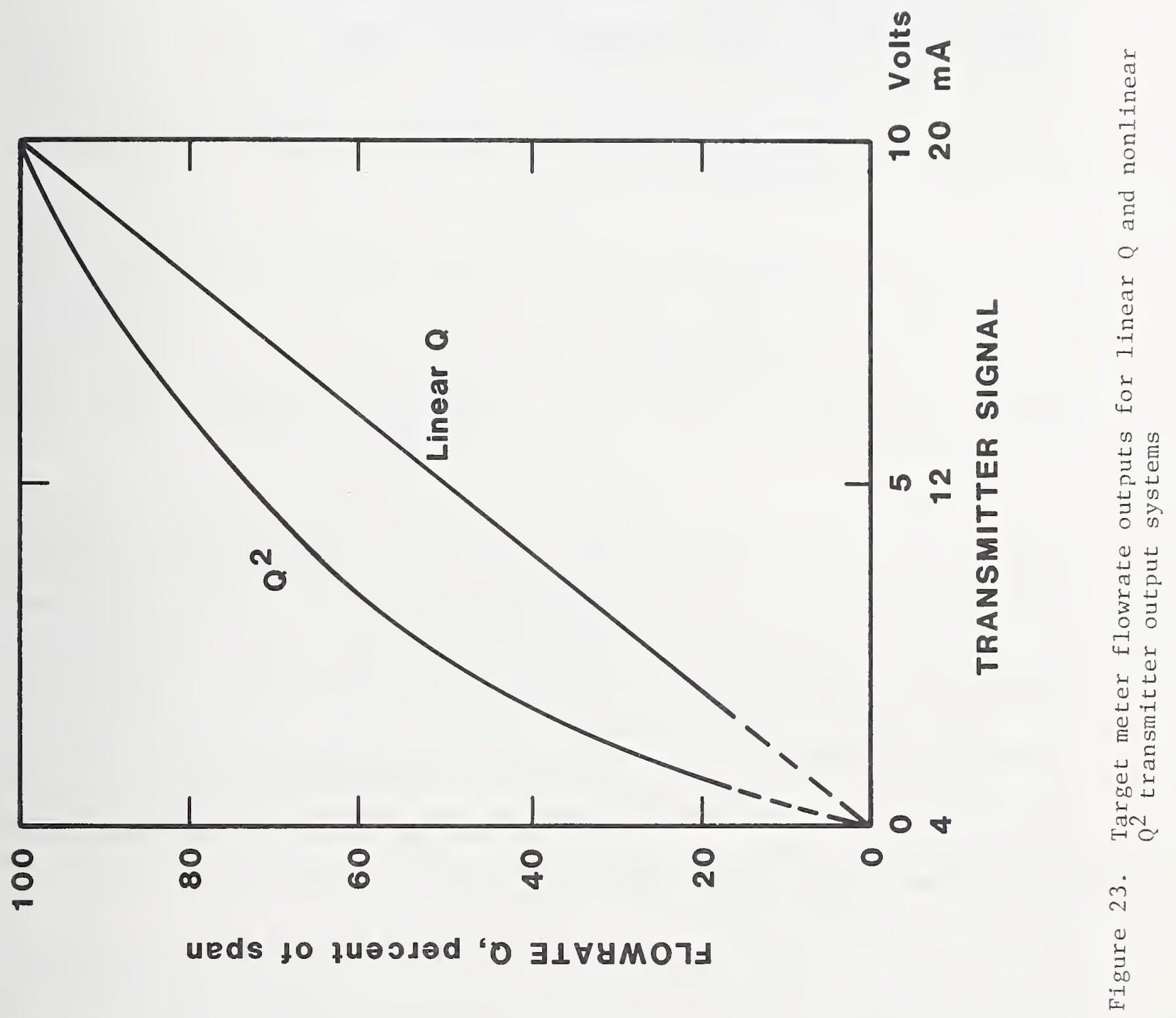




\subsection{MULTIPLE PITOT-STATIC AND REVERSE-PITOT TUBE ASSEMBLIES}

Several designs of flowmeters of these types are available. Figure 24 shows the schematic diagrams of an assembly designed for mounting in an air duct system. It contains 16 pitot-tubes spaced on an equal area traverse basis and connected to a common impact pressure line, and four static legs connected to a common static pressure line. Since the velocity profile varies in the duct cross section, an average value of impact pressure and a average value of static pressure are obtained. The $\Delta$ P is measured by means of a manometer or pressure transducer system. An advantage of this assembly is that a single $\Delta \mathrm{P}$ measurenent is used instead of 16 measurements, or instead of the traversing approach with a single tube. Because of the variation in impact pressure (velocity) from tube to tube and to account for the blockage effect of the assembly, reliable measurement of flowrates require that the assembly be calibrated on site over the range of velocities to be encountered. A flow straightener (honeycomb) is installed upstream of the assembly to eliminate transverse or swirling velocity components.

Figure 25 shows a commercially available reversed type of pitot tube assembly. This consists of a probe which extends completely across the diameter of a pipe and which senses impact pressure at four specific openings along the upstream side of the probe. The resulting impact pressure is some average value which connects to a manometer or $\Delta \mathrm{P}$ transducer system. A single reversed pressure tube senses the pressure on the downstream side of the probe. Advantages include increased differential pressure for a given fluid velocity compared to a conventional pitot-static tube, and ease of probe installation.

In fully developed turbulent flow, the velocity profile (velocity $\mathrm{V}$ as a function of radius $r$ ) changes with Reynolds number $R_{D}$ becoming more uniform as $\mathrm{R}_{\mathrm{D}}$ increases; or with a single fluid, as flowrate increases. For a detailed analytical analysis of the influence of the velocity profile on the coefficient of discharge, see reference 16. A significant influence on the coefficient of discharge by an increase in velocity can be expected. Also, when the flow is asymmetrical, such as the case downstream of elbows and valves, significant errors on the impact pressure will result. The static hole is located in the probe wake region; a region of higher turbulence and fluctuating pressures. For all these reasons, it is strongly recommended that the probe be mounted in a metering section such as shown on figure 7 and calibrated on site with the working fluid over the range of flowrates to be encountered. If necessary, to aid in producing a symmetrical velocity profile, the flow straightener should be of the perforated plate design rather than the tubular design (at the expense of a larger pressure loss). (See figures 12 and 13.)

The reversed pitot-tube sensing probes are suitable for flowing air, water or steam. However, flowing hot water at pressure levels approaching the vapor pressure should be avoided to eliminate possible cavitation at the static hole. Building system pressures of 50 to 100 psig should present no problem. To illustrate this point, consider the static pressure behind a circular cylinder where the static pressure has an approximate value corresponding to $C_{p}=-1.3$. The dimensionless pressure coefficient $C_{p}$ is defined by the following relationship: 


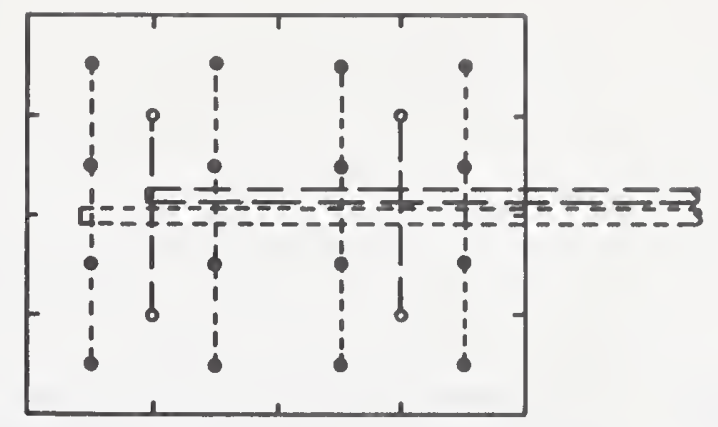

- Velocity taps at centers of 16 equal areas

- Static pressure taps at centers of 4 equal areas

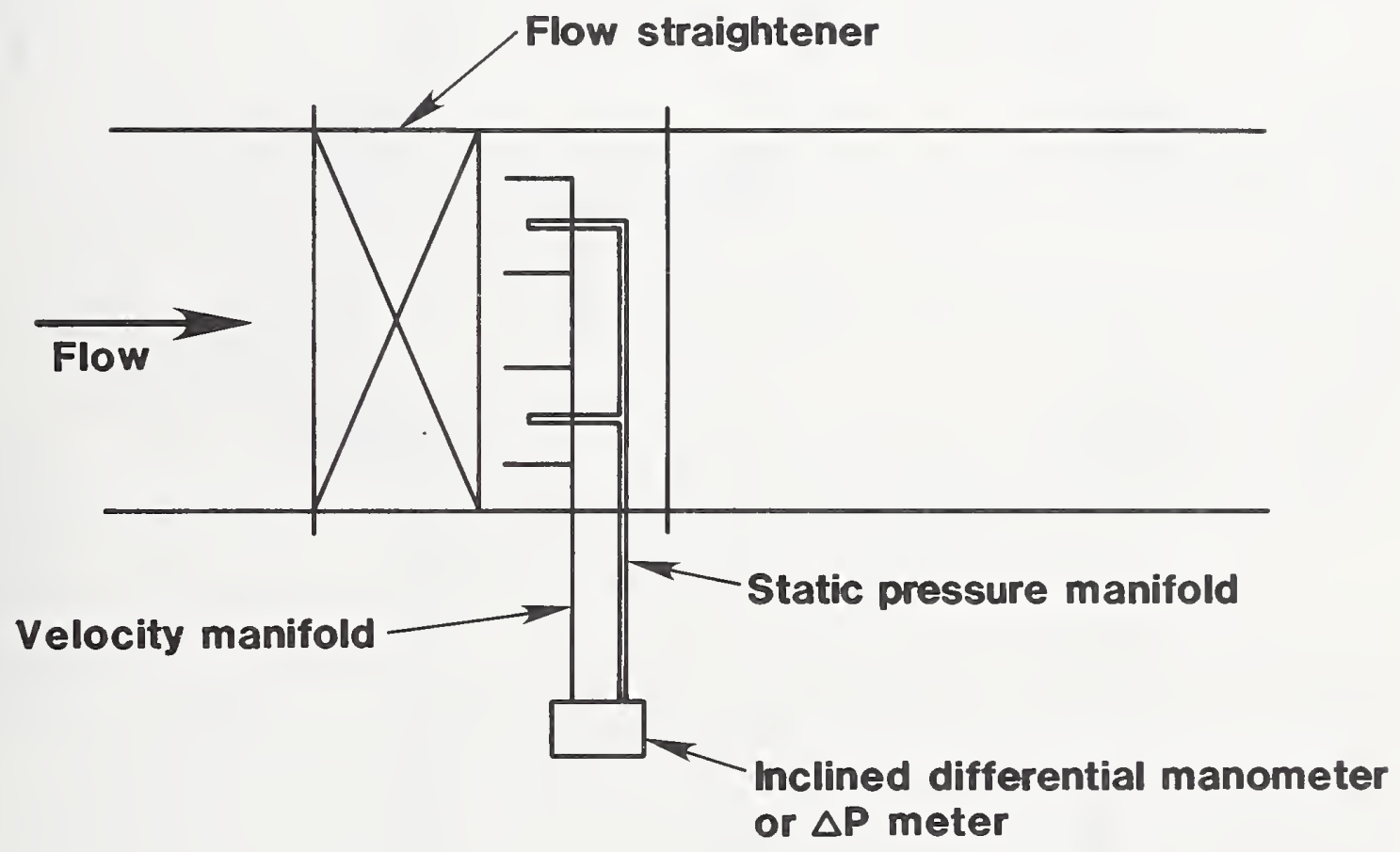

Figure 24. Pitot-static rake assembly for measuring air flow in a duct. The ends of the velocity taps are open to receive the impact pressure. The ends of the static pressure taps are closed and a ring of radial perforations receive the static pressure 


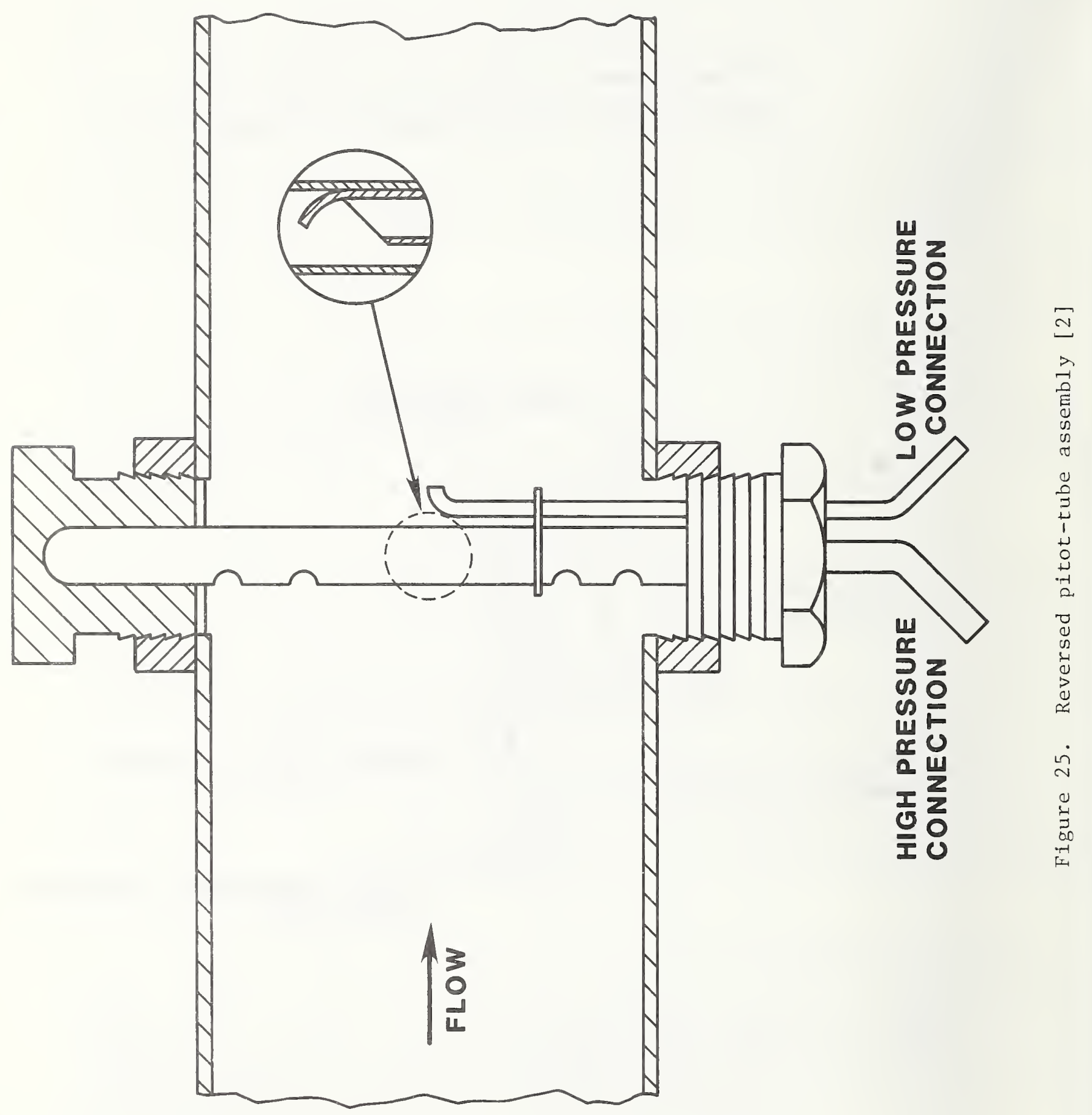




$$
C_{p}=\frac{2 g_{c}\left(p-p_{o}\right)}{\rho V^{2}} .
$$

For example, with water flowing at $\mathrm{V}=20 \mathrm{ft} / \mathrm{s}$

$$
\begin{aligned}
P-P_{O} & =\left(C_{p} \rho v^{2}\right) /\left(2 g_{c}\right) \\
& =\frac{(-1.3)\left(62.41 b / \mathrm{ft}^{3}\right)(20 \mathrm{ft} / \mathrm{s})^{2}}{(2)(32.174)\left[(1 b \cdot f t) /\left(\mathrm{s}^{2} \cdot 1 b_{f}\right)\right]\left(144 \mathrm{in} .2 / \mathrm{ft}^{2}\right)} \text {, or } \\
P-P_{O} & =-3.5 \mathrm{psi}
\end{aligned}
$$

This means the pressure $P$ at the static hole is 3.5 psi less than system pressure $\mathrm{P}_{\mathrm{O}}$. Thus, if the water temperature is $212^{\circ} \mathrm{F}$, system pressure ${ }^{\circ}$ must be at least $14.7+3.5=18.2$ psia (or 3.5 psig) to avoid flashing of the water at the static hole. A pressure $\mathrm{P}_{\mathrm{O}}$ of 7 to 10 psig would probably provide an adequate degree of safety from flashing.

The pressure differential, $\Delta \mathrm{P}$, for both of these probe systems is nonlinear with flowrate, where $\Delta \mathrm{P} \propto \mathrm{Q}^{2}$ or $\Delta \mathrm{P} \propto \mathrm{M}^{2}$. When used with a $\Delta \mathrm{P}$ transmitter where the current or voltage output varies directly with $\Delta P$, or when used with a manometer system, a calibration factor of the following form must be used:

$$
\mathrm{CF}=\text { flowrate/(output) } 1 / 2 \text {. }
$$

This will allow direct calculation of flowrate $Q$ (or M) from an expression such as

$$
\begin{aligned}
& Q=(C F)\left(I-I_{O}\right)^{1 / 2} \text { or } \\
& Q=(C F)(\text { inches of manometer fluid })^{1 / 2}
\end{aligned}
$$

Refer to figure 23 and the discussion in section 4.4 which discusses a similar situation for the target meter. In these mutliple assemblies, with an on-line calibration, the calibration factor CF will then account for any effects of changing velocity profiles on the probe performance.

Multiple pressure probe assemblies offer the advantage of a single $\Delta \mathrm{P}$ output resulting from sensing impact pressure (velocity) and static pressure at multiple points. For reliable flow measurement, calibration is required. For a large flow range such as $10: 1, \mathrm{HIGH}$ and LOW $\triangle \mathrm{P}$ transmitter systems such as discussed in section 3.3 may be necessary. The nonlinearity in the $\Delta \mathrm{P}$ can be accommodated by using a calibration factor of the form: flowrate/(output) 1/2. Electronic noise from a $\Delta \mathrm{P}$ transducer generated by small changes in the velocity profiles can also be a problem which is usually solved with little effort.

\subsection{ULTRASONIC FLOWMETER}

Ultrasonic flowmeters can be readily attached to the outside of existing liquidfilled pipes without shutdown, diversion, special sections, or isolation valves. The economic advantage of ultrasonic flowmeters over conventional flowmeters increases with pipe size. 
The primary elements are nonintrusive and are sensitive over a wide range of velocities of the liquid flowing within the pipe without inducing a pressure drop or other disturbance to the medium being monitored.

Several ultrasonic techniques are used in the measurement of flow. The majority of instruments of this type use various configurations of acoustic sources (transmitters) and detectors (receivers). The velocity of the fluid flowing in the pipe is detected from the effect of the moving liquid on the sound waves. In general, this effect is determined by comparing the signals transmitted with those received. The two techniques most commonly used to detect the effect of the flowing liquid on the sound waves are known as the transit-time meters and the Doppler meters.

The transit-time flowmetẹrs utilize the fact that fluid flow along the acoustic path affects the time it takes for the acoustical signal to travel from the transmitter to the receiver. Transit-time meters transmit bursts of ultrasonic energy across the pipe as shown in figure 26. The transit times in the downstream $(t+)$ and upstream $(t-)$ directions are given by:

$$
t+=\frac{\text { distance }}{\text { conduction velocity }}=\frac{\mathrm{L}}{\mathrm{c}+\hat{\mathrm{u}} \cos \theta} \text {, and, } \mathrm{t}-=\frac{\mathrm{L}}{\mathrm{c}-\hat{\mathrm{u}} \cos \theta}
$$

where $t=$ time in seconds

$\mathrm{L}=$ distance between the two transceivers

$c=$ velocity of sound in the liquid being monitored

$\hat{\mathrm{u}}=$ velocity of the liquid averaged along the path of the ultrasound. $\widehat{\mathrm{u}} \cong 1.33 \overline{\mathrm{u}}$ for laminar flow, and, for turbulent flow, $\widehat{\mathrm{u}} \cong 1.07 \overline{\mathrm{u}}$ where $\overline{\mathrm{u}}=$ the average velocity of the flow over the cross-sectional area.

$\theta=$ angle between the direction of travel of the acoustical signals and direction of fluid flow

Note that $\widehat{u}$ differs from $\bar{u}$ because the ultrasonic path is along a single line rather than averaged over the cross-sectional area.

The downstream transit time is shorter than the upstream transit time by

$$
\Delta \mathrm{t} \cong \frac{2 \mathrm{~L} \hat{\mathrm{u}} \cos \theta}{\mathrm{c}^{2}}
$$

and thus the average fluid velocity along the acoustical path, $\hat{u}$, is proportional to $\Delta t$. A short acoustic pulse is transmitted alternately in the upstream and downstream directions. Unfortunately, the resulting $\Delta t$ is in the nanosecond range and higher quality electronics are required to achieve adequate stability. It should be noted that this type of meter requires relatively clean liquids since minute particles can absorb or disperse sound energy.

Ultrasonic flowmeter utilizing the Doppler effect function on the shift in frequency produced when the sound waves are reflected from moving bodies. In this type of ultrasonic flowmeter, a single transmitter projects a continuous ultrasonic beam at about $0.5 \mathrm{MHz}$ through the pipe wall to the liquid flow being 


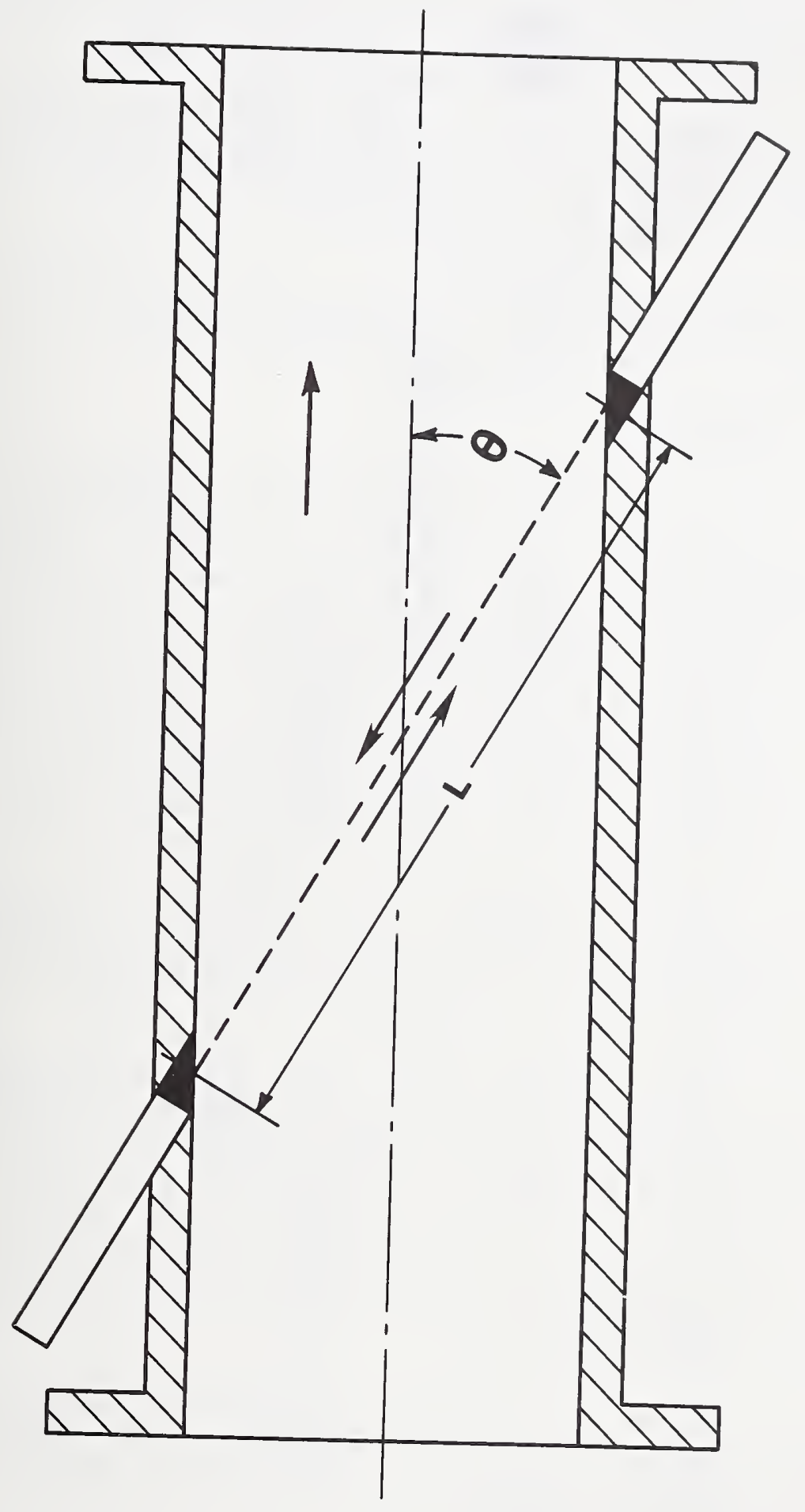

D 
monitored. The particles carried by the liquid have velocity components in the direction of the ultrasonic beam since the beam makes an angle which is less than $90^{\circ}$ to the direction of flow. The reflected ultrasonic waves detected at the receiver (which can be located adjacent to the transmitter or on the opposite side of the pipe) are shifted in frequency in proportion to the velocity of the liquid. The shift in frequency is determined and used to measure the flow rate. Doppler meters are suitable for liquids containing a consistent density of acoustically reflective particles.

Since the transmit-time meters require relatively clean liquids and the Doppler type meters require relatively small acoustically reflective particles, and these conditions are rapely met in typical EMCS applications, frequent periodic calibrations of these meters are required.

The vast differences in the designs of currently available ultrasonic flowmeters requires that the reader consult a particular manufacturer's literature for further information on calibration procedures $[17,18,19]$.

\subsection{INSERTION TYPE TURBINE METER}

This is another type of turbine meter in which a meter assembly is mounted on the end of a stem or strut and positioned as desired in a large pipe, duct, or open channel. Figure 27 shows a typical installation sketch. Advantages include low cost compared to the "full bore" turbine meter for large pipe installations; easy installation including no discuption to the fluid flow when an isolation valve is used, insuring essentially no pressure loss; and a digital output. Dther characteristics, including the influence of fluid properties, density and viscosity, fluid lubricity, the effects of retarding forces due to bearing friction and electronganetic loading, and the effects of flow patterns have all been discussed above for full bore turbine meters (section 4.3). These characteristics apply generally to the insertion meter. Again, a clean fluid is imperative for satisfactory, long-term operation.

Insertion turbine meters are available for use in water, air, and steam. Typical velocities range from 50 or $60 \mathrm{feet} / \mathrm{second}$ maximum for liquids to 300 feet/second maximum for gases. Manufacturers typically claim a linearity of \pm 1 percent full scale for $10: 1$ flow range.

The insertion turbine meter, like the target meter, senses local fluid velocity only and thus, for measuring flow in closed conduits (pipes and ducts), the performance is dependent on the velocity profile. Figure 28 shows velocity profiles for fully developed turbulent flow as a function of Reynolds number $R_{D}$. Such profiles normally occur only in very long, straight pipes. Furthernore, it should be noted that the conversion factor between measured velocity and flowrate will be flow dependent. An iteration is recommended for each measurement. Note also that velocity gradients are lowest near the pipe center, indicating a preferred probe position.

The insertion type turbine meter is attractive because of its relatively low cost for large pipe sizes and its ease of installation. For best accuracy, the meter should be calibrated on site with the operating fluid over the operating flow and temperature ranges. 


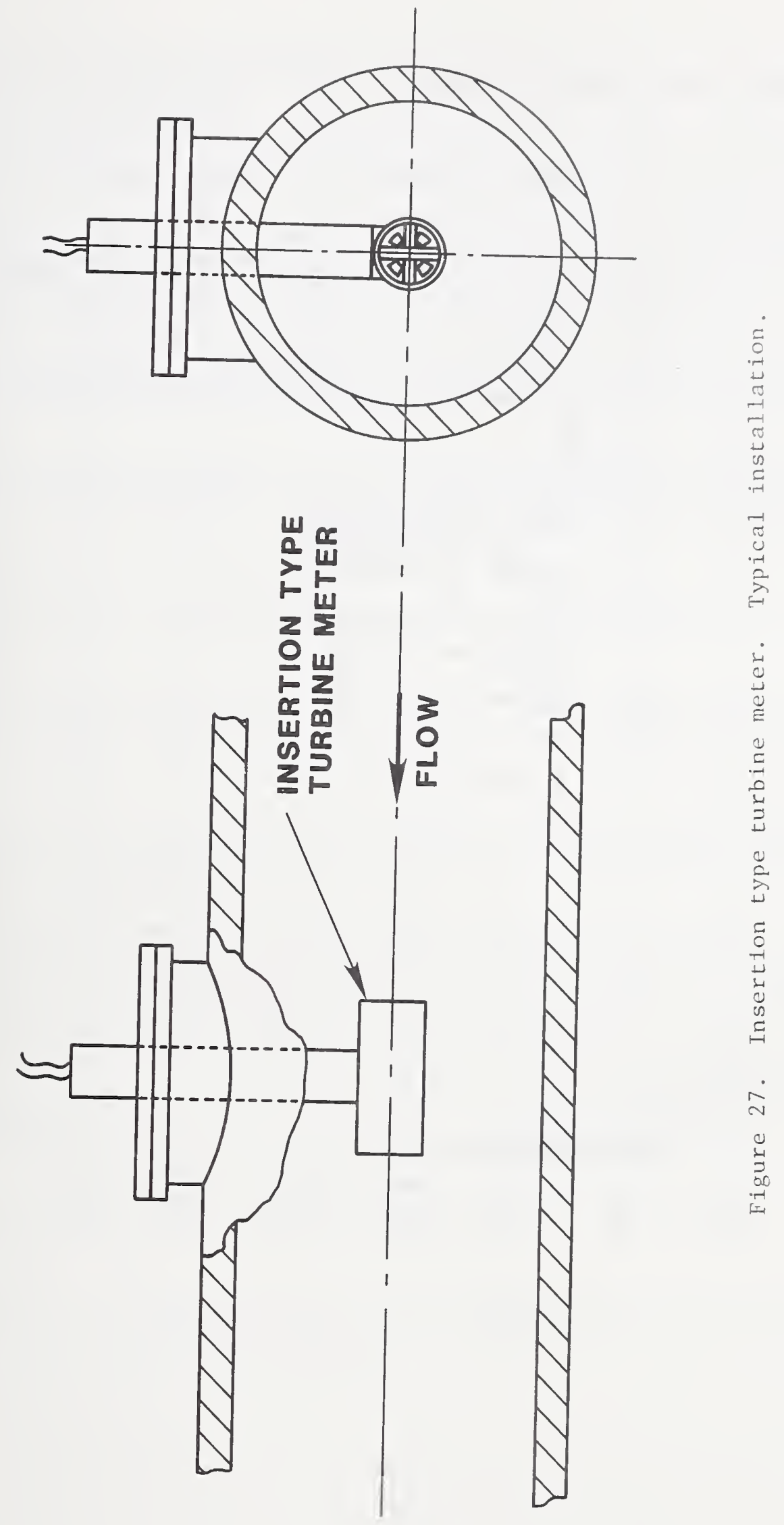




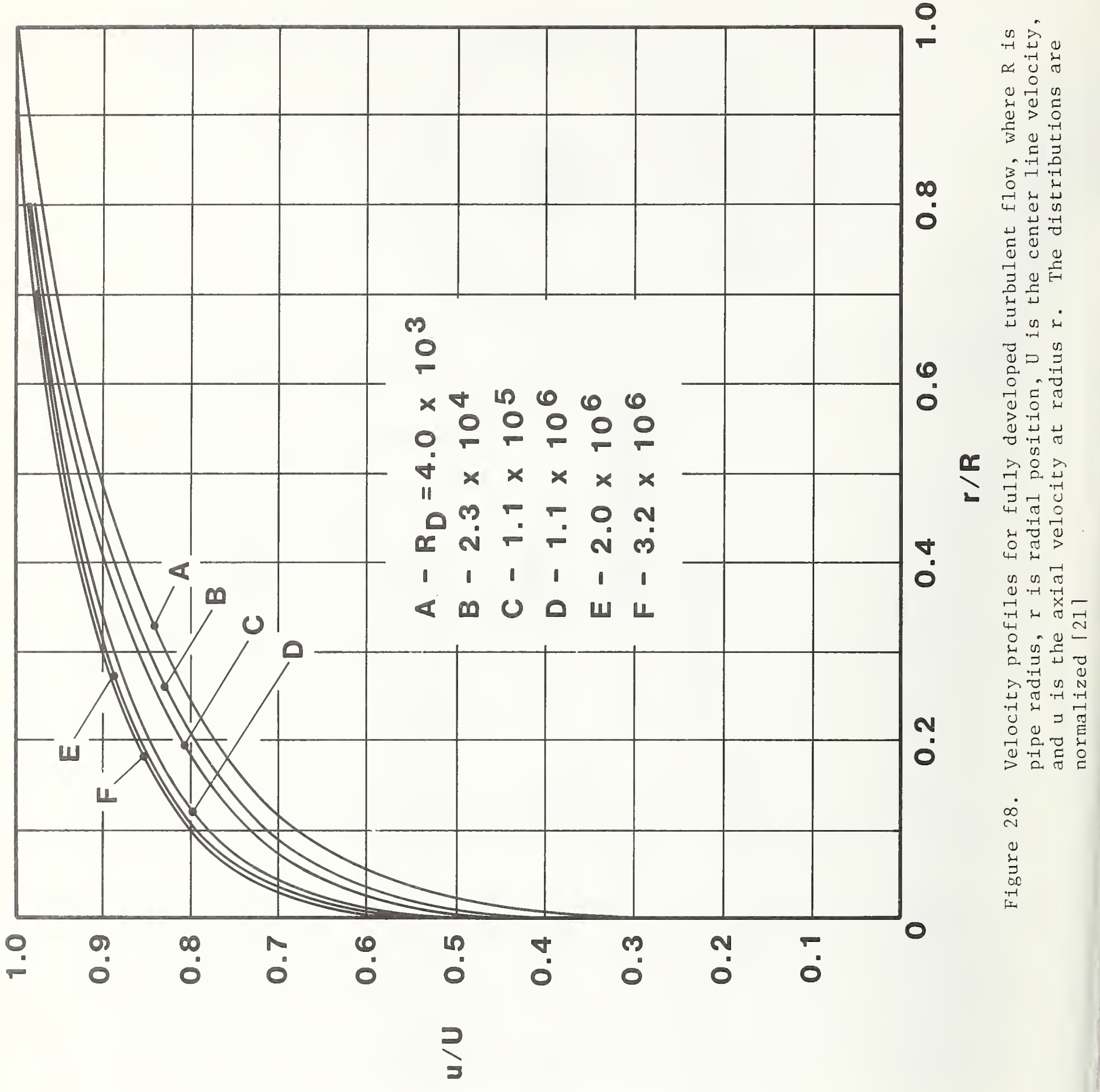


REFERENCES

1. "Handbook of Fundamentals, 1981," Chapter 13, ASHRAf, 1971 Tullie Circle, N.E., Atlanta, GA 30329.

2. Fluid Meters, Their Theory and Application, ASME, 6th ed., 1971.

3. Standard Methods for Measurement of Flow of Fluids - Liquids, ASHRAE Standard 41.8-78, 1978; and, Procedure for Fluid Flow Measurement of Gases, ASHRAE Standard 41.7-78, 1978.

4. S.J. Irwin, The Effect of Bends on the Discharge Coefficient of Orifice Plates, Flow Measurement of Fluids, Proceedings of FLOMEKO 1978, International Measurement Confederation, LMEKO Conference, pp. 247-252.

5. D.W. Baker and C.C. Sayre, Jr., Decay of Swirling Flow of Incompressible Fluids in Long Pipes, Proceedings of ISA/ASME Symposium on Flow, Its Measurement and Control in Industry, Vol. 1, Part 1, 1971, pp. 301-312.

6. Thermodynamic and Transport Properties of Steam, ASME, 3rd Ed., 1977.

7. Manometer Tables, Recommended Practice 2.1, Instrument Society of America, Pittsburgh, PA, 1962.

8. Units and Systems of Weights and Measures - Their Origin, Development, and Present Status, Letter Circular LC-1035, National Bureau of Standards, Washington, DC., January 1960.

9. M.R. Shafer, Jr. and D.W. Baker, Practical Considerations for Gas Flow Measurement, Proceedings of the Third Annual PMA Metrology Conference, Precision Measurements Association, Volume 1, pp. 187-227, 1970.

10. Measurement of Fluid Flow by Means of Orifice Plates, Nozzles, and Venturi Tubes Inserted in Circular Cross-Section Ducts Running Full, International Standard 5167, International Organization for Standardization, First Edition, 1980, American National Standards Institute, New York, N.Y.

11. The ISO-ASME Orifice Coefficient Equation, Research Committee on Fluid Meters, ASME, Mechanical Engineering, Volume 103, No. 7, July 1981, pp. 44-45.

12. Tables of Thermodynamic and Transport Properties of Air, Argon, $\mathrm{CO}_{2}, \mathrm{CO}$, $\mathrm{H}_{2}, \mathrm{~N}_{2}, \mathrm{O}_{2}$ and Steam, Joseph Hilsenrath et. al., Pergammon Press, New York, 1960 .

13. D.F. White, A.E. Rodely, and C.L. Murtrie, The Vortex Shedding Flowmeter, Proceedings of ISA/ASME Symposium on Flow, Its Measurement and Control, Vol. 1, Part 2, 1971, pp. 967-974. 
14. M.R. Shafer, Performance Characteristics of Turbine Flow Meters, Journal of Basic Engineering, Transactions of the ASME, Vol. 84, Series D, 1962, pp. $471-481$.

15. David E. Curran, Laboratory Determination of Flow Coefficient Values for the Target Type Flowmeter at Low Reynolds Number Flow, Proceedings of the Second International Symposium on Flow: Its Measurement and Control in Industry, ISA/ASME, 1981, pp. 263-276.

16. N.Q. Thoi and W.K. Soh, On the Averaging Technique and the Discharge Coefficient of the Annular-Averaging Flow Sensor, ISA Transactions, Volume 18, No. 1, January 1979, pp. 41-48.

17. Thomas R. Schmidt, What You Should Know About Clamp-On U1trasonic Flowmeters, ISA, InTech, May 1981, pp. 59-62.

18. Ronald E. Burner, Theoretical and Experimental Assessment of Uncertanities in Non-Intrusive, Ultrasonic Flow Measurement, Symposium on Flow Measurement in Opens Channels and Closed Circuits; Proceedings, NBS Special Publication 484, National Bureau of Standards, 1977.

19. Lawrence C. Lynnworth, Industrial Applications of Ultrasound - A Review II. Measurements, Tests, and Process Control Using Low-Intensity Ultrasonics, IEEE Transactions on Sonics and Ultrasonics, March 1975, Volume So-22, Number 2, pp. 71-101.

20. P.H. Bigg, The Density of Mercury, British Jol. of Applied Physics, Volume 15, 1964, pp. 1111 .

21. Hermann Schlichting, Boundary Layer Theory, 4th Edition, 1960.

22. M.R. Shafer and F.W. Ruegg, Liquid-Flowmeter Calibration Techniques, Transactions of the ASME, October 1958, pp. 1369-1379.

23. David W. Baker, James Y. Kao, and David A. Didion, "Performance Evaluation of a Typical Energy Monitoring System for Steam Flow in Buildings," National Bureau of Standards Report NBSIR 81-2313, January 1981. 
Discussions with Mr. Kenneth Benson of the Fluid Engineering Division at NBS on flowmeter characteristics and calibration techniques have been especially helpful. The authors also wish to acknowledge the excellent work of Dr. James F. Schooley of the NBS Center for Absolute Physical Quantities in editing this report and contributing many technical improvements. Also, long past discussions on similar subjects with Mr. Montgomery R. Shafer Jr. (retired, deceased) of the former Fluid Meters Section at NBS are recalled. Mr. Shafer's very significant contributions through his work on flowmeter characteristics and calibration techniques are remembered by many, and his paper (reference 14) on turbine meter characteristics is still a classic. 
APPENDIX A

Coefficient of Discharge $C$ and Fluid Expansion Factor Y for Orifices, Flow Nozzles and Venturi Meters

(The data in this appendix were taken from references 2,10 , or 11)

$A-1$ 
Table A.1. Coefficient of Discharge C

Orifice Plate with Corner Taps

\begin{tabular}{|c|c|c|c|c|c|c|c|c|c|c|}
\hline$R_{i j}$ & $5 \times 11^{3}$ & $10^{4}$ & $2 \times 10^{4}$ & $3 \times 10^{4}$ & $3 \times 10^{4}$ & $7 \times 10^{4}$ & $10^{5}$ & $3 \times 10^{5}$ & $10^{6}$ & $10^{7}$ \\
\hline 0.23 & 0.0012 & 0.5997 & 0.5987 & 0.5933 & 0.5980 & 0.5979 & 0.5977 & 0.5975 & ). .5974 & 0.5973 \\
\hline 10.24 & 0.0018 & 10.6000 & 0.5990 & 10.59366 & 0.5982 & 0.5981 & 0.4579 & 0.5977 & 0.5975 & 0.9575 \\
\hline 0.25 & 0.6031 & U.bU0Y & 0.5996 & 0.5991 & 0.5987 & 0.5985 & 0.5983 & 0.5980 & 0.5978 & 0.5978 \\
\hline $0.2 \ddot{~}$ & 0.6044 & 0.5019 & 0.6003 & 0.5997 & 0.5992 & 0.5989 & 0.5987 & 0.5983 & 0.5982 & 0.5981 \\
\hline 0.30 & 0.6060 & 0.6029 & 0.6011 & 0.6004 & 0.5997 & U.5994 & 0.5992 & 0.5987 & 0.5983 & 0.5984 \\
\hline 0.32 & 10.6077 & 0.6040 & 10.6019 & 0.6011 & 0.6003 & 0.6000 & 0.5997 & 0.5991 & 0.5989 & 0.5988 \\
\hline 0.34 & 0.0095 & 0.6053 & 0.6028 & 0.6013 & 0.6010 & 0.6005 & 0.6002 & 0.5996 & 0.5993 & 0.5991 \\
\hline 0.30 & 0.6115 & 0.6066 & 0.6037 & 0.6026 & 0.6016 & 0.6012 & 0.6003 & 0.6001 & 0.5997 & 0.5995 \\
\hline 0.38 & 0.6136 & 0.6081 & 0.6043 & 0.6035 & 0.6024 & 0.6018 & 0.6014 & 0.6005 & 0.6002 & 0.6000 \\
\hline 0.40 & 10.6159 & 0.6096 & 0.6059 & 0.6044 & 0.5031 & 0.6025 & 0.6020 & 0.6011 & 0.6006 & 0.6004 \\
\hline 0.42 & 0.6134 & 0.6113 & 0.6070 & 0.6054 & 0.6039 & 0.6032 & 0.6026 & 0.6016 & 0.6011 & 0.6008 \\
\hline 0.44 & 0.6210 & U.6130 & (1.6082 & 0.6064 & 0.6047 & 0.6039 & 0.6033 & 0.6021 & 0.6016 & 0.6013 \\
\hline 0.46 & 0.6238 & 0.6148 & 11.6095 & 0.6074 & 0.6056 & 0.6047 & 0.6040 & 0.6027 & 0.6021 & 0.6017 \\
\hline 0.48 & -- & 0.6167 & 0.6108 & 0.6085 & 0.6064 & 0.6055 & 0.6047 & 0.6032 & 0.6025 & 0.6021 \\
\hline 0.50 & -- & 0.6187 & 0.6121 & 0.5096 & 0.6073 & 0.6062 & 0.6053 & 0.6037 & 0.6030 & 0.6026 \\
\hline 0.52 & -- & 0.6027 & 0.6135 & 0.6107 & 0.6082 & 0.6070 & 0.6060 & 0.6042 & 0.6034 & 0.6029 \\
\hline 0.54 & -- & 0.6228 & 0.6148 & 0.6117 & 0.6090 & 0.6077 & 0.6066 & 0.6047 & 0.6037 & 0.6032 \\
\hline 0.56 & $\rightarrow$ & $0.624 y$ & 0.6162 & 0.6128 & 0.6098 & 0.6084 & 0.6072 & 0.6050 & 0.6040 & 0.6035 \\
\hline 0.53 & $\rightarrow$ & 0.0270 & 0.6175 & 0.6138 & 0.6105 & 0.6089 & 0.6077 & 0.6053 & 0.6042 & 0.6036 \\
\hline ט.ค0 & -- & 0.6291 & 0.6187 & 0.6147 & 0.6111 & 0.6094 & 0.6080 & 0.6055 & 0.6043 & 0.6036 \\
\hline 0.62 & -- & 0.6311 & 0.6198 & 0.6155 & 0.6116 & 0.6098 & 0.6083 & 0.6055 & 0.6042 & 0.6035 \\
\hline 0.64 & -- & 0.6330 & 0.6208 & 0.6161 & 0.6119 & 0.5099 & 0.6083 & 0.6053 & 0.6039 & 0.6031 \\
\hline 0.65 & - & 0.6339 & 0.6212 & 0.6104 & 0.6120 & 0.6099 & 0.6082 & 0.6051 & 0.6037 & 0.6028 \\
\hline 0.66 & -- & 0.6348 & $0.621 b$ & 0.6165 & 0.6120 & 0.6099 & 0.6081 & 0.6048 & 0.6033 & 0.6025 \\
\hline 0.67 & -- & 0.6356 & 0.6219 & 0.6167 & 0.6120 & U.6097 & 0.6079 & 0.6045 & 0.6029 & 0.6021 \\
\hline 0.68 & -- & 0.6363 & 0.6222 & 0.0167 & 0.6118 & ט.6u95 & 0.6076 & 0.6041 & 0.6025 & 0.6016 \\
\hline 0.69 & -- & 0.6370 & 0.6223 & 0.6167 & 0.6116 & 0.6092 & 0.6072 & 0.6036 & 0.6019 & 0.6010 \\
\hline 0.70 & -- & 0.6376 & 0.6224 & 0.6165 & 0.6113 & 0.6088 & 0.6067 & 0.6030 & 0.6012 & 0.6003 \\
\hline 0.71 & -- & 0.6382 & 0.6224 & 0.6163 & 0.6109 & 0.6083 & 0.6061 & 0.6023 & 0.6004 & 0.5994 \\
\hline 0.72 & -- & 0.6386 & 0.6222 & 0.6160 & 0.6103 & 0.6076 & 0.6054 & 0.6014 & 0.5995 & 0.5935 \\
\hline 0.73 & -- & 0.6389 & 0.6220 & 0.6155 & 0.6097 & 0.6069 & 0.6046 & 0.6004 & 0.5985 & 0.5974 \\
\hline 0.74 & -- & 0.6391 & 0.6216 & 0.6149 & 0.6089 & U.6060 & 0.6036 & 0.5993 & 0.5973 & 0.5962 \\
\hline 0.75 & -- & 0.6392 & 0.6211 & 0.6141 & 0.6079 & 0.6049 & 0.6025 & 0.5980 & 0.5959 & 0.5948 \\
\hline 0.76 & -- & 0.6391 & 0.6204 & 0.6132 & 0.6068 & 0.6037 & 0.6012 & 0.5966 & 0.5944 & 0.5932 \\
\hline 0.77 & -- & 0.6385 & 0.6196 & 0.6121 & 0.6055 & 0.6023 & 0.5997 & 0.5949 & 0.5927 & 0.5915 \\
\hline 0.73 & -- & -- & 0.6185 & 0.6108 & 0.6039 & 0.6007 & 0.5980 & 0.5931 & 0.5908 & 0.5895 \\
\hline 0.79 & -- & -- & 0.6173 & 0.6093 & 0.6022 & 0.5988 & 0.5960 & 0.5910 & 0.5886 & 0.5873 \\
\hline 0.80 & -- & -- & 0.6158 & 0.6076 & 0.6003 & 0.5968 & 0.5939 & 0.5887 & ט.5862 & 0.5849 \\
\hline
\end{tabular}


Table A.2. Coefficient of Discharge C

Orifice plate with Tays at 1D) and 1/2I)

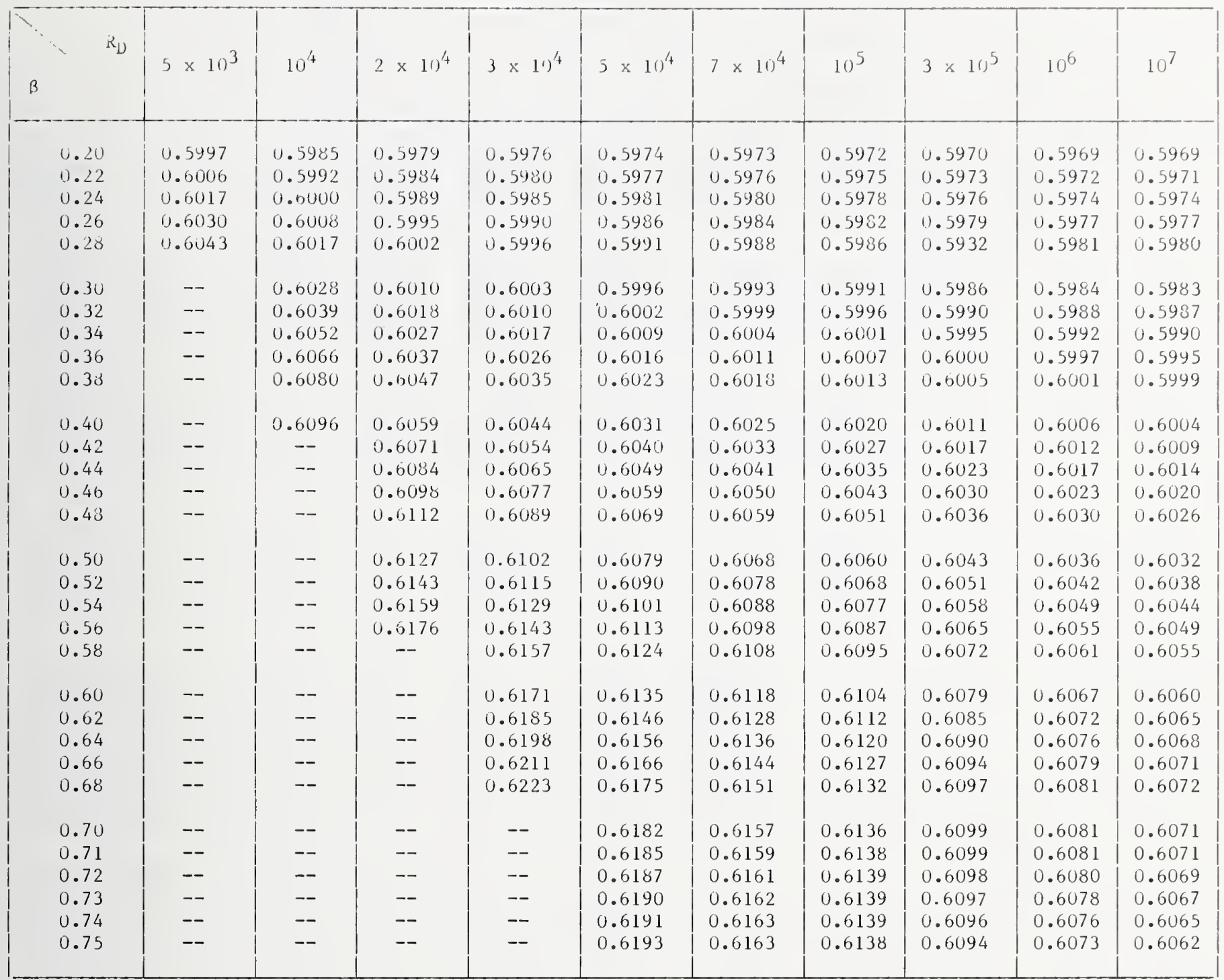


Table A.3. Coefficient of Discharge C

Orifice Plate with Flange Taps

$\mathrm{D}=2$ in.

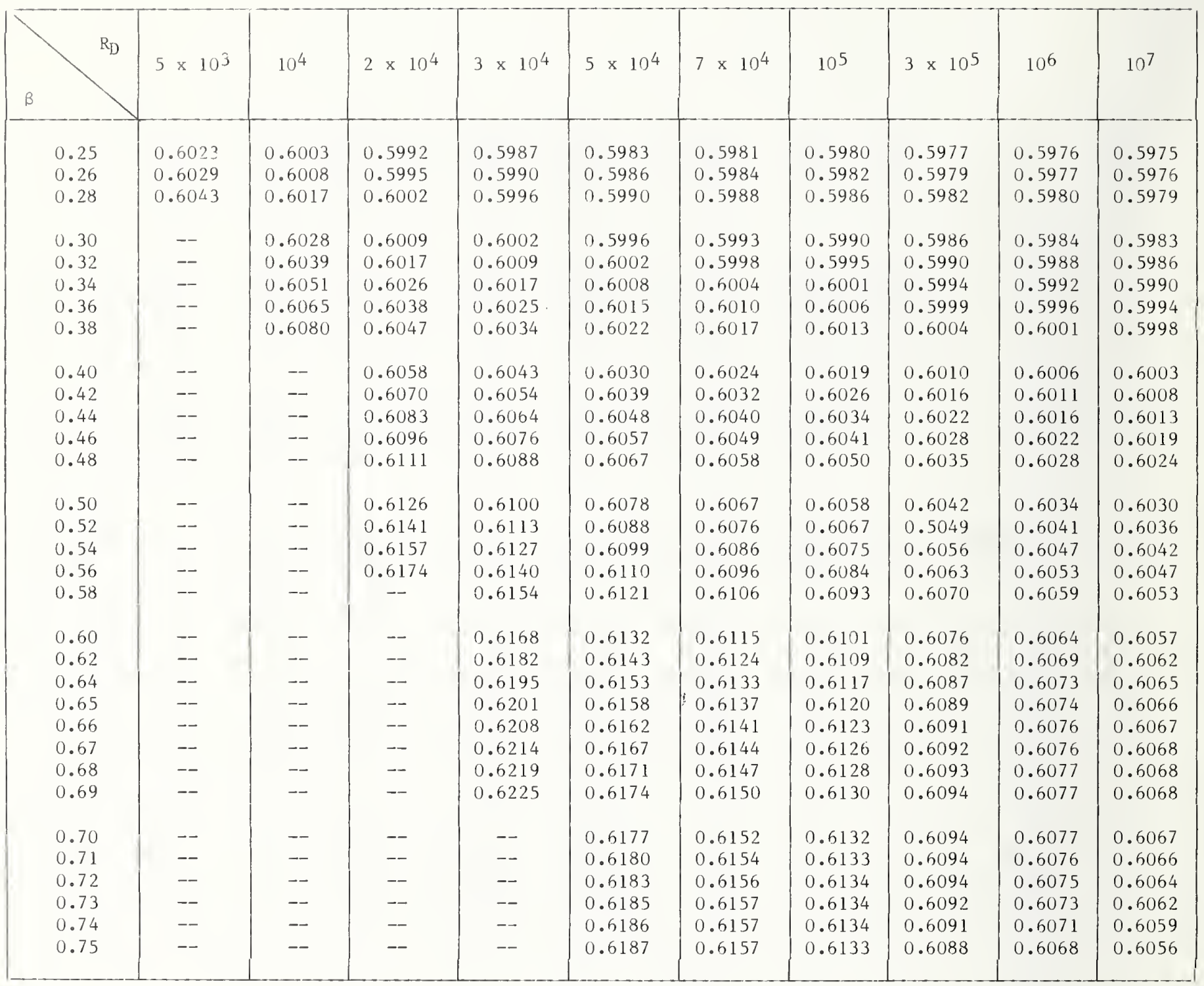


Table A.4. Coef"icient of Discharge C

Orifice Plate with Flange Taps

$\mathrm{D}=3 \mathrm{in.}$

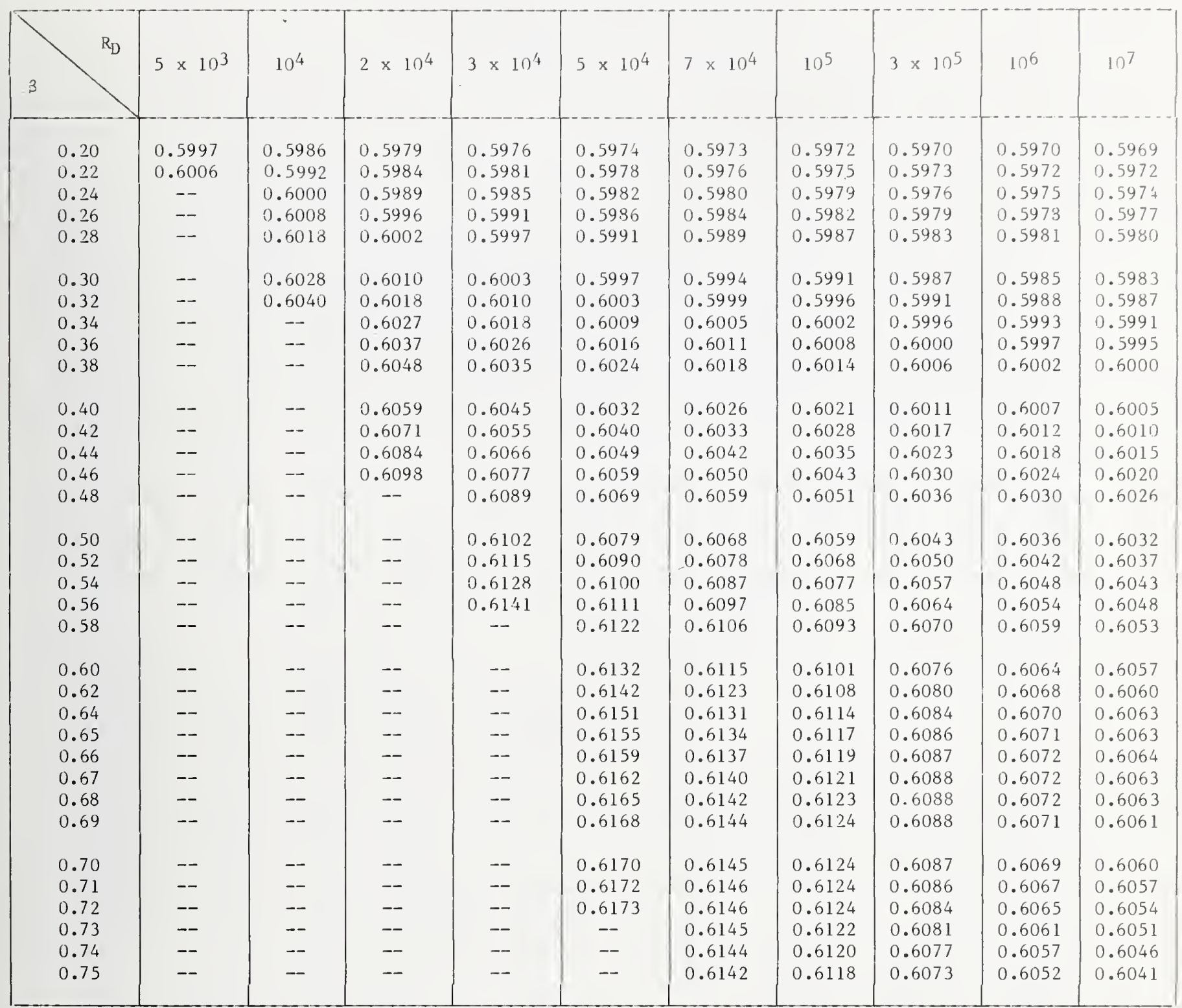


Table A.5. Coefticient of Discharse C

9) rifice Plate with Flange Taps

i) $=4 i n$.

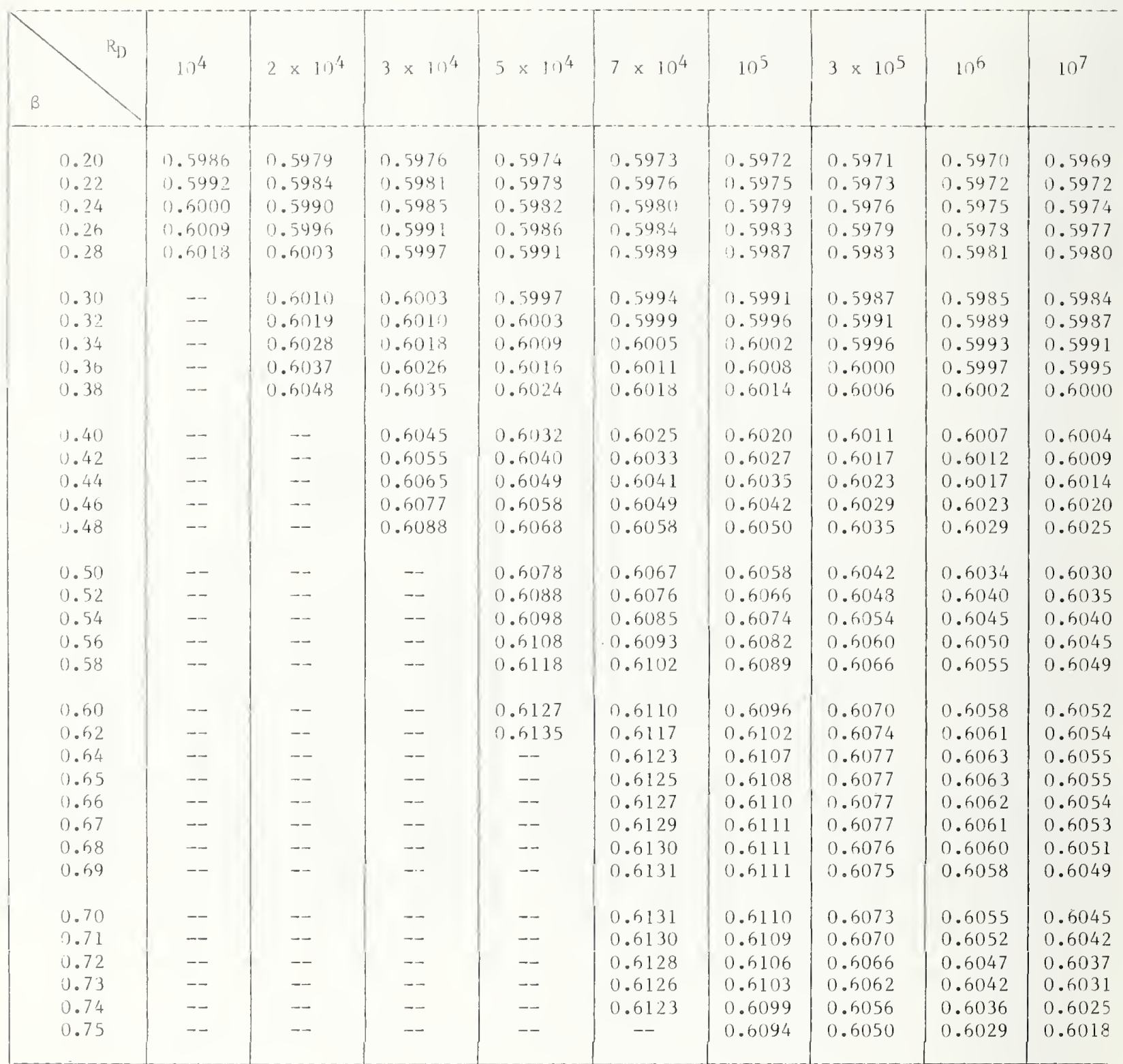


Table A.5. Coefficient of Discharge C

Orifice Plate with Flange Taps

$$
D=6 \text { in. }
$$

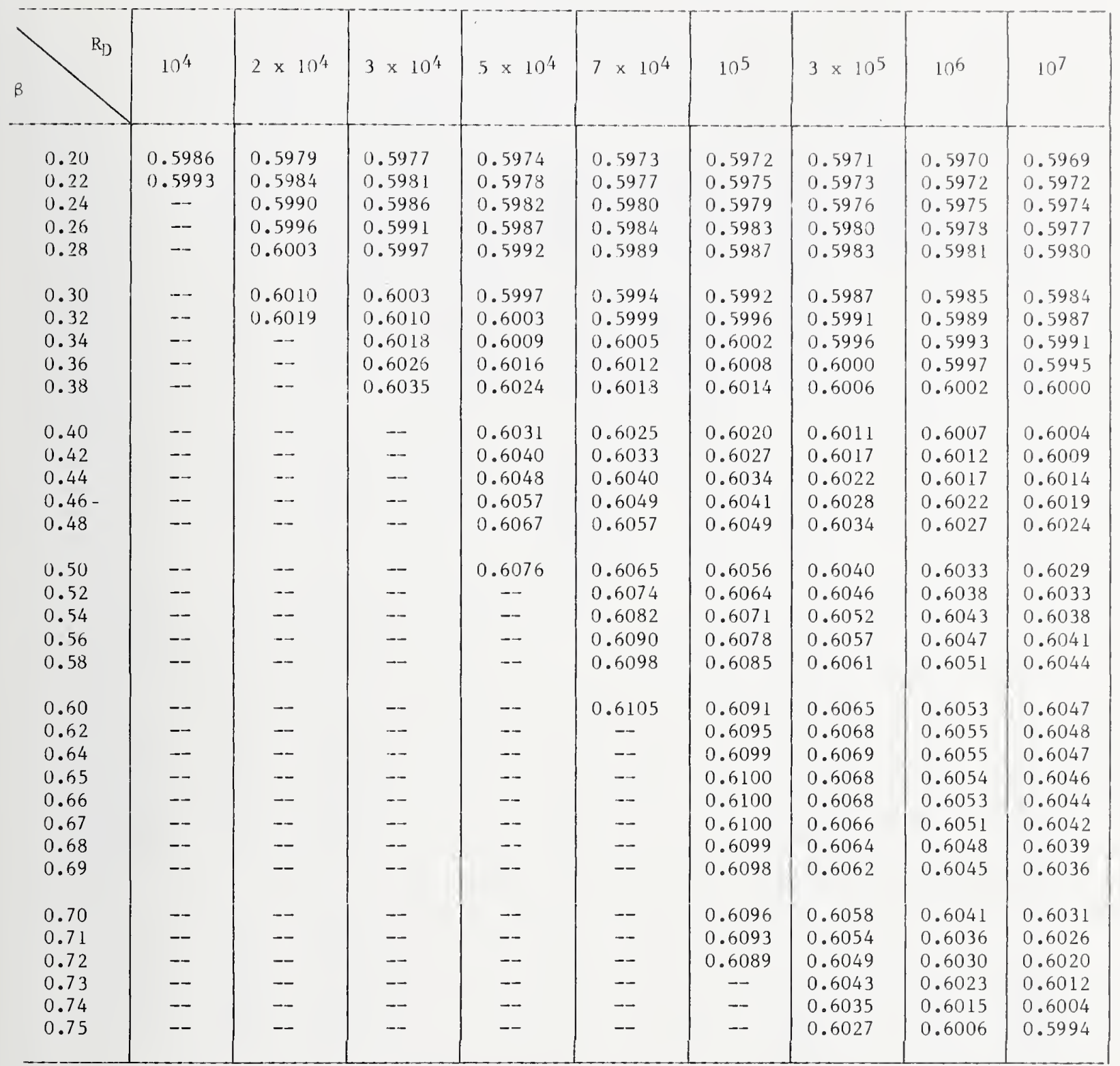


Tabie A.7. Coefficient of Discharge C

()rifice Plate with Flange Taps

1) $=8 \mathrm{in}$.

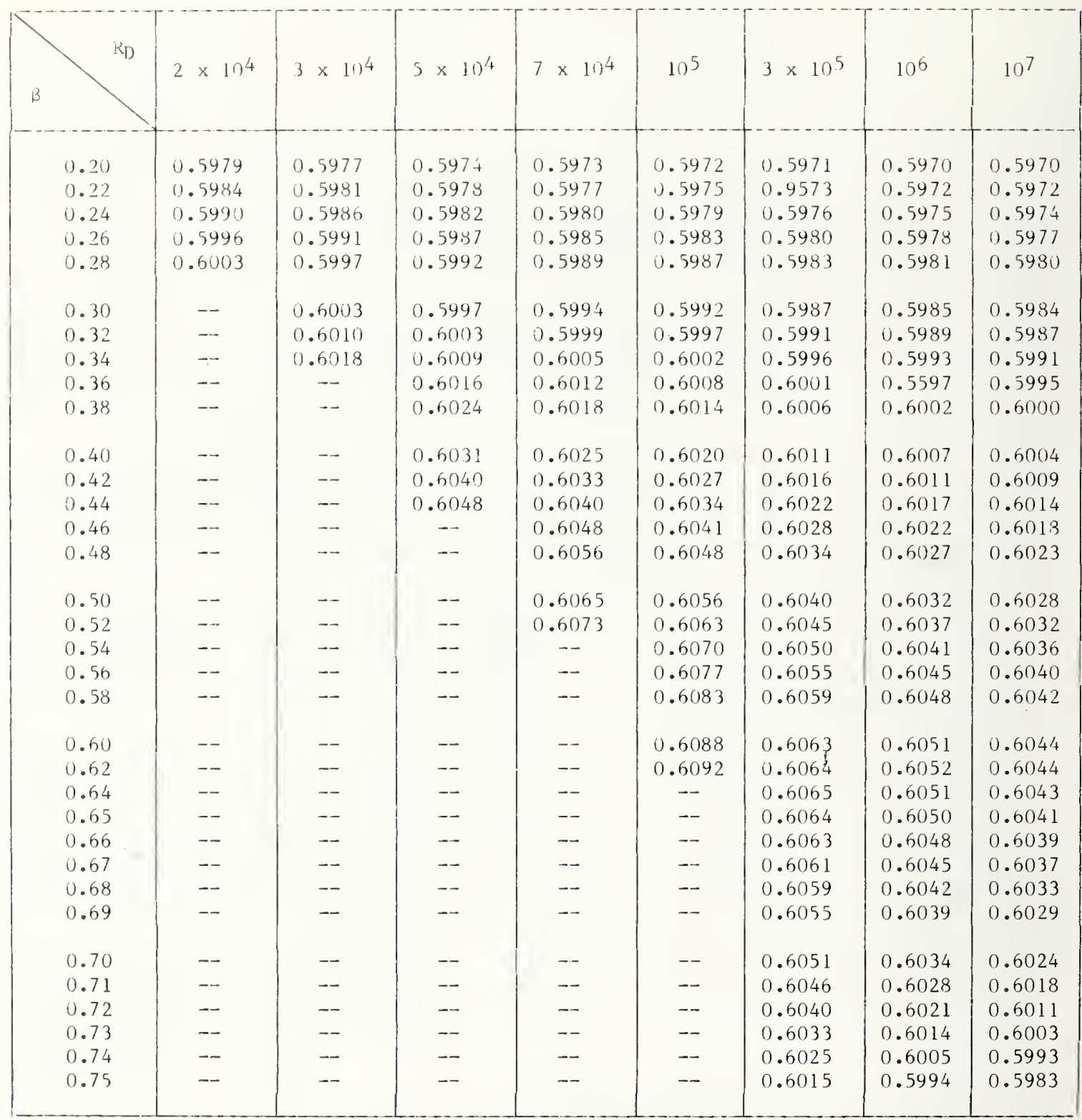


Table A.8. Coefficient of Discharge C

Orifice Plate with Flange Taps

$\mathrm{D}=10 \mathrm{in}$.

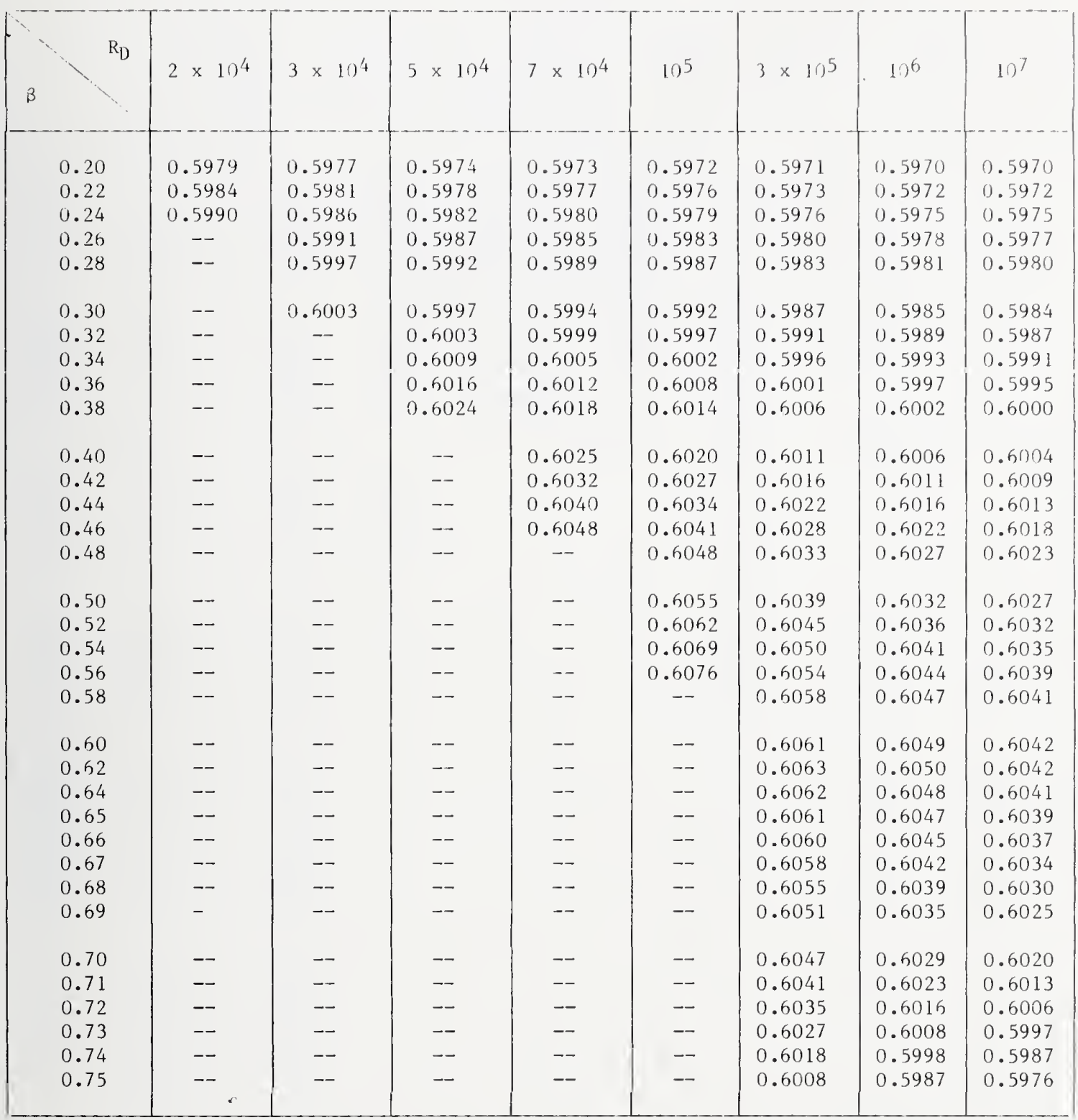


Thte A.9. Coefficient of Discharge C

Orifice Plate with Flange Taps

$$
\mathrm{D}=15 \mathrm{in} \text {. }
$$

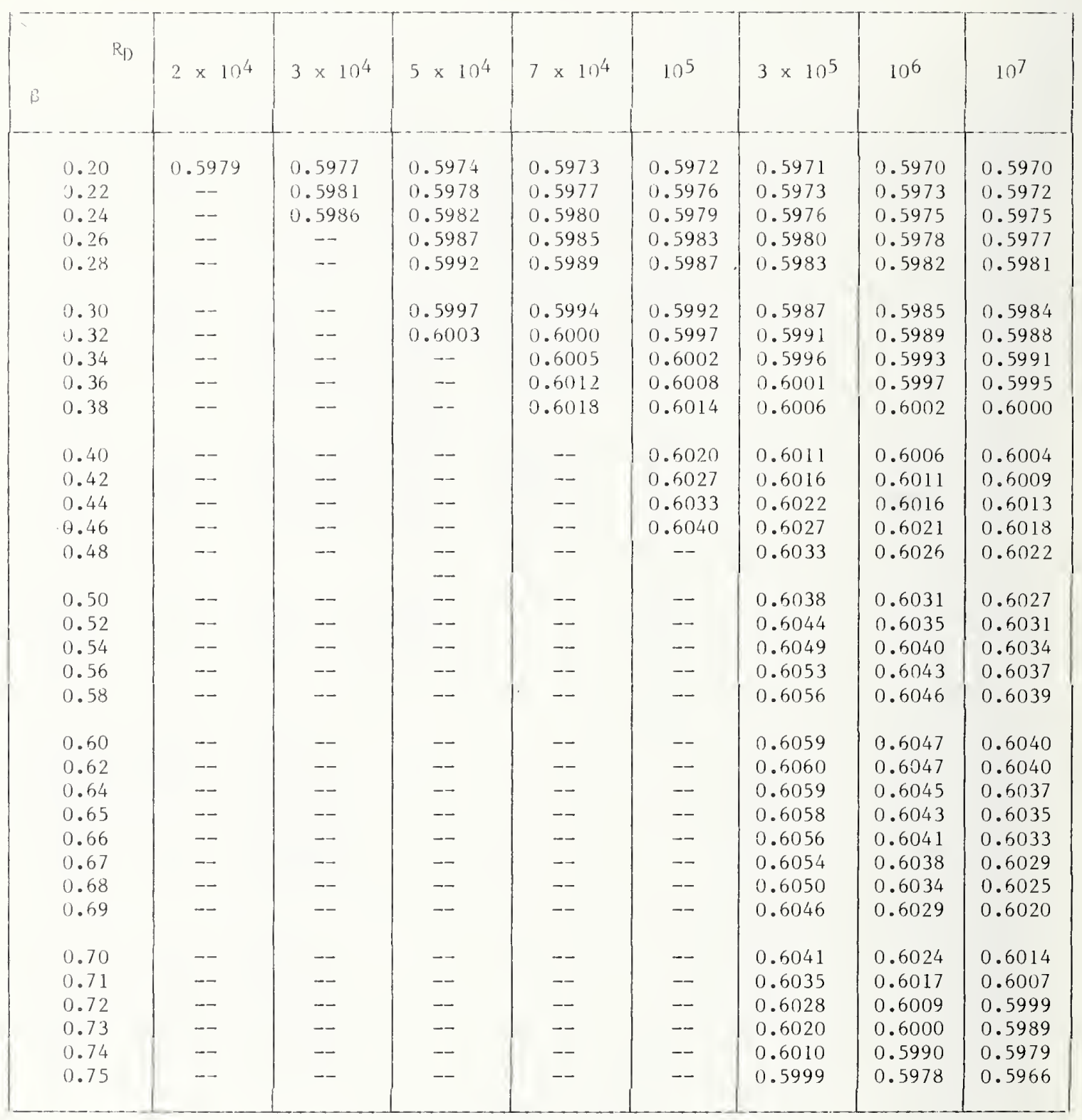


Table A.10. Coefficient of Discharge C

Orifice Plate with Flange Taps

$D=30$ in.

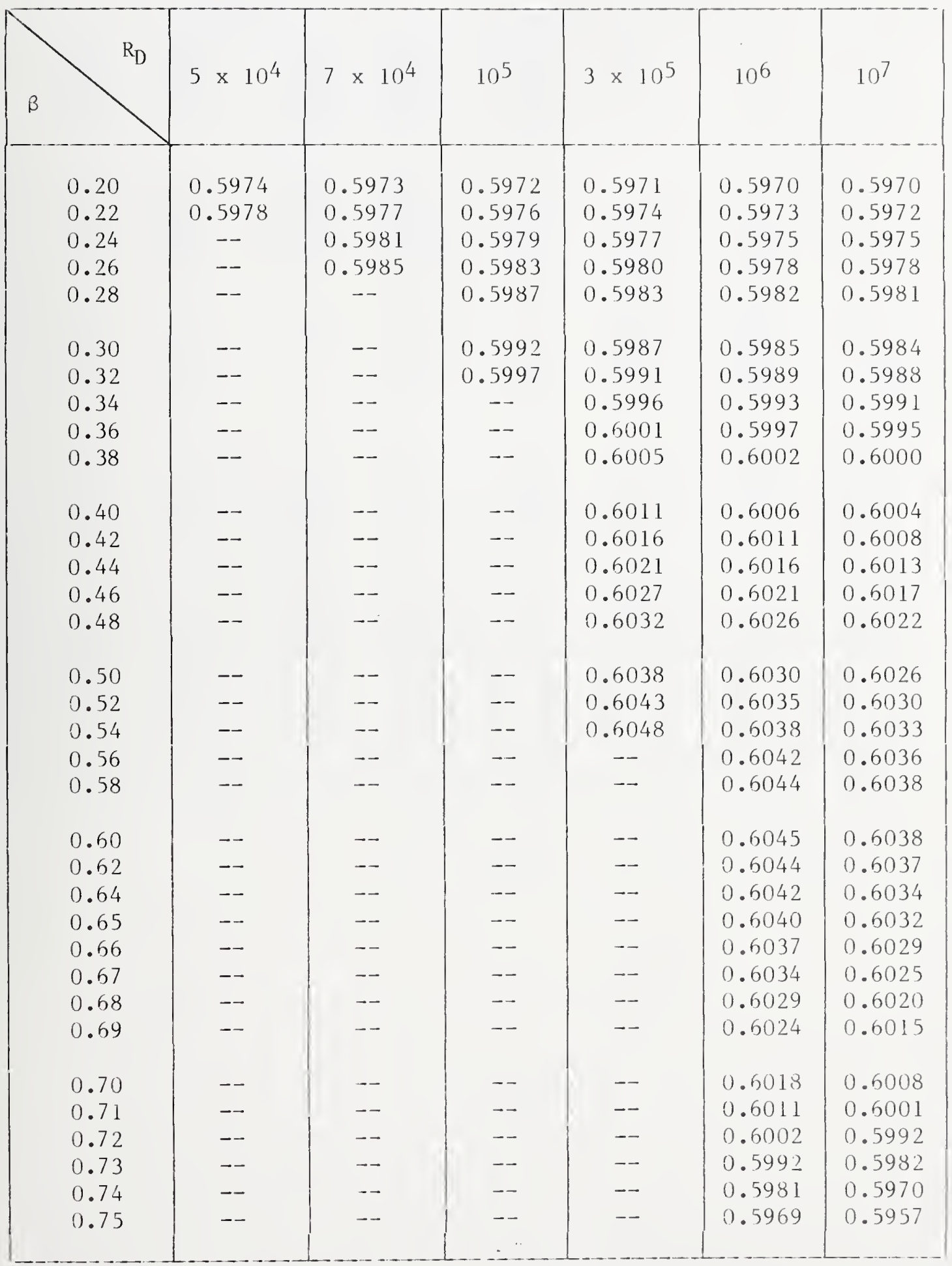


Table A.11. Coefficient of Discharge C

ISA 1932 Flow Nozzle

$2^{\prime \prime} \leq \mathrm{D}<20^{\prime \prime}$

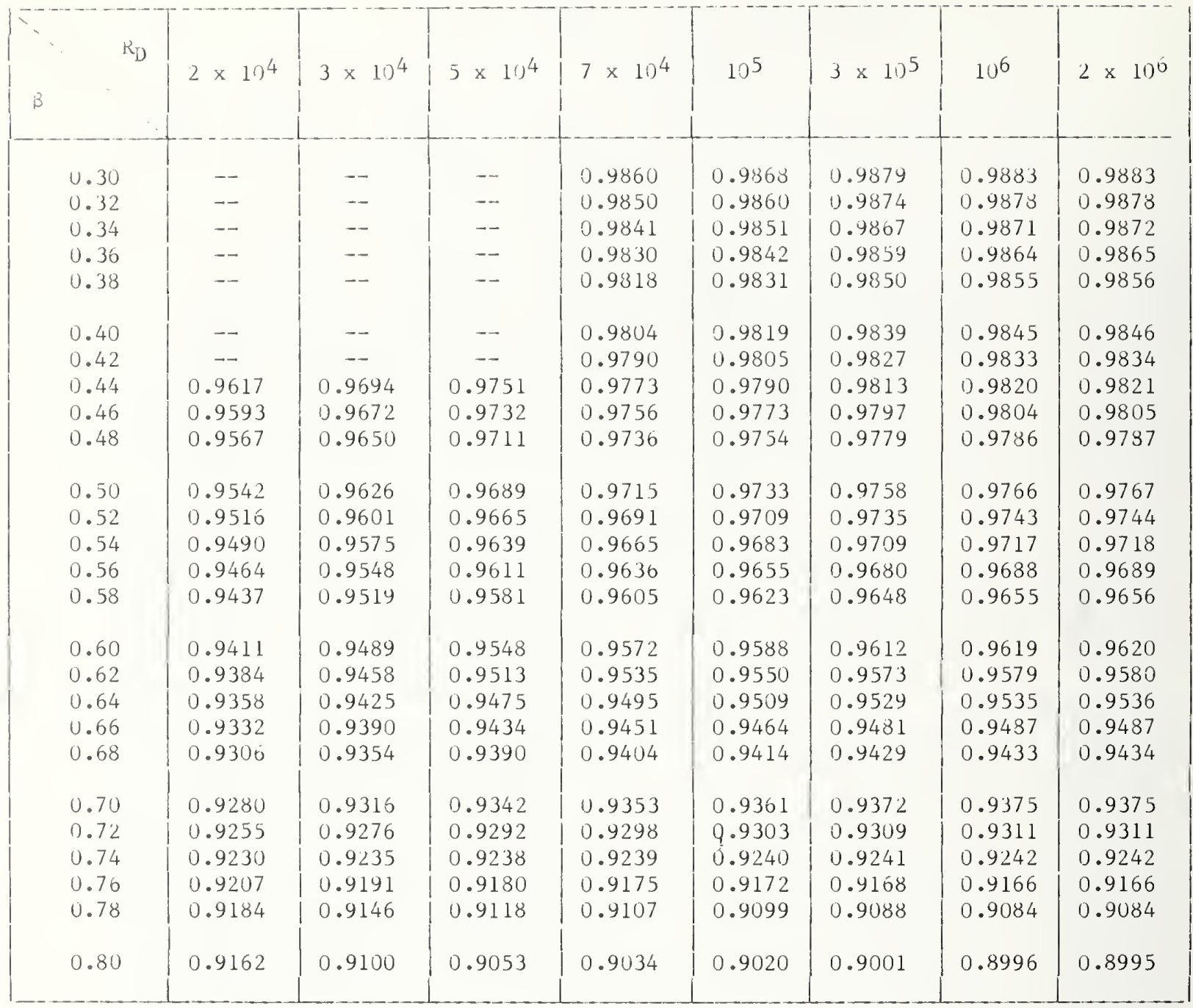


Table 4.12. CoefEicient of Discharge C

Long Radius fow Nozzle

$\left.2^{\prime \prime} \leq 1\right) \leq 24^{\prime \prime}$

\begin{tabular}{|c|c|c|c|c|c|c|c|c|c|}
\hline$R_{D}$ & $1 u^{4}$ & $2 \times 101^{4}$ & $5 \times 10^{4}$ & $10^{5}$ & $2 \times 10^{5}$ & $5 \times 10^{5}$ & $10^{6}$ & $5 \times 10^{6}$ & $1 u^{7}$ \\
\hline u. 20 & 0.9673 & 0.9759 & 0.9834 & 0.9873 & 0.9900 & 0.9924 & 0.9936 & 0.9952 & 0.9556 \\
\hline 0.22 & 0.9659 & 0.9748 & 0.9828 & 0.9868 & 0.9897 & 0.9922 & 0.9934 & 0.9951 & 1). 9955 \\
\hline 0.24 & 0.9645 & 0.9739 & 0.9822 & 0.9864 & 0.9893 & 0.9920 & 0.9933 & 0.9951 & 0.9955 \\
\hline 0.26 & 0.9632 & 0.9730 & 0.9816 & 0.9860 & 0.9891 & 0.9918 & 0.9932 & ט.9950 & 0.9954 \\
\hline .0 .28 & 0.9619 & 0.9721 & 0.9810 & 0.9856 & 0.9888 & 0.9916 & 0.9930 & ט.9950 & 0.9954 \\
\hline 0.30 & 0.9607 & 0.9712 & 0.9805 & 0.9852 & 0.9885 & 0.9914 & 0.9929 & 0.9949 & 0.9954 \\
\hline 0.32 & 0.9596 & 0.9704 & 0.9300 & 0.9848 & 0.9882 & 0.9913 & 0.9928 & 0.9948 & 0.9953 \\
\hline 0.34 & 0.9584 & 0.9696 & 0.9795 & 0.9845 & 0.9830 & 0.9911 & 0.99927 & 0.9948 & 0.9953 \\
\hline 0.36 & 0.9573 & 0.9638 & 0.9790 & 0.9841 & 0.9877 & 0.9910 & 0.9926 & 0.9947 & 0.9953 \\
\hline 0.38 & 0.9562 & 0.9680 & 0.9785 & 0.9838 & 0.9875 & 0.9908 & 0.9925 & 0.9947 & 0.9952 \\
\hline 0.40 & 0.9552 & 0.9673 & 0.9780 & 0.9834 & 0.9873 & 0.9907 & 0.9924 & 0.9947 & 0.9952 \\
\hline 0.42 & 0.9542 & U.9666 & 0.9776 & 0.9831 & 0.9870 & 0.9905 & 0.9923 & 0.9946 & 0.9952 \\
\hline 0.44 & 0.9532 & 0.9659 & 0.9771 & 0.9828 & 0.9868 & U.9904 & 0.9922 & 0.9946 & 0.9951 \\
\hline 0.46 & 0.9522 & 0.9652 & 0.9767 & 0.9825 & 0.9866 & 0.9902 & 0.9921 & 0.9945 & 0.9951 \\
\hline 0.48 & 0.9513 & 0.9645 & 0.9763 & 0.9822 & 0.9864 & 0.9901 & 0.9920 & 0.9945 & 0.9951 \\
\hline 0.50 & 0.9503 & 0.9639 & 0.9759 & 0.9819 & 0.9862 & 0.9900 & 0.9919 & 0.9944 & 0.9950 \\
\hline 0.52 & 0.9494 & 0.9632 & 0.9754 & 0.9816 & 0.9860 & 0.9848 & 0.9918 & 0.9944 & 0.9950 \\
\hline 0.54 & 0.9485 & 0.9626 & 0.9750 & 0.9813 & 0.9858 & 0.9897 & 0.9917 & 0.9944 & 0.9950 \\
\hline 0.56 & 0.9476 & 0.9619 & 0.9746 & 0.9810 & 0.9856 & 0.9896 & 0.9916 & 0.9943 & 0.9950 \\
\hline 0.58 & 0.9468 & U.9613 & 0.9743 & 0.9808 & 0.9854 & 0.9895 & 0.9915 & 0.9943 & 0.9949 \\
\hline 0.60 & 0.9459 & 0.9607 & 0.9739 & 0.9805 & 0.9852 & 0.9893 & 0.9914 & 0.9942 & 0.9949 \\
\hline 0.62 & U.y451 & 0.9601 & 0.9735 & 0.9802 & 0.9850 & 0.9892 & 0.9914 & 0.9942 & 0.9949 \\
\hline 0.64 & 0.9443 & 0.9596 & 0.9731 & 0.9800 & 0.9848 & 0.9891 & 0.9913 & 0.9942 & 0.9948 \\
\hline 0.66 & 0.9435 & 0.9590 & 0.9728 & 0.9797 & 0.9846 & 0.9890 & 0.9912 & 0.9941 & 0.9948 \\
\hline 0.68 & 0.9427 & 0.9584 & 0.9724 & 0.9745 & 0.9845 & 0.9889 & 0.9911 & 0.9941 & 0.9948 \\
\hline 0.70 & 0.9419 & 0.9579 & 0.9721 & 0.9792 & 0.9843 & 0.9888 & 0.9910 & 0.9941 & 0.9948 \\
\hline 0.72 & 0.9411 & 0.9573 & 0.9717 & 0.9790 & 0.9841 & 0.9887 & 0.9910 & 0.9940 & 0.9947 \\
\hline 0.74 & 0.9403 & 0.9568 & 0.9714 & $0.97: 87$ & 0.9839 & 0.9886 & 0.9909 & 0.9940 & 0.9947 \\
\hline 0.76 & 0.9396 & 0.9562 & 0.9710 & 0.9735 & 0.9838 & 0.9884 & 0.9908 & 0.9940 & 0.9947 \\
\hline 0.78 & 0.9388 & 0.9557 & 0.9707 & 0.9783 & 0.9836 & 0.9883 & 0.9907 & 0.9939 & 0.9947 \\
\hline 0.80 & 0.9381 & 0.9552 & 0.9704 & 0.9780 & 0.9834 & 0.9882 & 0.9907 & 0.9939 & 0.9947 \\
\hline
\end{tabular}


Table A.13. Coefficient of Discharge C Nozzle Venturi Meter

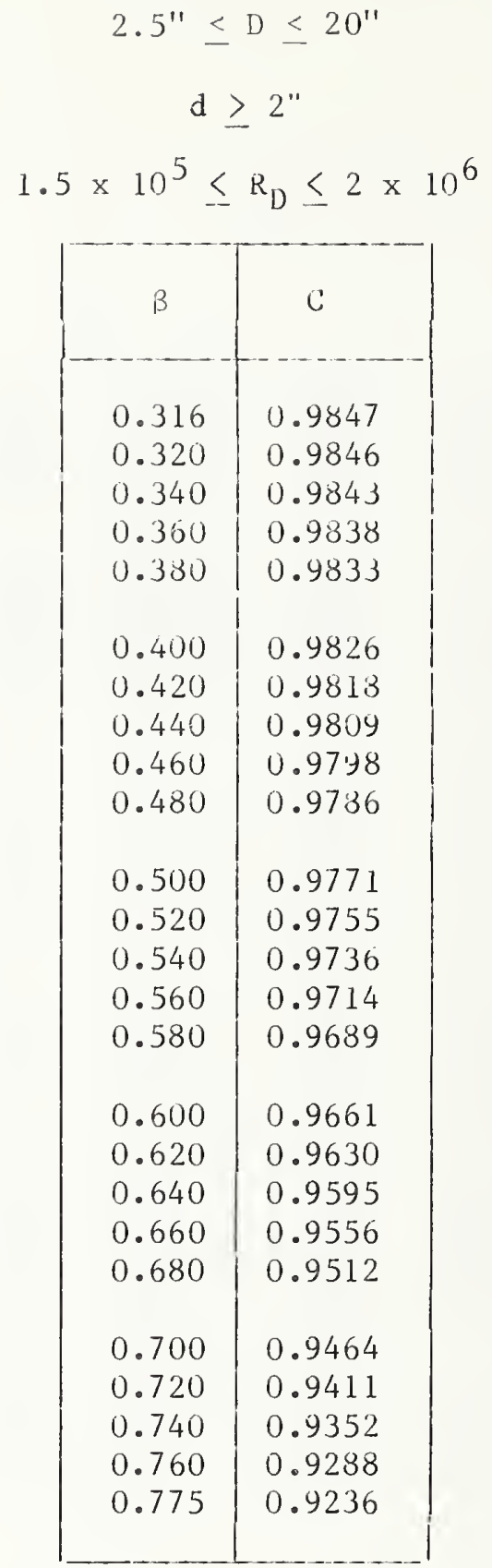


Table A.14. Coefticient of Discharge C Classical Venturi Meter

\begin{tabular}{|c|c|c|c|}
\hline & $\begin{array}{c}\text { Rough-cast } \\
\text { Entrance Cone }\end{array}$ & $\begin{array}{c}\text { Machined } \\
\text { Entrance Cone }\end{array}$ & $\begin{array}{l}\text { Rough Welded } \\
\text { Sheet-Metal } \\
\text { Entrance Cone. }\end{array}$ \\
\hline Coefficient $C$ & 0.984 & 0.995 & 0.985 \\
\hline $\begin{array}{l}\text { Tolerance on } \\
\mathrm{C}, \%\end{array}$ & 0.70 & 1.00 & 1.50 \\
\hline B & 0.30 to 0.75 & 0.40 to 0.75 & 0.40 to 0.70 \\
\hline D, in. & 4 to 32 & 2 to 10 & 8 to 48 \\
\hline$R_{D}$ & $2 \times 10^{5}$ to $2 \times 10^{6}$ & $2 \times 10^{5}$ to $1 \times 10^{6}$ & $2 \times 10^{5}$ to $2 \times 1$ \\
\hline
\end{tabular}


Table A.15. References for Equations for Coefficient of Discharge C

Primary Element

Thin-plate, square-edge orifice

for corner, flange, and D, D/ 2

taps

ISA 1932 flow nozzle

Long radius f́low nozzle

Nozzle venturi meter

i

Classical venturi meter
Source

Reference 11

or

Reference 10

Reference 10

Reference 10

Reference 10

No known references 
Table A.16. Fluid Expansion Factor Y for Elow Nozzles and Venturi Meters

$$
\gamma=1.3(\text { steam) }
$$

\begin{tabular}{|c|c|c|c|c|c|c|c|c|c|c|}
\hline$\beta$ & $\beta^{4} \cdot r$ & 0.95 & 0.90 & 0.85 & 0.80 & 0.75 & 0.70 & 0.55 & 0.60 & 0.55 \\
\hline $\begin{array}{r}0.20 \\
.30 \\
.40\end{array}$ & $\begin{array}{r}0.0016 \\
.0081 \\
.0256\end{array}$ & $\begin{array}{r}0.9707 \\
.9705 \\
.9698\end{array}$ & $\begin{array}{r}0.9407 \\
.9402 \\
.9390\end{array}$ & $\begin{array}{r}0.9099 \\
.9092 \\
.9074\end{array}$ & $\begin{array}{r}0.8781 \\
.8773 \\
.8750\end{array}$ & $\begin{array}{r}0.8454 \\
.8445 \\
.8417\end{array}$ & $\begin{array}{r}0.8117 \\
.8106 \\
.8075\end{array}$ & $\begin{array}{r}0.7768 \\
.7756 \\
.7722\end{array}$ & $\begin{array}{r}0.7406 \\
.7393 \\
.7357\end{array}$ & $\begin{array}{r}0.7030 \\
.7016 \\
.5973\end{array}$ \\
\hline $\begin{array}{r}0.50 \\
.55 \\
.60\end{array}$ & $\begin{array}{l}.0625 \\
.0915 \\
.1296\end{array}$ & $\begin{array}{l}.9633 \\
.9671 \\
.9654\end{array}$ & $\begin{array}{l}.9362 \\
.9338 \\
.9305\end{array}$ & $\begin{array}{l}.9034 \\
.9001 \\
.8954\end{array}$ & $\begin{array}{l}.8700 \\
.8658 \\
.8599\end{array}$ & $\begin{array}{l}.8358 \\
.8309 \\
.8240\end{array}$ & $\begin{array}{l}.8008 \\
.7952 \\
.7876\end{array}$ & $\begin{array}{l}.7648 \\
.7588 \\
.7505\end{array}$ & $\begin{array}{l}.7278 \\
.7214 \\
.7126\end{array}$ & $\begin{array}{r}.5895 \\
.5829 \\
.5738\end{array}$ \\
\hline $\begin{array}{c}0.65 \\
.70 \\
.725\end{array}$ & $\begin{array}{l}.1785 \\
.2401 \\
.2763\end{array}$ & $\begin{array}{l}.9629 \\
.9594 \\
.9570\end{array}$ & $\begin{array}{l}.9259 \\
.9193 \\
.9150\end{array}$ & $\begin{array}{l}.8889 \\
.8798 \\
.8739\end{array}$ & $\begin{array}{l}.8519 \\
.8406 \\
.8333\end{array}$ & $\begin{array}{l}.8146 \\
.8016 \\
.7933\end{array}$ & $\begin{array}{l}.7771 \\
.7627 \\
.7535\end{array}$ & $\begin{array}{l}.7392 \\
.7237 \\
.7139\end{array}$ & $\begin{array}{l}.7007 \\
.6844 \\
.6742\end{array}$ & $\begin{array}{l}.6614 \\
.5447 \\
.5343\end{array}$ \\
\hline $\begin{array}{l}0.75 \\
.775 \\
.80\end{array}$ & $\begin{array}{l}.3164 \\
.3608 \\
.4096\end{array}$ & $\begin{array}{l}.9542 \\
.9507 \\
.9462\end{array}$ & $\begin{array}{l}.9098 \\
.9034 \\
.8955\end{array}$ & $\begin{array}{l}.8667 \\
.8580 \\
.8473\end{array}$ & $\begin{array}{l}.8246 \\
.8141 \\
.8013\end{array}$ & $\begin{array}{l}.7833 \\
.7714 \\
.7570\end{array}$ & $\begin{array}{l}.7426 \\
.7297 \\
.7141\end{array}$ & $\begin{array}{l}.7023 \\
.6886 \\
.6723\end{array}$ & $\begin{array}{l}.5622 \\
.6481 \\
.5313\end{array}$ & $\begin{array}{l}.6221 \\
.5077 \\
.5908\end{array}$ \\
\hline $\begin{array}{r}0.82 \\
.84 \\
.86\end{array}$ & $\begin{array}{l}.4521 \\
.4979 \\
.5470\end{array}$ & $\begin{array}{l}.9418 \\
.9362 \\
.9292\end{array}$ & $\begin{array}{l}.8876 \\
.8779 \\
.8658\end{array}$ & $\begin{array}{l}.8368 \\
.8241 \\
.8084\end{array}$ & $\begin{array}{l}.7888 \\
.7739 \\
.7557\end{array}$ & $\begin{array}{l}.7431 \\
.7266 \\
.7067\end{array}$ & $\begin{array}{l}.6992 \\
.6817 \\
.6608\end{array}$ & $\begin{array}{l}.6568 \\
.6387 \\
.6172\end{array}$ & $\begin{array}{l}.6155 \\
.5971 \\
.5756\end{array}$ & $\begin{array}{l}.5750 \\
.5567 \\
.5353\end{array}$ \\
\hline
\end{tabular}

$\gamma=1.4$ (air)

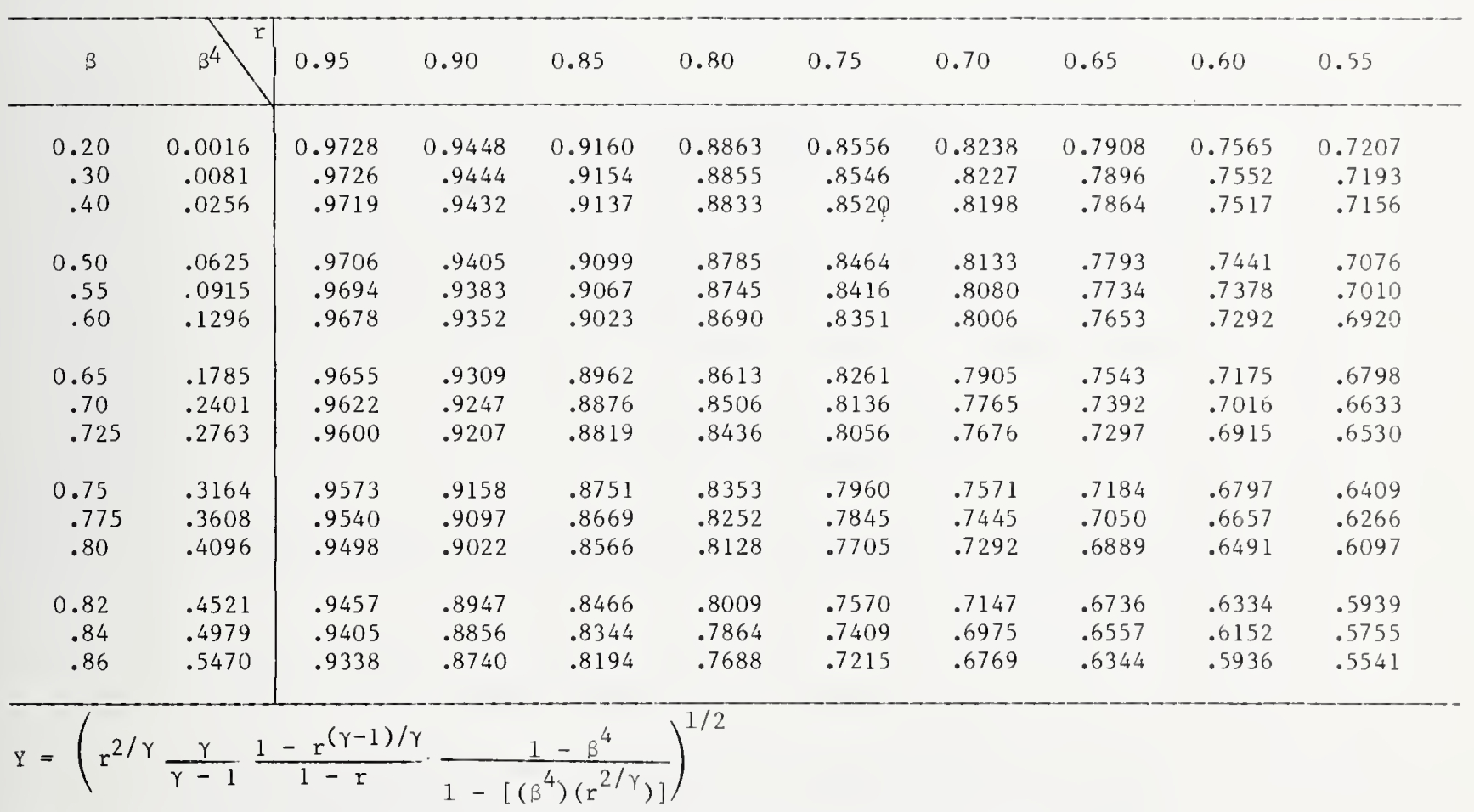

where $r$ is the pressure ratio $P_{2} / P_{1}$ and $\gamma$ is the specific heat ratio $c_{p} / c_{V}$.

Limits of use are given in reference 10 and are the same as those for discharge coefficient $C$. See tables A-11 through A.14. $P_{2} / P_{1} \leq 0.75$. 
Table A.17. Uncertainty of Discharge Coefficients

Orifice Meters

$\begin{array}{cccc} & \text { Corner Taps } & \text { Flange Taps } & \text { D and D/2 taps } \\ \beta \leq 0.6 & 0.6 \% & 0.6 \% & 0.6 \% \\ 0.6 \leq \beta \leq 0.8 & \beta \% & & \\ 0.6<\beta \leq 0.75 & & \beta \% & \beta \%\end{array}$

Flow Nozzles

ISA $1983 \quad$ Long Radius

$$
\begin{array}{cc}
\beta \leq 0.6 & 0.8 \% \\
\beta>0.6 & (2 \beta-0.4) \%
\end{array}
$$$$
0.2 \leq \beta \leq 0.8
$$

$2 \%$

\section{Classical Venturi}

$\begin{array}{lc}\text { Rough cast entrance } & 0.7 \% \\ \text { Machined entrance } & 1.0 \% \\ \text { Rough-welded sheet iron entrance } & 1.5 \%\end{array}$

Nozzle Venturi Méter

The uncertainty in $\alpha$ is $\left(1.2+1.5 \beta^{4}\right) \%$ where $\alpha=C /\left(1-\beta^{4}\right)^{1 / 2}$

Source: Reference 10

Notes: Quantities $\beta, R_{D}$ and $D$ are assumed known withour error.

The above uncertainties are given for reference purposes. They would be useful in estimating the uncertainty in flowrate when the primary element is used uncalibrated and the secondary element ( $\Delta \mathrm{P}$ transducer) only receives calibration. 
Table A.18. Uncertainty of Expansion Factors [10]

\title{
Orifice Meters
}

\author{
$\beta \leq 0.75$ \\ $4\left(\Delta \mathrm{P} / \mathrm{P}_{1}\right) \%$ \\ $0.75<\beta \leq 0.8$ \\ $8\left(\Delta \mathrm{P} / \mathrm{P}_{1}\right) \% \quad$ (corner taps only)
}

Flow Nozzles

ISA 1932 and Long Radius 2( $\left.\Delta \mathrm{P} / \mathrm{P}_{1}\right) \%$

\section{Venturi Meters}

Nozzle venturi and Classical venturi meters $\left(4+100 \beta^{8}\right)\left(\Delta \mathrm{P} / \mathrm{P}_{1}\right) \%$

liotes: Quantities $\beta, \Delta P$ and $P_{1}$ are assuned known without error.

The above uncertainties are given for reference purposes. They would be useful in estimating the uncertainty in flowrate when the primary element is used uncalibrated and the secondary element ( $\Delta \mathrm{P}$ transducer) only receives calibration, or when the primary element has been calibrated with a liquid and is to be used to monitor gas (air or steam). 


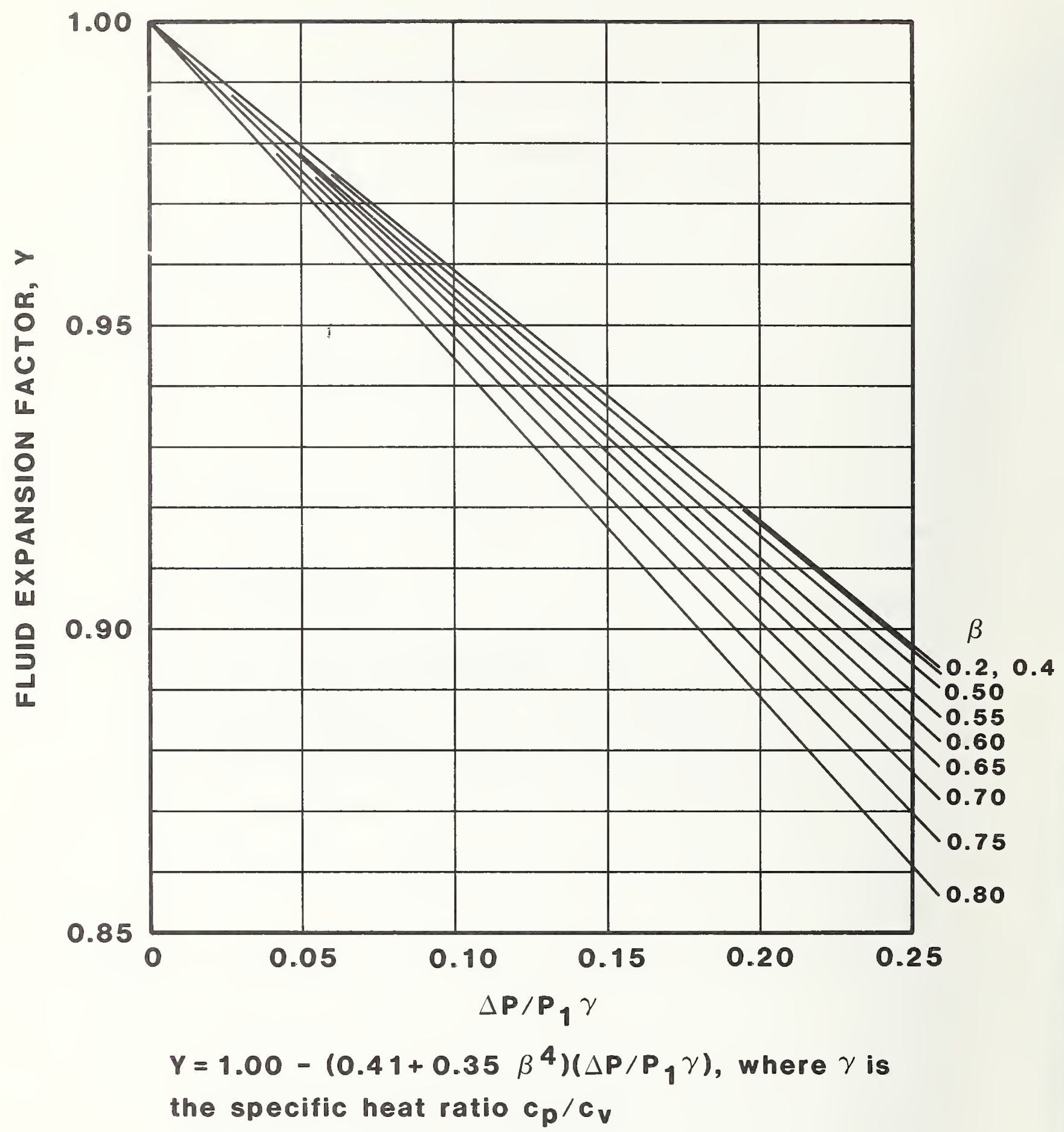

Figure A.1. Fluid expansion factor Y for thin-plate, square-edged orifice plates with corner taps, flange taps, and $1 \mathrm{D}$ and $1 / 2 \mathrm{D}$ taps. Pressure ratio $\mathrm{P}_{1} / \mathrm{P}_{2} \leq 0.75$. Limits of use for $B$ and $\mathrm{R}_{\mathrm{D}}$ are the same as those for $C$. See tables A-1 through A-10. [2,10] 


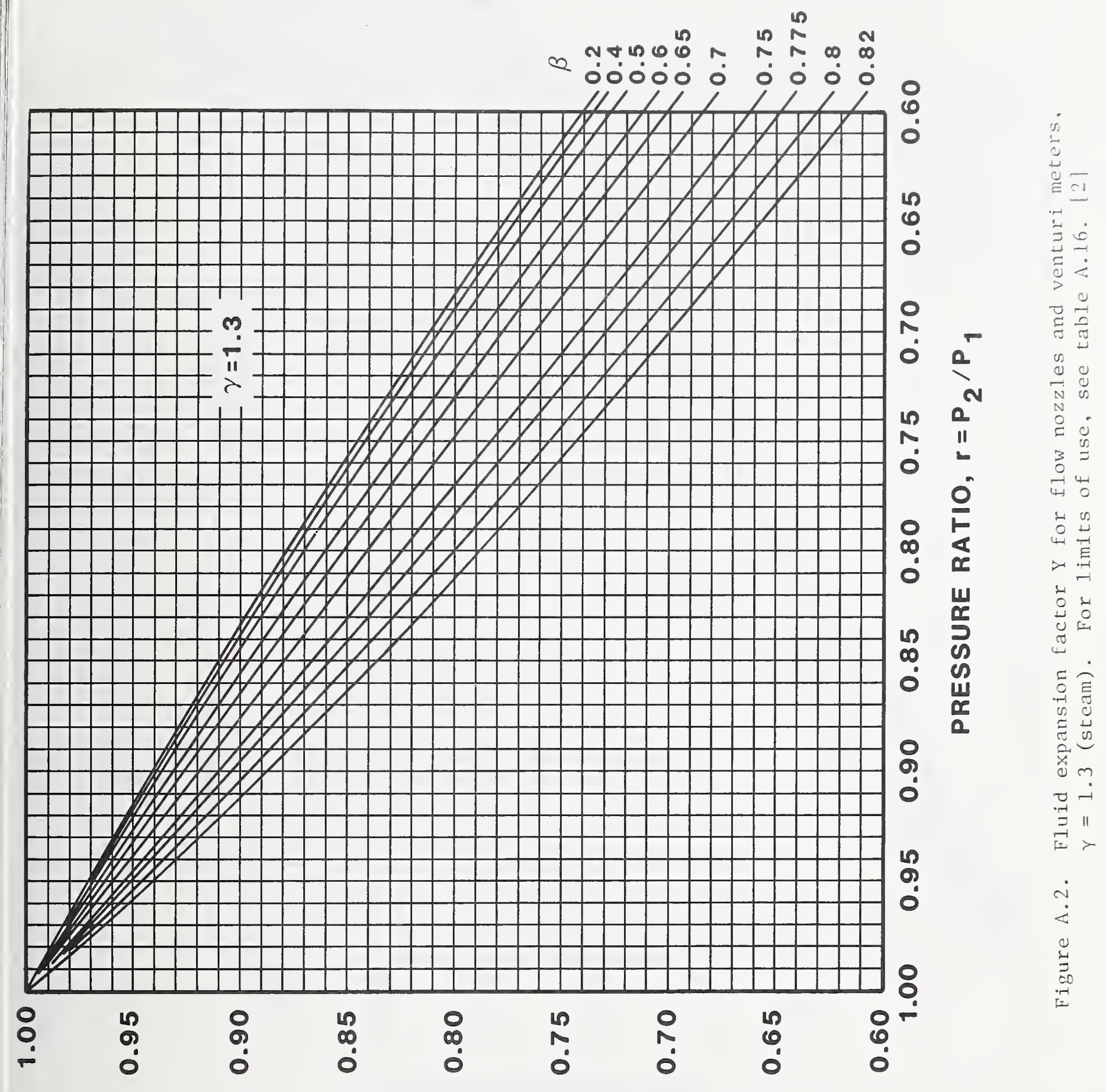

^ ' $y O \perp O \forall \unlhd$ NOISN $\forall d X \exists$ aInา 


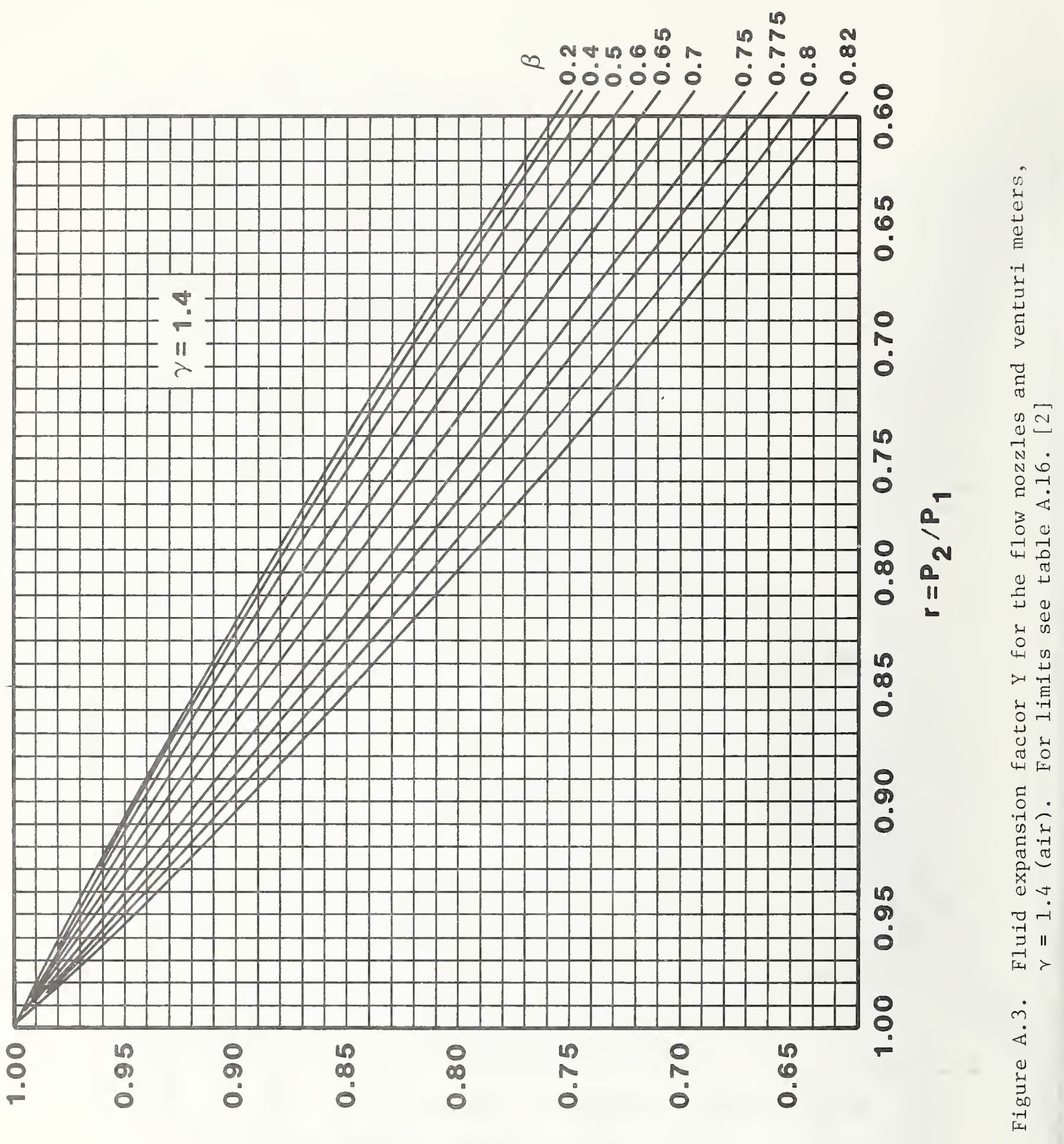

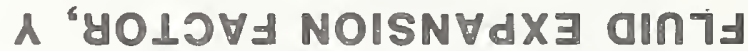


APPENDIX B

FLUID PROPERTLES AND FLOW QUANTITY CONVERSION FACTORS

B-1 
Table B.1. Density of Saturated and Compressed Liquid Water (1b/ft ${ }^{3}$ ) [6]

\begin{tabular}{|c|c|c|c|c|c|c|c|}
\hline \multirow{2}{*}{$\begin{array}{c}\text { Temperature } \\
\left({ }^{\circ} \mathrm{F}\right) \\
\end{array}$} & \multicolumn{3}{|c|}{ Pressure, psia } & \multirow{2}{*}{$\begin{array}{c}\text { Temperature } \\
\left({ }^{\circ} \mathrm{F}\right) \\
\end{array}$} & \multicolumn{3}{|c|}{ Pressure, Psia } \\
\hline & Saturated & 500 & 1000 & & Saturated & 500 & 1000 \\
\hline 32 & 62.4140 & 62.5217 & 62.6288 & 75 & 62.2654 & 62.3618 & 62.4575 \\
\hline 33 & .4167 & .5240 & .6308 & 76 & .2568 & .3530 & .4486 \\
\hline \multirow[t]{2}{*}{34} & .4191 & .5260 & .6324 & 77 & .2479 & .3440 & .4395 \\
\hline & & & & 78 & .2389 & .3349 & .4302 \\
\hline 35 & 62.4212 & 62.5277 & 62.6336 & 79 & .2297 & .3255 & .4207 \\
\hline 36 & .4229 & .5289 & .6345 & & & & \\
\hline 37 & .4242 & .5299 & .6351 & 80 & 62.2203 & $62 \cdot 3160$ & 62.4111 \\
\hline 38 & .4252 & .5305 & .6353 & 81 & .2107 & .3063 & .4013 \\
\hline \multirow[t]{2}{*}{39} & .4258 & .5308 & .6352 & 82 & .2009 & .2964 & .3913 \\
\hline & & & & 83 & .1910 & .2864 & .3811 \\
\hline 40 & 62.4261 & 62.5307 & 62.6348 & 84 & .1809 & .2762 & .3708 \\
\hline 41 & .4261 & .5304 & .6341 & & & & \\
\hline 42 & .4257 & .5297 & .6330 & 85 & 62.1706 & 62.2658 & 62.3603 \\
\hline 43 & .4251 & .5287 & .6317 & 90 & .1166 & .2113 & .3055 \\
\hline 44 & .4241 & .5274 & .6301 & 95 & .0585 & .1529 & .2467 \\
\hline 45 & 62.4229 & 62.5258 & 62.6282 & 100 & 61.9964 & .0906 & .1841 \\
\hline 46 & .4213 & .5239 & .6260 & 105 & .9307 & .0246 & .1180 \\
\hline 47 & .4194 & .5218 & .6235 & & & & \\
\hline 48 & .4173 & .5193 & .6208 & 110 & 61.8612 & 61.9551 & 62.0483 \\
\hline \multirow[t]{2}{*}{49} & .4149 & .5166 & .6178 & 115 & .7884 & .8821 & 61.9754 \\
\hline & & & & 120 & .7121 & .8059 & .8992 \\
\hline 50 & 62.4122 & 62.5136 & 62.6145 & 125 & .6326 & .7265 & .8198 \\
\hline 51 & .4092 & .5104 & .6110 & 130 & .5500 & .6440 & .7375 \\
\hline 52 & .4059 & .5068 & .6072 & & & & \\
\hline 53 & .4024 & .5031 & .6031 & 135 & 61.4643 & 61.5584 & 61.6521 \\
\hline \multirow[t]{2}{*}{54} & .3986 & .4990 & .5988 & 140 & .3757 & .4700 & .5640 \\
\hline & & & & 145 & .2842 & .3787 & .4730 \\
\hline 55 & 62.3946 & 62.4947 & 62.5943 & 150 & .1899 & .2847 & .3793 \\
\hline 56 & .3903 & .4902 & .5895 & 155 & .0928 & .1880 & .2830 \\
\hline 57 & .3858 & .4854 & .5845 & & & & \\
\hline 58 & .3810 & .4804 & .5793 & 160 & 60.9932 & 61.0887 & 61.1841 \\
\hline \multirow[t]{2}{*}{59} & .3760 & .4752 & .5738 & 165 & .8909 & 60.9868 & .0827 \\
\hline & & & & 170 & .7862 & .8824 & 60.9789 \\
\hline 60 & 62.3707 & 62.4697 & 62.5681 & 175 & .6789 & .7756 & .8726 \\
\hline 61 & .3652 & .4640 & .5622 & 180 & .5693 & .6665 & .7640 \\
\hline 62 & .3595 & .4581 & .5560 & & & & \\
\hline 63 & .3535 & .4519 & .5497 & 185 & 60.4573 & 60.5549 & 60.6531 \\
\hline \multirow[t]{2}{*}{64} & .3474 & .4455 & .5431 & 190 & .3430 & .4411 & .5400 \\
\hline & & & & 195 & .2265 & .3250 & .4246 \\
\hline 65 & 62.3410 & 62.4390 & 62.5363 & 200 & .1076 & .2068 & .3070 \\
\hline 66 & .3344 & .4322 & .5293 & 205 & 59.9866 & .0863 & .1873 \\
\hline 67 & .3275 & .4251 & .5221 & & & & \\
\hline 68 & .3205 & .4179 & .5147 & 210 & 59.8635 & 59.9636 & 60.0655 \\
\hline \multirow[t]{2}{*}{69} & .3132 & .4105 & .5071 & 215 & .7382 & .8389 & 59.9416 \\
\hline & & & & 220 & .6108 & .7120 & .8156 \\
\hline 70 & 62.3058 & 62.4029 & 62.4993 & 225 & .4813 & .5830 & .6875 \\
\hline 71 & .2981 & .3950 & .4914 & 230 & .3497 & .4520 & .5574 \\
\hline 72 & .2902 & .3870 & .4832 & & & & \\
\hline 73 & .2822 & .3788 & .4748 & 235 & 59.2161 & 59.3189 & 59.4253 \\
\hline 74 & .2739 & .3704 & .4663 & 240 & .0804 & .1838 & .2912 \\
\hline
\end{tabular}


Table B.1. Density of Saturated and Compressed Liquid Water (1b/ft $\left.{ }^{3}\right)$ [6]

\begin{tabular}{|c|c|c|c|c|c|c|c|}
\hline \multirow{2}{*}{$\begin{array}{c}\text { Temperature } \\
\left({ }^{\circ} \mathrm{F}\right)\end{array}$} & \multicolumn{3}{|c|}{ Pressure, psia } & \multirow{2}{*}{$\begin{array}{c}\text { Temperature } \\
\left({ }^{\circ} \mathrm{F}\right)\end{array}$} & \multicolumn{3}{|c|}{ Pressure, Psia } \\
\hline & Saturated & 500 & 1000 & & Saturated & 500 & 1000 \\
\hline 245 & 58.9428 & 0.0467 & .1551 & 385 & 54.2597 & 54.3546 & 54.5140 \\
\hline 250 & .8031 & 58.9075 & .0171 & 390 & .0606 & .1531 & .3155 \\
\hline 255 & .6614 & .7663 & 58.8770 & 395 & 53.8590 & 53.9489 & .1144 \\
\hline & & & & 400 & .6548 & .7418 & 53.9105 \\
\hline $\begin{array}{l}260 \\
265\end{array}$ & $\begin{array}{r}58.5177 \\
.3720\end{array}$ & $\begin{array}{r}58.6231 \\
.4779\end{array}$ & $\begin{array}{r}58.7350 \\
.5910\end{array}$ & 405 & .4481 & .5318 & .7039 \\
\hline 270 & .2244 & .3306 & .4450 & 410 & 53.2387 & 53.3187 & 53.4944 \\
\hline 275 & .0747 & .1814 & .2970 & 415 & .0267 & .1026 & .2819 \\
\hline 280 & 57.9231 & .0301 & .1471 & 420 & 52.8119 & 52.8833 & .0665 \\
\hline & & & & 425 & .5942 & .6607 & 52.8480 \\
\hline $\begin{array}{l}285 \\
290\end{array}$ & $\begin{array}{r}57.7695 \\
.6139\end{array}$ & $\begin{array}{r}57.8768 \\
.7215\end{array}$ & $\begin{array}{r}57.9952 \\
.8413\end{array}$ & 430 & .3737 & .4348 & .6262 \\
\hline 295 & .4563 & .5641 & .6854 & 435 & 52.1503 & 52.2053 & 52.4012 \\
\hline 300 & .2966 & .4046 & .5275 & 440 & 51.9238 & 51.9723 & .1728 \\
\hline 305 & .1350 & .2431 & .3675 & 445 & .6942 & .7354 & 51.9409 \\
\hline & & & & 450 & .4615 & .4948 & .7054 \\
\hline 310 & 56.9713 & 57.0795 & 57.2056 & 455 & .2255 & .2501 & .4661 \\
\hline 315 & .8056 & 56.9137 & .0415 & & & & \\
\hline 320 & .6378 & .7459 & 56.8754 & 460 & 50.9862 & 51.0012 & 51.2229 \\
\hline 325 & .4680 & .5758 & .7072 & 465 & .7434 & 50.7479 & 50.9757 \\
\hline 330 & .2960 & .4036 & .5369 & 470 & .4971 & .4971 & .7243 \\
\hline & & & & 475 & .2472 & .2472 & .4686 \\
\hline 335 & 56.1220 & 56.2291 & 56.3644 & 480 & 49.9935 & 49.9935 & .2082 \\
\hline 340 & 55.9458 & .0524 & .1897 & & & & \\
\hline 345 & .7674 & 55.8735 & .0128 & 485 & 49.7359 & 49.7359 & 49.9431 \\
\hline 350 & .5869 & .6922 & 55.8337 & 490 & .4744 & .4744 & .6731 \\
\hline 355 & .4042 & .5085 & .6523 & 495 & .2087 & .2087 & .3978 \\
\hline & & & & 500 & 48.9387 & 48.9387 & .1170 \\
\hline 360 & 55.2192 & 55.3225 & 55.4687 & & & & \\
\hline 365 & .0320 & .1340 & .2826 & & & & \\
\hline 370 & 54.8424 & 54.9430 & .0942 & & & & \\
\hline 375 & .6506 & .7495 & 54.9033 & & & & \\
\hline 380 & .4563 & .5534 & .7099 & & & & \\
\hline
\end{tabular}


Table B.2. Density of Mercury (1b/ft ${ }^{3}$ ) [20]

\begin{tabular}{|c|c|c|c|c|c|c|c|}
\hline $\begin{array}{l}\text { Temperature } \\
\quad\left({ }^{\circ} \mathrm{F}\right)\end{array}$ & $p$ & $\begin{array}{c}\text { Temperature } \\
(\mathrm{F})\end{array}$ & $\rho$ & $\begin{array}{c}\text { Temperature } \\
\left({ }^{\circ} \mathrm{F}\right)\end{array}$ & $\rho$ & $\begin{array}{c}\text { Temperature } \\
\left({ }^{\circ} \mathrm{F}\right)\end{array}$ & $\rho$ \\
\hline-5 & 851.88814 & 35 & 848.45654 & 75 & 845.04735 & 115 & 841.65689 \\
\hline-4 & .80205 & 36 & .37101 & 76 & 844.96245 & 116 & .57198 \\
\hline-3 & .71598 & 37 & .28611 & 77 & .87692 & 117 & .48771 \\
\hline-2 & .62992 & 38 & .20059 & 78 & .79202 & 118 & .40343 \\
\hline-1 & .54388 & 39 & .11506 & 79 & .70712 & 119 & .31853 \\
\hline 0 & .45785 & 40 & .02953 & 80 & .62221 & 120 & .23425 \\
\hline 1 & .37184 & 41 & 847.94401 & 81 & .53731 & 121 & .14997 \\
\hline 2 & .28584 & 42 & .85848 & 82 & .45241 & 122 & .06507 \\
\hline 3 & .19963 & 43 & .77295 & 83 & .36751 & 123 & 840.98079 \\
\hline 4 & .11390 & 44 & .68805 & 84 & .28261 & 124 & .89651 \\
\hline 5 & .02795 & 45 & .60253 & 85 & .19770 & 125 & .81161 \\
\hline 6 & 850.94201 & 46 & .51700 & 86 & .11280 & 126 & .72733 \\
\hline 7 & .85609 & 47 & .43210 & 87 & .02790 & 127 & .64306 \\
\hline 3 & .77019 & 48 & .34657 & 88 & 843.94300 & 128 & .55815 \\
\hline 9 & .68430 & 49 & .26104 & 89 & .85810 & 129 & .47388 \\
\hline 10 & .59843 & 50 & .17552 & 90 & .77319 & 130 & .38960 \\
\hline 11 & .51257 & 51 & .08999 & 91 & .68829 & 131 & .30532 \\
\hline 12 & .42673 & 52 & .00509 & 92 & .60401 & 132 & .22104 \\
\hline 13 & .34090 & 53 & 846.91956 & 93 & .51911 & 133 & .13677 \\
\hline 14 & .25509 & 54 & .83465 & 94 & .43421 & 134 & .05249 \\
\hline 15 & .16956 & 55 & .74913 & 95 & .34931 & 135 & 839.96821 \\
\hline 16 & .08404 & 56 & .66423 & 96 & .26441 & 136 & .88393 \\
\hline 17 & 849.99851 & 57 & .57871 & 97 & .17950 & 137 & .79965 \\
\hline 18 & .91236 & 58 & .49380 & 98 & .09523 & 138 & .71538 \\
\hline 19 & .82683 & 59 & .40828 & 99 & .01032 & 139 & .63110 \\
\hline 20 & .74068 & 60 & .32338 & 100 & 842.92542 & 140 & .54682 \\
\hline 21 & .65516 & 61 & .23847 & 101 & .84114 & 145 & .12543 \\
\hline 22 & .56963 & 62 & .15295 & 102 & .75624 & 150 & 838.70467 \\
\hline 23 & .48348 & 63 & .06805 & 103 & .67196 & 155 & .28390 \\
\hline 24 & .39795 & 64 & 845.98314 & 104 & .58706 & 160 & 837.86376 \\
\hline 25 & .31243 & 65 & .89762 & 105 & .50216 & 165 & .44362 \\
\hline 26 & .22690 & 66 & .81272 & 106 & .41788 & 170 & .02348 \\
\hline 27 & .14137 & 67 & .72719 & 107 & .33298 & 175 & 836.60397 \\
\hline 28 & .05522 & 68 & .64229 & 108 & .24870 & 180 & .18445 \\
\hline 29 & 848.96970 & 69 & .55739 & 109 & .16380 & 185 & 835.76556 \\
\hline 30 & .88417 & 70 & .47248 & 110 & .07952 & 190 & .34667 \\
\hline 31 & .79864 & 71 & .38758 & 111 & 841.99462 & 195 & 834.92778 \\
\hline 32 & .71312 & 72 & .30268 & 112 & .91034 & 200 & .50888 \\
\hline 33 & .62759 & 73 & .21715 & 113 & .82544 & 205 & .09062 \\
\hline \multirow[t]{2}{*}{34} & .54207 & 74 & .13225 & 114 & .74116 & 210 & 883.67297 \\
\hline & & & & & & 212 & 833.50567 \\
\hline
\end{tabular}


Table B.3. Conversion Factors for Mass, Volme, and ilass and Volume kate of Flow

VOLUUME

\begin{tabular}{|c|c|c|c|c|c|}
\hline $\begin{array}{l}\text { Multiply } \\
\text { Number of } \\
\text { By. } \\
\text { To obtain }\end{array}$ & 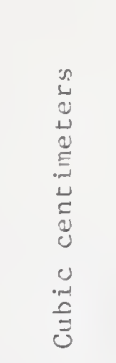 & 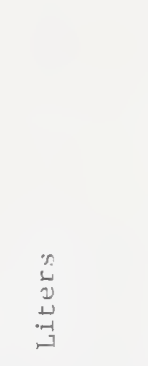 & 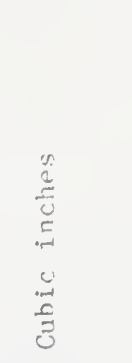 & 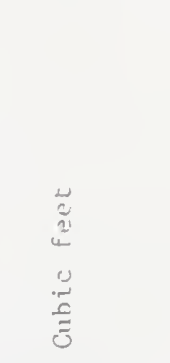 & 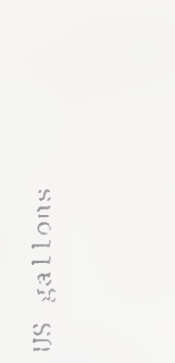 \\
\hline Cubic centimeters & 1 & $\begin{array}{l}1.0000 \\
\times 103\end{array}$ & 16.387 & $\begin{array}{l}2.8317 \\
\times 10^{4}\end{array}$ & 3795.4 \\
\hline Liters & $\begin{array}{l}1.0000 \\
\times \quad 10^{-3}\end{array}$ & 1 & $\begin{array}{r}1.6387 \\
\times 10^{-2}\end{array}$ & 28.316 & 3.7853 \\
\hline Cubic inches & $\begin{array}{l}6.1024 \\
\times 10^{-2}\end{array}$ & 61.025 & 1 & 1728 & 231 \\
\hline Cubic feet & $\begin{array}{r}3.5315 \\
\times \quad 10^{-5}\end{array}$ & $\begin{array}{l}3.531 n \\
\times 10^{-2}\end{array}$ & $\begin{array}{l}5.7870 \\
\times 10^{-4}\end{array}$ & 1 & 0.13368 \\
\hline US gallons & $\begin{array}{l}2.6417 \\
\times \quad 10^{-4}\end{array}$ & 0.26418 & $\begin{array}{r}4.3290 \\
\times 10^{-3}\end{array}$ & 7.4805 & 1 \\
\hline
\end{tabular}

Al1 underlined figures are exact

VOLUME RATE OF FLOW :

\begin{tabular}{|c|c|c|c|c|c|}
\hline $\begin{array}{l}\text { Multiply } \\
\text { Number of }\end{array}$ & 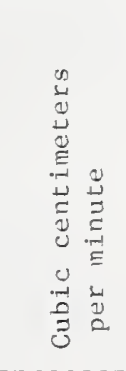 & 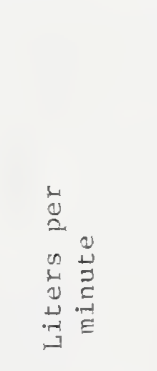 & 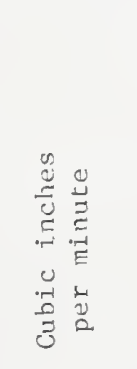 & 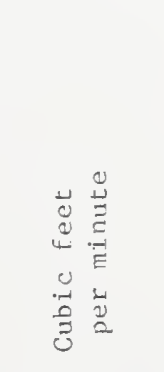 & 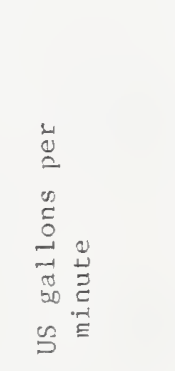 \\
\hline $\begin{array}{l}\text { Cubic centimeters } \\
\text { per minute }\end{array}$ & 1 & $\begin{array}{r}1.0000 \\
\times 10^{3}\end{array}$ & 16.387 & $\begin{array}{l}2.8317 \\
\times 10^{4}\end{array}$ & 3785.4 \\
\hline $\begin{array}{l}\text { Liters per } \\
\text { minute }\end{array}$ & $\begin{array}{l}1.0000 \\
\times 10^{-3}\end{array}$ & 1 & $\begin{array}{l}1.6387 \\
\times \quad 10^{-2}\end{array}$ & 28.316 & 3.7853 \\
\hline $\begin{array}{l}\text { Cubic inches } \\
\text { per minute }\end{array}$ & $\begin{array}{r}6.1024 \\
\times 10^{-2}\end{array}$ & 61.025 & 1 & 1728 & 231 \\
\hline $\begin{array}{l}\text { Cubic feet } \\
\text { per minute }\end{array}$ & $\begin{array}{l}3.5315 \\
\times 10^{-5}\end{array}$ & $\begin{array}{r}3.5316 \\
\times 10^{-2}\end{array}$ & $\begin{array}{l}5.7870 \\
\times 10^{-4}\end{array}$ & 1 & 0.13368 \\
\hline $\begin{array}{l}\text { US gallons per } \\
\text { minute }\end{array}$ & $\begin{array}{l}0.26417 \\
\times 10^{-3}\end{array}$ & 0.26418 & $\begin{array}{l}4.3290 \\
\times 10^{-3}\end{array}$ & 7.4805 & 1 \\
\hline
\end{tabular}


Table B.3. Conversion Factors for llass, Volume, and ilass and Volume Rate of Flow [8] (Continued)

?ASS

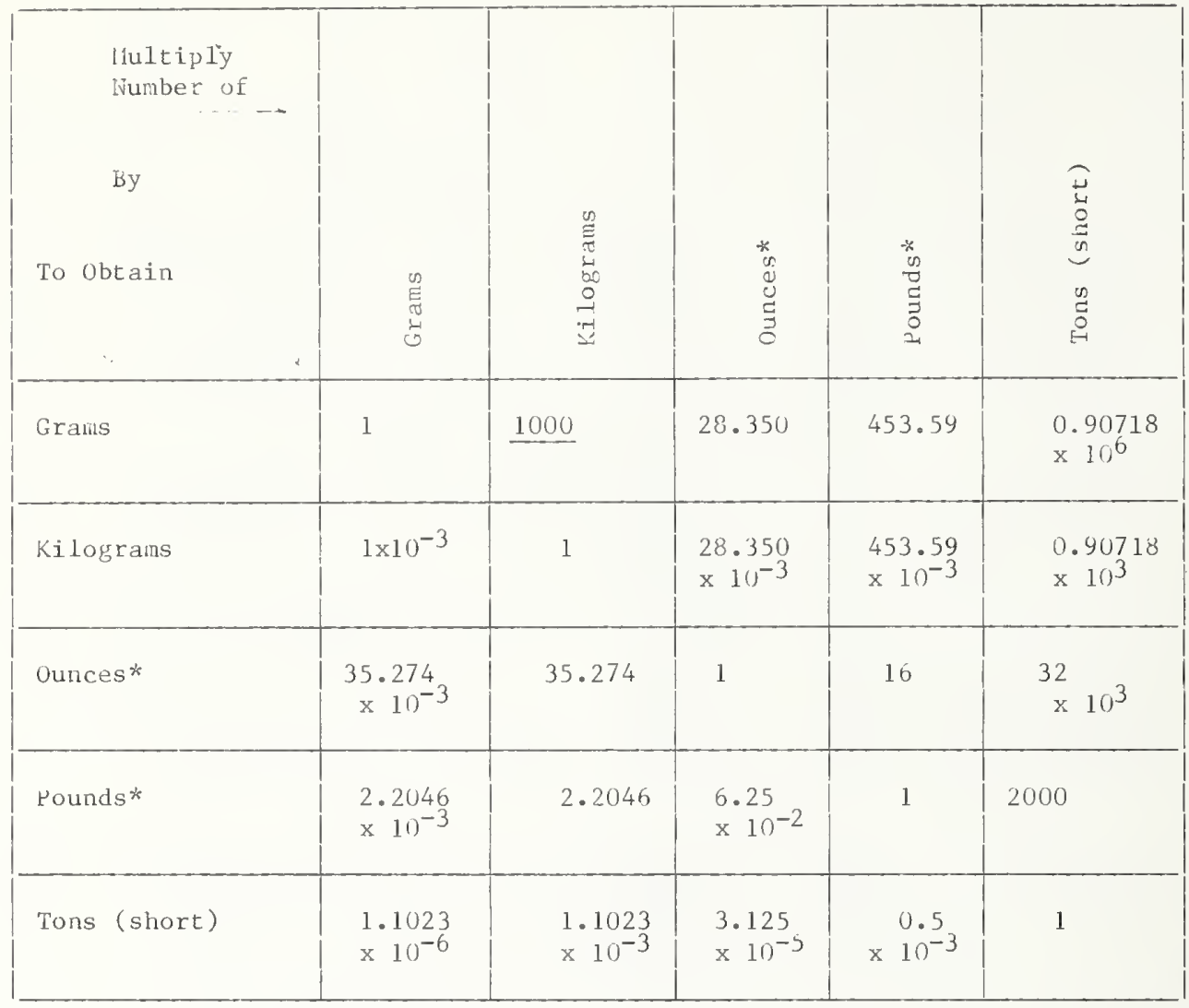

All underlined figures are exact

* Avoirudupois

LASS RATE OF FLOW

\begin{tabular}{|c|c|c|c|c|c|}
\hline $\begin{array}{l}\text { liultiply } \\
\text { Number of } \\
\text { By } \\
\text { To Obtain }\end{array}$ & 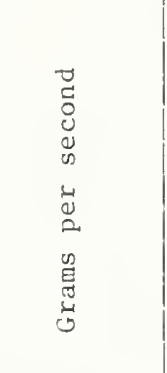 & 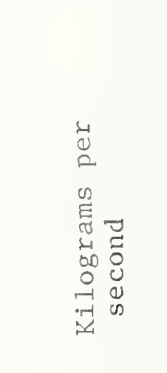 & 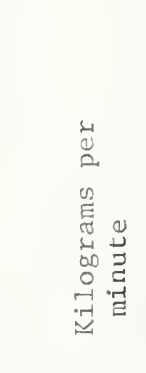 & 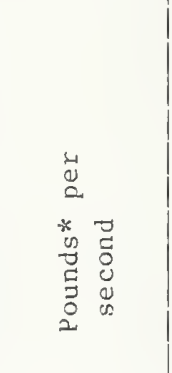 & 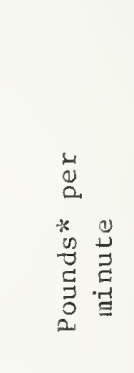 \\
\hline Grams per second & 1 & 1000 & 16.667 & 453.59 & 7.5599 \\
\hline $\begin{array}{l}\text { Kilograms per } \\
\text { second }\end{array}$ & 0.001 & 1 & $\begin{array}{l}1.6667 \\
\times 10^{-2}\end{array}$ & 0.45359 & $\begin{array}{l}7.5599 \\
\times 10^{-3}\end{array}$ \\
\hline $\begin{array}{l}\text { Kilograms per } \\
\text { minute }\end{array}$ & $60 \times 10^{-3}$ & 60 & 1 & 27.216 & 0.45359 \\
\hline $\begin{array}{l}\text { Pounds* per } \\
\text { second }\end{array}$ & $\begin{array}{c}2.2046 \\
\times 10^{-3}\end{array}$ & 2.2046 & $\begin{array}{l}3.6744 \\
\times 10^{-2}\end{array}$ & 1 & $\begin{array}{l}1.6667 \\
\times \quad 10^{-2}\end{array}$ \\
\hline $\begin{array}{l}\text { Pounds* per } \\
\text { minute }\end{array}$ & 0.13228 & 132.28 & 2.2046 & 60 & 1 \\
\hline
\end{tabular}

* Avoirudupois 


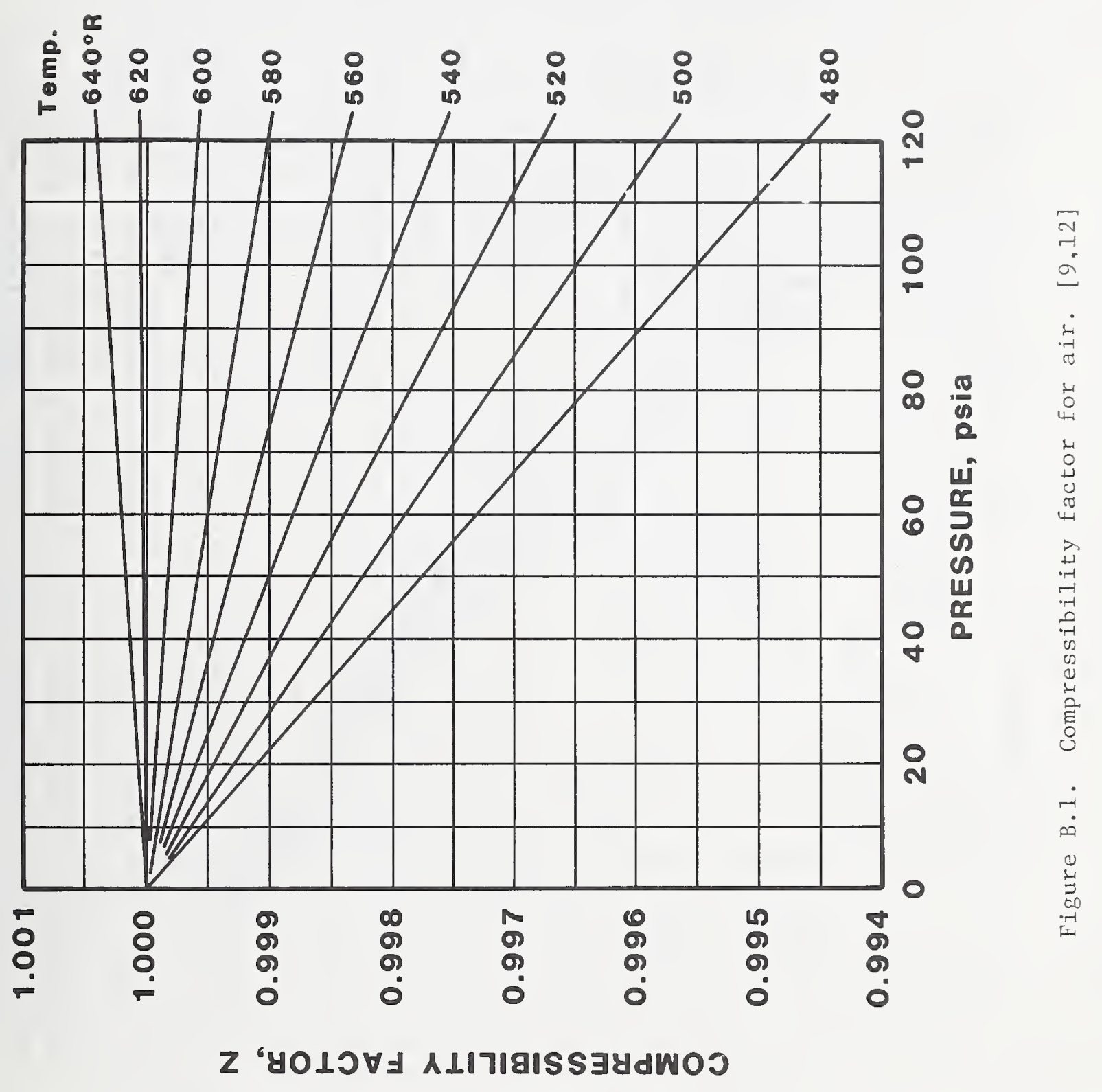




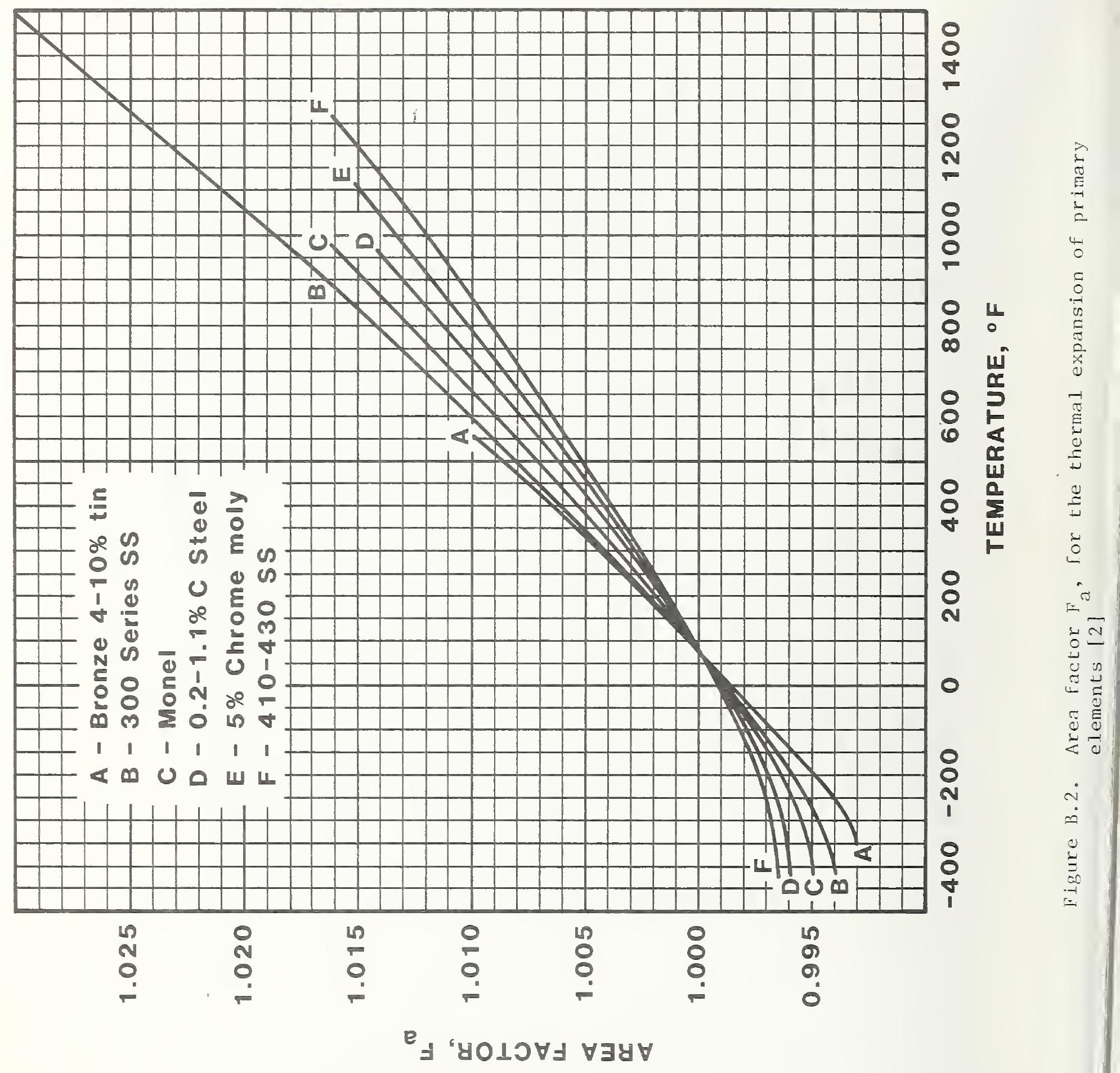




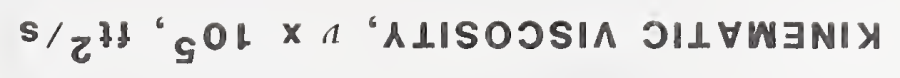

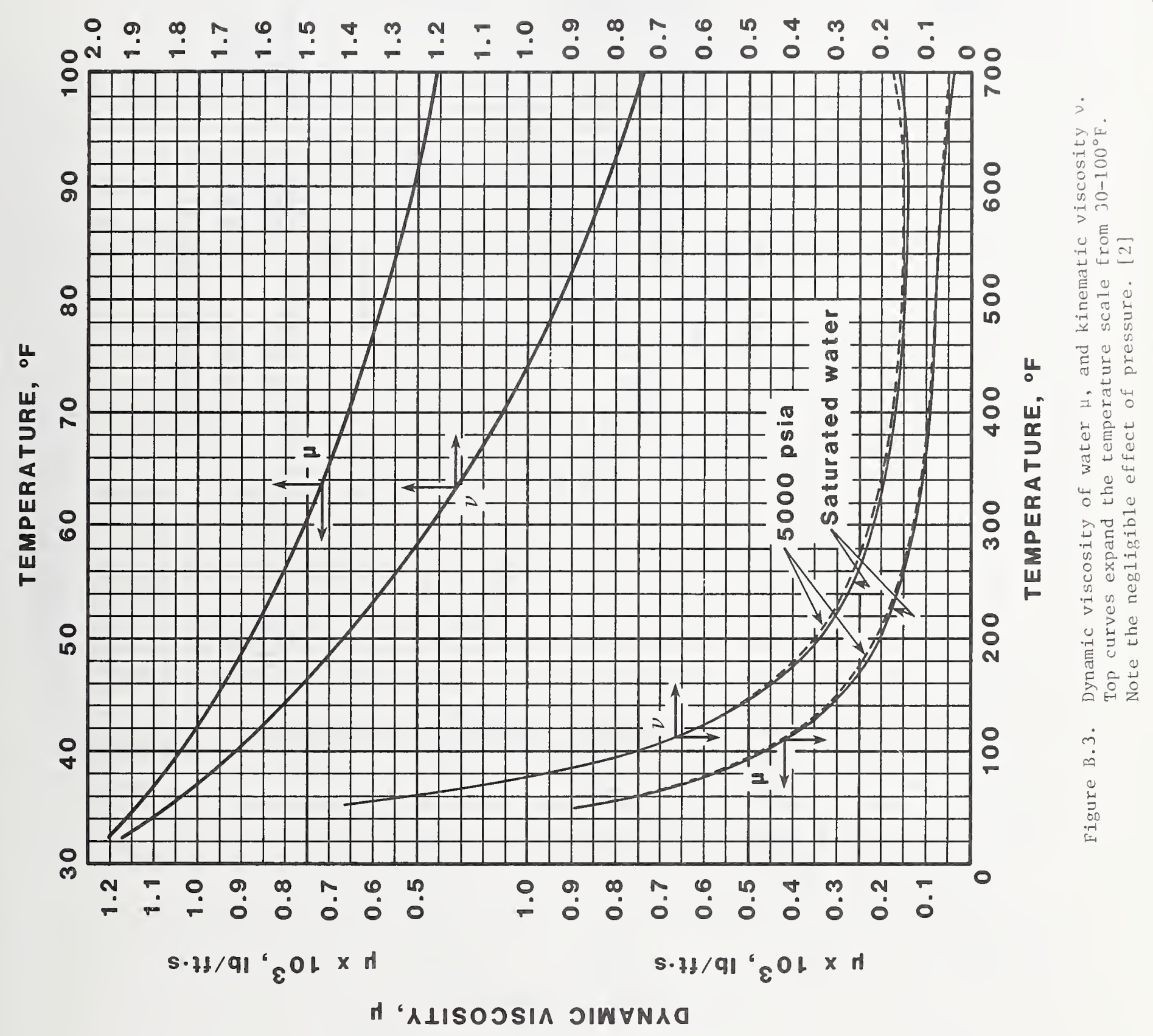




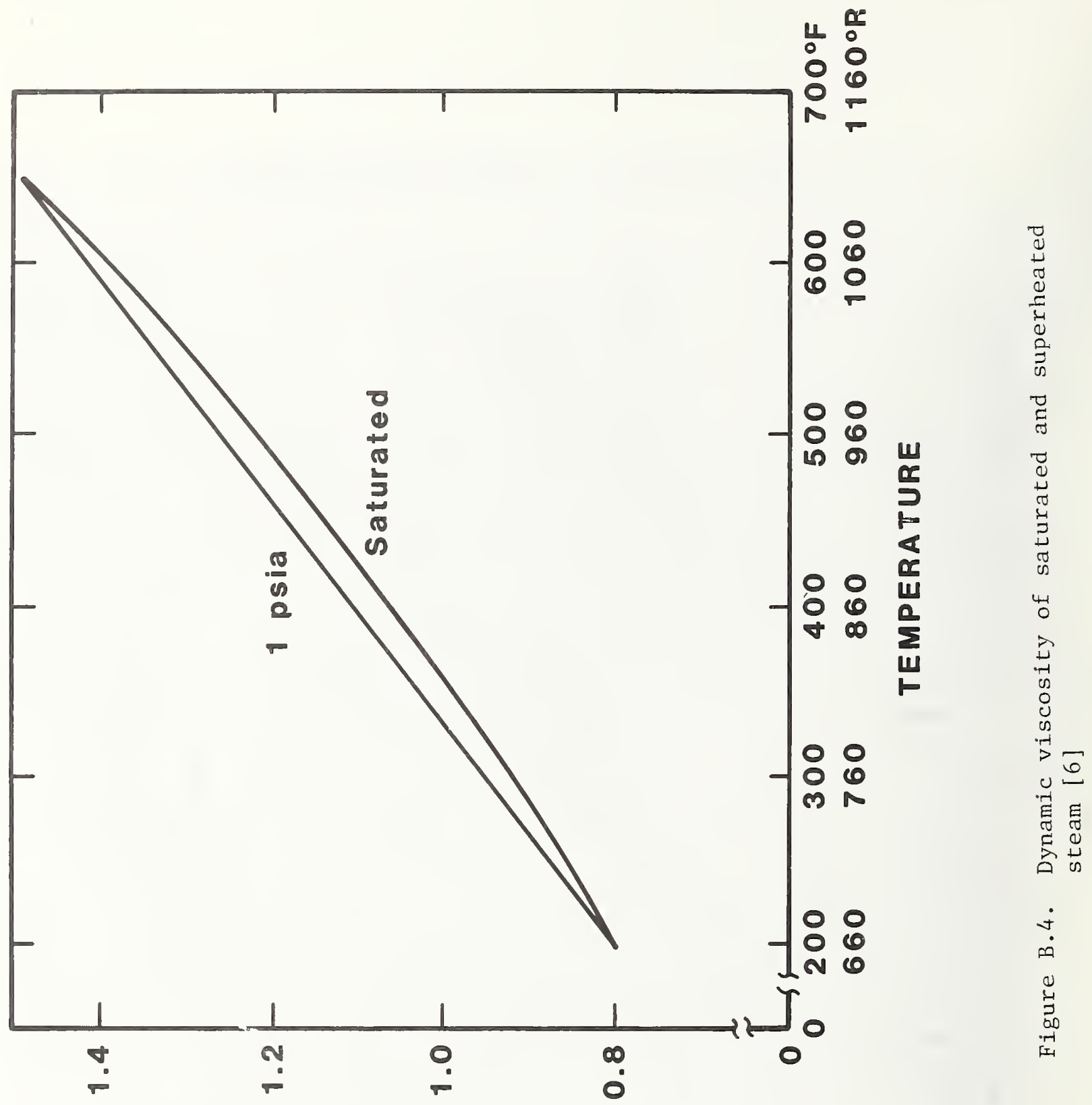

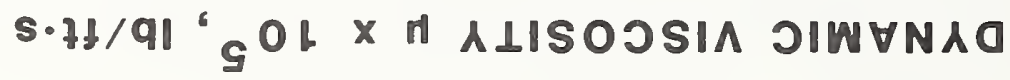




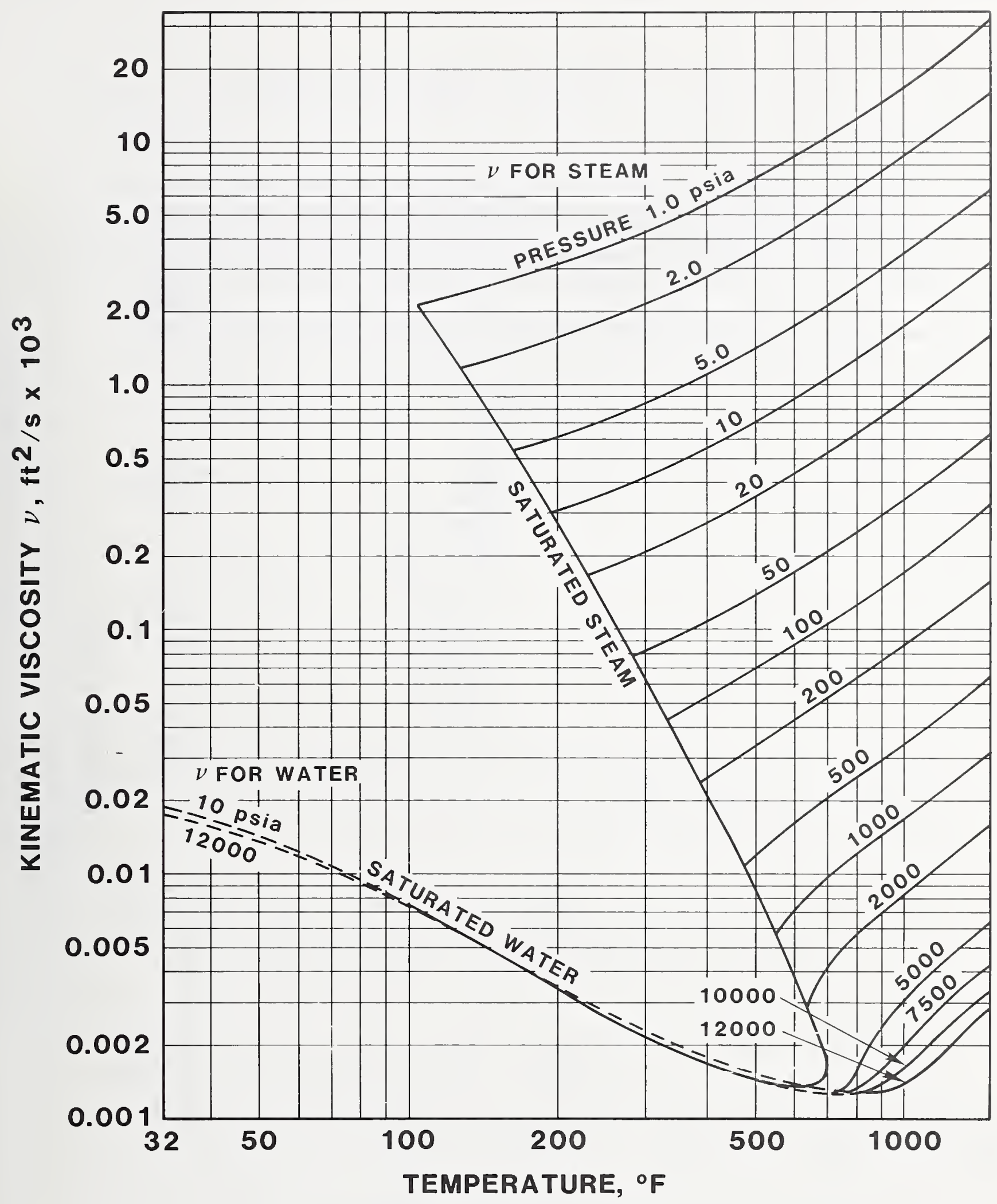

Figure B.5. Kinematic viscosities of steam and water [6] 


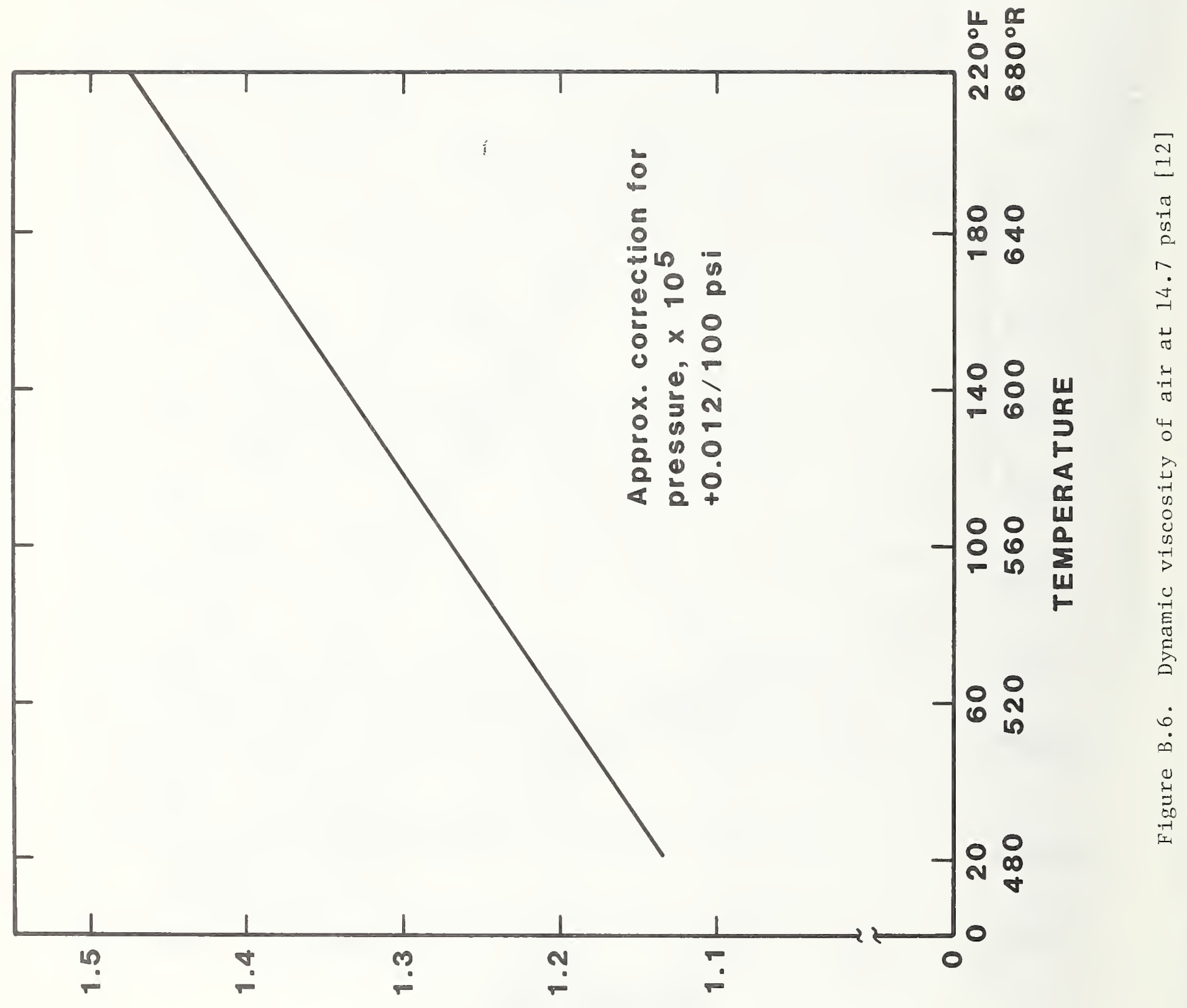

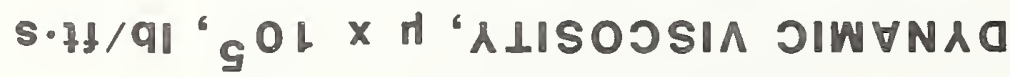


APPENDIX C. TEMPERATURE AND PRESSURE RELATIONS

\section{C.1 TEMPERATURE}

The units of temperature commonly used are the degree Fahrenheit, ${ }^{\circ} \mathrm{F}$, and degree Celsius, ${ }^{\circ} \mathrm{C}$; and the corresponding units of absolute temperatures, degree Rankine, ${ }^{\circ} \mathrm{R}$, and the kelvin, $\mathrm{K}$. Absolute temperature in degrees Rankine, designated by the symbo ${ }^{\circ} \mathrm{R}$, will be used frequently in our compressible fluid calculations. Temperature in degrees Fahrenheit will be designated by the symbol $t$.

The relations existing among these different units of temperature are:

$$
\begin{aligned}
& { }^{\circ} \mathrm{F}=\frac{9}{5}\left({ }^{\circ} \mathrm{C}\right)+32 \\
& { }^{\circ} \mathrm{C}=\frac{5}{9}\left({ }^{\circ} \mathrm{F}-32\right) \\
& { }^{\circ} \mathrm{R}={ }^{\circ} \mathrm{F}+459.67 \\
& \mathrm{~K}={ }^{\circ} \mathrm{C}+273.15 \\
& { }^{\circ} \mathrm{R}=\frac{9}{5}(\mathrm{~K}) .
\end{aligned}
$$

\section{C.2 PRESSURE}

The unit of pressure to be used in our calculations is pounds force per square inch. We will also express differential pressure in terms of the pressure exerted by a column of water at $68^{\circ} \mathrm{F}$ and subjected to standard acceleration of gravity, $32.1740 \mathrm{ft} / \mathrm{s}^{2}$. It will be necessary to designate whether a value of pressure is:

a) Pressure difference between two points in a flow system

$\Delta \mathrm{P}$ in psid (pounds per square inch differential), or

$\Delta \mathrm{P}$ in inches of water at $68^{\circ} \mathrm{F}$;

b) A pressure relative to the existing atmospheric pressure, using negative values to indicate pressures below atmosphere

p in psig (pounds per square inch gauge); or

c) Absolute pressure

$P$ in psia (pounds per square inch absolute). 
In the direct measurement of pressure difference $\Delta P$, it is necessary that both sides of the pressure sensing element be connected to pressure taps in the flow system. The pressure difference between these two taps will be derived from the instrument indication. Instruments used for the measurement of pressure difference include liquid manometers, differential pressure gauges of the elastic element type, and $\Delta p$ transducers using electrical sensing elements.

Instruments used for the sensing of pressure p relative to atmospheric pressure have une side of the pressure sensing element vented to the atmosphere. Instruments used here include manometers, Bourdon tube and diaphragm capsule gauges, and electrical transducers.

For the direct measurement of absolute pressure $P$, it is necessary that one side of the pressure sensing element be exposed to zero absolute pressure. Baroneters are one form of such instruments. However, the absolute pressure of a point in a flow system usually is not measured directly. Rather, gauge pressure $\mathrm{p}$ in psig and barometric pressure $\mathrm{P}_{\mathrm{b}}$ in psia are measured. 'The absolute pressure is then computed by the relation

$$
P=p+P_{b}=\text { absolute pressure in psia. }
$$

Barometric pressure, absolute pressure, gauge pressure, and differential pressure are sensed by many different types of instruments which read out in many different units of pressure or head. These instruments will be classified into three types: namely, Mechanical Pressure Gauges, Manometers, and Electrical Pressure Transducer Systems, defined as follows:

Mechanical Pressure Gauges contain an elastic element such as a Bourdon tube, diaphragm capsule, or spring bellows having a free end whose position changes with variation in pressure and a mechanical linkage system to transinit these variations in position to a revolving pointer located adjacent to a scale calibrated in units of pressure. Such a device senses and indicates directly, and will measure pressure difference $\Delta P$, gauge pressure $p$, or absolute pressure $P$ depending upon its design.

Manometers contain a liquid such as water or mercury in which the difference in liquid levels increases with increased pressure difference. In elementary designs the positions of the liquid levels are indicated by a scale, calibrated in units of length, placed beside the manometer column(s). Thus, this device senses pressure directly, but its indication, i.e., the difference in liquid levels, is only proportional to pressure. Like the pressure gauge, a manometer will measure pressure difference, gauge pressure, or absolute pressure depending upon its design.

Electrical Pressure Transducer Systems use electrical sensing elements such as metallic or semiconductor strain gauges, variable capacitance or variable inductance devices, differential transformers, potentiometers, or piezeolectric elements to sense deformation of the elastic element. The electrical output of these elements is usually an analog signal which is processed using electronic circuitry producing an analog output such as 4-20 mA DC or 0-10 volts DC, or a variable frequency digital signal. 


\section{C.2.1 Corrections and Use of Conversion Factors for Mechanical Pressure Gauges}

Calibration of a pressure gauge may show a measurable scale error which varies with gauge reading. When significant, scale error corrections should be applied to change the indicated readings to actual pressures. Aside from applying the scale error correction, it is only necessary to convert from units of pressure in which the gauge is calibrated to pounds per square inch (psi) or to inches of water at $68^{\circ} \mathrm{F}\left(h_{\mathrm{w}}\right)$. When gauges are calibrated in units of pressure other than psi, the Conversion Factors for Pressure, table C-1, will apply.

\section{C.2.2 Corrections and Use of Conversion Factors Manometers}

In converting an indicated level difference or height, $h$, of a manometer column to pressure in psi, it is necessary to consider the following:

a) The units of length in which the height is expressed (inches, centimeters, etc.),

b) The manometer liquid (water, mercury, etc.),

c) The temperature of the manometer liquid,

d) The density of the fluid in the high pressure leg of the manometer. (This correction is usually applied only when the manometer is used to measure pressure differential between two pressures taps in a flow system.)

e) The local acceleration due to gravity, $g_{L}$.

At times, corrections d) and e) will be too small to affect significantly the accuracy of the pressure determination. They may be omitted when such is the case. Correction procedures for each of these five items will now be discussed.

Corrections for Units of Length of the Manometer Scale.

When the scale of the manometer is calibrated in units of length other than inches, it is convenient to convert the length to inches using the conversion factors of figures C.1 and C.2.

Combined Conversion Factor for the Manometer Liquid and its Temperature

A conversion or multiplication factor $\mathrm{F}_{\mathrm{w} 1}$ will be used to convert inches of water at a known temperature to pounds per square inch. Similarly, a multiplication factor $\mathrm{F}_{\mathrm{ml}}$ will be used to convert inches of mercury at a known temperature to pounds per square inch. Values of these two factors may be obtained from figures $\mathrm{C} .1$ and $\mathrm{C} .2$ for water and mercury manometers, respectively, by entering these figures with the temperature of the liquid in the manometer column. This temperature is usually equivalent to room temperature. Figures $\mathrm{C} .1$ and C.2 cover just the manometer temperature range $50^{\circ} \mathrm{F}$ and $110^{\circ} \mathrm{F}$, but a larger range $32^{\circ} \mathrm{F}$ to $200^{\circ} \mathrm{F}$ is covered in tables 12 and 16 of reference 7 , for water and mercury, respectively. 
Usually a differential pressure is measured simply by the height of the liquid column. Actually, when air is in the high pressure leg, the differential pressure is proportional to the difference of the densities of the liquid column and of the column of equal height of the air on the high pressure side.

Multiplication Eactors, $\mathrm{F}_{\mathrm{W} 2}$ for a water manometer and $\mathrm{F}_{\mathrm{m} 2}$ for a mercury manometer, will be used to correct for the density of the air in the high pressure leg or well of a manometer used to measure differential pressure between two pressure taps in a flow system. Values of these factors are given in figures C. 3 and C.4 for the water and mercury columns, respectively. These figures apply for manometer temperatures in the approximate range of $60^{\circ} \mathrm{F}$ to $100^{\circ} \mathrm{F}$. For practial purposes, the factor $\mathrm{F}_{\mathrm{m} 2}$ may have an assumed value of 1.000 except when the manometer is used to measure differential presure between two pressures taps in a flow system at an elevated pressure.

When liquid water is in the high pressure leg of a mercury manometer, the multiplication Eactor $\mathrm{F}_{\mathrm{m} 3}$ will be used to correct for the density of the water. A value of $\mathrm{F}_{\mathrm{m} 3}=0.9263$ may be used for the range of $60^{\circ} \mathrm{F}$ to $100^{\circ} \mathrm{F}$ manometer temperature and pressures to 500 psia.

Correction for the Local Value of the Acceleration Due to Gravity

A multiplication factor $F_{g}$ will be used to correct the manometer reading for the local acceleration due to gravity. The value of this correction factor may be determined by the relation

$$
\mathrm{F}_{\mathrm{g}}=\mathrm{g}_{\mathrm{L}} / 32 \cdot 1740
$$

where $\mathrm{g}_{\mathrm{L}}$ is the value of the local acceleration due to gravity existing in the laboratory and expressed in $\mathrm{ft} / \mathrm{s}^{2}$.

\section{C.2.3 Equations for Converting Manometer Readings to Pressure in Pounds Per} Square Inch

A water manometer reading is converted to psi by the relation:

$$
\text { psi }=(\text { inches of water })\left(\mathrm{F}_{\mathrm{w} 1} \mathrm{~F}_{\mathrm{W} 2} \mathrm{~F}_{\mathrm{g}}\right)
$$

A inercury manometer reading is converted to psi by the relation:

$$
\text { psi }=(\text { inches of mercury })\left(\begin{array}{llll}
F_{m 1} & F_{m 2} & F_{g}
\end{array}\right)
$$

When liquid water is in the high pressure leg, a mercury manometer reading is converted to psi by the relation:

$$
\text { psi }=(\text { inches of mercury })\left(\begin{array}{lll}
F_{\mathrm{m} 1} & \mathrm{~F}_{\mathrm{m} 3} & \mathrm{~F}_{\mathrm{g}}
\end{array}\right)
$$


C.2.4 Equations for Converting Manometer Readings to Inches of Water at $68^{\circ} \mathrm{F}, \mathrm{h}_{\mathrm{W}}$

In all cases:

$$
h_{W}=27.729(p s i)
$$

(Table C.1)

The following may also be used. A water manoneter reading is converted to $h_{\text {r }}$ by the relation:

$$
\mathrm{h}_{\mathrm{w}}=(\text { inches of water })\left(\rho / \rho_{68}\right)\left(\mathrm{F}_{\mathrm{w} 2} \mathrm{~F}_{\mathrm{g}}\right)
$$

where $\rho$ is the density of water at the manometer temperature, and 968 is the density of water at $68^{\circ} \mathrm{F}$.

A mercury manometer reading is converted to $h_{w}$ by the relation:

$$
h_{\mathrm{w}}=\text { (inches of mercury) }\left(\rho_{\mathrm{Hg}} / \rho_{68}\right)\left(\mathrm{F}_{\mathrm{m} 2} \mathrm{~F}_{\mathrm{g}}\right)
$$

where $\rho_{\mathrm{Hg}}$ is the density of inercury at the manometer temperature.

When liquid water is in the high pressure leg, a mercury manometer reading is converted to $h_{w}$ by the relation:

$$
h_{w}=(\text { inches of mercury })\left(\rho_{\mathrm{Hg}} / \rho_{68}\right)\left(F_{m 3} F_{g}\right)
$$

\section{C.2.5 Barometers and Barometric Pressure}

It is essential that the barometric or ambient air pressure existing within the laboratory be determined with good accuracy during tests involving the flow of compressible fluids. For computations here, the pressure $\mathrm{P}_{b}$ of the existing atmosphere above zero is expressed in pounds force per square inch absolute, psia. Barometric pressure varies continually throughout the day and from dayto-day depending upon outside atmospheric conditions and the ventilation equipment used to supply air to the laboratory. Normally, $\mathrm{P}_{\mathrm{b}}$ at sea level will be within the range 14.2 to 14.9 psia. Exceptions will be noted when severe atmospheric disturbances occur or in laboratories having elevations appreciably different from sea level, e.g., several hundred feet. Two different types of barometers, aneroid and mercury column, are commonly used. Their designs and the conversion of their readings to psia are discussed below.

Aneroid Barometers are essentially a refined version of a mechanical pressure gauge designed to measure absolute pressure. They contain an evacuated diaphragm capsule whose configuration varies with changes in ambient air pressure together with a mechanical linkage system which moves an indicating pointer positioned adjacent to a calibrated scale. The scale units are usually inches of mercury at $32{ }^{\circ} \mathrm{F}$ or millimeters of mercury at $0{ }^{\circ} \mathrm{C}$.

Readings from the aneroid barometer do not require corrections for the local acceleration due to gravity. Also, temperature correction factors applicable to mercury columns must not be applied to readings of this instrument. If the 
aneroid barometer is not self-compensating for changes in ambient temperature, a temperature correction chart or table will be required.

The special temperature correction, if any, as well as any correction for scale error should be applied to the reading of the aneroid barometer to obtain a corrected barometer reading. Conversion factors for pressure from table C. 1 are then applied to the corrected reading to convert from the instruments units to psia.

Mercury Column Barometers contain a reservior, vented to the atmosphere, and a vertical column of mercury. A brass scale, calibrated in inches or millimeters, is placed beside the mercury column; and arrangements are provided for the adjustment of this scale prior to each reading.

To obtain an accurate measure of the barometric pressure, the reading from a nercury barometer must be corrected for the thermal expansion of both the mercury and the brass scale, and for the local acceleration due to gravity. It is also necessary to convert the corrected reading of length into pressure units, pounds per square inch absolute, psia.

Tables 17 and 18 of reference 7 give Temperature Corrections for Mercury Barometers with Brass Scales. Correction factors obtained from these tables compensate for the combined thermal expansion of both the mercury and the brass scale. The temperature to be used in entering these tables is the temperature of mercury in the barometer. This is usually indicated by a thermometer permanently attached to the instrument.

\section{C.2.6 Corrections and Use of Conversion Factors for Electrical Pressure Transducers}

The pressure transducer system may include readout instrumentation indicating pressure directly, or the output may be an analog signal such as 4-20 mA DC or 0-10 volts DC, or it may be a variable frequency signal. In any case, calibration may show a measurable error which varies with pressure or pressure differential. When significant, error corrections should be applied to change the indicated reading to actual pressures, or corrections should be applied to the electrical output.

The transducer should be calibrated periodically, preferably on site, first to establish and then to monitor any significant errors. The calibration equipment may range in complexity from liquid manometers (vertical, inclined, or micro type using water, mercury, or special manometer fluids) to laboratory reference type pressure transducer equipment incorporating a digital readout and automated computational features.

When the pressure transducer is part of a flowmeter system, its output signal may be expressed in the meter calibration factor CF, for example:

$$
\mathrm{CF}=\mathrm{GPM} /(\mathrm{mA})^{1 / 2}
$$


The mA value may refer to transducer (or transmitter) output current, uncorrected. Although corrections would not be made directly, it is still very important that a calibration program be established to determine the transducer error and that the transducer performance be monitored by periodic calibration checks. otherwise, the meter calibration factor will no longer represent the actual system performance. 


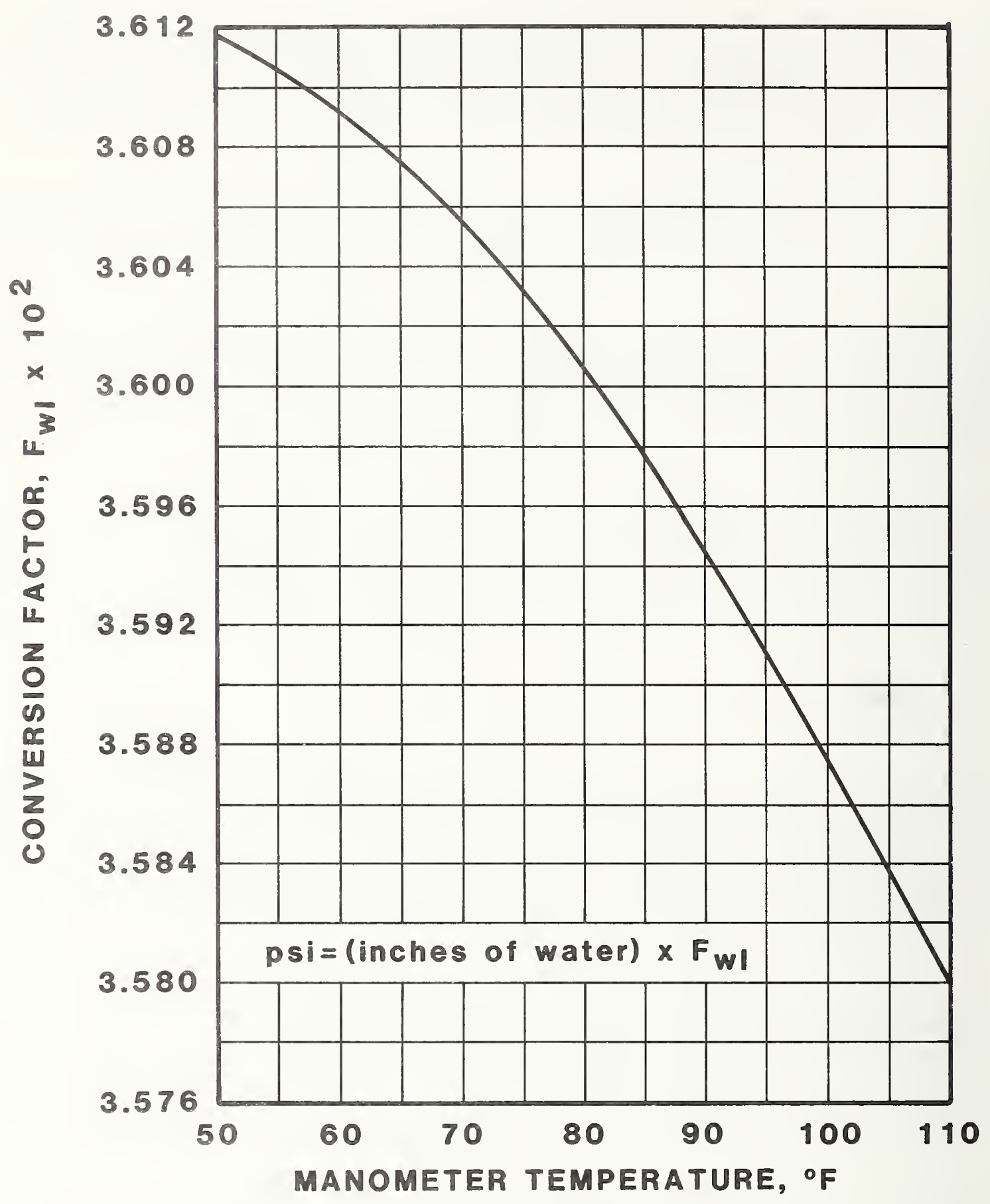

Figure C.1. Conversion factor $F_{w 1}$ for water columns [7,9] 


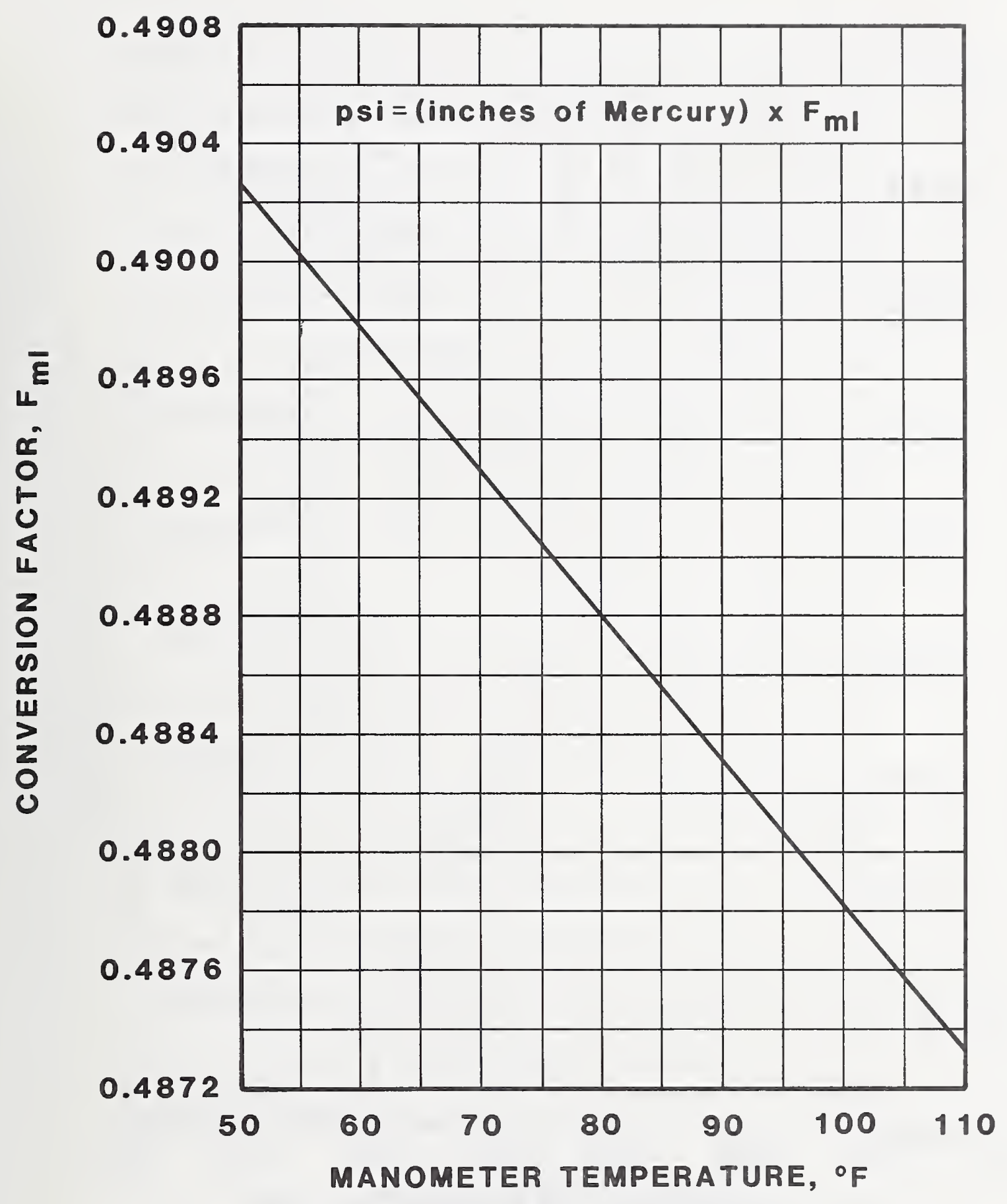

Figure C.2. Conversion factor $\mathrm{F}_{\mathrm{ml}}$ for mercury columns [7,9] 


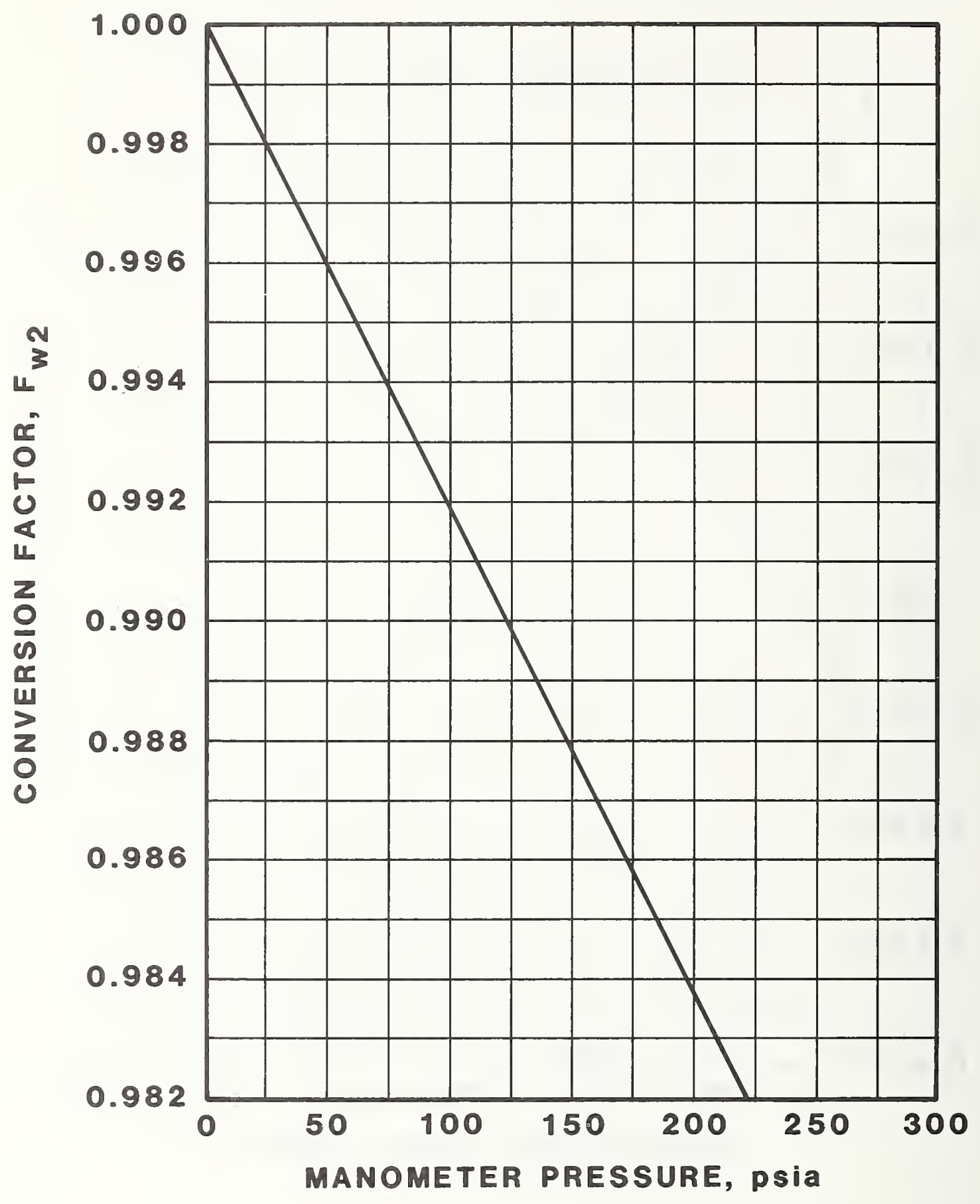

Figure C.3. Water manometer correction factor $\mathrm{F}_{\mathrm{W}} 2$ for air column density $[7,9]$ 


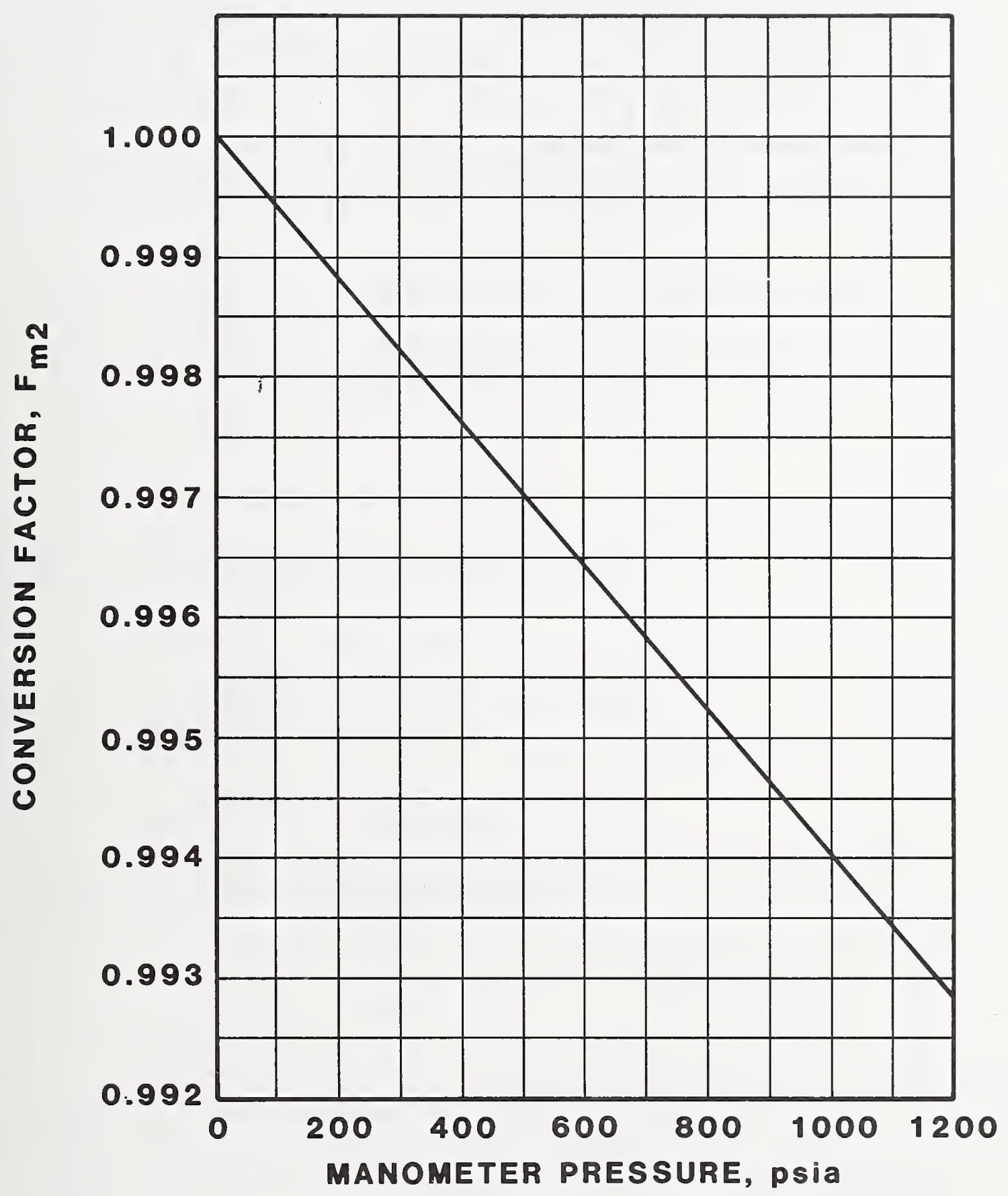

Figure C.4. Mercury manometer correction factor $F_{m 2}$
for air column density $[7,9]$ 


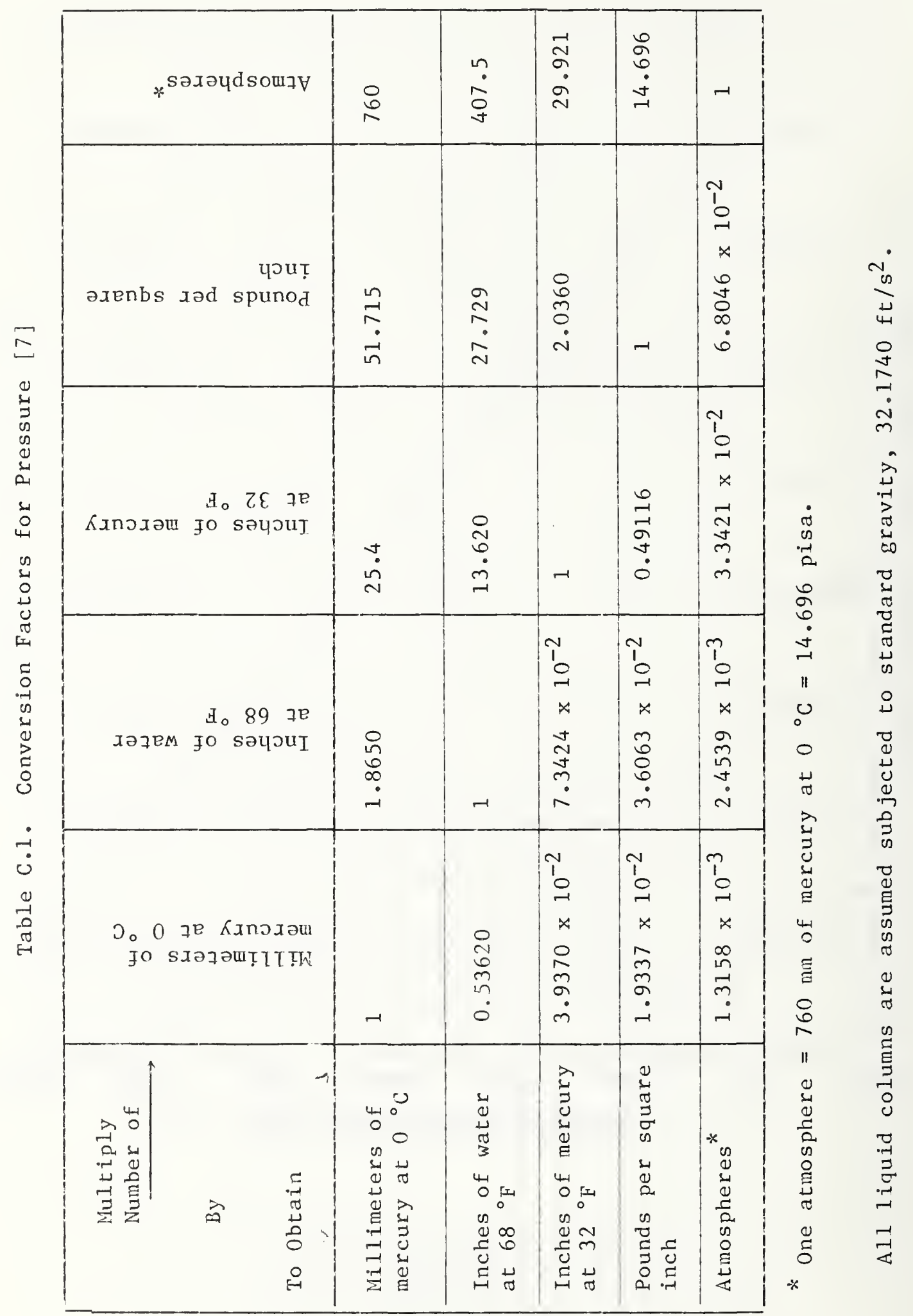


When calibrating a working meter on site, the occasion may arise when the flow at the transfer conditions of temperature and pressure need to be expressed in terms of the flow at a different temperature and/or pressure existing at the working meter; or at a single station, a mass flowrate may need conversion to a volume flowrate. Thus, the relation between mass and volume rate of flow needs consideration.

Under steady-flow conditions, the mass flowrate $M$ is constant throughout a system provided no leakage occurs. For example in figure 5, using subscripts to denote positions with the system, the conservation of mass flowrate $M$ may be stated by:

$$
\text { Mass flowrate }=M=M_{1}=M_{2}=M_{3}=M_{4}=\ldots=M_{X}
$$

The volume rate of $f$ low $Q_{x}$ at any point $x$ in the system is the mass flowrate divided by the fluid density $\rho_{X}$ at that point, or

$$
\begin{aligned}
& Q_{x}=M / \rho_{x} \text { from which } \\
& Q_{1}=M / \rho_{1} ; Q_{2}=M / \rho_{2} ; \ldots . Q_{x}=M / \rho_{x}
\end{aligned}
$$

When water (incompressible fluid) is flowing, density $\rho$ will be essentially constant at building system pressure levels and

$$
Q_{1}=Q_{2}=Q_{3}=Q_{4}=\ldots .=Q_{x}
$$

When a gas (air, steam) is flowing, the density $\rho_{X}$ varies point to point as a function of the temperature and pressure. Since

$$
\begin{aligned}
& M=M_{1}=M_{2}=\ldots=M_{X} \text {, then } \\
& \left(\rho_{1} Q_{1}\right)=\left(\rho_{2} Q_{2}\right)=\ldots .=\left(\rho_{x} Q_{x}\right)
\end{aligned}
$$

\section{D.1 DENSITY OF DRY AIR, STEAM, AND MOIST AIR}

With dry air, the density $\rho$ can be calculated from an equation of state:

$$
\rho=P /\left(\begin{array}{lll}
Z & R & T
\end{array}\right)
$$

where $\mathrm{P}$ is the absolute pressure and $\mathrm{T}$, the absolute temperature.

The quantity $R$ is known as the "gas constant" with its value different for each gas and also dependent on the units used in expressing $\rho, P$ and $T$. The quantity $Z$ is known as the "compressibility factor." It corrects for sinall variations in the behavior of real gases compared to ideal gases, and its value depends on the gas, and its temperature and pressure. The value of $Z$ is dimensionless, and it is not dependent upon the units of pressure and temperature. A graph giving the Compressibility Factor $\mathrm{Z}$ for dry air as a function of $\mathrm{P}$ and $\mathrm{T}$ is given in appendix $B$, figure $B-1$. 
For dry air, with $\mathrm{P}$ in units pounds force per square inch absolute, psia, and $\mathrm{T}$, the absolute temperature in degrees Rankine ${ }^{\circ} \mathrm{R}$, the relation for density is

$$
\rho=2.6990 \mathrm{P} /(\mathrm{Z} \mathrm{T}) 1 \mathrm{~b} / \mathrm{ft}^{3} \text {, }
$$

where 2.6990 equals the molecular weight of dry air (28.964 1b/1b-mole) divided by the Universal Gas Constant $\bar{R},(10.7315)\left(\mathrm{psia} \cdot \mathrm{ft}^{3}\right) /\left(1 \mathrm{~b}-\mathrm{mole}^{\circ} \mathrm{R}\right)$,

and $1 \mathrm{~b}$ has units pounds mass.

With steam, the properties including specific volume, $\mathrm{ft}^{3} / 1 \mathrm{~b}$, are given in tabular form as a function of temperature and pressure in reference 6 . Thus:

$$
\rho_{\mathrm{v}}=1 /\left(\text { specific volume) } 1 \mathrm{~b} / \mathrm{ft}^{3}\right. \text {, }
$$

where $\rho_{\mathrm{V}}$ is the density of steam or water vapor.

For moist air, a relation for the density $\rho_{\mathrm{m}}$ of the mixture is:

$$
\rho_{\mathrm{m}}=\frac{2.6990\left(\mathrm{P}-\mathrm{P}_{\mathrm{V}}\right)}{(\mathrm{ZT})}+\rho_{\mathrm{v}} 1 \mathrm{~b} / \mathrm{ft}^{3}
$$

where $P-P_{V}=$ partial pressure of the air, and

$\mathrm{P}_{\mathrm{v}}=$ partial pressure of the water vapor

The relation for $\rho_{\mathrm{m}}$ is valid at low values of $\mathrm{P}_{\mathrm{v}}$ where the behavior of steam approaches ideal gas behavior. The value of $\mathrm{P}_{\mathrm{v}}$ depends on the relative humidity, $\mathrm{RH}$, expressed in percent and $\mathrm{P}_{\mathrm{g}}$, the saturation pressure for steam at temperature $\mathrm{T}$, as follows:

$$
\mathrm{P}_{\mathrm{V}}=(\mathrm{RH} / 100) \mathrm{P}_{\mathrm{g}}
$$

Example calculations E.1, E.2, and E.3 in appendix E deal with relations between mass and volume rate of flow. Example E.4 gives results of calculations for $\rho_{\mathrm{m}}$ for moist air at several pressures, temperatures and moisture contents.

It is noted for both air and steam flow calculations, when the actual volume flowrate at a definite temperature and pressure is known, the volume flowrate may be determined at some other location having a definite temperature and pressure with computation of the mass flowrate unnecessary, i.e.,

$$
\mathrm{Q}_{\mathrm{X}}=\left(\rho_{1} \mathrm{Q}_{1}\right) / \rho_{\mathrm{X}}
$$

With air flow, substituting equation (D-5) gives:

$$
\mathrm{Q}_{\mathrm{x}}=\frac{\left(\mathrm{P}_{1} \mathrm{Z}_{\mathrm{x}} \mathrm{T}_{\mathrm{x}}\right)}{\left(\mathrm{P}_{\mathrm{x}} \mathrm{Z}_{1} \mathrm{~T}_{1}\right)} \mathrm{Q}_{1}
$$

since $R$ for any gas is constant. Thus, this relation is convenient to use when mass flowrate is neither known nor required, and volume flowrate at a definite temperature and pressure is known. 


\section{D.2 "STANDARD CONDITIONS," ITS MEANING AND USE}

As discussed above and shown in example E.3, the actual volumetric flowrate ACFM is not a convenient nor direct measure of the quantity of matter because the numerical value varies with both temperature and pressure. The absolute pressure and temperature of the gas at the particular location must also be stated if the actual volume at that location is to be meaningful in terms of the quantity of matter.

It has also been noted that mass flow is a direct measure of the quantity of matter and its value is independent of the pressure and temperature at the location under consideration.

One other quantity is used, especially in commerical transactions, as a direct indication of the quantity of matter involved in gaseous flow. This is volume flow converted to selected standard conditions of absolute pressure $P_{S}$ and absolute temperature $\mathrm{T}_{\mathrm{S}}$. Values of volume flow converted to these standard conditions will be referred to as standard cubic feet per minute, SCFM.

The selected standard conditions of pressure and temperature are not necessarily the same for all industries or for all laboratories. Any organization may select any value of $\mathrm{P}_{S}$ and $\mathrm{T}_{S}$ for its standard conditions; however, to prevent confusion, once values for $\mathrm{P}_{S}$ and $\mathrm{T}_{\mathrm{S}}$ are selected, they should be used without exception. When two organizations select different standard conditions of pressure and temperature, their values of SCFM will not concur because their standard cubic feet will refer to different quantities of matter. Therefore, the value of SCFM has no definite, accurate meaning unless the values of $P_{S}$ and $\mathrm{T}_{\mathrm{S}}$ associated with the value of SCFM are definitely known.

From the preceding, it should be understood that the "Standard" in SCFM is not standard at all but varies among different industries and laboratories. Hence, this term SCFM has a tendency to confuse as well as help. 

Example E.l Mass and Volume Rates of Flow, Superheated Steam. Steam flows at a mass rate of flow of $2000 \mathrm{lb} / \mathrm{hr}$ in a pipe. It is desired to calculate the actual volume rate of flow, cubic feet per minute (ACFM) at two stations, 1 and 2. Pressures are measured with bourdon tube gauges, with cases vented to the atmosphere. Following are the measurements made:

\section{Measurement}

Barometric pressure

Pressure $\mathrm{p}_{1}$

Temperature $t_{1}$

Pressure $\mathrm{P}_{2}$

Temperature $t_{2}$

\section{Instrument}

Aneroid barometer, inches of mercury at $32^{\circ} \mathrm{F}$

Bourdon tube gauge

Resistance thermometer, output converted to ${ }^{\circ} \mathrm{F}$

Bourdon tube gauge

Resistance thermoneter
Reading

$29.83 \mathrm{in.} \mathrm{Hg}$ at $32^{\circ} \mathrm{F}$

35.0 psig

$300^{\circ} \mathrm{F}$

15.0 psig

$260^{\circ} \mathrm{F}$

Compute barometric pressure $\mathrm{P}_{\mathrm{b}}$ in psia. No corrections for temperature or local acceleration due to gravity are applied to the aneroid barometer reading. Refer to table $\mathrm{C}-1$ for the conversion factor for $\mathrm{P}_{\mathrm{b}}$.

$$
\begin{aligned}
& \mathrm{P}_{b}=(0.49116)\left(\text { inches of mercury at } 32^{\circ} \mathrm{F}\right) \\
& \mathrm{P}_{b}=(0.49116)(29.83)=14.65 \text { psia }
\end{aligned}
$$

Computation for station 1 :

$$
\mathrm{P}_{1}=\left(\mathrm{p}_{1}+\mathrm{p}_{\mathrm{b}}\right)=(35.0+14.65)=49.65 \text { psia }
$$

To determine $\rho_{l}$, use data from steam tables, reference 6 , table 3 . Interpolation of data for $300^{\circ} \mathrm{F}$ gives:

$$
\underline{\text { P, psia }}
$$

48

49.55

50

$$
\mathrm{v}, \mathrm{ft} \mathrm{t}^{3} / 1 \mathrm{~b}
$$

$$
9.147
$$

8.835

8.769

The specific volume at station 1 is:

$$
\begin{aligned}
& v_{1}=3.835 \mathrm{ft}^{3} / 1 \mathrm{~b}=1 / \rho_{1} \\
& \rho_{1}=1 / 8.835=0.11319 \mathrm{lb} / \mathrm{ft}^{3}
\end{aligned}
$$


The volume flowrate is:

$$
\begin{aligned}
& Q_{1}=M / \rho_{1}=(2000) /(60)(0.11319)=294.5 \mathrm{ACFM}, \text { or } \\
& Q_{1}=\left(M v_{1}\right)=(2000)(8.835) /(60)=294.5 \mathrm{ACFM}
\end{aligned}
$$

Computatior for station 2:

$$
\mathrm{P}_{2}=\left(\mathrm{p}_{2}+\mathrm{P}_{\mathrm{b}}\right)=(15.0+14.65)=29.65 \mathrm{psia}
$$

Interpolation at $t_{2}=260^{\circ} \mathrm{F}$ :

$$
\text { P, psia }
$$

29.00

29.65

30.00 v, $\mathrm{ft}^{3} / \mathrm{lb}$

14.447

14.127

13.954

$\mathrm{v}_{2}=14.127 \mathrm{ft}^{3} / 1 \mathrm{~b}$

$\mathrm{Q}_{2}=\left(M \mathrm{v}_{2}\right)=(2000)(14.127) /(60)=470.9 \mathrm{ACFM}$

The actual volume rate of flow at station 1 is $295.4 \mathrm{ft}^{3} /$ minute and at station 2 , it is $470.9 \mathrm{ft}^{3} / \mathrm{minute}$. It should be noted that while the mass flowrate is constant, the volume flowrate is not constant, but varies with the density or specific volume.

Example E.2 Mass and Volume Rates of Flow, Wet Steam. This example deals with wet steam, that is, steam in the saturation state which contains both liquid and vapor. While it is outside the scope of this document, a basic computation for mass and volume flowrates follows. Consider steam flowing at a flowrate of $100 \mathrm{ACFM}$, at a temperature of $288^{\circ} \mathrm{F}$, and a pressure of 55.8 psig. It is desired to compute the mass flowrate in $1 \mathrm{~b} / \mathrm{hr}$.

Referring to reference 6 , it is noted that the temperature and pressure correspond to saturation conditions. Therefore, no determination of density is possible with the information given. In addition, the steam quality " $x$ " (ratio of the mass of vapor to the mass of mixture) is needed.

Assume the quality $\mathrm{x}$ is 97.0 percent.

For the saturated state, the specific volume is

$$
\mathrm{v}=(1-\mathrm{x})\left(\mathrm{v}_{\mathrm{f}}\right)+(\mathrm{x})\left(\mathrm{v}_{\mathrm{g}}\right)
$$

where $\mathrm{x}$ is expressed as a decimal, $\mathrm{v}_{\mathrm{f}}$ is the specific volume of saturated liquid, and $v$ is the specific volume of the saturated vapor. 
Using equation E2-1 and data in reference 6, table 1 , at temperature $288^{\circ} \mathrm{F}$, the specific volume is

$$
\begin{aligned}
& v=(0.03)(0.0174)+(0.97)(7.5807) \text {, or } \\
& v=7.451 \mathrm{ft}^{3} / 1 \mathrm{~b}
\end{aligned}
$$

The mean flow rate, $M$, is:

$$
\begin{aligned}
M & =(\rho Q)=Q / V \\
& =(100)(60) /(7.451), \text { or } \\
M & =805.31 \mathrm{~b} / \mathrm{hr}
\end{aligned}
$$

Example E.3 Mass and Volume Rates of Flow, Dry Air. Dry air flows through a system as shown in figure 5 . Valve $\mathrm{Vl}$ is closed. The mass flowrate is known to be 18.00 pounds per minute. It is desired to determine the flowrate entering 21 , and leaving, 24 in actual cubi.c feet per minute, ACFM. Local acceleration due to gravity is $32.150 \mathrm{ft} / \mathrm{s}^{2}$. Pressures and temperatures have been measured as follows:

\section{Measurement}

Barometric pressure

Pressure $\mathrm{p} 1$

Temperature $t_{1}$

Pressure $h_{4}$

Temperature $t_{4}$
Instrument

Aneroid barometer, in. Hg at $32^{\circ} \mathrm{F}$

Bourdon tube gauge, case vented to atmosphere, psig

Mercury thermometer, ${ }^{\circ} \mathrm{F}$

Mercury manometer, low pressure leg vented to atmosphere, in. $\mathrm{Hg}$

Mercury thermometer, ${ }^{\circ} \mathrm{C}$
Reading

29.836 in. $\mathrm{Hg}$ at $32^{\circ} \mathrm{F}$

$105.0 \mathrm{psig}$

$73.7^{\circ} \mathrm{F}$

55.47 in. $\mathrm{Hg}$ at $81.0^{\circ} \mathrm{F}$

$23.5^{\circ} \mathrm{C}$

Compute the barometric pressure $\mathrm{P}_{\mathrm{b}}$ in psia. Note that corrections for instrument temperature and local acceleration due to gravity are not applied to the aneroid barometer reading.

$$
\begin{aligned}
\mathrm{P}_{\mathrm{b}} & \left.=0.49116 \text { (inches of mercury at } 32^{\circ} \mathrm{F}\right) \quad \text { (Table C.1) } \\
& =(0.49116)(29.836) \text {, or } \\
\mathrm{P}_{\mathrm{b}} & =14.65 \text { psia }
\end{aligned}
$$

Computation for location 1: 


$$
\begin{aligned}
& \mathrm{P}_{1}=\left(\mathrm{p}_{1}+\mathrm{p}_{\mathrm{b}}\right)=(105.0+14.65)=119.65 \mathrm{psia} \\
& \mathrm{T}_{1}=\left(\mathrm{t}_{1}+459.67\right)=(73.7+459.67)=533.37{ }^{\circ} \mathrm{R} \\
& \mathrm{z}_{1}=0.9973 \quad\left(\text { for air at } 120 \mathrm{psia} \text { and } 533^{\circ} \mathrm{R}\right) \\
& \rho_{1}=2.6990 \mathrm{P}_{1} /\left(\mathrm{Z}_{1} \mathrm{~T}_{1}\right)=\frac{(2.6990)(119.65)}{(0.9973)(533.37)} \text {, or } \\
& \rho_{1}=0.6071 \mathrm{lb} / \mathrm{ft}^{3} \\
& \mathrm{Q}_{1}=\mathrm{M} / \rho_{1}=(\mathrm{C}-3) \\
& \mathrm{Q}_{1}=(18.00) /(\mathrm{min}) /\left(\mathrm{lb} / \mathrm{ft}^{3}\right)
\end{aligned}
$$

Computation for location 4:

Determine the mercury manometer correction factors $F_{g}, F_{m 1}$ and $F_{m 2}$

$$
\begin{aligned}
& \mathrm{F}_{\mathrm{g}}=\mathrm{g}_{\mathrm{L}} / 32.1740=32.150 / 32.1740=0.9993 \\
& \mathrm{~F}_{\mathrm{ml}}=0.48873 \mathrm{psi} / \mathrm{in} \cdot \mathrm{Hg} \quad\left(\text { at } 81.0^{\circ} \mathrm{F}\right) \\
& \mathrm{F}_{\mathrm{m} 2}=0.9998\left(\text { at } \mathrm{P}_{4}=42 \text { psia }\right) \\
& \left.\mathrm{p}_{4}=\text { (inches of mercury at } 81^{\circ} \mathrm{F}\right)\left(\mathrm{F}_{\mathrm{m} 1} \mathrm{~F}_{\mathrm{m} 2} \mathrm{~F}_{\mathrm{g}}\right. \text { ) } \\
& =(55.47)(0.48873)(.9998)(0.9993) \text { or } \\
& p_{4}=27.09 \text { psig } \\
& P_{4}=P_{4}+P_{b}=27.09+14.65=41.74 \text { psia } \\
& t_{4}=\left({ }^{\circ} \mathrm{C}\right)(9 / 5)+32=23.5(9 / 5)+32=74.3^{\circ} \mathrm{F} \\
& T_{4}=t_{4}+459.67=74.3+459.67=533.97{ }^{\circ} \mathrm{R} \\
& z_{4}=0.9991 \quad\left(\text { air at } 42 \text { psia and } 534^{\circ} \mathrm{R}\right) \\
& \rho_{4}=2.6990 \mathrm{P}_{4} /\left(\mathrm{Z}_{4} \mathrm{~T}_{4}\right)=2.6990(41.74) /[(0.9991)(533.97)] \\
& \rho_{4}=0.21121 \mathrm{~b} / \mathrm{ft}^{3} \\
& 2_{4}=11 / \rho_{4} \text { or } \\
& \mathrm{Q}_{4}=18.000 / 0.2112=85.23 \mathrm{ft}^{3} / \mathrm{min} \text { ( at } 41.74 \mathrm{psia} \text { and } 534.0{ }^{\circ} \mathrm{R} \text { ) }
\end{aligned}
$$

Thus, $Q_{1}$ is $29.65 \mathrm{ft}^{3} / \mathrm{min}$ at $119.65 \mathrm{psia}$ and $533.4^{\circ} \mathrm{R}$ and $Q_{4}$ is $85.23 \mathrm{ft}^{3} / \mathrm{min}$ at 41.75 psia and $534.0^{\circ} \mathrm{R}$. It should be noted that the quantity of air flow is constant at $18.00 \mathrm{lb} / \mathrm{min}$. However, the volume rate of flow is not constant thro:ighout the system, but rather varies with temperature and pressure. Thus 
whenever the volumetric rate of flow $Q$ is used as a measure of quantity of matter, is is necessary that the absolute pressure and temperature associated with this measurement be stated along with the value of $Q$.

Example E.4 Density of Moist Air. Calculate the density, $\rho_{\mathrm{m}}$ for moist air at pressure $\mathrm{P}=14.7,50$ and $100 \mathrm{psia}$, temperature $\mathrm{t}=80^{\circ} \mathrm{F}$ and $170^{\circ} \mathrm{F}$, and relative humidity/100 $=0.50$ and 1.0 (saturated air). Compare with dry air $(\mathrm{RH}=0)$.

Calculation for $\mathrm{P}=14.7$ psia, $t=170^{\circ} \mathrm{F}$ and $\mathrm{RH} / 100=0.5$ :

Density of the moist air:

$$
\begin{aligned}
& \rho_{\mathrm{m}}=\frac{2.6990\left(\mathrm{P}-\mathrm{P}_{\mathrm{v}}\right)}{(\mathrm{ZT})}+\rho_{\mathrm{v}} \\
& \mathrm{T}=170.0+459.67=629.7^{\circ} \mathrm{R}
\end{aligned}
$$

At $t=170^{\circ} \mathrm{F}$, the saturation pressure of steam is:

$$
\mathrm{P}_{\mathrm{g}}=5.9926 \text { psia }
$$

The partial pressure of the water vapor is

$$
\mathrm{P}_{\mathrm{V}}=(\mathrm{RH} / 100)\left(\mathrm{P}_{\mathrm{g}}\right)=(0.5)(5.9926)=2.9963 \text { psia }
$$

The partial pressure of the air is

$$
\mathrm{P}-\mathrm{P}_{\mathrm{V}}=14.7-2.9963=11.7 \text { psia }
$$

Compressibility $\mathrm{Z}$ (air) at $\mathrm{T}=629.7^{\circ} \mathrm{R}$ and pressure $11.7 \mathrm{psia}$

$$
\mathrm{Z}=1.000
$$

When $\mathrm{RH} / 100<1.000$, the water vapor is superheated, and its properties are found in the tables for superheated steam. At $t=170^{\circ} \mathrm{F}$ and pressure $\mathrm{P}_{\mathrm{V}}=$ 2.9963 psia, the specific volume $v$ is found through interpolation:

$$
\begin{array}{lr}
\underline{\mathrm{P}, \text { psia }} & \mathrm{v}, \mathrm{ft}^{3} / \mathrm{lb} \\
2.9 & 128.81 \\
2.9963 & 124.66 \\
3.0 & 124.50
\end{array}
$$

(Reference 6 , table 3)

The density $\rho_{\mathrm{v}}$ is:

$$
\rho_{\mathrm{v}}=1 / \mathrm{v}=1 / 124.66=0.00802 \mathrm{Lb} / \mathrm{ft}^{3}
$$

Substituting the data above into equation (D-7):

$$
\mathrm{E}-5
$$




$$
\begin{aligned}
& \rho_{\mathrm{m}}=\frac{(2.6990)(11.70)}{(1.000)(629.7)}+0.00802, \text { or } \\
& \rho_{\mathrm{m}}=0.05817 \mathrm{lb} / \mathrm{ft}^{3}
\end{aligned}
$$

For dry air:

$$
\begin{aligned}
& \rho=\frac{(2.6990)(P)}{(Z T)}=\frac{(2.6990)(14.7)}{(1.000)(629.7)}=0.06301 \mathrm{lb} / \mathrm{ft}^{3} \\
& \rho_{\mathrm{n}} / \rho=0.05817 / 0.06301=0.923
\end{aligned}
$$

\begin{tabular}{|c|c|c|c|c|c|c|c|}
\hline $\begin{array}{c}\text { P } \\
\text { psia }\end{array}$ & RH/ 100 & $\begin{array}{c}\mathrm{P}_{\mathrm{V}} \\
\text { psia }\end{array}$ & $\begin{array}{c}\mathrm{Z} \\
---\end{array}$ & $\stackrel{\rho_{\mathrm{V}}}{1 \mathrm{~b} / \mathrm{ft}} 3$ & $\underset{1 \mathrm{~b} / \mathrm{ft}^{3}}{\rho_{\mathrm{In}}}$ & $\stackrel{\rho}{1 \mathrm{~b} / \mathrm{ft}^{3}}$ & $\begin{array}{l}\rho_{\mathrm{m}} / \rho \\
---\end{array}$ \\
\hline \multicolumn{8}{|c|}{$\mathrm{t}=80^{\circ} \mathrm{F}$} \\
\hline 100 & $\begin{array}{l}0.0 \\
0.5 \\
1.0\end{array}$ & $\begin{array}{r}0.0 \\
.2534 \\
.5068\end{array}$ & $\begin{array}{r}0.998 \\
.998 \\
.998\end{array}$ & $\begin{array}{l}0.0 \\
.00079 \\
.00158\end{array}$ & $\begin{array}{r}0.5011 \\
.5006 \\
.5001\end{array}$ & $\begin{array}{c}0.5011 \\
-- \\
--\end{array}$ & $\begin{array}{l}1.000 \\
0.999 \\
0.998\end{array}$ \\
\hline 50 & $\begin{array}{l}0.0 \\
0.5 \\
1.0\end{array}$ & $\begin{array}{r}0.0 \\
.2534 \\
.5068\end{array}$ & $\begin{array}{l}.999 \\
.999 \\
.999\end{array}$ & $\begin{array}{l}0.0 \\
.00079 \\
.00158\end{array}$ & $\begin{array}{l}.2503 \\
.2498 \\
.2493\end{array}$ & $\begin{array}{l}.2503 \\
-- \\
--\end{array}$ & $\begin{array}{l}1.000 \\
0.998 \\
0.996\end{array}$ \\
\hline 14.7 & $\begin{array}{l}0.0 \\
0.5 \\
1.0\end{array}$ & $\begin{array}{r}0.0 \\
.2534 \\
.5068\end{array}$ & $\begin{array}{l}.9997 \\
.9997 \\
.9997\end{array}$ & $\begin{array}{l}0.0 \\
.00079 \\
.00158\end{array}$ & $\begin{array}{r}.07354 \\
.07306 \\
.07256\end{array}$ & $\begin{array}{l}.07354 \\
-- \\
-\end{array}$ & $\begin{array}{l}1.000 \\
0.993 \\
0.987\end{array}$ \\
\hline \multicolumn{8}{|c|}{$\mathrm{t}=170^{\circ} \mathrm{F}$} \\
\hline 100 & $\begin{array}{l}0.0 \\
0.5 \\
1.0\end{array}$ & $\begin{array}{l}0.0 \\
2.9963 \\
5.9926\end{array}$ & $\begin{array}{l}1.0002 \\
1.0002 \\
1.0002\end{array}$ & $\begin{array}{l}0.0 \\
.00802 \\
.01611\end{array}$ & $\begin{array}{r}0.4286 \\
.4237 \\
.4190\end{array}$ & $\begin{array}{c}0.4286 \\
-- \\
--\end{array}$ & $\begin{array}{l}1.000 \\
0.989 \\
0.978\end{array}$ \\
\hline 50 & $\begin{array}{l}0.0 \\
0.5 \\
1.0\end{array}$ & $\begin{array}{l}0.0 \\
2.9963 \\
5.9926\end{array}$ & $\begin{array}{l}1.0001 \\
1.0001 \\
1.0001\end{array}$ & $\begin{array}{l}0.0 \\
.00802 \\
.01611\end{array}$ & $\begin{array}{l}.2143 \\
.2095 \\
.2047\end{array}$ & $\begin{array}{l}.2143 \\
-- \\
--\end{array}$ & $\begin{array}{l}1.000 \\
0.978 \\
0.955\end{array}$ \\
\hline 14.7 & $\begin{array}{l}0.0 \\
0.5 \\
1.0\end{array}$ & $\begin{array}{l}0.0 \\
2.9963 \\
5.9926\end{array}$ & $\begin{array}{l}1.0000 \\
1.0000 \\
1.0000\end{array}$ & $\begin{array}{l}0.0 \\
.00802 \\
0.1611\end{array}$ & $\begin{array}{r}0.06301 \\
.05818 \\
.05343\end{array}$ & $\begin{array}{c}0.06301 \\
-- \\
--\end{array}$ & $\begin{array}{l}1.000 \\
0.923 \\
0.848\end{array}$ \\
\hline
\end{tabular}

The following table sumarizes the remaining calculations:

'lable E.1. Moist Air Data 
The previous table may be helpful in deciding when a correction for the density of moist air is needed. The data show, for example, with ambient temperature $\left(t=80^{\circ} \mathrm{F}\right)$ and ambient pressure and higher $(\mathrm{P}=14.7$ to $100 \mathrm{psia})$, that the correction would never exceed about 1 percent, and may often be ignored. On the other hand, when temperatures are higher, the partial. pressure of the water vapor becomes more significant and the density $\rho_{m}$ may be quite different from that of dry air. For example, at 50 psia with saturated air, this difference amounts to about 4.5 percent $\left(\rho_{\mathrm{m}} / \rho=0.955\right)$.

Example E.5 Direct Calibration of an Orifice Metex on Site with a Gravimetric Calibrator. An orifice meter with flange taps and diameter $d=1.200$ in. is mounted in a 2-inch pipe and monitors the flow of water. It is desired to calibrate the meter over a flow range of 10,000 to $20,0001 \mathrm{~b} / \mathrm{hr}$ using a direct calibration method with static weigh operation as shown in figure 8 . Five repeat runs will be taken at four flowrates in the above range. The meter $\Delta \mathrm{P}$ will be measured by means of a vertical water manometer. Local acceleration due to gravity is $32.145 \mathrm{ft} / \mathrm{s}^{2}$. Following are the measurements made:

\begin{tabular}{|c|c|c|}
\hline Measurement & Instrument & Reading \\
\hline Barometric pressure & $\begin{array}{l}\text { Aneroid barometer, in. } \mathrm{Hg} \\
\text { at } 32{ }^{\circ} \mathrm{F}\end{array}$ & $30.41 \mathrm{in} . \mathrm{Hg}$ at $32{ }^{\circ} \mathrm{F}$ \\
\hline $\begin{array}{l}\text { Inlet water } \\
\text { pressure }\end{array}$ & $\begin{array}{l}\text { Bourdon tube gauge, case } \\
\text { vented to atmosphere, psig }\end{array}$ & $59.0 \mathrm{psig}$ \\
\hline $\begin{array}{l}\text { Inlet water } \\
\text { temperature }\end{array}$ & Mercury thermometer, ${ }^{\circ} \mathrm{F}$ & See data below \\
\hline $\begin{array}{l}\text { Manometer } \\
\text { temperature }\end{array}$ & Mercury thermometer, ${ }^{\circ} \mathrm{F}$ & See data \\
\hline $\begin{array}{l}\text { Meter pressure } \\
\text { differential, h }\end{array}$ & $\begin{array}{l}\text { Water manometer, inverted, } \\
\text { air in the low pressure } \\
\text { leg at } 59.0 \text { psig; inches } \\
\text { of water at manometer } \\
\text { temperature }\end{array}$ & See data \\
\hline Weigh time & $\begin{array}{l}\text { Electronic timer, } 5 \text { digits, } \\
\text { start/stop actuated thru } \\
\text { switch connected to } \\
\text { diverter valve }\end{array}$ & See data \\
\hline Mass of water & $\begin{array}{l}\text { Beam type scale, } 10001 b \\
\text { capacity }\end{array}$ & See data \\
\hline
\end{tabular}

The following data were collected during five repeat runs at four flowrates. Flowrate was adjusted as necessary through the flow control valve to maintain $\mathrm{h}$ within \pm 0.10 inch of water. The manometer temperature was measured with a thermometer attached, sensing ambient air. The indicated flowrate is net mass/time, designated $M^{\prime}$. 
Table F.2. Sample Data Eor Calibration of an Orifice Meter

\begin{tabular}{|c|c|c|c|c|c|c|c|c|c|}
\hline \multicolumn{5}{|c|}{ Temperature } & \multicolumn{3}{|c|}{ Mass } & \multirow{2}{*}{$\begin{array}{c}\text { Flow } \\
M^{\prime} \\
1 \mathrm{~b} / \mathrm{s}\end{array}$} & \\
\hline${ }^{\mathrm{Man}} \mathrm{F}$ & $\begin{array}{l}\text { Water } \\
{ }^{\circ} \mathrm{F}\end{array}$ & & $\begin{array}{c}\mathrm{h} \\
\mathrm{i} n \cdot \mathrm{H}_{2} \mathrm{O}\end{array}$ & $\begin{array}{c}\text { Tine } \\
\mathrm{s}\end{array}$ & $\begin{array}{c}\text { Tare } \\
\text { lb }\end{array}$ & $\begin{array}{c}\text { Gross } \\
1 b\end{array}$ & $\begin{array}{l}\mathrm{Net} \\
\mathrm{Lb}\end{array}$ & & \\
\hline 80.0 & 82.3 & & $\begin{array}{r}64.00 \\
+\quad .10\end{array}$ & $\begin{array}{l}77.799 \\
80.843 \\
72.008 \\
74.238 \\
70.805\end{array}$ & $\begin{array}{l}162.3 \\
139.3 \\
140.9 \\
191.1 \\
175.6\end{array}$ & $\begin{array}{l}615.4 \\
609.0 \\
562.0 \\
624.5 \\
590.8\end{array}$ & $\begin{array}{l}453.1 \\
469.7 \\
421.1 \\
433.4 \\
415.2\end{array}$ & $\begin{array}{l}5.824 \\
5.810 \\
5.848 \\
5.838 \\
5.864 \\
5.837\end{array}$ & Avg \\
\hline $80 \cdot 3$ & 83.0 & & $\begin{array}{r}46.00 \\
\pm .10\end{array}$ & $\begin{array}{l}77.225 \\
67.376 \\
70.264 \\
71.919 \\
72.546\end{array}$ & $\begin{array}{l}179.3 \\
155.6 \\
166.8 \\
156.5 \\
138.2\end{array}$ & $\begin{array}{l}561.1 \\
490.8 \\
513.2 \\
512.5 \\
498.1\end{array}$ & $\begin{array}{l}381.8 \\
335.2 \\
346.4 \\
356.0 \\
359.9\end{array}$ & $\begin{array}{l}4.944 \\
4.975 \\
4.930 \\
4.950 \\
4.961 \\
4.952\end{array}$ & Avg \\
\hline 80.0 & 83.3 & & $\begin{array}{r}30.00 \\
\pm \quad .10\end{array}$ & $\begin{array}{l}84.837 \\
97.446 \\
95.675 \\
75.927 \\
83.579\end{array}$ & $\begin{array}{l}173.0 \\
185.1 \\
188.5 \\
155.2 \\
206.8\end{array}$ & $\begin{array}{l}514.3 \\
574.2 \\
571.2 \\
460.2 \\
541.7\end{array}$ & $\begin{array}{l}341.3 \\
389.1 \\
382.7 \\
305.0 \\
334.9\end{array}$ & $\begin{array}{l}4.023 \\
3.993 \\
4.000 \\
4.017 \\
4.007 \\
4.008\end{array}$ & Avg \\
\hline$\frac{80 \cdot 2}{80 \cdot 0}$ & $\frac{83.6}{83.0}$ & $\mathrm{Avg}$ & $\begin{array}{r}16.00 \\
\pm \quad .10\end{array}$ & $\begin{array}{l}103.55 \\
119.06 \\
107.88 \\
129.62 \\
104.29\end{array}$ & $\begin{array}{l}188.6 \\
183.6 \\
162.4 \\
194.2 \\
199.0\end{array}$ & $\begin{array}{l}491.7 \\
534.6 \\
478.7 \\
573.6 \\
505.2\end{array}$ & $\begin{array}{l}303.1 \\
351.0 \\
316.3 \\
379.4 \\
306.2\end{array}$ & $\begin{array}{l}2.927 \\
2.948 \\
2.932 \\
2.927 \\
2.936 \\
2.934\end{array}$ & Avg \\
\hline
\end{tabular}

Calibration results are to be expressed in terms of the discharge coefficient $C$, as a function of the pipe Reynolds Number $R_{D}$, where $C$ will be determined for each flowrate from equation (2-1):

$$
M=358.93\left(C Y d^{2} F_{a}\right)\left[\left(\rho h_{W}\right) /\left(1-\beta^{4}\right)\right]^{1 / 2} 1 b / h r
$$

Fluid expansion factor $Y=1.000$ since a liquid is flowing.

Orifice thermal expansion $\mathrm{F}_{\mathrm{a}}=1.000$ since the average water

(Figure B.2) temperature is $83^{\circ} \mathrm{F}$.

For 2 -inch pipe, $D=2.067$ inches (schedule 40 ). Thus $B=d / D=1.200 / 2.067=$ 0.5806 . 
At $t=83.0^{\circ} \mathrm{F}$ and $\mathrm{p}=59.0 \mathrm{psig}$, the water is only slightly compressed and density $\rho$ may be assumed equal to that at saturation temperature with negligible error (0.02 percent). Therefore, $\rho=62.191 \mathrm{lb} / \mathrm{ft}^{3}$. (Table B.1)

Since the water was weighed in air, the indicated mass flowrate $M^{\prime}$ needs a correction for the air buoyancy. A nominal yalue for air density will suffice for this correction. Let $\rho_{\text {air }}=0.0751 \mathrm{~b} / \mathrm{ft}^{3}$.

$$
\text { Buoyancy Correction }=1+\left(\rho_{\text {air }} / \rho_{W}\right)=1+(0.075 / 62.191)=1.0012 \text {, and }
$$

$$
M=1.0012(3600)\left(M^{\prime}\right)
$$

where $M^{\prime}$ has units $1 \mathrm{~b} / \mathrm{s}$.

Before calculating $\mathrm{C}$, the meter pressure differential $\mathrm{h}$ ( $h$ is in in. of $\mathrm{H}_{2} \mathrm{O}$ at the manometer temperature) needs correction to account for the local. acceleration due to gravity $\left(F_{g}\right)$, the air in the low pressure leg $\left(F_{w 2}\right)$, and the water manometer temperature of $80^{\circ} \mathrm{F}\left(\mathrm{F}_{\mathrm{Wl}}\right)$. These corrections are explained in appendix C. Using table C.l and equation ( $C-8)$ :

$$
h_{\mathrm{w}}=(27.729)(\mathrm{h})\left[\left(\mathrm{F}_{\mathrm{w} 1}\right)\left(\mathrm{F}_{\mathrm{w} 2}\right)\left(\mathrm{F}_{\mathrm{g}}\right)\right]
$$

(Table C.1), ( C-8)

At $t=80^{\circ} \mathrm{F}$

$$
\mathrm{F}_{\mathrm{w} 1}=0.036005 \mathrm{psi} / \mathrm{inch} \text { of water. }
$$

(Figure C.1)

At $p=59.0 \mathrm{psig}$

$$
\begin{array}{rlr}
\mathrm{P} & =59.0+(0.49116)(30.41)=73.94 \mathrm{psia}, \text { and } & \text { (Table C.l), }(\mathrm{C}-6) \\
\mathrm{F}_{\mathrm{w} 2} & =0.9940 \\
\text { with } \mathrm{g}_{\mathrm{L}} & =32.145 \mathrm{ft} / \mathrm{s}^{2} \\
\mathrm{~F}_{\mathrm{g}} & =\mathrm{g}_{\mathrm{L}} / 32.1740=0.9991 . & \text { (Figure C.3) }
\end{array}
$$

Thus, at a water temperature of $68^{\circ} \mathrm{F}$ :

$$
\begin{aligned}
& \mathrm{h}_{\mathrm{w}}=27.729(0.036005)(0.994)(0.9991)(\mathrm{h}) \text {, or } \\
& \mathrm{h}_{\mathrm{w}}=0.9915(\mathrm{~h})
\end{aligned}
$$

Substituting equations (E5-1) and (E5-2) into equation (2-1), and solving for C:

$$
C=\left(\frac{(1.0012)\left(M^{\prime}\right)(3600)}{(358.93)\left(d^{2}\right)}\right)\left(\frac{\left(1-\beta^{4}\right)}{(p)(0.9915)(h)}\right)^{1 / 2}
$$

Substituting above data for $\rho, \beta$, and $d$, this becones:

$$
C=0.83608\left(\mathrm{M}^{\prime}\right) /(\mathrm{h})^{1 / 2}
$$


where $M^{\prime}$ has units $1 \mathrm{~b} / \mathrm{s}$ and $\mathrm{h}$ has units inches of water. Next, the quantity pipe Reynolds Number $R_{D}$ needs calculation.

$$
R_{D}=\frac{(D V p)}{\mu}
$$

where $D$ = pipe inside diameter

$\mathrm{V}=$ average velocity

$0=$ density of the water

$\mu=$ dynamic viscosity

Since $M=(p A V)$, where cross sectional area $A=\pi D^{2} / 4, R_{D}$ can be written, after substituting for $V$ :

$$
\begin{aligned}
& R_{D}=\frac{D(M / p A) p}{\mu}=\frac{(D M)}{\left(\mu \pi D^{2}\right) / 4} \text {, or } \\
& R_{D}=4(M) /\left(\begin{array}{lll}
\mu & \pi & D
\end{array}\right)
\end{aligned}
$$

$R_{D}$ is dimensionless, thus $(\mathrm{E} 5-4)$ becomes

$$
\begin{aligned}
& R_{D}=\frac{4 M}{(3600 \mu) \pi(D / 12)} \text {, or } \\
& R_{D}=0.004244(M) /(\mu D)
\end{aligned}
$$

where 1 has units of $1 \mathrm{~b} / \mathrm{hr}, \mu$ has units of $1 \mathrm{~b} /(\mathrm{ft} \cdot \mathrm{s})$, and $\mathrm{D}$ has units of inches. At a water temperature of $83^{\circ} \mathrm{F}, \mu=0.56 \times 10^{-3} 1 \mathrm{~b} /(\mathrm{ft} \cdot \mathrm{s})$.

(Figure B-3)

From the data collected and equations (E5-3) and (E5-5), the following final results are tabulated:

\begin{tabular}{cccccc}
$\begin{array}{c}\mathrm{h} \\
\text { in. } \mathrm{H}_{2} \mathrm{O}\end{array}$ & $\mathrm{M}^{\prime}$ & $\mathrm{M}$ & $\mathrm{R}_{\mathrm{D}}$ & $\mathrm{C}$ & $\mathrm{M} /(\mathrm{h})^{\mathrm{I} / 2}$ \\
$\underline{\mathrm{at} 80^{\circ} \mathrm{F}}$ & $\underline{1 \mathrm{~b} / \mathrm{s}}$ & $\underline{1 \mathrm{~b} / \mathrm{hr}}$ & $-\ldots$ & $-\cdots$ & $\underline{\text { 1b/hr(in.) }}$ \\
\hline 64.00 & 5.837 & 21038 & 77130 & 0.6100 & 2630 \\
46.00 & 4.952 & 17849 & 65450 & .6104 & 2632 \\
30.00 & 4.008 & 14446 & 52960 & .6118 & 2637 \\
16.00 & 2.934 & 10575 & 38770 & .6132 & 2644
\end{tabular}

Thus, this orifice meter has been "calibrated". Its performance has been demonstrated and is known through the discharge coefficient $C$ as determined from direct physical measirements. With such an on-site calibration using a static weigh procedure, quite accurate results for $C$ are possible, comparable to those produced routinely by primary calibration laboratories, about 0.2 percent uncertainty. 
When this orifice neter is in service, the above data may be used in several ways. With the discharge coefficient being known as a function of Reynolds nunber, the orifice could be used in different fluids within the above range of $R_{D}$. Since in this case, the discharge coefficient $C$ varied only through a snall range of about 0.5 percent (Erora 0.6100 to 0.6132 ), an average value of $c=$ 0.6114 could be utilized and the flowrate il determined directly from equation (2-1). If nigher accuracy is desired, an iterative procedure is needed since $R_{D}$ is never known initially: Using $C=0.61$, one would calculate 1 tron equation ( $2-1$ ); then calculate $R_{D}$ fron equation (E5-4), then determine $C$ exactly from the data above (by plotting $C$ vs. $R_{p}$ and interpolating at the neasured value of $\mathrm{R}_{\mathrm{D}}$ ); and finally calculate 1 from equation $(2-1)$. When the neter is calibrated with water at or near $83^{\circ} \mathrm{F}$, one could plot the quantity $\mathrm{M} /(\mathrm{h})^{1 / 2}$ as a function of $\mathrm{h}$ and calculate il directly. In this latter case, some variation in water temperature in the pipe and in the nanoneter can be tolerated with a small sacrifice in accuracy. For example, when temperature $t$ varies within a range of $+10^{\circ} \mathrm{F}$ and pressure $\mathrm{p}$ varies within +10 psi, the "worst case" effect on $M$ would be about to.2 percent, explained as follows: from figure C.1, $\mathrm{F}_{\mathrm{Wl}}$ varies about -0.17 percent $/ 10^{\circ} \mathrm{F}$ at $80^{\circ} \mathrm{F}$ as does the density $\rho$ of water from table i.1. Fron figure C.3, $F_{w 2}$ varies -0.08 percent/10 psi. The worse case occurs when $t$ and $p$ both increase (or both decrease) together. In equation (2-1), accounting for effects of $t$ on $\rho$, and $t$ and $p$ on $\mathrm{h}_{\mathrm{W}}$, the absolute value of the error becones $(1 / 2)(0.17+0.17+0.08)=0.2$ percent for a change of $+10^{\circ} \mathrm{F}$ and $+10 \mathrm{psi}$ ( or $-10^{\circ} \mathrm{F}$ and $-10 \mathrm{psi}$ ). The "1/2" factor comes from the exponential $1 / 2$ in equation (2-1) and differential calculus. The change in $C$ (through temperature effects on $\rho$ and $\mu$ in $R_{D}$ ) is negligible. Thus, under limited conditions, accurate measurements of $M$ can be nade directly from $h$.

Exanple E.6. Calibration of an Orifice Meter on Site Using The Transfer lieter Method. A stainless steel orifice meter with corner pressure taps and $=$ $\overline{3.750}$ inches is mounted in a 6 -inch pipe flowing chilled water. A differential pressure transducer system calibrated to read out in incines of water at $68^{\circ} \mathrm{F}$ neasures the orifice meter $\Delta \mathrm{H}$. It is desired to calibrate the orifice neter using a transfer reference meter system located downstrean, as shown in figure 5. The transfer meter is a stainless steel nozzle venturi with a throat diameter of $d=4.030$ inches and a coefficient of discharge $C=0.9512$ as deternined by calibration on water at $65^{\circ} \mathrm{F}$ at a primary calibration facility. This calibration was on water at $65^{\circ} \mathrm{F}$ covering a range $1.5 \times 10^{5} \leq \mathrm{R}_{\mathrm{D}} \leq 1 \times 10^{6}$. A mercury manometer is used to measure the nozzle venturi $\Delta \mathrm{P}$. Local acceleration due to gravity is $32.172 \mathrm{ft} / \mathrm{s}^{2}$.

The following represent average values of data taken from 5 repeat observations at a single flowrate: 
Chilled water

temperature

Water pressure

Working meter (orifice)

pressure differential $h_{W}$

Transfer meter (nozzle

venturi), pressure

differential, h

Manometer temperature
Dial type thermometer, ${ }^{\circ} \mathrm{F}$

Bourdon tube gauge, psig

Pressure transducer system inches of water at $68^{\circ} \mathrm{F}$

Mercury manometer, inches of mercury, water in high pressure leg

Mercury thermometer, ${ }^{\circ} \mathrm{F}$ $42.0^{\circ} \mathrm{F}$

85.3 psig

320.32 in. $\mathrm{H}_{2}$ ? at $68^{\circ} \mathrm{F}$

7.26 in. $\mathrm{Hg}$ at $78.0^{\circ} \mathrm{F}$

$78.0^{\circ} \mathrm{F}$

Calculations for the nozzle venturi meter:

$$
\begin{aligned}
& \mathrm{C}=0.9512 \\
& \mathrm{~d}=4.030 \text { inches } \\
& \mathrm{D}=6.065 \text { inches }(6 \text {-inch pipe, schedule } 40) \\
& \mathrm{B}=\mathrm{d} / \mathrm{D}=0.6645 \\
& \rho=62.4431 \mathrm{~b} / \mathrm{ft}^{3}\left(\mathrm{at} 42.0^{\circ} \mathrm{F} \text { and } 100\right. \text { psia) } \\
& \mathrm{Y}=1.000(1 \mathrm{iquid}) \\
& \mathrm{F}_{\mathrm{a}}=0.9995 \text { at } 42^{\circ} \mathrm{F}(300 \text { Series Stainless Steel) }
\end{aligned}
$$

Obtain $h_{w}$, inches of water at $68^{\circ} \mathrm{F}$, for the nozzle meter as follows:

$$
\begin{aligned}
\mathrm{h}_{\mathrm{W}} & =27.729(\mathrm{psi}) \\
\mathrm{h}_{\mathrm{W}} & \left.=27.729 \text { (inches of } \mathrm{Hg} \text { at } 78^{\circ} \mathrm{F}\right)\left(\mathrm{F}_{\mathrm{ml}} \mathrm{F}_{\mathrm{m} 3} \mathrm{~F}_{\mathrm{g}}\right) \\
\mathrm{F}_{\mathrm{m} l} & =0.48892 \mathrm{psi} / \mathrm{in} . \mathrm{Hg} \text { at } 78^{\circ} \mathrm{F} \\
\mathrm{F}_{\mathrm{m} 3} & =0.9263 \\
\mathrm{~F}_{\mathrm{g}} & =\mathrm{g}_{\mathrm{L}} / 32.1740=32.172 / 32.1740=0.99994 \text { (neglect) } \\
\mathrm{h}_{\mathrm{W}} & =(27.729)(7.26)(0.48892)(0.9263), \text { or } \\
\mathrm{h}_{\mathrm{W}} & =91.17 \text { inches of water at } 68^{\circ} \mathrm{F}
\end{aligned}
$$

(Table C.1)

(Figure C.2)

(Appendix C) 
Next, calculate the flowrate $M$;

$$
\begin{aligned}
M & =358.93\left(C Y d^{2} F_{a}\right)\left[\rho h_{w} /\left(1-\beta^{4}\right)\right]^{1 / 2} \\
& =358.93(0.9512)(1.000)(4.030)^{2}(0.9995)\left(\frac{(62.443)(91.17)}{1-(0.6645) 4}\right)^{1 / 2} \text {, or } \\
M & =466,1001 \mathrm{~b} / \mathrm{hr}
\end{aligned}
$$

The pipe Reynolds Number $R_{D}$ is also needed.

$$
\begin{aligned}
R_{D} & =0.004244(M) /(\mu D) \\
\mu & =1.00 \times 10^{-3} 1 \mathrm{~b} /(\mathrm{ft} \cdot \mathrm{s}) \text { at } 42^{\circ} \mathrm{F} \\
R_{D} & =0.004244(466,100) /\left(1.00 \times 10^{-3}\right)(6.065) \text {, or } \\
R_{D} & =326,000 .
\end{aligned}
$$

The calculation for the transfer meter is complete. The reference flowrate $M$ is $466,100 \mathrm{lb} / \mathrm{hr}$. The pipe Reynolds Number is 326,000 which lies within the range of calibration for the nozzle venturi meter.

Calculation for the orifice meter:

$$
\begin{aligned}
\mathrm{Y} & =1.000 \\
\mathrm{~d} & =3.750 \text { inches } \\
\mathrm{B} & =\mathrm{d} / \mathrm{D}=3.750 / 6.065=0.6183 \\
\mathrm{~F}_{\mathrm{a}} & =0.9995 \text { at } 42^{\circ} \mathrm{F}(300 \text { Series SS }) \\
\rho & =62.443 \mathrm{1b} / \mathrm{ft}^{3} \\
\mathrm{M} & =466,100 \mathrm{1b} / \mathrm{hr} \\
\mathrm{h}_{\mathrm{W}} & =320.32 \mathrm{in} . \text { of water at } 68^{\circ} \mathrm{F}
\end{aligned}
$$

Solving for the discharge coefficient $C$ in equation (2-1)

$$
\begin{aligned}
C & =\left[\frac{M}{(358.93)(Y)\left(d^{2}\right)\left(F_{a}\right)}\right]\left[\frac{\left(1-\beta^{4}\right)}{\left(\rho h_{w}\right)}\right]^{1 / 2} \\
& =\left[\frac{466,100}{(358.93)(1.000)(3.750)^{2}(0.9995)}\right]\left[\frac{1-(0.6183)^{4}}{(62.443)(320.32)}\right]^{1 / 2}, \text { or } \\
C & =0.6036
\end{aligned}
$$


Therefore, the coefficient of discharge C for the orifice (working) meter is 0.6036 at $\mathrm{R}_{\mathrm{D}}=326,000$.

In particular, it may be noted:

1. The calibration is usually conducted at several flowrates which correspond to building service conditions. Thus, a set of values of $C$ vS. $\mathrm{R}_{\mathrm{D}}$, would be obtained. With an installation conforming to good metering practice, the data for $\mathrm{C}$ should be in good agreement with the discharge coefficient data given for corner taps in appendix A.

2. Once a particular meter has been calibrated, i.e., discharge coefficient $C$ established as a function of $R_{D}$, it may be used in different fluids within its calibrated range of $R_{D}$. Since $C$ changes very slowly with $R_{D}$ when $R_{D}>10^{5}$, a single value can be used for $C$ with small error, usually not exceeding 0.2 to 0.3 percent, when flowing a given fluid over a flow range not exceeding, say, $2: 1$. When the flow range is larger, or when maximum accuracy is needed, $C$ should be plotted as function of $R_{D}$ and an iteration approach used to determine $C$. (See discussion at the end of example E.5.)

3. The coefficient of discharge $C$ for the transfer meter system applies only to a designated range of $\mathrm{R}_{\mathrm{D}}$, as determined from calibration at an independent facility. Thus, use of the transfer meter outside its calibrated range as expressed in terms of $R_{D}$ should be avoided.

Example E.7 On-Site Calibration of a Positive Displacement Meter Using The Transfer Meter Method. A positive displacement meter monitors the flow of water at $150^{\circ} \mathrm{F}$ and $100 \mathrm{psig}$. It is to be calibrated on site at nominal 20 GPM using an orifice meter as the transfer reference installed downstream of the PD meter as shown in figure 5. The orifice meter has been calibrated with water with results given in previous example E.5 and plotted here in figure E.1. Salient features of the PD meter and associated electronics equipment are:

Size: $\quad$ 2-inch

Type: $\quad$ rotary piston

Output: $\quad 1$ pulse per 0.15 gallon, nominal

Rating: $\quad 200$ psig and $300^{\circ} \mathrm{F}$

Installation: The PD meter is mounted in a horizontal 2-inch pipe, insulated, with 75 diameters of straight pipe upstream, 5D downstream, no flow straightener

The orifice meter has the following features:

Size: $\quad$ Diameter $d=1.200$ inches mounted in a 2-inch pipe $(\mathrm{D}=2.067$ inches $), B=0.5806$ 


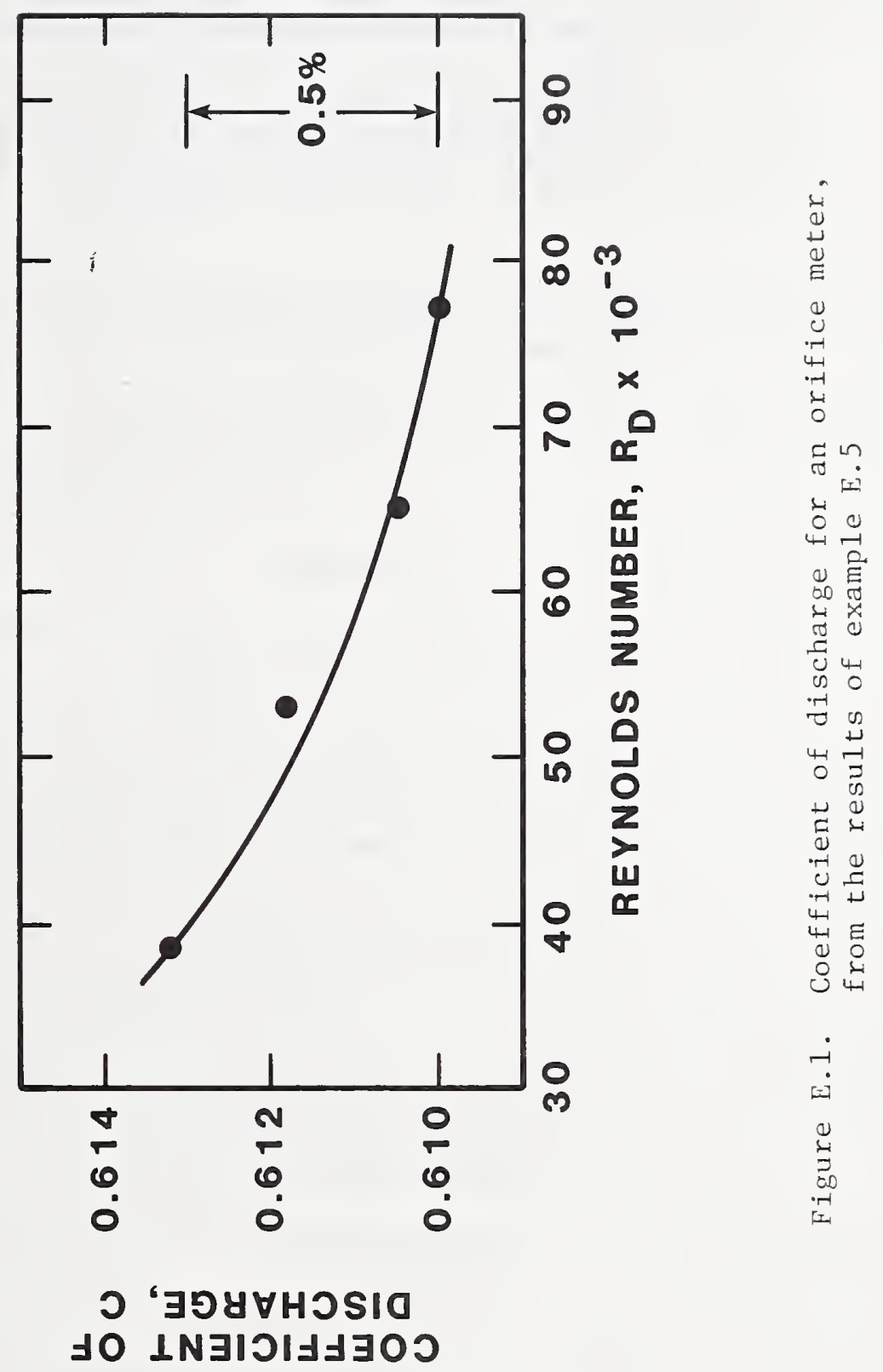


Calibration: On water at $83^{\circ} \mathrm{F}$, using a gravimetric calibrator, with $\Delta \mathrm{P}$ measured by a vertical water manometer. (See example E.5).

Installation: The orifice metering section is installed in a horizontal position downstream of the PD meter as shown in figure 5, with a flow straightener and with the metering section insulated. Temperature and pressure taps are installed at the exit. The differential pressure taps, including the reservoirs are insulated. The sensing lines to the manometer are bare, and installed adjacent to each other. The $\Delta \mathrm{P}$ is measured by the vertical water manometer.

The time for a preselected number of PD pulses is measured. From the flowrate as measured by the orifice meter, the calibration constant $K$ for the PD meter, gallons per pulse, can be determined for the flowrate of interest.

The following are the measurements made where "Reading" data are the average of 5 repeat runs. The local acceleration due to gravity is $32.10 \mathrm{ft} / \mathrm{s}^{2}$.

Measurement

Exit water pressure

Exit water temperature

Manometer temperature

Orifice meter $\Delta \mathrm{P}$

PD meter, test time
Instrument

Bourdon tube gauge, case vented to atmosphere, psig

Dial type thermometer with bulb and capillary, ${ }^{\circ} \mathrm{F}$

Mercury thermometer, ${ }^{\circ} \mathrm{F}$

Water manometer, inverted, air in the low pressure leg at 102 psig, inches of water

Electronic preset counter/ timer, timer start/stop activated to time period for 150 meter pulses, preset
Reading

102.0 psig

$152.0^{\circ} \mathrm{F}$

$72.0^{\circ} \mathrm{F}$

17.20 in. at $72^{\circ} \mathrm{F}$

63.150 seconds

The flowrate for the orifice is calculated from:

$$
Q=5.982\left(C Y d^{2} F_{a}\right)\left[h_{w} / \rho\left(1-\beta^{4}\right)\right]^{1 / 2}
$$

Quantities first needing evaluation are $C, F_{a}, h_{w}$, and $p$.

The (flowing) fluid properties $\rho$ and $v$ are as follows: At $152^{\circ} \mathrm{F}$ and $102 \mathrm{psig}$, the water is a compressed liquid. While the density is nearly that of saturated Liquid, interpolation of table B.1 data gives $p=61.172 \mathrm{lb} / \mathrm{ft}^{3}$. At $152^{\circ} \mathrm{F}$, the kinematic viscosity of water $v$ is $0.47 \times 10^{-5} \mathrm{ft}^{2} / \mathrm{s}$, from figure B. 3 . Thus, at $152^{\circ} \mathrm{F}$ : 


$$
\begin{aligned}
& \rho=61.1721 \mathrm{~b} / \mathrm{ft}^{3} \\
& v=0.47 \times 10^{-5} \mathrm{ft}^{2} / \mathrm{s}
\end{aligned}
$$

The coefficient of discharge $C$ is needed at pipe Reynolds Number $R_{D}$ for water at $152^{\circ} \mathrm{F}$. Estimate $R_{D}$ from the $\mathrm{PD}$ meter using the nominal output of 0.15 gallon/pulse as follows:

$$
\begin{aligned}
Q & =\frac{(150)(0.15)}{(63.150)(7.4805)},\left[\frac{\text { pulses }}{\mathrm{s}}\right] \quad\left[\frac{\text { gallon }}{\text { pulse }}\right] \quad\left[\frac{\mathrm{ft}^{3}}{\text { gallon }}\right] \\
Q & =0.047 \mathrm{ft}^{3} / \mathrm{s} \\
R_{D} & =(D V \rho) / \mu=(D V) / \nu=4(Q) /(\pi D V)
\end{aligned}
$$

since $\nu=\mu / \rho$, and $V=Q / A=4(Q) /\left(\pi D^{2}\right)$. Thus

$$
\begin{aligned}
& R_{D}=\frac{(4)(0.047)}{\pi(2 / 12)\left(0.47 \times 10^{-5}\right)} \\
& R_{D}=76,000 \text { estimated }
\end{aligned}
$$

From figure E.l, $\mathrm{C}=0.6100$ at $\mathrm{R}_{\mathrm{D}}=76,000$

Since the fluid is incompressible, $Y=1.000$.

With the orifice plate at the fluid temperature, $152^{\circ} \mathrm{F}$, a small correction for the expansion of the plate can be made through $\mathrm{F}_{\mathrm{a}}$. The orifice plate material is 300 Series SS (stainless steel). From figure B.2:

$$
\mathrm{F}_{\mathrm{a}}=1.0015
$$

The orifice $\Delta P$ manometer reading in inches of water needs correction to $68{ }^{\circ} \mathrm{F}$. The manometer temperature is $72^{\circ} \mathrm{F}$.

$$
\begin{array}{rlrl}
\mathrm{h}_{\mathrm{W}} & =(\text { inches of water })\left(\rho / \rho_{68}\right)\left(\mathrm{F}_{\mathrm{w} 2} \mathrm{~F}_{\mathrm{g}}\right) & & (\mathrm{C}-1 \mathrm{l}) \\
& =(17.20)(62.2902 / 62.3205)(0.9903)(0.9977), \text { or } & \\
\mathrm{h}_{\mathrm{W}} & =16.986 \text { inches of water, where } & \\
\rho & =62.2902 \mathrm{lb} / \mathrm{ft}^{3}\left(\text { at } 72^{\circ} \mathrm{F}\right) & & \text { (Table B.1) } \\
\rho_{68} & =62.3205 \mathrm{Lb} / \mathrm{ft}^{3}\left(\text { at } 68^{\circ} \mathrm{F}\right) & & \text { (Table B.1) } \\
\mathrm{F}_{\mathrm{W} 2} & =0.9903 \text { (at } 102+14.7=117 \text { psia) } & & \text { (Figure C.3) }
\end{array}
$$

and with $\mathrm{g}_{\mathrm{L}}=32.10 \mathrm{ft} / \mathrm{s}^{2}$

$$
F_{g}=g_{L} / 32.1740=0.9977
$$


Inserting the above data into equation (2-2), the actual volumetric flowrate through the orifice is:

$$
\begin{aligned}
Q & =5.982(0.6100)(1.000)(1.200)^{2}(16.986)^{1 / 2} /\left[61.172\left(1-(0.5806)^{4}\right)\right]^{1 / 2} \\
& =2.941 \mathrm{ft}^{3} / \mathrm{min}, \text { or } \\
Q & =2.941(7.4805)=22.00 \mathrm{GPM}
\end{aligned}
$$

Next, recalculate $\mathrm{R}_{\mathrm{D}}$ and check $\mathrm{C}$ through $\mathrm{R}_{\mathrm{D}}$ :

$$
\mathrm{R}_{\mathrm{D}}=\frac{4(\mathrm{Q})}{(\pi \mathrm{D} v)}=\frac{4(2.941) / 60}{\pi(2 / 12)\left(0.47 \times 10^{-5}\right)}=80,000
$$

From figure E.1, the corresponding value of $\mathrm{C}$ for the orifice is 0.609 and, through equation (2-2), the flowrate $Q$ can be adjusted:

$$
Q=22.00(0.509 / 0.6100)=21.96 \mathrm{GPM}
$$

This completes the flow calculation for the orifice. Now, compute the calibration factor for the PD meter. Express $\mathrm{K}$ in units gallon/pulse.

$$
\begin{aligned}
& K=\frac{63.15(21.96)}{150(60)},\left[\frac{\text { seconds }}{\text { pulse }}\right] \quad\left[\frac{\text { gallons }}{\text { minute }}\right] \quad\left[\frac{\text { minutes }}{\text { seconds }}\right] \\
& K=0.1540 \text { gallon/pulse }
\end{aligned}
$$

Thus, the calibration factor for this meter is $\mathrm{K}=0.1540 \mathrm{gallon} / \mathrm{pulse}$ when water is flowing at or near $22 \mathrm{GPM}, 152^{\circ} \mathrm{F}$ and $100 \mathrm{psig}$. At other flowrates, temperatures, and for large changes in pressure, $\mathrm{K}$ could vary. With these conditions of $150^{\circ} \mathrm{F}$ and 100 psig, and with this orifice meter and manometer, thus PD meter could be calibrated at flowrates down to about 10 GPM, as limited by the orifice calibration for $C$ in the range $40,000<R_{D}<80,000$. However, in this case $h_{W} \approx 4.00$ inches of water; accurate measurement becomes increasing1y difficult at such a low $\triangle \mathrm{P}$. To calibrate the PD meter at flowrates greater than 20 GPM, the orifice would need additional calibration.

Example E.8 On-Site Calibration of a Vortex Shedding Meter Using the Transfer Meter Method. A vortex shedding meter monitors the flow of steam at $360^{\circ} \mathrm{F}$ and 45 psig. It is to be calibrated on site using a nozzle venturi meter as the transfer reference meter. The venturi meter is installed downstream of the vortex meter as shown in figure 5. The nozzle venturi meter has been previously calibrated using water as noted below. Salient features of the vortex meter and associated electronics are:

$$
\begin{array}{ll}
\text { Size: } & 6 \text {-inch } \\
\text { Output: } & 8 \text { pulses } / \mathrm{ft}^{3}, \text { nominal }
\end{array}
$$


Rating:

250 psig and $600^{\circ} \mathrm{F}$

Installation: The vortex meter is installed in a vertical 6-inch insulated pipe within a metering section as shown in figure 7 including a perforated plate flow straightener. (See figure 13.)

The nozzle venturi neter has the following features:

Size: Throat diameter $d=2.426$ inches. Meter mounted in a 6 -inch pipe, $\mathrm{D}=6.065$ inches, $B=0.400$.

Calibration: On water at $60^{\circ} \mathrm{F}, \mathrm{C}=0.9675$ for $\mathrm{R}_{\mathrm{D}}$ range $3 \times 10^{5}$ to $1 \times 10^{6}$

Installation: Mounted in a metering section with a flow straightener. Installed in a vertical pipe, downstream of the vortex meter as shown in figure 5, with the metering section insulated. A temperature tap is installed at the metering section inlet and the pressure taps are located at the venturi inlet $\left(P_{1}\right)$ and throat $\left(P_{2}\right)$. The sensing lines with drain and vent lines connect to a $\Delta P$ transducer system calibrated in inches of water at $68^{\circ} \mathrm{F}$.

Material: Bronze, 6 percent tin.

Pulses are counted from the vortex meter with an electronic counter for a preset gate time to accumulate at least, say, 5000 pulses. When the neter frequency is low resulting in excessive run time, a preset counter measuring a time period for a preset number of pulses may be used instead.

From the flowrate measured by the nozzle venturi meter, the calibration constant $\mathrm{K}$ for the vortex meter, $\mathrm{ft}^{3} /$ pulses, is calculated for the flowrate of interest.

Following are the measurements made where "reading" data are the averages of 5 repeat runs. 
Measurement

Barometric pressure $\mathrm{P}_{\mathrm{b}}$

Inlet nozzle venturi

pressure, $\mathrm{p}_{1}$

Inlet nozzle venturi

temperature, $t_{1}$

Nozzle venturi $\Delta P, h_{W}$

Vortex meter pulse count
Instrument

Aneroid barometer in. $\mathrm{Hg}$ at $32^{\circ} \mathrm{F}$

Bourdon tube gauge, psig

Thermocouple, ${ }^{\circ} \mathrm{F}$

Differential pressure transducer system, in. water at $68^{\circ} \mathrm{F}$

Electronic preset counter/tiner, pulses for a 45-second time interval, average of five runs $\underline{\text { Reading }}$

30.41 in. $\mathrm{Hg}$ at $32^{\circ} \mathrm{F}$

44.6 psig

$360^{\circ} \mathrm{F}$

$123.83 \mathrm{in}$. water at $68^{\circ} \mathrm{F}$

5478

The flowrate for the nozzle venturi meter is calculated from:

$$
Q=5.982\left(\mathrm{C} \mathrm{Y} \mathrm{d} \mathrm{F}_{\mathrm{a}}\right)\left[\mathrm{h}_{\mathrm{w}} / \rho\left(1-\mathrm{B}^{4}\right)\right]^{1 / 2} \mathrm{ft} \mathrm{t}^{3 / \mathrm{min}}
$$

Quantities needing evaluation are: $Y, F_{a}$ and $\rho$. First, evaluate density $\rho$ as follows. The inlet pressure and temperature at the nozzle venturi inlet are:

$$
\begin{aligned}
& \mathrm{P}_{1}=\left(\mathrm{p}_{1}+\mathrm{P}_{\mathrm{b}}\right)=44.6+(30.41)(0.49116)=59.54 \mathrm{psia} \quad(\text { Table C.1), (C-6) } \\
& \mathrm{t}_{1}=360^{\circ} \mathrm{F}
\end{aligned}
$$

Using steam tables, reference 6, table 3, and from interpolation, the specific volume $v_{1}$ at $360^{\circ} \mathrm{F}$ and $59.54 \mathrm{psia}$ is $7.989 \mathrm{ft}^{3} / 1 \mathrm{~b}$.

$$
p_{1}=1 / v_{1}=1 / 7.989=0.12521 \mathrm{~b} / \mathrm{ft}^{3}
$$

To evaluate the expansion factor $\mathrm{Y}$, first find $\mathrm{P}_{2} / \mathrm{P}_{1}$.

$$
\begin{aligned}
\Delta P & =\left(P_{1}-P_{2}\right)=\left(3.6063 \times 10^{-2}\right)\left(\text { in. water at } 68^{\circ} \mathrm{F}\right) \text { or } \quad(T a b l e ~ C .1) \\
\Delta P & =\left(3.6063 \times 10^{-2}\right)(123.33)=4.466 \text { psia } \\
P_{2} & =\left(P_{1}-\Delta P\right)=59.54-4.47=55.07 \text { psia, and } \\
P_{2} / P_{1} & =55.07 / 59.54=0.925=r
\end{aligned}
$$

The expansion factor $\mathrm{Y}$ is found from table A.16 or figure A.2. With $\mathrm{r}=0.925$, the specific heat ratio $\gamma=1.3$ for steam, and $\beta=0.400$, then with interpolation:

$$
Y=0.9544
$$

(Table A.16) 
With the nozzle venturi at a fluid temperature of $360^{\circ} \mathrm{F}$ and constructed of bronze, 6 percent tin:

$$
\mathrm{F}_{\mathrm{a}}=1.0056
$$

(Figure B.2)

The flowrate $Q$ can now be calculated. Reynolds number $R_{D}$ will be calculated later and compared to the $R_{D}$ range for $C$. In equation (2-2):

$$
\begin{aligned}
& Q=\frac{5.982(0.9675)(0.9544)(2.426)^{2}(1.0056)(123.83)^{1 / 2}}{\left[0.1252\left(1-0.400^{4}\right)\right]^{1 / 2}} \\
& Q=1042 \mathrm{ft}^{3 / \mathrm{min}} .
\end{aligned}
$$

Now check that $R_{D}$ falls within range of calibration for discharge coefficient C. For steam at $360^{\circ} \mathrm{F}$ and 59.54 psia:

$$
\begin{aligned}
\mu & =1.02 \times 10^{-5} 1 \mathrm{~b} / \mathrm{s} \mathrm{ft} \\
\rho & =0.12521 \mathrm{~b} / \mathrm{ft}^{3}, \text { and } \\
\nu & =\mu / \rho=8.147 \times 10^{-5} \mathrm{ft}^{2} / \mathrm{s} \\
R_{D} & =4(Q) /(\pi \mathrm{D} \quad v)=\frac{(4)(1042 / 60)}{(\pi)(6 / 12)\left(8.147 \times 10^{-5}\right)}=5.4 \times 10^{5}
\end{aligned}
$$

which conforms to the calibration range for $C\left(3 \times 10^{5} \leq R_{D} \leq 1 \times 10^{6}\right)$.

Finally, calculate the calibration constant $k$ for the vortex meter.

$$
\mathrm{K}=\operatorname{pulses} / \mathrm{ft}^{3}=\frac{(\mathrm{pulses} / \mathrm{min})}{(\mathrm{ft} / \mathrm{min})}
$$

From the vortex meter measurements:

$$
\begin{aligned}
& \mathrm{f}=5478 \text { pulses } / 45 \text { seconds }=121.73 \mathrm{~Hz} \text {, or } \\
& \mathrm{f}=121.73(60)=7304 \text { pulses } / \mathrm{min}
\end{aligned}
$$

From the nozzle venturi measurements:

$$
Q=1042 \mathrm{ft}^{3} / \mathrm{min}
$$

Thus:

$$
\mathrm{K}=7304 / 1042=7.010 \text { pulses } / \mathrm{ft}^{3}
$$

This value of $\mathrm{K}$ applies to one set of conditions: namely, steam temperature $360^{\circ} \mathrm{F}$ and steam pressure 45 psig at the vortex meter exit, and to a meter frequency of $122 \mathrm{~Hz}$. Normally, the meter would be calibrated over a range of flowrates, and with constant steam temperature and pressure, the calibration

$$
\text { E-2]. }
$$


constant $K$ would be plotted as a function of frequency, $f$. When the steam temperature and/or pressure vary, $K$ would be plotted as a function of $f / v$ to account for variation of viscosity $\nu$ with temperature and pressure. See figure 18, for example. Since the vortex meter has no moving parts, its performance can be predicted through the $\mathrm{f} / \mathrm{\nu}$ plot from results with a single fluid (steam at constant $\mathrm{T}$ and $\mathrm{P})$. However, by actual calibration for a few test points with "different" fluids (sets of $\mathrm{T}$ and $\mathrm{P}$ covering the operating range), the meter performance over a range of conditions can be validated.

Note that the volumetric flowrate measured by the vortex shedding meter is the volume flowrate at the meter exit temperature and pressure. If the volumetric flowrate is needed at a different location in the system or at different values of temperature and/or pressure, or if the mass flowrate is needed, these quantities can be calculated by procedures discussed in appendix D and illustrated in examples E.l and E.2.

Note also that while the nozzle venturi was calibrated using water, it was used as a reference meter on a compressible fluid (steam in the case mentioned) througl use of the fluid expansion factor $Y$ and the meter expansion factor $F_{a}$. This is done, in particular, when primary facilities flowing steam are not available but at the expense of an increase in the calibration uncertainty through tolerance values assigned to Y. (See table A.18.)

Example E.9 On-Site Calibration of a Turbine Meter. Water at $160^{\circ} \mathrm{F}$ and $50 \mathrm{psig}$ is being monitored by a turbine meter. It is to be calibrated on site using a positive displacement meter as the transfer reference meter. The PD meter has been calibrated previously using water at $160^{\circ} \mathrm{F}$, and it is installed upstream of the turbine meter as shown in figure 6 . Salien features of the turbine meter are:
Size:
3-inch
Output:
45 pulses/gallon, nominal
Rating:
600 GPM rated flow, $300 \mathrm{psig}$ and $400^{\circ} \mathrm{F}$
Pressure Loss: 5 psi at rated flow, 600 GPM
Installation: The turbine meter is installed in a horizontal 3-inch insulated pipe within a metering section as shown in figure 7. The flow straightener is a tubular type as shown in figure 12 .

The transfer reference (PD) meter has the following features;
Size:
3-inch
Output:
pulse type, 10 pulses/gallon nominal
Rating:
700 GPM rated flow, 150 psig and $300^{\circ} \mathrm{F}$
Pressure Loss: 2 psi at rated flow 
Installation: The PD meter is installed in the insulated horizontal pipe immediately upstream of the turbine metering section in the same (horizontal) position existing during calibration. No flow straightener is used since previous tests showed no significant influence of swirling flow on meter performance.

Calibration: Water in the range $145-180^{\circ} \mathrm{F}$ at a primary facility yielded an average value of the calibration factor $K=10.145$ pulses/ gallon, and $\mathrm{K}$ data scatter +0.2 percent for the flow range 30 to 700 GPM.

Pulses are counted from each meter with an electronic counter during concurrent time intervals, counting at least 500 pulses from the PD meter and at least 1000 pulses from the turbine meter. The flow range to be covered by the calibration is 50 to 500 GPM.

The test should be conducted at a pressure level sufficient to avoid cavitation in each meter. At $160^{\circ} \mathrm{F}$, the vapor pressure of water is about 5 psia. From guidelines mentioned in section 5.3, a (minimum) inlet pressure to the turbine meter of 55 psia should be adequate to prevent cavitation. For the PD meter, an absolute pressure level equivalent to the vapor pressure plus 3 or 4 times the meter pressure loss at the rated flow is probably sufficient, as discussed in section 5.1. For this PD meter, this amounts to $5+4(2)=13$ psia. Since the PD meter is upstream of the turbine meter, cavitation in the turbine meter would likely occur first. It is noted, however, cavitation usually occurs initially at higher rates of flow, resulting in (sometimes) an abrupt increase in pulse rate/throughput.

Table E. 3 summarizes the measurements made and results of the calibration, where the pulse data are averages of 5 repeat runs. The results show no abrupt changes of the calibration factor $\mathrm{K}$ for the turbine meter, and it is assumed no cavitation occurred.

Calculations for the PD meter are:

$$
\begin{aligned}
& \mathrm{f}=\text { pulses/time } \\
& \mathrm{Q}=60(\mathrm{f} / \mathrm{K})
\end{aligned}
$$

For Run No. 1:

$$
\begin{aligned}
& \mathrm{f}=2561 / 30.000=85.37 \mathrm{~Hz} \\
& Q=(60)(85.37) /(10.145)=504.9 \mathrm{GPM}
\end{aligned}
$$

Calculations for the turbine meter are:

$$
\begin{aligned}
& \mathrm{f}=\text { pulses } / \text { ime } \\
& K=60(\mathrm{f} / \mathrm{Q}) \text { pulses/gallon }
\end{aligned}
$$


Table E.3. Turbine Meter Calibration Data

Water: $162^{\circ} \mathrm{F} \pm 2^{\circ} \mathrm{F}, 50 \pm \mathrm{psig}$

\begin{tabular}{|c|c|c|c|c|c|c|c|c|}
\hline \multicolumn{5}{|c|}{$\begin{array}{c}\text { Positive Displacement Meter } \\
\text { (Reference) } \\
\mathrm{K}=10.145 \text { pulses/gallon }\end{array}$} & \multicolumn{4}{|c|}{ Turbine Meter } \\
\hline Run & Pulses & $\begin{array}{l}\text { Time } \\
\text { Seconds }\end{array}$ & $\begin{array}{c}\text { Erequency } \\
\mathrm{Hz}\end{array}$ & $\begin{array}{l}\text { Flowrate } \\
\text { GPM }\end{array}$ & Pulses & $\begin{array}{l}\text { Time } \\
\text { Seconds }\end{array}$ & $\begin{array}{c}\text { Frequency } \\
\mathrm{Hz}\end{array}$ & $\frac{\mathrm{K}}{\text { Pulses/gallon }}$ \\
\hline 1 & 2561 & 30.000 & 85.37 & 504.9 & 11180 & 30.000 & 372.67 & 44.29 \\
\hline 2 & 1943 & 30.000 & 64.77 & 383.0 & 8484 & 30.000 & 282.8 & 44.30 \\
\hline 3 & 1281 & 30.000 & 42.70 & 252.5 & 5602 & 30.000 & 186.7 & 44.38 \\
\hline 4 & 717 & 30.000 & 23.9 & $1+1.0$ & 3154 & 30.000 & 105.1 & 44.61 \\
\hline 5 & 820 & 60.000 & 13.7 & 80.8 & 3580 & 60.000 & 59.67 & 44.3 \\
\hline 6 & 512 & 60.000 & 8.53 & 50.5 & 2204 & 60.000 & 36.73 & 43.6 \\
\hline
\end{tabular}


For Run No. 1:

$$
\begin{aligned}
& \mathrm{f}=11180 / 30.000=372.67 \mathrm{~Hz} \\
& \mathrm{~K}=(60)(372.67 / 504.9)=44.29 \text { pulses } / \text { gallon }
\end{aligned}
$$

A plot of the calibration results are shown in figure $E .2$ where $K$ is plotted as a function of frequency $f$. These results show that the calibration factor $K$ varies +0.5 percent for a flow range of about 70 to 500 GPM $(50 \leq \mathrm{f} \leq 375 \mathrm{~Hz})$. Also, i $\bar{t}$ should be noted, these data apply only when the water is near $1 \overline{6} 0^{\circ} \mathrm{F}$.

Example E.10 On-Site Calibration of a Target Meter. A target meter monitors water flowing at $45^{\circ} \mathrm{F}$ and $100 \mathrm{psig}$. It is to be calibrated on site with a transfer meter system consisting of two turbine meters mounted in series. The turbine meters have been calibrated previously on water at $42{ }^{\circ} \mathrm{F}$. Two turbine meters are used instead of one as a check on the transfer-meter operation. Should differences in turbine meter performance be (or appear) larger than an allowed maximum, meter trouble would be suspected and this performance would be investigated This approach is favored since this type meter tends to be incompatible with foreign material entrained in water and since water is considered to have poor lubricating properties. However, these meters have definite advantages for transfer meter applications, including small size, digital output, and a calibration factor that is essentially constant over large flow ranges when used with a low-viscosity liquid such as water. The turbine meters are installed downstream of the target meter in a metering section as shown in figure 5 . At the entrance to the metering section a 50-micron filter is installed. The target meter is installed in a metering section including a flow straightener. Salient features of the target meter are:

Size: $\quad$ 2-inch

Output: 4-20 mA DC, slope and span adjusted for 0-270 GPM nominal, transmitter output varies with $\mathrm{Q}^{2}$

The turbine meters have the following features:

Size: $\quad 2-i n c h$

Output: $\quad$ pulse type, 3300 pulses/ft ${ }^{3}$ nominal

Rating: $\quad 300$ GPM rated flow, $300 \mathrm{psig}$ and $250^{\circ} \mathrm{F}$

Calibration: On water in the range $40^{\circ} \mathrm{F}$ to $42^{\circ} \mathrm{F}$ at a primary facility. Meter No. 1 has a calibration factor $K=3303$ pulses $/ \mathrm{ft}^{3}$ with a variation of +0.2 percent in the upper $3: 1$ flow range. Meter No. $2, \bar{K}=3286$ pulses $/ \mathrm{ft}^{3}$, with a variation of \pm 0.2 percent in the upper $3: 1$ flow range.

The target meter will be calibrated over a range of 100 to 270 GPM, expressing the calibration factor CF in units $G \mathrm{PM} /(\mathrm{mA})^{1 / 2}$ as discussed in section 4.4 . 


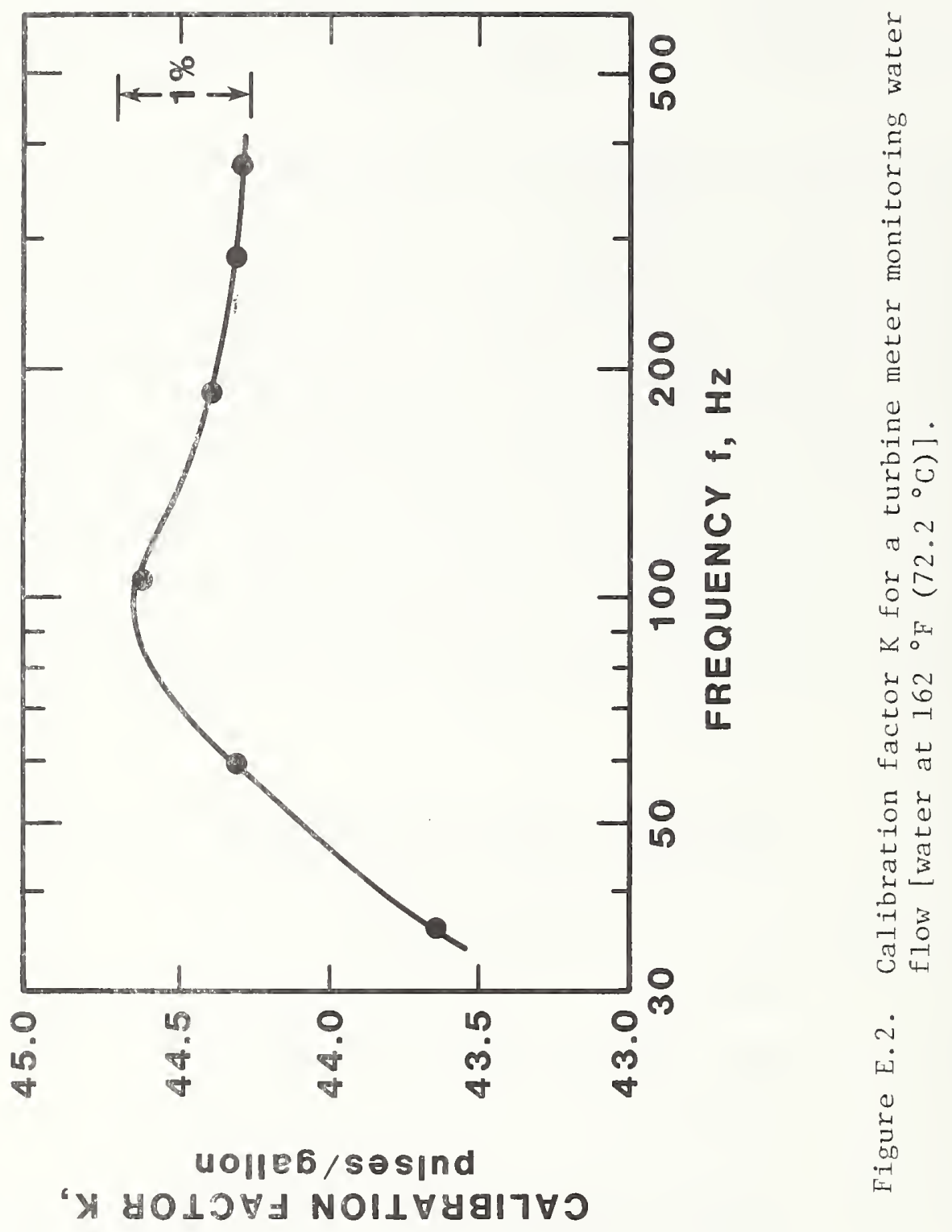


The reference flowrate will be based on the average readings of the two turbine meters. The target meter transmitter output current will be measured by a digital voltmeter (DVM) ( $41 / 2$ digits) and the two turbine meter ouputs by variable-time-base electronic counters. The time interval should be set large enough to assure a steady count; i.e., no influence of random flow fluctuations, or set to accumulate at least 5000 pulses, whichever is larger.

To check on the turbine meter operation, the frequencies $f_{1}$ and $f_{2}$ will be compared. To account for the difference and the variation $(+0.2$ percent) in calibration factors for the two turbine meters, and to allow for meter repeatability, a criterion of $1.000 \leq \mathrm{f}_{1} / \mathrm{f}_{2} \leq 1.010$ will be used to signify satisfactory transfer meter operation. (Note $\overline{3} 303+0.2$ percent $=3309 ; 3286-0.2$ percent $=3280 ; 3309 / 3280=1.009)$. In particular, vaines of $\mathrm{f}_{1} / \mathrm{f}_{2}$ which show drift or large scatter outside this range should be investigated.

Table E.4 sumnarizes the measurements and results of the calibration of the target meter, where data for each test are the average of 5 repeat runs. Note that the transmitter current, $I$, was checked at zero flow at the beginning and end of each run, test points 1 and 6 . Also note that frequency ratio $\mathrm{f}_{1} / \mathrm{f}_{2}$ for the turbine meters stayed in the range 1.000 to 1.010 , indicating satisfactory meter operation according to the criterion stated previously.

Calculations for the turbine meters are:

$$
\begin{aligned}
\mathrm{f} & =\text { pulses } / \text { time } \\
\mathrm{Q} & =60(\mathrm{f} / \mathrm{K}) \\
\mathrm{Q}_{\text {avg }} & =\left(\mathrm{Q}_{1}+\mathrm{Q}_{2}\right) / 2
\end{aligned}
$$

For test point No. 2:

$$
\begin{aligned}
\mathrm{E}_{1} & =7224 / 10=722.4 \mathrm{~Hz} \\
\mathrm{Q}_{1} & =(60)(722.4)(7.4805) / 3303=98.16 \mathrm{GPM} \\
\mathrm{F}_{2} & =7202 / 10=720.2 \mathrm{~Hz} \\
\mathrm{Q}_{2} & =(60)(720.2)(7.4805) / 3286=98.37 \mathrm{GPM} \\
\mathrm{Q}_{\text {avg }} & =\left(\mathrm{Q}_{1}+\mathrm{Q}_{2}\right) / 2=98.27 \mathrm{GPM}
\end{aligned}
$$

Calculations for the target meter are:

$$
I_{0}=\left(I_{1}+I_{6}\right) / 2=(3.998+4.002) / 2=4.000 \mathrm{~mA}
$$

The calibration factor is:

$$
\begin{aligned}
& \mathrm{CF}=\mathrm{GPM} /(\mathrm{mA})^{1 / 2}, \text { and } \\
& \mathrm{CF}=98.27 /(6.074-4.000)^{1 / 2}=68.24 \mathrm{GPM} /(\mathrm{mA})^{1 / 2}
\end{aligned}
$$


The calibration results are plotted in figure E. 3 showing the calibration factor CF, GPM/(I - $\left.I_{0}\right)^{1 / 2}$ plotted as a function of transmitter current $L$. These data apply only for water at or near $45^{\circ} \mathrm{F}$. To obtain the

flowrate at any current I, equation (4-11) is applied. For example, when $I=16.00 \mathrm{~mA}:$

$$
\begin{aligned}
\mathrm{CF} & =69.41 \mathrm{GPM} /(\mathrm{mA})^{1 / 2}, \text { and } \\
Q & =(\mathrm{CF})\left(\mathrm{I}-\mathrm{I}_{\mathrm{O}}\right)^{1 / 2}=(69.41)(16-4)^{1 / 2} \text { or } \\
Q & =240.4 \mathrm{GPM}
\end{aligned}
$$


Table E.4. Target Meter Calibration Data

Water at $45^{\circ} \mathrm{F}$

Turbine Meters (Reference)

$$
\begin{gathered}
\text { No. } 1 \\
K_{1}=3303 \text { pulses } / \mathrm{ft}^{3} \quad \mathrm{~K}_{2}=3286 \text { pulses } / \mathrm{ft}^{3}
\end{gathered}
$$

\begin{tabular}{|c|c|c|c|c|c|c|c|c|}
\hline $\begin{array}{l}\text { Test } \\
\text { Point }\end{array}$ & Pulses & $\begin{array}{c}\text { Time } \\
\mathrm{s}\end{array}$ & $\begin{array}{l}\mathrm{f}_{1} \\
\mathrm{~Hz}\end{array}$ & $\begin{array}{r}\mathrm{Q}_{1} \\
\mathrm{GPM}_{3}\end{array}$ & Pulses & $\begin{array}{c}\text { Time } \\
\mathrm{s}\end{array}$ & $\begin{array}{l}\mathrm{f}_{2} \\
\mathrm{~Hz}\end{array}$ & $\begin{array}{l}\mathrm{Q}_{2} \\
\mathrm{GPM}\end{array}$ \\
\hline 1 & -- & -- & -- & 0 & -- & - & -- & 0 \\
\hline 2 & 7224 & $10 i$ & 722.4 & 98.16 & 7202 & 10 & 720.2 & 98.37 \\
\hline 3 & 10281 & 10 & 1028.1 & 139.70 & 10196 & 10 & 1019.6 & 139.27 \\
\hline 4 & 7372 & 5 & 1474.4 & 200.3 & 7364 & 5 & 1472.8 & 201.2 \\
\hline 5 & 10176 & 5 & 2035.2 & 276.55 & 10095 & 5 & 2019.0 & 275.77 \\
\hline 6 & -- & -- & -- & 0 & -- & -- & -- & 0 \\
\hline \multicolumn{3}{|c|}{ Reference Meters } & & \multicolumn{5}{|c|}{ Target Meters } \\
\hline & $\mathrm{E}_{1} / \mathrm{E}_{2}$ & $\begin{array}{l}\text { Qavg } \\
\text { GPM }\end{array}$ & & $\begin{array}{l}\text { I } \\
\text { in A }\end{array}$ & \multicolumn{3}{|c|}{ 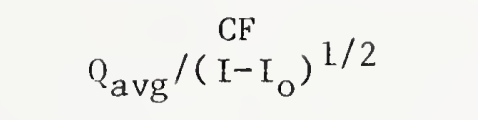 } & $\underset{\mathrm{GPM}}{\mathrm{Q}}$ \\
\hline 1 & -- & 0 & & 3.998 & & -- & & 0 \\
\hline 2 & 1.003 & 98.27 & & 6.074 & & 68.24 & & 98.27 \\
\hline 3 & 1.008 & 139.49 & & 8.139 & & 59.56 & & 141.52 \\
\hline 4 & 1.001 & 200.8 & & 12.447 & & 69.08 & & 200.8 \\
\hline 5 & 1.008 & 276.16 & & 19.736 & & 69.62 & & 276.17 \\
\hline 6 & & 0 & & 4.002 & & -- & & 0 \\
\hline
\end{tabular}




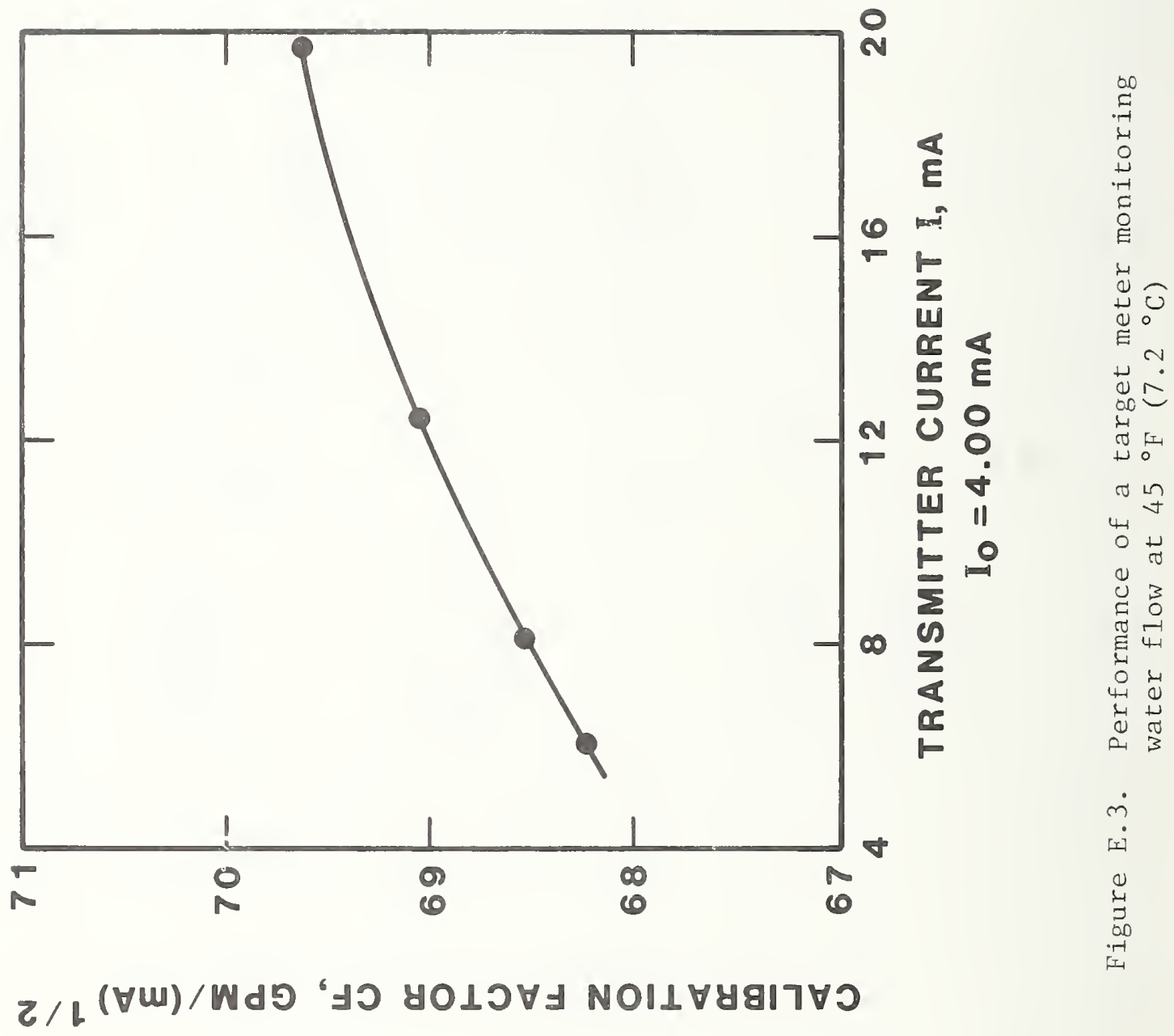


NBS-114A (REV. 2-8C)

\begin{tabular}{|c|c|c|c|}
\hline $\begin{array}{c}\text { U.S. DEPT. OF COMM. } \\
\text { BIBLIOGRAPHIC DATA } \\
\text { SHEET (See instructions) }\end{array}$ & $\begin{array}{l}\text { 1. PUBLICATION OR } \\
\text { REPORT NO. } \\
\text { NBS BSS 159 }\end{array}$ & 2. Performing Organ. Report No. Publication Date \\
\hline
\end{tabular}

4. TITLE AND SUBTITLE

On-Site Calibration of Flow Metering Systems Installed in Buildings

5. $\operatorname{AUTHOR}(S)$

David W. Baker and C. Warren Hurley

\begin{tabular}{|l|l}
\hline 6. PERFORMING ORGANIZATION (If joint or other than NBS, see instructions) & 7 . Contract/Grant No.
\end{tabular}

NATIONAL BUREAU OF STANDARDS

DEPARTMENT OF COMMERCE

WASHINGTON, D.C. 28234

8. Type of Report \& Period Covered

Fina $]$

9. SFONSORHA ORCANHZA.THON NAME AHC COMFLETE ADDRESE (Street, City, Stote, ZIR)

Naval Civil Engineering Laboratory

Port Hueneme, CA 93043

10. SUPPLEMENTARY NOTES

Library of Congress Catalog Card Number: 83-600626

[D Document describes a computer program; SF-185, FIPS Software Summary, is attached.

11. ABSTRACT

The measurement of flow of the various fluids (air, water, steam) used in building service systems is usually the most difficult parameter to obtain and maintain. Consequently, in energy management and control systems (EMCS), the flowrate or the total quantity of fiow is often the least accurate measurement. However, in most systems the energy consumed depends directly on this parameter.

Since the majority of fluid flow measuring techniques require the sensing element to be located in the stream of the fluid being monitored, flow measuring devices often are the most difficult instruments to calibrate initially and to maintain in calibration within the required accuracy. This report summarizes the various types of flowmetering devices used in EMCS, various methods for their initial calibration and, when practical, techniques for maintaining their calibration while they are in service. Emphasis is placed on the use of transfer reference meter systems, where the working meter is calibrated on site by connecting it in series with a calibrated transfer meter of any variety. Other methods of calibration are also described.

Reference tables and the necessary equations for flow calculations are presented throughout the text and in the appendicies. Iliustrative examples are given in detail for the calculation of flow using each type of metering device described. These examples are extremely helpfui in field calibration when the meiering being calibrated is of a different type than the meter being used as a reference.

Because of this, the reader is encouraged to review these examples.

12. KEY WORDS Calibration methods; flowmetering devices; flow nozzle meters; multiple pitot-static tube assemblies; orifice meters; positive displacement meters: reversepitot tube assemblies; target meters; turbine meters; ultrasonic flowmeters; venturi shedding meters.

13. AVAILABILITY

$[X]$ Unlimited

$\square$ For Official Distribution. Do Not Release to NTIS

$[X]$ Order From Superintendent of Documents, U.S. Government Printing Office, Washington, D.C. 20402.

14. NO. OF PRINTED PAGES

Order From National Technical Information Service (NTIS), Springfield, VA. 2216I

$\lceil 54$

15. Price 



\section{NBS TECHNICAL PUBLICATIONS}

\section{PERIODICALS}

JOURNAL OF RESEARCH-The Journal of Research of the National Bureau of Standards reports NBS research and development in those disciplines of the physical and engineering sciences in which the Bureau is active. These include physics, chemistry, engineering, mathematics, and computer sciences. Papers cover a broad range of subjects, with major emphasis on measurement methodology and the basic technology underlying standardization. Also included from time to time are survey articles on topics closely related to the Bureau's technical and scientific programs. As a special service to subscribers each issue contains complete citations to all recent Bureau publications in both NBS and nonNBS media. Issued six times a year. Annual subscription: domestic $\$ 18$; foreign $\$ 22.50$. Single copy, $\$ 5.50$ domestic; $\$ 6.90$ foreign.

\section{NONPERIODICALS}

Monographs--Major contributions to the technical literature on various subjects related to the Bureau's scientific and technical activities.

Handbooks-Recommended codes of engineering and industrial practice (including safety codes) developed in cosperation with interested industries, professional organizations, and regulatory bodies.

Special Publications-Include proceedings of conferences sponsored by NBS, NBS annual reports, and other special publications appropriate to this grouping such as wall charts, pocket cards, and bibliographies.

Applied Mathematics Series-Mathematical tables, manuals, and studies of special interest to physicists, engineers, chemists, biologists, mathematicians, computer programmers, and others engaged in scientific and technical work

National Standard Reference Data Series-Provides quantitative data on the physical and chemical properties of materials, compiled from the world's literature and critically evaluated. Developed under a worldwide program coordinated by NBS under the authority of the National Standard Data Act (Public Law 90-396).

NOTE: The principal publication outlet for the foregoing data is the Journal of Physical and Chemical Reference Data (JPCRD) published quarterly for NBS by the American Chemical Society (ACS) and the American Institute of Physics (AIP). Subscriptions, reprints, and supplements available from ACS, 1155 Sixteenth St. NW, Washington, DC 20056
Building Science Series--Disseminates technical irformation developed at the Bureau on building materials, components, systems, and whole structures. The series presents research results, test methods, and performance criteria related to the structural and environmental functions and the durability and safety characteristics of building elements and systems.

Technical Notes-Studies or reports which are complete in themselves but restrictive in their treatment of a subject. Analogous to monographs but not so comprehensive in scope or definitive in treatment of the subject area. Often serve as a vehicle for final reports of work performed at NBS under the sponsorship of other government agencies.

Voluntary Product Standards-Developed under procedures published by the Department of Commerce in Part 10, Title 15, of the Code of Federal Regulations. The standards establish nationally recognized requirements for products, and provide all concerned interests with a basis for common understanding of the characteristics of the products. NBS administers this program as a supplement to the activities of the private sector standardizing organizations

Consumer Information Series-Practical information, based on NBS research and experience, covering areas of interest to the consumer. Easily understandable language and illustrations provide useful background knowledge for shopping in today's technological marketplace.

Order the above NBS publications from: Superintendent of Documents. Government Printing Office, Washington, DC 20402.

Order the following NBS publications-FIPS and NBSIR's-from the National Technical Information Service, Springfield, VA 22161.

Federal Information Processing Standards Publications (FIPS PUB)-Publications in this series collectively constitute the Federal Information Processing Standards Register. The Register serves as the official source of information in the Federal Government regarding standards issued by NBS pursuant to the Federal Property and Administrative Services Act of 1949 as amended. Public Law 89-306 (79 Stat. 1127), and as implemented by Executive Order I1717 (38 FR 12315, dated May 11, 1973) and Part 6 of Title IS CFR (Code of Federal Regulations)

NBS Interagency Reports (NBSIR) - A special series of interim or final reports on work performed by NBS for outside sponsors (both government and non-government). In general. initial distribution is handled by the sponsor; pub'ic distribution is by the National Technical Information Service. Springfield, VA 22161. in paper copy or microfiche form. 
Washington, D.C. 20234

Official Business

Penalty for Private Use $\$ 300$ COM-215

SPECIAL FOURTH-CLASS RATE BวOK 